
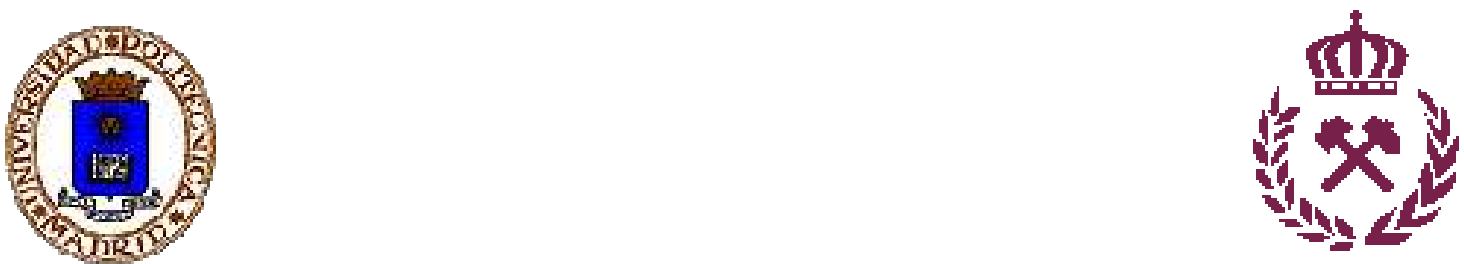

Universidad Politécnica de Madrid

Escuela Técnica Superior de Ingenieros de Minas y Energía

\title{
EVOLUCIÓN GEOMORFOLÓGICA DEL ABANICO ALUVIAL DE LIMA Y SUS RELACIONES CON LA PELIGROSIDAD POR INUNDACIONES
}

\author{
Tesis Doctoral
}

Sandra Paula Villacorta Chambi

Ingeniero Geólogo

Noviembre de 2018 

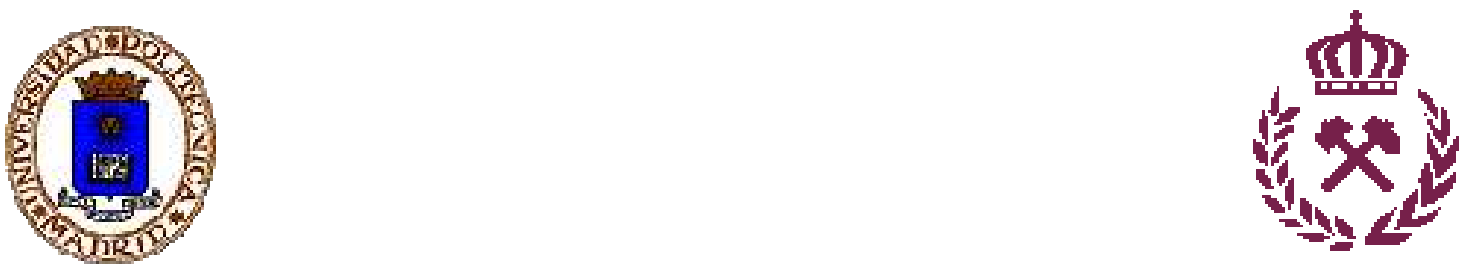

Universidad Politécnica de Madrid

Escuela Técnica Superior de Ingenieros de Minas y Energía

\title{
EVOLUCIÓN GEOMORFOLÓGICA DEL ABANICO ALUVIAL DE LIMA Y SUS RELACIONES CON LA PELIGROSIDAD POR INUNDACIONES
}

\author{
Tesis Doctoral
}

MEMORIA

\author{
Sandra Paula Villacorta Chambi \\ Ingeniero Geólogo
}

Director: Trinidad De Torres Pérez-Hidalgo

Doctor Ingeniero de Minas

Noviembre de 2018 

El Tribunal nombrado por el Magnífico y Excelentísimo Sr. Rector de la Universidad Politécnica de Madrid, el día 14 de octubre de 2018

$\begin{array}{ll}\text { Presidente } & \text { D. } \\ \text { Vocal } & \text { D. } \\ \text { Vocal } & \text { D. } \\ \text { Vocal } & \text { D. } \\ \text { Secretario } & \text { D. }\end{array}$

Realizado el acto de defensa y lectura de la Tesis Doctoral el día 14 de noviembre de 2018, en Madrid

Calificación:

EL PRESIDENTE

LOS VOCALES

\author{
EL SECRETARIO
}





\section{DEDICATORIA}

A mis hijos quienes han sido siempre mi mayor motivación para alcanzar mis metas más caras.

A mi madre, Prudencia Chambi por su apoyo a lo largo de mi carrera profesional y sobretodo en los años en que desarrollé esta investigación.

A mis hermanos Ricardo y Regina quienes siempre me apoyaron en la medida de su alcance.

En especial dedico esta memoria a mi padre Ricardo Villacorta quien me enseñó a amar la lectura y que seguro estará celebrando conmigo este nuevo triunfo en el más allá. 


\section{AGRADECIMIENTOS}

Esta investigación ha sido cofinanciada por el Instituto Geológico Minero y Metalúrgico (INGEMMET) y la Universidad Politécnica de Madrid. En tal sentido mi mayor agradecimiento al Ing. Lionel Fidel y su sucesor Ing. Bilberto Zavala en la jefatura de la Dirección de Geología Ambiental y Riesgo Geológico del INGEMMET. A mis colegas del "Programa Nacional de Riesgos Geológicos" y la ACT01 "Apoyo en Riesgo Geológico a Entidades Públicas", un agradecimiento por su acompañamiento en las actividades laborales en el INGEMMET que desarrollaba coetáneamente a esta investigación.

Quiero manifestar un agradecimiento profundo al Dr. Trinidad de Torres, quien aceptó el reto de dirigir esta tesis a distancia y quien tuvo paciencia y siempre tenía palabras alentadoras y confianza en que lograríamos la meta; sobre todo durante las última fase del desarrollo de la tesis en que parecía de nunca acabar. Gracias por su amable disposición y apoyo, aun en los temas administrativos relacionados a la pre-lectura y lectura final.

Del mismo modo quiero expresar mi especial agradecimiento al Dr. Miguel Llorente por todas las orientaciones, sobretodo en la parte metodológica, así como por su minuciosa revisión del texto final de la tesis. Además de brindarme la posibilidad de acceder a las oficinas del IGME en Galicia donde desarrollé parte fundamental de la tesis. Mil gracias por el tiempo y los consejos brindados en lo profesional y personal.

La obtención de resultados de dataciones fue posible gracias al Instituto Peruano de Energía Nuclear (IPEN) y al laboratorio de datación del Servicio Geológico de Estados unidos (Denver, Colorado), por ello mi agradecimiento a la Dra. Susana Petrick e Ing. Sheyla Malpartida del IPEN y a la Dra. Shannon Mahan por su apoyo y amistad. Los datos geológicos de base fueron proporcionados por la Dirección de Geología Regional del Instituto Geológico Minero y Metalúrgico (INGEMMET), los datos satelitales fueron cedidos para este trabajo por la Comisión Nacional de Investigación y Desarrollo Aeroespacial (CONIDA) y el Centro de Estimación y Prevención de Desastres. Miguel Miranda, de CONIDA, ha prestado apoyo en la obtención y tratamiento de los MDEs. Luis Ayala y Carlos Benavente, proporcionaron apoyo en los trabajos de campo y revisando los capítulos de aspectos geológicos y geomorfológicos, por lo cual les manifiesto mi agradecimiento más profundo. Nicanor Prendes, Walter León y Jesús Pernas han contribuido como revisores externos al 
documento por lo cual les expreso mi especial agradecimiento por el tiempo dedicado a brindarme sus observaciones y comentarios que me permitieron abordar muchos temas de los cuales no me considero experta.

En especial mi agradecimiento al Dr. Ken Evans de la Universidad de Charles Darwin (Australia) quien colaboró con la elaboración del artículo sobre la tesis en Inglés y quien me brindó la oportunidad de hacer una pasantía y conocer el trabajo que desarrolla en Darwin.

Un agradecimiento especial a los amigos que viven en España, peruanos y españoles que siempre me apoyaron y recibieron y acogieron durante mis idas y vueltas EspañaPerú. En especial a Cosme Perez-Puig y al Dr. Jose Antonio Espí, sin su apoyo no habría sido igual.

No olvido al El sr. Wigberto Jiménez quien elaboró los moldes para la extracción de muestras para la datación por OSL, así como a Luz Marina Villanueva y Jennipher Carruitero siempre diligentes y colaboradoras para mis tramites de viaje cuando me tocaba hacer las estancias en España.

Les pido las disculpas a todos aquellos que de una $u$ otra forma me han apoyado y acompañado en la trayectoria seguida hasta obtener este grado, no sería capaz de nombrar a todas porque nunca acabaría. 


\section{RESUMEN}

Esta tesis Doctoral supone la primera investigación enfocada en el análisis, desde el punto de vista geomorfológico, de la evolución dinámica del abanico aluvial de Lima, ubicado en la costa central del Perú (Suramérica).

El área del abanico aluvial del Lima, pertenece a la ciudad capital, un punto neurálgico de un país en vías de desarrollo. Por su constante crecimiento urbano y gran densidad poblacional, parte de la población está expuesta a procesos como inundaciones y flujos de detritos que han producido daños en el pasado. Es por ello de especial sensibilidad el estudio y tratamiento de los riesgos asociados a estos eventos.

La metodología empleada ha abordado técnicas geológicas y geomorfológicas para conocer la actividad tectónica actual. Por un lado, se incluye el análisis de fotografías aéreas, ortofotos, imágenes de satélite, modelos digitales del terreno (MDT's) de alta resolución y registro de columnas estratigráficas; cartografía geológica, geomorfológica y estructural. Así mismo se aplicaron técnicas de muestreo y dataciones radiométricas de los materiales aluviales que conforman el abanico que fueron efectuadas en los laboratorios del Instituto Peruano de Energía Nuclear y el USGS, empleando Luminiscencia Ópticamente Estimulada.

Además se ha recurrido a la modelización numérica de flujos de detritos simulando las condiciones de contorno deducidas de modelos hidrológico-hidraulicos y extrapolando la simulación ante futuros eventos excepcionales tipo ENSO.

Los resultados señalan que el abanico se formó en un marco tectónico seguido de una sucesión de eventos asociados a la fenomenología derivada de los cambios climáticos en el pasado geológico. Es un relieve que resulta de las aportaciones del río Rímac y la coalescencia de los aluviones de sus afluentes. Está influenciado por el paleorelieve heredado de un clima semiárido y probablemente bajo condiciones ambientales próximas a las de un clima tropical. La secuencia sedimentaria superior del abanico, expuesta en la Costa Verde, es de edad Pleistoceno superior-Holoceno. Los sedimentos que la forman no son cohesivos y son muy móviles durante las inundaciones y los terremotos. La secuencia corresponde a facies de canal entrelazados y flujos laminares que habrían sido influenciadas por la transgresión marina postglacial del Holoceno. 
La mejor comprensión de la evolución del abanico, resultante de este estudio, brinda revelaciones acerca del desarrollo de abanicos influenciados por tectónica activa y cambios climáticos. Asimismo, contribuye a una mejor definición de áreas de alto riesgo de desastre por los procesos que actúan en los abanicos aluviales. El ciclo de desarrollo del abanico, actualmente es controlado por la geomorfología, la tectónica y las condiciones climáticas que continuarán actuando a pesar de la intervención humana que intenta prevenir los desastres asociados a su evolución.

La información compartida posibilitará un nuevo enfoque de gestión de riesgo de desastre ante fenómenos geohidrológicos en la ciudad de Lima Metropolitana tomando a consideración aspectos geocientíficos nunca antes abordados.

\section{ABSTRACT}

This Doctoral thesis is the first research focused on the geomorphic evolution of the alluvial fan of Lima, located on the central coast of Peru. The Lima alluvial fan forms the basis of the Peruvian capital city, a nerve centre of a developing country, with a population of more than 10 million inhabitants. Due to its constant urban growth with infrequent planning and inadequate infrastructure, part of the population is exposed to frequent natural hazards such as floods and debris-flows. These hazards result in the subsequent loss of human life and properties, both now and in the past, and, more importantly, in the future. The challenges of controlling damage from natural geological events include informing the population of the risks and integrating both government and community activities in response to the threats.

The alluvial fan of Lima is a complex landform that is formed from the sediment contributions of the Rimac River and the coalescence of the alluvial fans of its tributaries. Depositional zones, changing characteristics in the main channel, and affluent courses influenced by the paleo-relief inherited from a semi-arid climate and by the climatic changes are preserved in the alluvial fan. The upper sedimentary sequence of the fan, dominant on the Costa Verde, is Pleistocene-Holocene in age and was deposited about 110,000 years ago. The sediments that were deposited were noncohesive and are highly mobile during floods and earthquakes. The dominant features in this sequence are braided channel facies and laminar flows which were influenced by the Pleistocene-Holocene postglacial marine transgression. 
The methodology used to study and define the recurrence periods of the large floods, which have generated the current soil of Lima, is geomorphology and field-based hydraulic techniques. These preserved stratigraphic sections have also been used to show the relation between evolution and climatic changes. Research also includes the analysis of aerial photographs, orthophotos and satellite images, the use of high resolution digital terrain models (MDT's) and stratigraphic column surveys, as well as the application of optically stimulated luminescence dating (OSL). The OSL data has been produced by the laboratories of the Peruvian Institute of Nuclear Energy and the United States. Geological Survey. Finally, numerical modelling of hyper-concentrated flows simulating the contour conditions as deduced in the Rímac River have been used to extrapolate the simulation of future exceptional ENSO events.

The analytical results have indicated that the fan was repeatedly formed after tectonic movements followed by successive climatic crises (i.e. floods) even though the environmental conditions were primarily semiarid. The ages of the alluvial fan sediment show that there are flood contributions from deglaciation and climate changes of the upper headwaters, which carried large volumes of sediment into the Lima area and built up the fan in very specific times of the geological past.

The results presented here have improved understanding of the fan's evolution, which contribute to a better definition of high-risk areas in the city of Lima. Furthermore, the knowledge of cyclic fan development and its structural/climatic controls will allow the government of Peru to develop policies of prediction to prevent future disasters in Lima. For this reason, the study of the ages, volume, and patterns of sediment in the fan will make it possible to correctly manage disaster risks and predict where and when ENSO derived moisture will deposit large volumes of water and sediment in Metropolitan Lima. 


\section{Contenido}

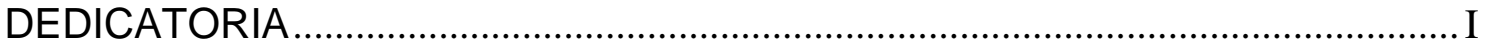

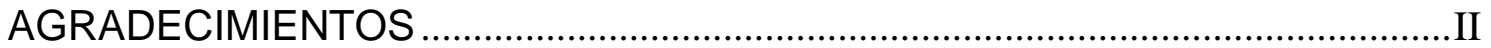

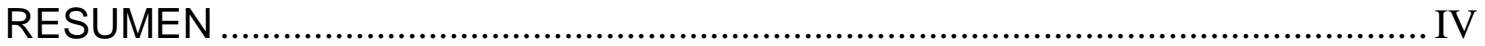

ABSTRACT

I. PRESENTACIÓN....................................................................................... 17 -

1.1 CONTENIDO Y ORGANIZACIÓN DEL DOCUMENTO …...................- 17 -

1.2 INTRODUCCIÓN …….........................................................................- 18 -

1.3 HIPOTESIS DE TRABAJO ..............................................................- 20 -

1.4 JUSTIFICACIÓN .........................................................................- 20 -

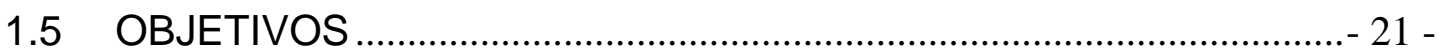

II. ESTADO DEL ARTE .........................................................................- 22 -

2.1 CARACTERÍSTICAS DE LOS ABANICOS ALUVIALES .................... 23 -

2.2 FORMACIÓN DE ABANICOS ALUVIALES........................................- 24 -

2.2.1 Factores que controlan la formación de un abanico aluvial.........-24 -

2.2.2 Procesos sedimentarios en los abanicos aluviales ........................ 29 -

2.2.3 Sucesiones sedimentarias en abanicos aluviales .........................- 39 -

2.3 ABANICOS ALUVIALES EN SURAMÉRICA Y EL CASO DE LIMA - 41 -

2.4 CLIMA Y FENÓMENOS METEOROLÓGICOS .................................... 46 -

2.4.1 Factores que configuran el clima ................................................- 46 -

2.4.2 Cambios climáticos en el cuaternario en el Perú Central ............- 51 -

2.5 MÉTODOS PARA EL ESTUDIO DE INUNDACIONES FLUVIALES- 58 -

2.5.1 Modelamiento hidrológico................................................................- 58 -

2.5.2 Modelamiento hidráulico .................................................................- 68 -

2.5.3 Métodos Geomorfológicos e históricos ........................................ 79 -

2.6 REGISTRO DE PALEOINUNDACIONES EN LIMA METROPOLITANA$81-$

2.6.1 Análisis de eventos históricos.........................................................- 81 -

3.1.1 Flujos de detritos de Chosica en 1986 ........................................ 83 -

3.1.2 Flujos de detritos de 1998 ........................................................... 84 -

3.1.3 Flujos de detritos del río Huaycoloro del 2012.............................- 85 -

3.1.4 Flujos de detritos de Chaclacayo y Chosica en el 2012..............- 85 -

3.1.5 Flujos de Chosica del 2015 .......................................................... 86 -

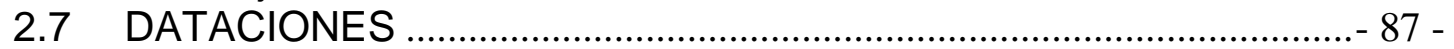

2.7.1 Conceptos asociados ......................................................................- 88 -

2.7.2 Procedimiento de la Datación por OSL..........................................- 91 -

III. GENERALIDADES SOBRE LA ZONA DE ESTUDIO ……......................- 92 -

3.1 UBICACIÓN DEL ÁREA DE ESTUDIO, GEOGRAFÍA E

HIDROGRAFÍA ......................................................................................... 92 -

3.2 COBERTURA VEGETAL, TIPO Y USO DE SUELOS ………............... 93 -

3.2.1 Cobertura vegetal ................................................................... 93 -

3.2.2 Tipos y usos de suelo ..................................................................- 96 -

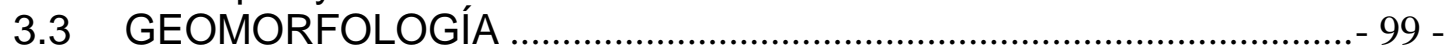

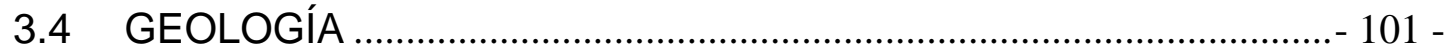

3.4.1 Sedimentología ....................................................................... 101 -

3.4.2 Litología ........................................................................................ 103 -

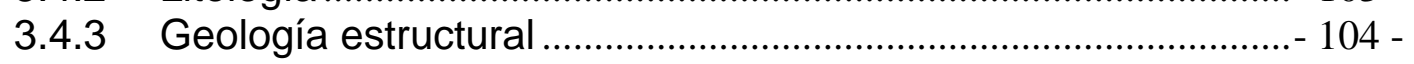

3.4.4 Edad del Abanico de Lima ............................................................. 107 - 
IV. METODOLOGÍA Y DESARROLLO …………......................................... 108 -

4.1 TRABAJOS DE LABORATORIO........................................................- 108 -

4.1.1 Recopilación de información .........................................................- 109 -

4.1.2 Interpretación de imágenes satelitales y fotos aéreas.................- 109 -

4.1.3 Dataciones .................................................................................. 110 -

4.1.4 Sistematización de la información..................................................- 116 -

4.2 TRABAJO DE CAMPO .........................................................................- 120 -

4.2.1 Validación de la cartografía geomorfológica...............................- 120 -

4.2.2 Cartografía estructural, tectónica y sedimentaria........................- 121 -

4.2.3 Levantamiento de columnas estratigráficas .................................- 122 -

4.3 CÁLCULOS HIDROLÓGICOS E HIDRÁULICOS ............................. 125 -

4.3.1 Análisis de precipitaciones ..........................................................- 126 -

4.3.2 Regionalización ..........................................................................- 128 -

4.3.3 Intensidad de las precipitaciones ..............................................- 130 -

4.3.4 Cálculo del CN ........................................................................ 130 -

4.3.5 Análisis hidrológico-hidráulico ...................................................... 132 -

4.3.6 Simulación numérica de flujos híper-concentrados e inundaciones $136-$

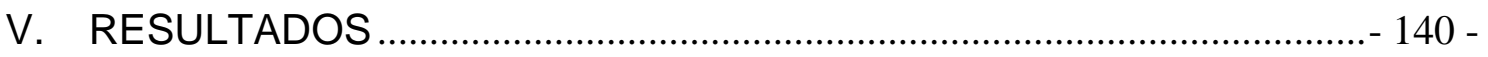

5.1 TRABAJO DE LABORATORIO ……………...............................- 140 -

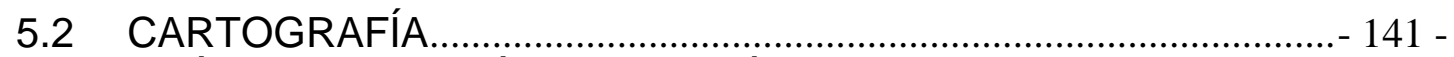

5.3 ANÁLISIS HIDROLÓGICO-HIDRÁULICO …………………………......- 147 -

5.3.1 Análisis hidrológico .................................................................... 147 -

5.3.2 Modelización numérica de flujos híper-concentrados en Flo2D - 147

5.3.3 Comparación con información histórica y geomorfológica ........- 149 -

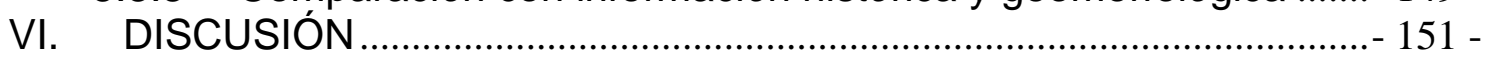

6.1 SOBRE EL ORIGEN DEL ABANICO.................................................. 151 -

6.2 SOBRE ESCENARIO FUTURO DE SU EVOLUCIÓN.......................- 153 -

6.2.1 Modelo hidrológico-hidráulico ......................................................- 154 -

VII. CONCLUSIONES Y RECOMENDACIONES ......................................... 156 -

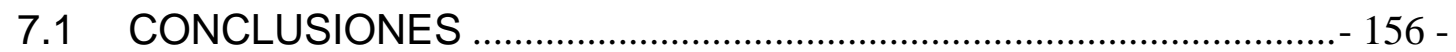

7.1.1 Sobre el origen del abanico ....................................................... 156 -

7.1.2 Evolución del Abanico de Lima ....................................................- 158 -

7.1.3 Sobre escenario futuro de su evolución..........................................- 163 -

7.2 RECOMENDACIONES ...........................................................................- 165 -

7.2.1 Propuestas enfocadas a la prevención de desastres ..................- 166 -

VIII. REFERENCIAS................................................................................ 172 -

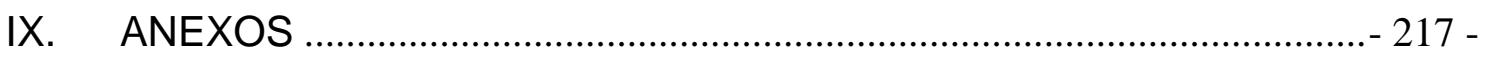

8.1 Datos de precipitación máxima diaria anual empleados ...................- 217 -

8.2 Funciones de probabilidad de ajuste .................................................- 217 -

8.3 Mapa Geomorfologico ....................................................................- 217 -

8.4 Mapa Geológico .............................................................................- 217 -

8.5 Velocidad y Altura de depósito asociado al mapa de peligrosidad.- 217 -

8.6 Mapa de Peligrosidad por flujo de detritos y desbordes para un periodo de retorno de 500 años en el río Rímac.........................................................- 217 -

8.7 Guía para la extracción de datos climático del modelo internacional ERA-INTERIM Reanalysis .

8.8 Guía para el uso del modelo MAGRITH para la afinación de cauces.....217 - 


\section{FIGURAS}

Figura 1. Morfología de un abanico aluvial en la salida de un cauce de quebradas que confluyen, con sus direcciones de flujo respectivas. Tomado de: Pedraza (1996). ...- 24 Figura 2. Falla de borde de cuenca estable. Muestra la relación entre la acumulación de las «Brechas del Violín» y las fracturas asociadas a la falla de San Andrés (Crowell, 1973). $-25-$

Figura 3. Borde de cuenca limitado por una falla retrogradante (Bull, 1968). Modelo basado en la disposición de la sedimentación carbonífera continental en cuencas atlánticas canadienses (Belt, 1968). $-26-$ Figura 4. Borde de cuenca con fallas seriadas escalonadas (Steel \& Wilson, 1975). - 26 Figura 5. Aspectos de la generación de los abanicos aluviales mediante un control climático en la hipótesis de equilibrio: A) agradación durante los períodos de lluvias; B) encajamiento de los canales durante el período seco donde se produce el abandono de algunos cauces y crecimiento de un nuevo sector del abanico (Lustic, 1965) ............ 28 Figura 6. Esquema de los estadíos evolutivos del desarrollo de un abanico. Se indican los procesos geodinámicos predominantes. Modificado de Blair y MacPherson (1994)..30 -

Figura 7. Sectores de un abanico aluvial 1. Zona proximal (ápice) 2. Zona media, 3 Zona distal y 4: Zona de coalescencia con otros abanicos (Bull, 1964a). $40-$ Figura 8. Distribución de facies en un abanico aluvial. El perfil se muestra cóncavo indicando a los sedimentos más gruesos en la zona proximal, los intermedios en el cuerpo medio y los más finos hacia la zona distal (McGowen, 1971). $-40-$ Figura 9 Comparación de vectores promedio de velocidad en los Andes Centrales de América del Sur. A) Velocidades GPS con respecto al interior estable de Suramérica y los vectores de convergencia para la placa de Nazca con respecto a Suramérica derivado de data GPS pronosticado por el modelo de movimiento de las placas mundial NUVEL1A. Los vectores discontinuos son transitoriamente elásticamente cargados y no directamente comparable en magnitud a los datos geológicos (B) Promedio de las velocidades geológicas en los últimos $25 \mathrm{Ma}$ (C) y (D) muestran las velocidades promedio para un campo de desplazamientos en dos fases, 25 a $10 \mathrm{Ma}$ y $10 \mathrm{Ma}$ hasta el presente. (Hindle et al., 2002). -42 Figura 10 Isobatas del basamento rocoso en el área de Lima Metropolitana, deducidas del análisis de la conductividad eléctrica del terreno. Modificado de Arce (1984). .- 45 Figura 11. Esquema general del patrón climático en la vertiente occidental de la Cordillera de los Andes. Indica una distribución vertical aproximada de la temperatura en la costa y donde estaría ubicada la capa de inversión térmica. Modificado de: Vargas, Ortlieb \& Rutllant (2000). $-47-$

Figura 12. Esquema de las Glaciaciones del Perú Central en correlación con las glaciaciones conocidas en Europa y Norteamérica. Tm1 representa el conjunto de niveles marinos holocenos. Las terrazas fluviales (Tf) y las acumulaciones de flujos detríticos esporádicos (c) están numeradas de más reciente al más antiguo. Nótese que la terraza Tf1 se correlaciona con las morrenas de la última glaciación g1 y que existe una relación similar entre Tf2 y las morrenas de la penúltima glaciación. Tomado de: Sébrier y Macharé (1980). $-53-$ Figura 13. Esquema morfológico en la desembocadura del río Chillón. 1,2 y 3: terrazas fluviales. 4 y 5: cordones litorales holocenos. 6: substrato volcanosedimentario. 7: Flujos de detritos esporádicos. 8: Acumulaciones eólicas. 9: cauce actual. 10: océano Pacífico. Modificado de: Sebrier y Macharé (1980). -56 - 
Figura 14. Perfiles de los niveles cuaternarios en la desembocadura del río Chillón. - 1 y 2 terrazas fluviales; 3 y 4 Cordones litorales; 5 Capa de limo que recubre las terrazas fluviales; 6 Substrato volcano-sedimentario cretáceo; 7 Material de flujos esporádicos. Tomado de: Sebrier y Macharé (1980)........................................................................ 56 Figura 15.Clasificación de modelos hidrológicos. Tomado de: (Chow et al., 1994) .- 59 Figura 16. Diagrama de Shield. Tomado de: Martín-Vide (2007) $-69-$ Figura 17. Salida del programa flo2d. a) Elevación máxima del flujo y b) velocidad del flujo en la quebrada Cerro Negro (San Juan de Lurigancho, Lima) para un periodo de retorno de 500 años $75-$

Figura 18. Salidas de simulación en el programa DAN-3D. a) Espesor del flujo y b) espesor del depósito para un sector de Italia. Tomado de Morelli et al. (2016).........- 77 Figura 19. Salida del modelo FLAT MODEL. Tomado de (Bateman, Medina, \& Velasco, 2010) $-78-$ Figura 20. Salida de simulación bidimensional en el software KANAKO (mostrando la profundidad de flujo). Tomado de Nakatani et al. (2007)........................................... 79 Figura 21. Fuentes de datos en los métodos históricos y geomorfológicos (Díez-Herrero, 2004). $-80-$

Figura 22. Gráfico que representa los eventos hidrometeorológicos registrados por el

INGEMMET en la región de Lima Metropolitana. $-83-$ Figura 23. Sectores urbanos afectados por los huaycos de 1987 en San Antonio de Pedregal (Chosica) sobre imagen de la plataforma Google Earth del año 2000. Tomado de:(Abad, 2009) -84 Figura 24. Eventos ocurridos en eel 2015 en Chosica (Villacorta et al., 2015). 1: Flujos del 23-03-15, 2: Flujos antiguos, 3: Avalanchas de detritos, 4: Depósitos coluviodeluviales, 5: Río Rímac..

Figura 25. Representación esquemática del ciclo geológico TL. La exposición a la luz reduce la señal TL de sedimentos a un bajo nivel definible. Después del entierro de sedimentos la radiación ionizante imparte progresivamente una señal TL. La señal de TL en el momento de la recolección se denomina la TL natural. La dosis beta añadida a la señal de TL natural define una función, que a menudo es la base para determinar la dosis equivalente. Modificado de (Wintle \& Huntley, 1982)..................................... 89 Figura 26. Ubicación del área evaluada en la cuenca del río Rímac ........................... 92 Figura 27. Unidades de cobertura vegetal del área a evaluar en la cuenca Rímac. Recorte extraído de Ministerio del Ambiente (2015)................................................ 96 Figura 28. Grupos hidrológicos de suelos en la cuenca del río Rímac. Elaborado en base a; Mockus, 1972; Boughton, 1989; Asociación Louis Berger International -Tropical.

Research - ECSA Ingenieros, 1998. -98 Figura 29. Usos de suelo en la cuenca del rio Rímac. Modificado de: Asociación Louis Berger International -Tropical. Research - ECSA Ingenieros (1998). - 99 -

Figura 30. Compilación de sistemas estructurales en el Perú y en área de estudio. Basado en: Le Roux et al. (2000); Macharé et al. (2009); Scherrenberg et al (2014) y Villacorta et al. (2015). -100 Figura 31. Bloque diagrama esquemático del área evaluada y alrededores. 1: Intrusivos ecoceno-miocenos exhumados. 2: Océano Pacífico. 3: Afloramientos Jurásicocretácicos. 4: sedimentos cuaternarios. 5: Arcillas. 6: Arenas y gravas. No a escala. - 102

Figura 32. Esquema de cómo están distribuidas las facies sedimentarias en la Costa Verde (entre Miraflores y Chorrillos). G: Gravas correspondientes a canales tractivos, A: Arenas de canales rellenados, Arc: Arcillas y limos correspondientes a llanuras de inundación. No a escala. Modificado de: Villacorta et al. (2015). - 103 - 
Figura 33. Principales estructuras geológicas en Lima Metropolitana. Modificado de: Le Roux et al. (2000); Macharé et al. (2009); Villacorta et al. (2015)......................... 105 Figura 34. Anticlinal de Lima inferido por Lisson. Modificado de Lisson (1907) ..- 106 Figura 35. Sección playa Márquez - cerro Pirámide (Comas). Fallas normales habrían causado la rotación de bloques que pueden dar una interpretación de un anticlinal fallado sin serlo. Modificado de Aleman et al. (2006). 1. Fm. Tambo Inga, 2. Puente Inga, 3. Ventanilla, 4. La Herradura, 5. Chilca, 6. Quilmaná, 7. Batolito de la Costa, 8. Basamento desconocido. $106-$ Figura 36. Esquema metodológico seguido en este estudio. Modificado de: Llorente (2014) -108 Figura 37. A) Equipo empleado en la datación por OSL (Sistema automatizado lector de termoluminiscencia y de luminiscencia ópticamente estimulada marca Ris $\varnothing$ ) en el Laboratorio de Dataciones de la Facultad de Física de la Universidad Nacional de Ingeniería (Perú). B) Análisis en microscopio las muestras de cuarzo a ser analizadas por OSL. -111 -

Figura 38. Vista de planta del área donde se trazaron los perfiles del análisis geomorfológico.......................................................................................... 118 Figura 39. Perfil Jicamarca -Cerro Candela.......................................................... 118 Figura 40. Perfil Cerro Mirador -Huertos de La Molina ...........................................- 118 Figura 41. Perfil Cajamarquilla-Playa Chorrillos .................................................. 118 Figura 42. Perfil Carapongo -Puerto del Callao.................................................... 118 Figura 43. Perfil Puerto del Callao-San Juan de Miraflores ......................................- 119 Figura 44. Reducción del ancho de cauce del río Rímac. Foto superiror: C, Wisse (1940); Abajo: imagen de Google Earth (2016)......................................................... 120 Figura 45. Material en el cauce del río Rímac a la altura del ápice (Ate) ................- 121 Figura 46. Sucesión observada en el club Regatas (Chorrillos). Se observa en la columna levantada las diferentes facies. grava (amarillo), arena (gris claro), arcilla (marrón).

Figura 47. Esquema metodológico para el análisis de zonas inundables. Tomado de: Llorente (2014) $-126-$ Figura 48. Ubicación de las estaciones meteorológicas empleadas en este estudio. - 127 Figura 49. Estimación con IDW de la precipitación máxima diaria para un periodo de retorno de 500 años en el área de cuenca del río Rímac. -129 Figura 50. Modelo de precipitación máxima diaria para un periodo de retorno de 500 años en el área de la cuenca del río Rímac empleando cokrigeado precipitación-altitud. 130 -

Figura 51. Numero de curva para la cuenca del río Rímac $-132-$ Figura 52. Hidrograma líquido de la sección en el punto Tokio y Los Laureles para un periodo de retorno de 500 años en la cuenca del río Rímac. $-133-$ Figura 53. Localización del perfil representativo Sector denominado Tokio y Los Laureles. $135-$

Figura 54. Sección transversal esquemática del sector Tokio y Los Laureles (a la altura del cerro Candela, ATE). 1. Depósitos aluviales, 2. Depósitos fluviales, 3. Cauce actual,4. Substrato intrusivo $135-$ Figura 55. MDT exportado desde ArcGIS (a) al GDS del FLO-2D (b)..................- 137 Figura 56. En el círculo verde se observan las condiciones de contorno de de entrada (inflow) con los datos del hidrograma.y en el circulo rojo lascondiciones de contorno de salida (outflow). 137 Figura 57. Ventana de dialogo en flo2d para ingresar los datos del hidrograma empleado en la modelización numérica. - 138 - 
Figura 58. Vista de la simulación por flujo de detritos en el río Rímac en FLO 2D....... 138 -

Figura 59. Hidrograma sólido de entrada para la simulación de un flujo de detritos en el abanico del río Rímac con periodo de retorno de 500 años....................................... 139 Figura 60. Ubicación de las muestras analizadas por OSL en este estudio...............- 141 Figura 61. Interpretación de las secuencias observadas en la parte central del abanico a la altura del museo de la memoria (Miraflores). $-142-$ Figura 62. Columna levantada en el sector Magdalena, zona norte del abanico de Lima 143 -

Figura 63. Columna levantada en el sector quebrada de Armendariz (Barranco)....- 143 Figura 64. Secuencias fluviales y aluviales observadas en Huachipa (río Huaycoloro, uno de los principales afluentes del río Rímac).

Figura 65. Geoformas identificadas en el área de estudio. 1. Ápice del abanico (Ate), 2. Quebrada Canto Grande, 3. Cerro El Agustino, 4. Circuito de playas de la Costa Verde (Miraflores), 5. Morro Solar. - 145 -

Figura 66. Imagen satelital (2006) donde se han interpretado las estructuras en los alrededores del abanico de Lima. $146-$ Figura 67. Geología generalizada del Abanico de Lima y alrededores mostrando las estructuras interpretadas.1: Huachipa, 2: San Juan de Lurigancho, 3: Cerro El Agustino, 4: Santa Anita. 5: Circuito de Playas Costa Verde, 6: Morro Solar, 7: San Juan de Miraflores. $147-$ Figura 68. Velicidad y altura de flujo de detrtitos en el río Rímac (apice del abanico hasta desembocadura). $148-$ Figura 69. Módulo Hazard Map del FLO2D ......................................................... 149 Figura 70. Comparación del cartografiado geomorfológico y el modelo hidraulico desarrollado para un periodo de retorno de 500 años. -150 Figura 71. Etapas del desarrollo del Abanico aluvial de Lima.................................. 162 Figura 72. Sección transversal esquemática entre los cerros La Milla (San Martin) y Casuarinas (Santiago de Surco) de que muestra las etapas de sedimentación en el abanico de Lima. T0 a T6: terrazas fluvio-aluviales. 1. Materiales del Holoceno, 2. Materiales del Pleistoceno, 3. Canal actual, 4. Substrato intrusivo. 5. Glacis..........- 162 Figura 73. Partes de una represa SABO tipo. Traducido de: Ikeda (2015) ..............- 168 Figura 74. Propuesta de Plan maestro SABO en la cuenca de la quebrada Rayos de Sol.$170-$

\section{FOTOS}

Foto 1. Flujo de detritos de Thistle (Utah, EE.UU.). Tomada de: http://www.floodsafety.noaa.gov/states/ut-flood.shtml..... $-33-$ Foto 2. Vista aérea del represamiento del río Spanish Fork en Thistle. Tomada de: https://pubs.usgs.gov/of/2001/ofr-01-0276/ $-33-$ Foto 3. Fotografía de la avalancha de rocas del 28 de julio de 1987 en Val Pola (Valtellina, Alpes italianos) con el lago embalsado aguas abajo hacia la derecha. Tomado de Crosta et al. (2004). $34-$ Foto 4. Flujos de detritos de Sarno (Italia). Tomado de: http://polaris.irpi.cnr.it/lecolate-rapide-di-sarno-del-maggio-1998/. $35-$ Foto 5. Vista aérea del flujo híper-concentrado de Páez (Colombia) en 1994. Tomado de: http://landslides.usgs.gov/learn/photos/largest_worldwide_landslides/1994_debris_flow 
s_triggered_by_paez_colomibia_earthquake/paezearthquakelahar1994casadevall.jpg..36 -

Foto 6. Vista aérea del aluvión que en 1970 enterró al poblado de Yungay y causó la muerte de 25000 personas. (tomado de: http://www.actualidadambiental.pe/?p=19482.37 -

Foto 7. Vista de la población de Yungay (Ancash) tras el paso de la avalancha. Tomado de http://peru.com/actualidad/nacionales/ancash-asi-quedo-yungay-luego-terremoto-79grados-y-aluvion-fotos-noticia-142301-542528?foto=1 $-37-$ Foto 8. Vista de la destrucción causada por el flujo de detritos de Aguas Calientes en la entrada a Machupicchu (Cusco, Perú). Tomado de Villacorta, Fidel \& Zavala (2012).... 38 -

Foto 9. Incipientes cementaciones cálcicas por aparente alteración de feldespatos de la granodiorita que conforma el substrato. A.H. Hacia El Desarrollo (San Juan de Lurigancho). - 97 -

Foto 10. Vista panorámica de La Costa Verde a la altura de Miraflores (tomado de: (Mixmade S.A.C., 2008) $-101-$ Foto 11. Cantera abandonada, rellenada con desmonte y basura en quebrada tributaria al río Rímac (sector Las Américas-Ate Vitarte). Tomado de Villacorta et al. (2015). - 104 Foto 12. Bloques rotados a causa de set de fallas normales asociadas que aparentan un anticlinal fallado. Tomado de: (Aleman et al., 2006). -107 -

Foto 13. Tubos para muestreo por OSL diseñado por la Dra. Susana Petrick del IPEN (Perú) $-112-$

Foto 14. Perfil vertical sobre el afloramiento de arenas de la duna Lomo de Corvina. En la foto se indican las elevaciones sobre la base del perfil donde se extrajo la arena (muestras LC 1, 2 y 3 ) en tubos de acero galvanizado para realizar los análisis de OSL. 114 -

Foto 15. Área de la duna Lomo de Corvina donde se extrajeron las muestras LC 4, 5 y

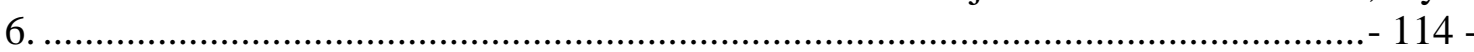

Foto 16. Ubicación de las muestras analizadas por OSL en la Estación Magdalena. - 115

Foto 17. Ubicación de las muestras analizadas por OSL en la Estación Regatas ....- 115 Foto 18. Ubicación de las muestras extraídas en Huachipa para su análisis por OSL......116 -

Foto 19. A) Falla en el sector Barbadillo (Ate) que corta intrusivos de la unidad Santa

Rosa. B) Plano de falla: Rumbo: N $96^{\circ}$ Buz: $61^{\circ} \mathrm{SW}$ -122 -

Foto 20. A, B. Terrazas depositadas en el área del río Huaycoloro como producto de diferentes episodios de flujos de detritos. Foto: Manrique, 2016. $124-$ Foto 21. a) Flujos de detritos polimíctico que engloba bloques, bolones, detritos, arena, limos y arcillas. b) Predominan los clastos intrusivos (I) y volcánicos (v). Foto:

Manrique, 2016. $124-$

Foto 22. A, B. Capas de lodo transportadas por aguas turbias, sedimentadas en capas en ambientes de calma. En este tipo de materiales se producen las grietas de desecación.

Foto: Manrique, 2016. $-125-$

Foto 23. Relicto de terraza aluvial en la quebrada Melgarejo (La Molina-Cieneguilla)...144 -

Foto 24. Esquema del Plan Maestro SABO en Minami-Aso Village (Kumamoto). Fotos: S. Villacorta (2015). 167 Foto 25. Represa SABO para el control de flujos de detritos en Minami-Aso Village (Kumamoto), a) vista de planta, b) vista frontal. Foto: S. Villacorta (2015). ..........- 169 Foto 26. Presa SABO tipo abierta. Tomado de: Ikeda (2015)............................... 170 - 


\section{TABLAS}

Tabla 1. Ecuaciones IDF de Froehlich (Froehlich, 1995) $66-$ Tabla 2.Valores de los coeficientes según región del Perú. Tomado de (Ministerio de Transportes y Comunicaciones (2014) $-67-$ Tabla 3. Eventos históricos de flujos e inundaciones en Lima Metropolitana (modificado de: (Zavala, Vílchez, \& Nuñez, 2012; Villacorta, Nuñez, \& Huarez, 2015) 82 -

Tabla 4. Descripción de los Grupos hidrológicos de suelos de la USDA-SCS (Mockus, 1972; Boughton, 1989) Traducido por: Ferrer, Rodríguez, \& Estrela (1995).............- 97 Tabla 5. Usos de suelo en el área de la quebrada cuenca del río Rímac ....................- 98 Tabla 6. Funciones de ajuste empleadas para cada estación evaluada en la cuenca del río Rímac $128-$

Tabla 7. Valores del umbral de escorrentía para condiciones medias de humedadasociación con grupo hidrológico y cobertura del terreno empleados para la cuenca Rímac (modificado de (Mockus, 1972; Boughton, 1989; Mishra et al., 2008)........- 131 Tabla 8. Datos empleados para calcular el caudal máximo para un periodo de retorno de 500 años mediante el método hidrológico -133 -

Tabla 9. Datos de entrada para calcular el caudal crític en el sector Tokio y Los Laureles (modelo hidráulico) $136-$ Tabla 10. Datos de entrada para la simulación de flujo de detritos en el río Rímac con periodo de retorno de 500 años en flo2d 139 Tabla 11. Edad estimada y parámetros de datación OSL ........................................- 140 Tabla 12. Resultados de la simulación numérica por flujos de detritos (Q500) en el área del abanico de Lima 148 Tabla 13. Criterios acerca del nivel de peligrosidad para flujos de detritos y procesos similares (Rickenmann, 2005). 149 


\section{PRESENTACIÓN}

Esta memoria, se presenta como prueba de aptitud para la obtención del Grado de Doctor por la Universidad Politécnica de Madrid (UPM) con mención en "Investigación, Modelización y Análisis del Riesgo en Medio Ambiente." Se ha buscado evaluar un área de interés para el Instituto Geológico Minero y Metalúrgico del Perú (INGEMMET), en el marco de la colaboración existente entre el INGEMMET, la UPM y el Instituto Geológico y Minero de España (IGME) con el objetivo de profundizar en el conocimiento del origen y evolución del abanico aluvial del río Rímac, con respecto a los fenómenos tectónicos y que se pueden relacionar además a los cambios climáticos en el pasado. La obtención de modelos de peligrosidad por inundaciones del río en cuyo valle se asienta la ciudad de Lima, capital del Perú, contribuirá a una planificación y ordenamiento territorial más eficaz para esta importante urbe peruana.

Su desarrollo, supervisión y asesoramiento científico y académico se ha realizado bajo la dirección del Dr. Trinidad de Torres, catedrático de la Escuela Técnico Superior de Ingeniería Geológica y Minera, y Responsable del laboratorio de Estratigrafía Biomolecular de la UPM.

\subsection{CONTENIDO Y ORGANIZACIÓN DEL DOCUMENTO}

Se encuentra estructurado en cinco capítulos (I, Introducción; II, Estado del Arte; III, Metodología y Desarrollo; IV, Resultados; V, Discusión; VI, Conclusiones y Recomendaciones) con sus correspondientes epígrafes y subtítulos.

Cuenta con un total de 180 páginas, 13 tablas, 74 figuras, 26 fotos y 07 anexos donde se incluye los datos empleados en el modelo hidrológico y la cartografía empleada.

El primer capítulo es la presentación, la cual contiene una descripción de la estructura del documento, esbozándose la problemática de partida y los objetivos que justifican su realización.

El segundo capítulo describe el estado del arte y todos los conceptos, terminologías, limitaciones y propuestas asociados a las temáticas abordadas.

En el tercer capítulo se desarrollan los métodos y procedimientos seguidos en este trabajo, y con los que se obtuvieron los resultados presentados que se justifican y 
detallan en los epígrafes de discusión (capítulos IV y V); seguidos de las conclusiones y recomendaciones respectivas, resumidos en el capítulo sexto, y último.

Finalmente, y después del apartado de las necesarias referencias, apuntes, reseñas, citas y notas bibliográficas, se adjuntan los anexos, en los que están a disposición todos los datos, mapas incluidos, para consultar las cartografías resultantes del trabajo de Tesis (anexos I y II).

Esta Tesis Doctoral se ha enmarcado en la línea de investigación que viene desarrollando el INGEMMET durante las cuatro últimas décadas, enfocada a un mejor y más profundo conocimiento e interpretación geológica del territorio peruano y cuya finalidad es la prevención de desastres de origen geológico. Los trabajos de esta labor de investigación, soportada durante este tiempo han generado diferentes publicaciones como informes técnicos, artículos de interés científico, algunos de ellos en curso en la actualidad, como parte de los proyectos GA11 y GA24 del "Programa Nacional de Riesgos Geológicos" desarrollados por el INGEMMET en el periodo comprendido entre el año 2011 y 2017, vigente a la actualidad, así como de la Actividad ACT01 "Apoyo en Riesgo Geológico a Entidades Públicas", del Plan operativo del INGEMMET 2016-2017.

\subsection{INTRODUCCIÓN}

La zona de estudio se encuentra enmarcada en la región de Lima Metropolitana, la más importante del Perú, desde el punto de vista financiero y económico, al ser su capital. Destaca, además, por su potencial turístico, histórico, cultural, arqueológico y gastronómico, entre otros aspectos.

Para el Perú es una preocupación constante los efectos asociados a los cambios climáticos, en especial los relacionados al incremento de lluvias en la zona desértica de la costa peruana (Sara, Jameson, Pfeffer, \& Baud, 2016) lo que exige ampliar los esfuerzos y planificación en las políticas de adaptación y mitigación por parte de las autoridades nacionales y las entidades científicas, Institutos técnicos y de investigación, universidades, entre otras (Villacorta, Nuñez, Tatard, Pari, \& Fidel, 2015). 
Uno de los efectos más inminentes, y recurrentes, entre los múltiples que se han contabilizado, sería el desencadenamiento de inundaciones y flujos híperconcentrados, que, en este caso, afectaría a parte de los distritos de Lima Metropolitana, la región más densamente poblada con casi un tercio de la población total del país (Instituto Nacional de Estadística e Informática, 2014).

La sociedad peruana desconoce las condiciones geológicas que dieron lugar al ámbito geográfico en el que viven. Esto hace que no sea lo suficientemente resiliente para afrontar desastres asociados a los procesos naturales que ocurren en su ámbito. En el caso del abanico del rio Rímac, donde se asienta la capital peruana, las geoformas observadas dan cuenta de que antes existirían condiciones climáticas diferentes (mayor precipitación y caudales), como se ha planteado de forma general en documentos como los de IMP (2008), Villacorta et al. (2015) y Sara et al. (2016).

Esta reflexión, así como la necesidad de contribuir a un desarrollo sostenible de la región de Lima Metropolitana, debido al alto riesgo que se concentra en la ciudad capital, hace necesario plantear y desarrollar estudios geocientíficos que sirvan como base metodológica y técnica para la generación de planes de gestión adecuados capaces de actuar frente a los desastres que, potencialmente, pueden vincularse con la fenomenología derivada de los cambios climáticos.

Este documento, contiene bases conceptuales que pueden considerarse en nuevos planes de prevención de desastres frente a procesos de inundaciones y flujos de detritos para la capital del Perú. La finalidad es abordar de forma científica y racional, una evaluación de cómo continuará evolucionando el relieve en el área del abanico de Lima y los riesgos asociados a este desarrollo, a fin de contribuir a minimizarlos y a su vez en una planificación y reordenamiento urbano que permitan un desarrollo regulado del área del abanico de Lima, inexistente hasta ahora, si bien ha habido algunas iniciativas tanto a escala local.

Estas temáticas, en la actualidad, tal y como avala la bibliografía existente, están siendo escasamente abordadas por otras entidades e investigadores. 


\subsection{HIPOTESIS DE TRABAJO}

Ante la problemática expuesta es que se plantea desarrollar una investigación, que además de incrementar el conocimiento geológico de este sector tan importante para el Perú, contribuya con un ordenamiento adecuado para la ciudad de Lima. La Hipótesis de partida es que la formación del abanico de Lima respondería al hundimiento de bloques fallados y en condiciones climáticas diferentes a las actuales. Asimismo, que los efectos de una obstrucción parcial o total del río Rímac podrían modificar las condiciones geomorfológicas existentes al día de hoy.

\subsection{JUSTIFICACIÓN}

La presente investigación se justifica, dado que el abanico de Lima tiene aproximadamente unos $216 \mathrm{~km}^{2}$ que no han sido estudiados suficientemente desde el punto de vista geodinámico (Aleman, Benavides, \& León, 2006; Le Roux, Tavares Correa, \& Alayza, 2000).

La escasez de ensayos de laboratorio y de campo, ha dificultado el poder determinar cómo y bajo qué condiciones se formó específicamente, así como su relación con los procesos que podrían modificarlo, su evolución geográfica, espacial y temporal, así como sus riesgos asociados.

Es necesario, además, integrar los efectos (en gran medida provocados en la segunda mitad del siglo XX) de la antropización (industrialización, urbanización, desarrollo de infraestructuras viales y de comunicación) en el valle del río Rímac, que ha cambiado su configuración geomorfológica -enclaustrado e impermeabilizado su cauce en toda el área urbana de Lima metropolitana-; tales como la deforestación, rigidificación de cauces y ocupación de áreas susceptibles a flujos de detritos e inundaciones.

Esta casuística pone en valor la necesidad de este tipo de estudios ya que los nuevos factores condicionantes elevan el riesgo a que se produzcan -en el caso de sobrepasar su nivel de almacenamiento actual- desbordes e inundaciones del río Rímac; temática que hasta el momento no ha sido estudiada, valorada ni contemplada. 


\subsection{OBJETIVOS}

Ante la búsqueda de generar información geocientífica que contribuya a solucionar la problemática presentada, se plantearon los siguientes objetivos:

- Determinar la génesis del abanico del río Rímac en relación a la tectónica andina y los cambios climáticos pasados.

- Evaluar el comportamiento del río Rímac, sobre todo en el área urbana de Lima Metropolitana ante fenómenos extremos como las lluvias excepcionales asociadas a EI Niño Southern Oscilation (ENSO).

- Desarrollar metodologías de modelos numéricos capaces de acotar áreas de potencial peligro por inundaciones que puedan luego extrapolarse a otras zonas del Perú. 


\section{ESTADO DEL ARTE}

En esta parte se consideran una serie de estudios anteriores sobre abanicos aluviales en el mundo, asi como una revisión de otros similares en Suramérica con el objetivo de contextualizar adecuadamente la zona de investigación. Posteriormente se revisan los conceptos aplicados adelante en la modelización hidrológica-geomorfológica del río Rímac y su abanico.

Los primeros trabajos de investigación de esta índole se desarrollaron durante el siglo XIX destacando los estudios realizados en Norteamérica y Nueva Zelanda (McGee, 1896; Miller, 1883; Von Haast, 1879) donde básicamente se hace caracterizaciones de los materiales componentes de los abanicos aluviales. Inicialmente se centraron en las características morfológicas de los depósitos de origen aluvial (Surrel, 1841), generalizándose con posterioridad el uso del término "abanico aluvial” (Drew, 1873).

En el siglo XX otros investigadores empezaron a diferenciar los depósitos de abanicos aluviales de aquellos producidos por los ríos y deltas (D. W. Johnson, 1932; Pack, 1923; Bryan, 1922; Davis, 1905). Posteriores trabajos incidieron en los procesos genéticos (Lawson, 1913; Pack, 1923; Tieje, 1923), lo que llevó a estudios más especializados sobre la relación de los abanicos aluviales y la tectónica (Eckis, 1928; Harvey, 2002; Longwell, 1930; Trowbridge, 1911).

Es a partir de los años 70 cuando esta temática tomó las siguientes vertientes: por un lado, la caracterización de abanicos aluviales por ambientes sedimentarios y de otro, la descripción de los procesos en abanicos aluviales de formación reciente. Entre los primeros destacan los manuscritos de: (Kukal, 1971; Spearing, 1974; Bull, 1977; Colombo, 1979; Reineck \& Singh, 1980; Fisher \& Brown, 1984; Saito, 1988); mientras que en el segundo caso habría que citar las investigaciones de (Beaty, 1963; Beaty, 1970; Beaumont, 1972; Denny, 1967; Gile \& Hawley, 1966; Hack, 1965; Hooke, 1968; Melton, 1965; G. E. Williams, 1969). De hecho, la mayoría de estos estudios se han desarrollado en regiones áridas/semiáridas y han establecido relaciones entre la morfología del abanico y el área fuente de los sedimentos.

La categorización por ambientes se inició con los trabajos de Bull (1968) en el desierto del Oeste de América del Norte, quien evaluó los abanicos existentes en el Valle de la 
Muerte, California. Posteriormente autores como Bull (1977); Schumm (1981); y Blair y McPherson (1994), dieron a conocer en todo el mundo dicha propuesta de tipificación.

Aunque, la mayoría de investigaciones sobre abanicos aluviales se han limitado a depósitos de los últimos 20Ma, como se puede corroborar en los estudios de Blair y McPherson (1994); Blum \& Törnqvist (2000); Harvey et al. (2005); Haug et al. (2010). Estudios más recientes como los de Gábris y Nagy (2005); Harvey y Wells, (2003); Kesel y Lowe (1987); y Pope y Wilkinson (2005) se enfocan en relacionar los parámetros geomorfológicos, tectónicos y climáticos.

\subsection{CARACTERÍSTICAS DE LOS ABANICOS ALUVIALES}

La primera definición de abanico aluvial se debe a Drew (1873) que utilizó dicho término para referirse a las "acumulaciones de gran potencia [..] en la cercanía de barrancos secundarios desde donde desembocan a un valle más amplio".

Definiciones más recientes aceptan que "son depósitos de material no consolidado (gravas, arena, limos, arcillas, etc.) acumulados en la base de una ladera en áreas montañosas generalmente, donde disminuye la pendiente (Blissenbach, 1954; Gómez, 1996). Autores como Bull (1977); Colombo (1979); Nilsen y Moore (1984); los denominan también como conos de deyección ya que su superficie forma un segmento de un cono que radia pendiente abajo desde el punto donde el curso de agua abandona el área fuente. Tienen por tanto un perfil radial cóncavo (Figura 1) de longitud limitada y pendiente de moderada a abrupta (Anstey, 1966; Wasson, 1975).

Según el régimen hídrico, y en función del ambiente climático dominante, normalmente los abanicos aluviales se diferencian en dos tipos: Los secos (Harvey, 1997), constituidos por la acumulación de diversos episodios de flujos de lodo y detritos; y los húmedos, asociados a flujos de agua permanentes o semi-permanentes (Kochel, 1990). 


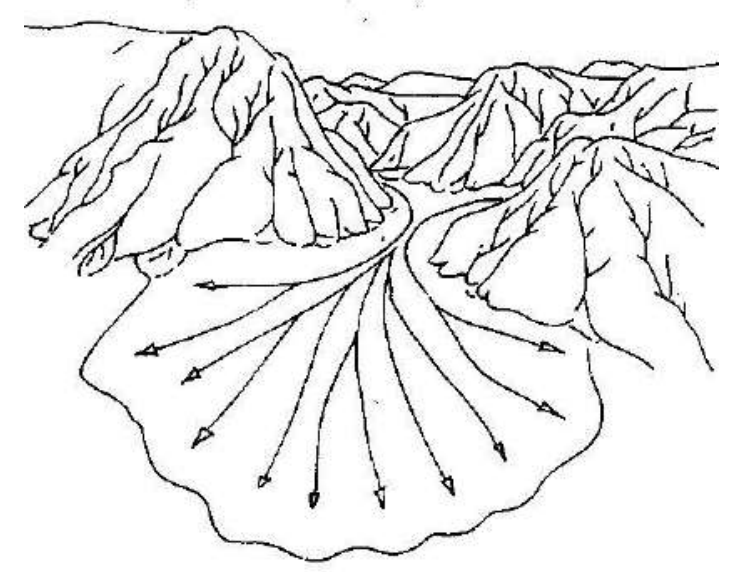

Figura 1. Morfología de un abanico aluvial en la salida de un cauce de quebradas que confluyen, con sus direcciones de flujo respectivas. Tomado de: Pedraza (1996).

Respecto a su tamaño pueden variar desde pequeños conos de menos de $50 \mathrm{~m}$ de longitud mayor (Brazier, Whittington, \& Ballantyne, 1988; Harvey \& Wells, 2003; Wells \& Harvey, 1987) hasta mega abanicos de decenas de kilómetros (Gohain, 1990; B. K. Horton \& DeCelles, 2001; Leier, DeCelles, \& Pelletier, 2005).

\subsection{FORMACIÓN DE ABANICOS ALUVIALES}

Los abanicos aluviales se forman frecuentemente en áreas montañosas donde las corrientes cargadas de sedimentos salen a zonas más llanas y pierden su capacidad de carga (Abalos, 1987; Denny, 1967; Rachocki, 1981). Otros solo requieren la presencia de desniveles topográficos (gap), en los que los depósitos estén por encima del ángulo de estabilidad de los materiales. Por esta razón es que en su formación y preservación intervienen múltiples factores y procesos.

\subsubsection{Factores que controlan la formación de un abanico aluvial}

Son diversos los factores que pueden influenciar tanto en la forma como en la existencia y preservación de abanicos aluviales. Entre los principales se consideran los condicionamientos tectónicos, climáticos y litológicos.

\subsubsection{Tectónica}

Según Bull (1977) en regiones tectónicamente activas las estructuras tectónicas son el principal factor para la ubicación de abanicos aluviales. Los grandes abanicos 
estudiados por Heward (1978), Nichols (1987) y Harvey (1989), dan cuenta de ello. En estos casos el control estructural configura la geometría del abanico al estar asociados a sistemas de fallas (Casas, 1995; Hooke, 1968; Meckel, 1975; Rockwell, Keller, \& Johnson, 1985; Scott, 1971; Steel \& Wilson, 1975; Steel, Næhle, Nilsen, Roe, \& Spinnangr, 1977). La actividad de las fallas favorece los procesos de agradación y preservación del propio abanico. Heward (1978) señala que hay tres ambientes tectónicos que controlan el espesor y extensión de las secuencias de los abanicos:

- Fallas de borde de cuenca relativamente estables, donde los sedimentos se acumulan a lo largo de una zona fallada (Figura 2).

- Fallas de retroceso de borde de cuenca con acumulación de abanicos alineados y de moderado espesor (Figura 3).

- Fallas de retroceso, escalonadas y seriadas, que pueden dar lugar a extensas secuencias de material grueso, más jóvenes en la dirección del retroceso de las fallas (Figura 4).

Según Crowell (1974) la geometría de los depósitos del abanico en ambientes tectónicos es compleja debido a la migración lateral de las corrientes que lo alimentan y del ápice del abanico cuando los movimientos de las fallas se producen en márgenes de cuencas. Los de gran espesor son considerados depósitos orogénicos (Bull, 1977), no solo porque la actividad tectónica favoreció el aporte de sedimentos desde áreas montañosas y por ende mayor competencia del material transportado, sino también porque el lugar de acumulación está controlado por la altura del frente montañoso (Bull, 1964a; Bull, 1968).

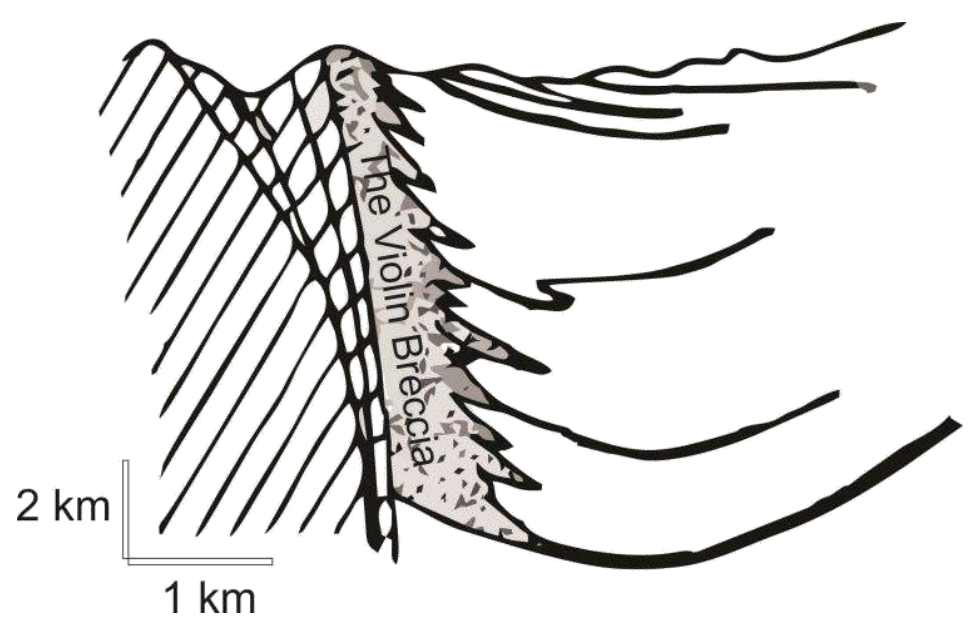

Figura 2. Falla de borde de cuenca estable. Muestra la relación entre la acumulación de las "Brechas del Violín» y las fracturas asociadas a la falla de San Andrés (Crowell, 1973). 


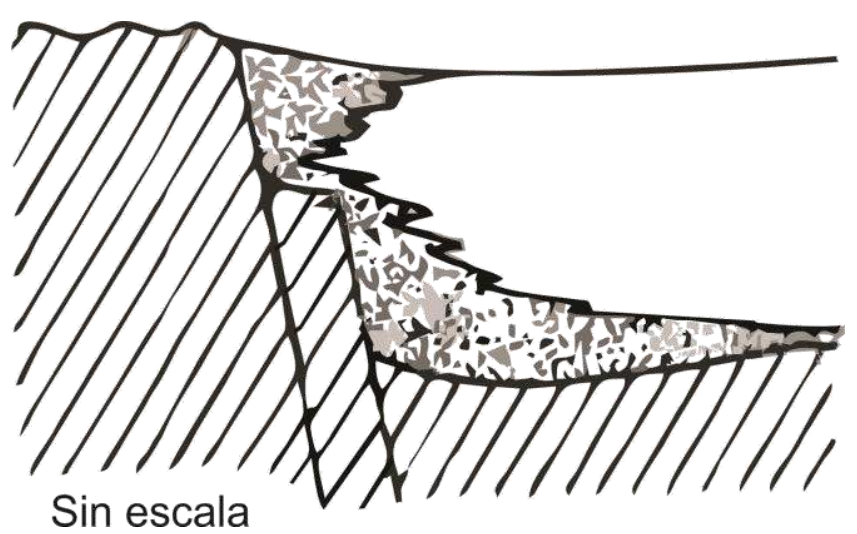

Figura 3. Borde de cuenca limitado por una falla retrogradante (Bull, 1968). Modelo basado en la disposición de la sedimentación carbonífera continental en cuencas atlánticas canadienses (Belt, 1968).

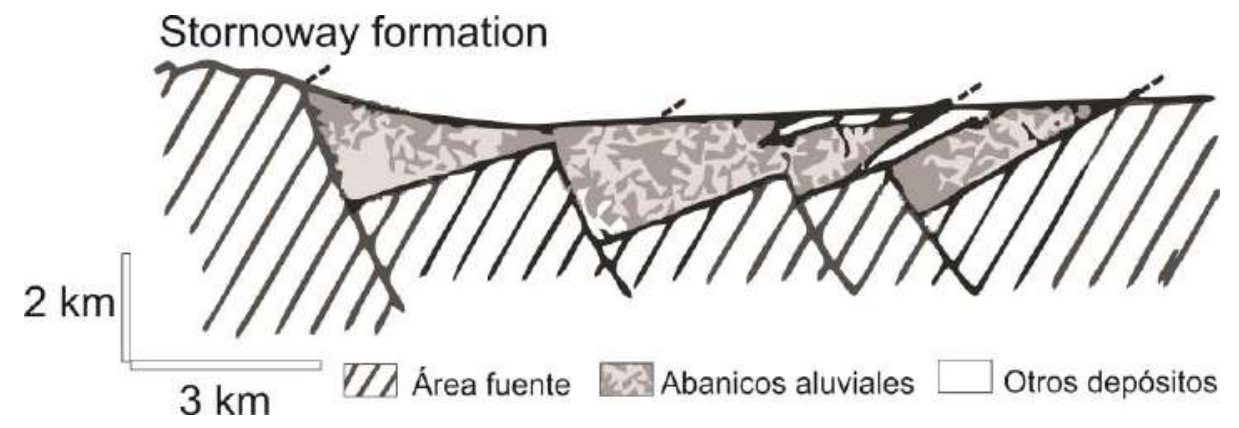

Figura 4. Borde de cuenca con fallas seriadas escalonadas (Steel \& Wilson, 1975).

Según Colombo (1979) en caso de que el abanico aluvial se encuentre condicionado principalmente por factores tectónicos, responderá a variaciones del equilibrio dependiendo de la relación entre las velocidades de levantamiento y de encajamiento del cauce principal. Si la velocidad del levantamiento es mayor a la del encajamiento se produce una acumulación de pequeños conos sobre impuestos a las partes más internas del abanico. Se origina entonces una grano-selección positiva asociada a la pérdida de energía a través del tiempo. Cuando ocurre lo inverso, toda la sedimentación se localizará hacia el pie del abanico, donde se construirán unos conos de deyección de menor tamaño y gradación negativa (materiales más finos en la base que en el techo) que obedece a ambientes reactivados de incremento de energía (Somoza \& Ghidella, 2005).

\subsubsection{Factores climáticos}

La climatología tiene gran influencia en la generación de sedimentos dentro de un abanico aluvial (Carryer, 1966). Sin embargo, la respuesta de los agentes 
geomorfológicos al cambio climático ha sido un campo de investigación poco explorado en geomorfología fluvial.

Además, los abanicos aluviales no suelen estar restringidos a zonas climáticas específicas, una gran cantidad de ellos han sido estudiados en ambientes áridos, semiáridos e híper-áridos (Beaumont, 1972; Frostick \& Reid, 1989; Harvey, 1990; Jansson, Jacobson, \& Le Hooke, 1993; Schick \& Lekach, 1987) en ambientes glaciares y paraglaciares (Boothroyd \& Ashley, 1975; Boothroyd \& Nummedal, 1977; Church \& Ryder, 1972; Gustavson, 1974; McGowen, 1971; Nossin, 1971; Ryder, 1971) y en ambientes tropicales (Mukerji, 1976a; Heward, 1978; Wescott \& Ethridge, 1980; Kesel, 1985; Kesel \& Spicer, 1985; Kesel \& Lowe, 1987).

También se han investigado aquellos abanicos que se formaron muy alejados del área-fuente, a los cuales se denomina abanicos terminales (Castelltort \& Marzo, 1986; Mukerji, 1976b; Sáez, 1985).

Lecce (1990) sugiere que los cambios climáticos influyen en la formación y desarrollo de los abanicos aluviales ya que controlan la magnitud y frecuencia de los procesos que dan lugar a sus rasgos y morfología.

Según Blissenbach (1954) la variación de la precipitación condiciona el desarrollo de un abanico (Figura 5), de tal forma que, a mayor cantidad de lluvia se produce una mayor incisión, una pendiente más suave y la acumulación de sedimentos es menor (Bull, 1964a; Lustig, 1965); mientras que al disminuir ésta, las pendientes del depósito son mayores y hay más acreción sedimentaria (Frostick \& Reid, 1989).

Algunos estudios han indagado acerca de la razón del incremento de actividad fluvial en los abanicos desde un clima árido (Baker, 1977; Harvey \& Wells, 1994) y lo atribuyen al mayor aporte de sedimentos por los flujos de detritos después de un cambio climático desde muy seco a muy húmedo (Al-Farraj, 1996).

Hasta cierto punto, la clasificación de tipos de abanico aluvial propuesta por Blair y McPherson (1994), basada en combinaciones de procesos, refuerza el concepto tradicional de "abanicos húmedos y secos" (Kochel, 1990); sin embargo, la diferenciación tipológica de abanicos asociados a un determinado clima actualmente se considera obsoleta y, ahora se basa en conceptos más complejos tal como la mecánica de depósito de los sedimentos (Harvey et al., 2005). 

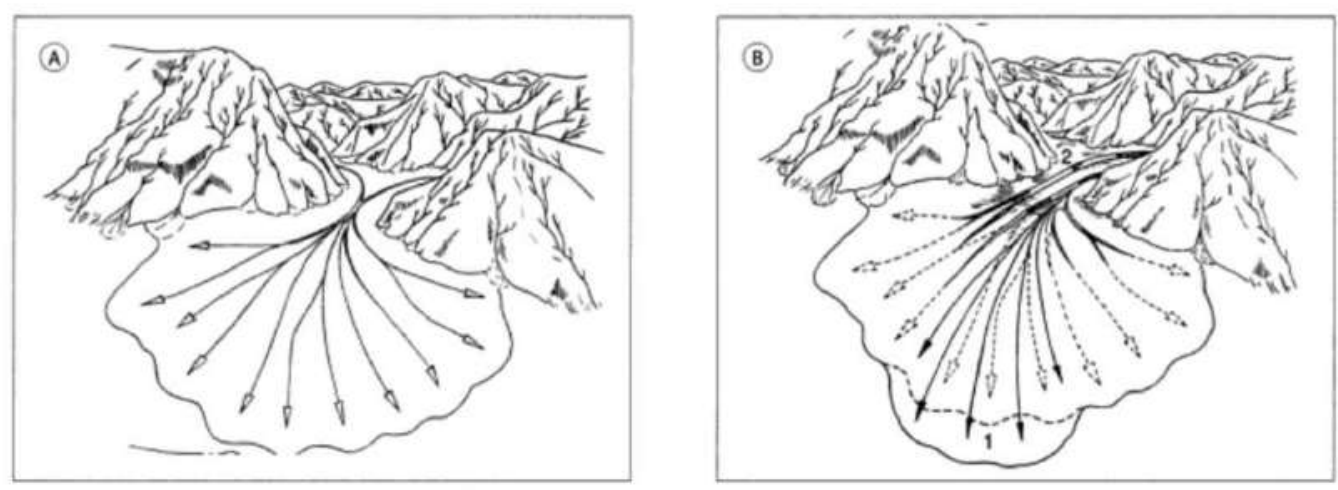

Figura 5. Aspectos de la generación de los abanicos aluviales mediante un control climático en la hipótesis de equilibrio: A) agradación durante los períodos de lluvias; B) encajamiento de los canales durante el período seco donde se produce el abandono de algunos cauces y crecimiento de un nuevo sector del abanico (Lustic, 1965)

\subsubsection{Factores de relieve (Geomorfología) y litológicos}

El relieve y la litología intervienen en la formación de abanicos, de tal forma que para comprender su evolución se debe estudiar previamente su área fuente: características geomorfológicas (relieve, pendiente, tipo de suelo y vegetación) y litológicas (aporte y tipo de sedimentos).

Estos factores combinados con el clima tienen que ver con los patrones de escorrentía superficial (Chow, 1964; Morgan, 1997) e influyen, en conjunto, en las características de los materiales depositados. Así, por ejemplo, si en el área fuente se produjesen movimientos en masa de materiales de una litología específica, el posterior depósito mostrará una textura y composición representativa (Colombo, 2010).

Montgomery \& Buffington (1998) observan que la capacidad de transporte de los cursos de agua disminuye con la pendiente, hasta que ya no se evacuan los sedimentos. Es entonces cuando se empieza a almacenar el material aluvial (Bull, 1968). Por ello Harvey (1997; 2002) propone que los abanicos aluviales juegan un papel amortiguador en los sistemas sedimentarios de montañas, configurando la dinámica de sedimentación del sistema. Por tanto se puede relacionar a la pendiente de forma directa en los procesos erosivos, así como en la frecuencia de los gravitacionales, en la escorrentía y el transporte de sedimentos (Bull, 1977; Harris \& Gustafson, 1993; Kostaschuk, MacDonald, \& Putnam, 1986; Marchi, Pasuto, \& Tecca, 1993). 
Según Blair y McPherson (1994), los distintos gradientes en la superficie de los abanicos resultan de diferentes procesos de acumulación, naciendo así el concepto de "slope gap" (pendiente del talud específico) entre los gradientes de un abanico aluvial y un río (Harvey, 2002; Saito \& Oguchi, 2005).

La litología del área fuente (o madre) también influye en la proporción de sedimentos aportados a los abanicos por medio de una relación inversa entre la resistencia de la roca y grado de erosión, la cual, a su vez tiene que ver con el diaclasamiento y fractura de la roca (Hooke \& Rohrer, 1977). Ello explica, además, el tamaño de los fragmentos, las características del transporte y los procesos acumulativos, y en consecuencia influye en la morfología y tamaño de los abanicos (Bull, 1962; Denny, 1965; Lecce, 1991).

\subsubsection{Procesos sedimentarios en los abanicos aluviales}

Están asociados con las características del transporte, que condicionan, a su vez, la proporción de materiales gruesos y finos en ellos (Gómez, 1996; Blair \& McPherson, 1994; Harvey, 1989, figura 6).

Así por ejemplo, una alta concentración de finos conduce a una sedimentación laminar, mientras que la presencia constante de sedimentos gruesos favorece la presencia de flujos masivos (Miall, 1978).

La importancia de los procesos laminares frente a los canalizados ha sido reconocida en abanicos aluviales de clima árido (Blair \& McPherson, 1994) en el sentido de que es necesario discriminar los principales procesos responsables de su construcción. Actualmente se diferencia entre los procesos formadores, a los flujos de detritos de los híper-concentrados (Blair \& McPherson, 1998; Blair \& McPherson, 1994; Wells \& Harvey, 1987) gracias a los avances en la comprensión de las características de los suelos o reología de los diferentes tipos de flujos (Lavigne \& Suwa, 2004; Cronin, Neall, Lecointre, \& Palmer, 1997); y en ingeniería hidráulica (Wang, Larsen, \& Xiang, 1994; Rickenmann, 1991; Julien \& Lan, 1991; Engelund \& Zhaohui, 1984).

La mayoría de procesos para la formación de abanicos estudiados corresponden a sistemas áridos o semiáridos. Así se han identificados procesos asociados a corrientes acuosas, confinadas y no confinadas (Colombo, 2010). 


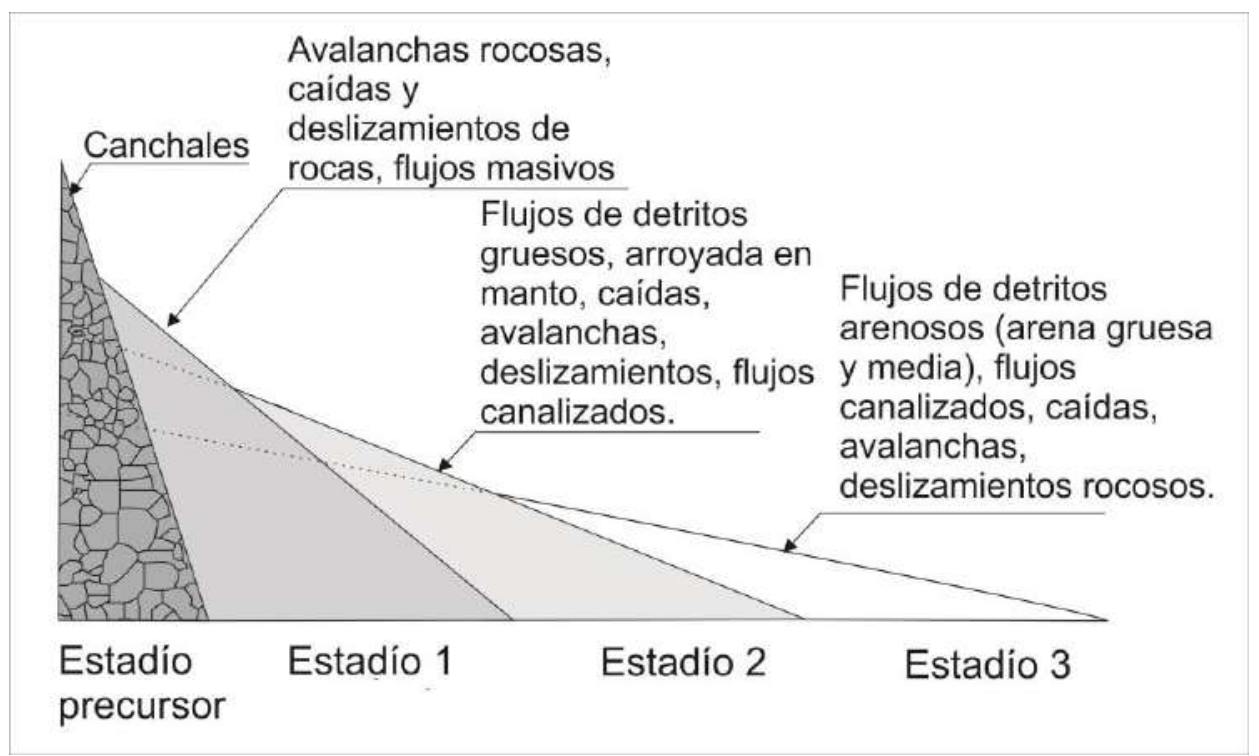

Figura 6. Esquema de los estadíos evolutivos del desarrollo de un abanico. Se indican los procesos geodinámicos predominantes. Modificado de Blair y MacPherson (1994).

\subsubsection{Procesos en corrientes acuosas}

Los flujos asociados a corrientes acuosas se clasifican, a menudo, como de tipo laminar (sheetflood) o flujos canalizados (Gómez, 1996).

Las corrientes laminares son producto de la arroyada en manto. Los torrentes, cargados de sedimentos, se expanden a medida que se mueven, aguas abajo, del abanico debido a que el canal de alimentación ya no los confina. Suelen localizarse en la parte media y distal a manera de láminas delgadas que pueden ser incididas por canales trenzados estrechos que se unen en las etapas de inundación (Gómez, 1996; Wasson, 1977; Bull, 1964b).

Los flujos canalizados (streamfloods) se confinan a los canales preexistentes cerca del ápice del abanico y con frecuencia son rectilíneos dentro de la parte superior del abanico aluvial (Wasklewicz, Mihir, \& Whitworth, 2008; Allen, 1981). Pueden profundizar el cauce en función de la descarga que evacuan y por la elevada pendiente que muestran. Podría corresponder a una inundación repentina también conocida en habla hispana como "avenida de tormenta" y suelen ubicarse en la parte media o baja de los abanicos (Arzani, 2005).

En abanicos formados por conglomerados, todas las características de estos materiales (forma, gradación granulométrica positiva, estratificación cruzada de bajo 
ángulo, bases erosivas) sugieren que el transporte ha sido producido por corrientes acuosas tractivas e intensas.

Los sedimentos granulares con participación de flujos acuosos se movilizan en función a su pendiente, la profundidad y la velocidad del flujo. Cuando el transporte decrece, los sedimentos empiezan a acumularse en función a su densidad y tamaño. Los abanicos suelen presentar pendientes longitudinales elevadas, inclinación que puede condicionar el comportamiento de los flujos de detritos producidos.

\subsubsection{Flujo de detritos}

Los flujos de detritos (o debris flow) son una fuente común de material en el desarrollo de abanicos aluviales a largo plazo (Wasklewicz \& Scheinert, 2016). El término fue propuesto por (T. Takahashi, 1981) para definir a flujos constituidos por una mezcla de agua y sedimentos con fragmentos rocosos heterogéneos (en composición y tamaño). Se pueden clasificar en función de su comportamiento reológico y de la proporción de fases sólida y líquida presentes (Hürlimann, Rickenmann, Medina, \& Bateman, 2008).

La velocidad de estos procesos, pueden ser muy rápidos a extremadamente rápidos (5 a $10 \mathrm{~m} / \mathrm{s}$ ) y con alcances de 100 a $1000 \mathrm{~m}$ de longitud, excepto los eventos extremos que pueden alcanzar velocidades cercanas a los $80 \mathrm{~m} / \mathrm{s}$ y viajar decenas de kilómetros (Huggel et al., 2005; Turnbull, Bowman, \& McElwaine, 2015).

Generalmente se originan en cuencas de alta montaña, de pendientes elevadas (entre 25 y 45 grados). La mezcla de materiales involucrados (arena, grava y cantos rodados) contiene una fase sólida (mayor al $60 \%$ en volumen) y su comportamiento reológico responde a un sistema no-newtoniano. La arcilla también forma parte de la mezcla en los flujos de detritos, pero a menudo contribuye con menos del $10 \%$ (Iverson, 1997).

Los flujos híper-concentrados son detríticos, con una mezcla en la que la parte sólida constituye entre el 20 y $60 \%$ del volumen total, con propiedades físicas intermedias entre un flujo de detritos y un flujo de lodo (Pierson, 2005). Estos transportan grandes cantidades de sedimento en suspensión o arrastre de fondo según el tamaño del material, la velocidad del flujo y su nivel de turbulencia. Su comportamiento reológico es cercano al de los fluidos newtonianos y está controlado por la fase líquida.

Los flujos de detritos son el resultado de una variedad de procesos como: la evolución de un deslizamiento de poca profundidad (Iverson, Reid, \& LaHusen, 1997; Costa, 
1984; T. Takahashi, 1981); sobrecargas en laderas de fuerte pendiente (Bovis \& Dagg, 1992); efecto lavado de las áreas fuente por conductos tipo sufusión (“fire-hosing”) en la interfase roca y material coluvial (Coe, Kinner, \& Godt, 2008; A. M. Johnson \& Rodine, 1984); aumento progresivo del volumen de sedimentos almacenado por la red de drenaje (Cannon, Gartner, Parrett, \& Parise, 2003), persistencia de lluvias en un largo periodo de tiempo, o de corta duración pero elevada intensidad, sismos o actividad volcánica que desestabilizan ciertas formaciones superficiales; erosión fluvial que produce socavación y movilización de laderas, incremento de la presión intersticial de agua asociada con acuíferos o una combinación de las anteriores (Ayala-Carcedo \& Olcinas, 2002; Proyecto Multinacional Andino, 2007).

\subsubsection{Flujos híper-concentrados y debris flow destacados a nivel mundial}

Como se ha podido observar, este tipo de procesos son comunes en casi todos los ambientes de depósito y son la causa de haber provocado pérdidas de vidas humanas y daños materiales cuantiosos en diferentes partes del mundo.

Así por ejemplo, se puede destacar los flujos de loess en Gansu (China) a raíz del terremoto de 1920, donde perecieron 200000 personas (Schuster \& Wieczorek, 2002); el flujo de detritos de Thistle (Utah, EEUU, Foto 1), desencadenado por fusión de nieve y lluvias intensas, que en 1983 causó el represamiento del río Spanish Fork e inundó Thistle (Foto 2) provocando cuantiosas pérdidas en obras viales (Kaliser \& Fleming, 1986). 


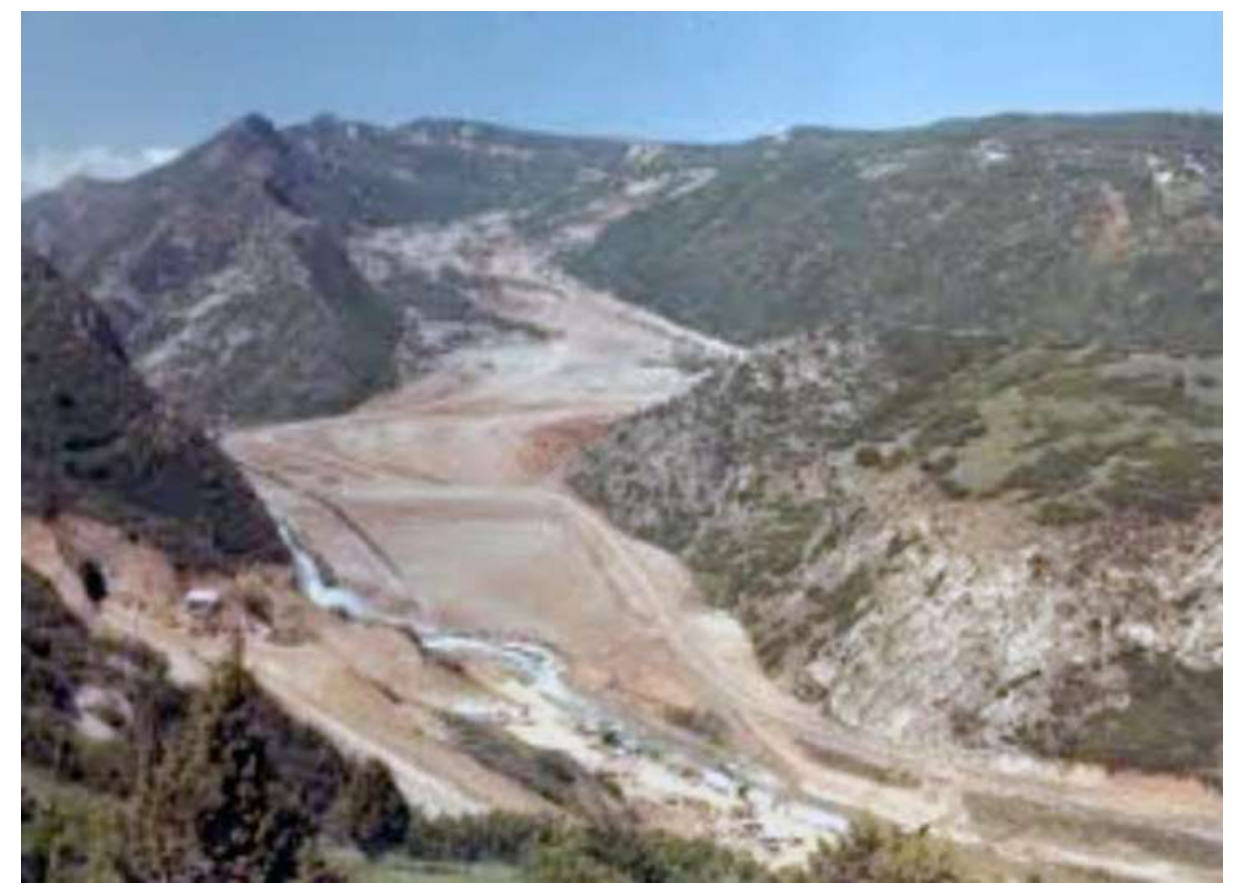

Foto 1. Flujo de detritos de Thistle (Utah, EE.UU.). Tomada de: http://www.floodsafety.noaa.gov/states/ut-flood.shtml

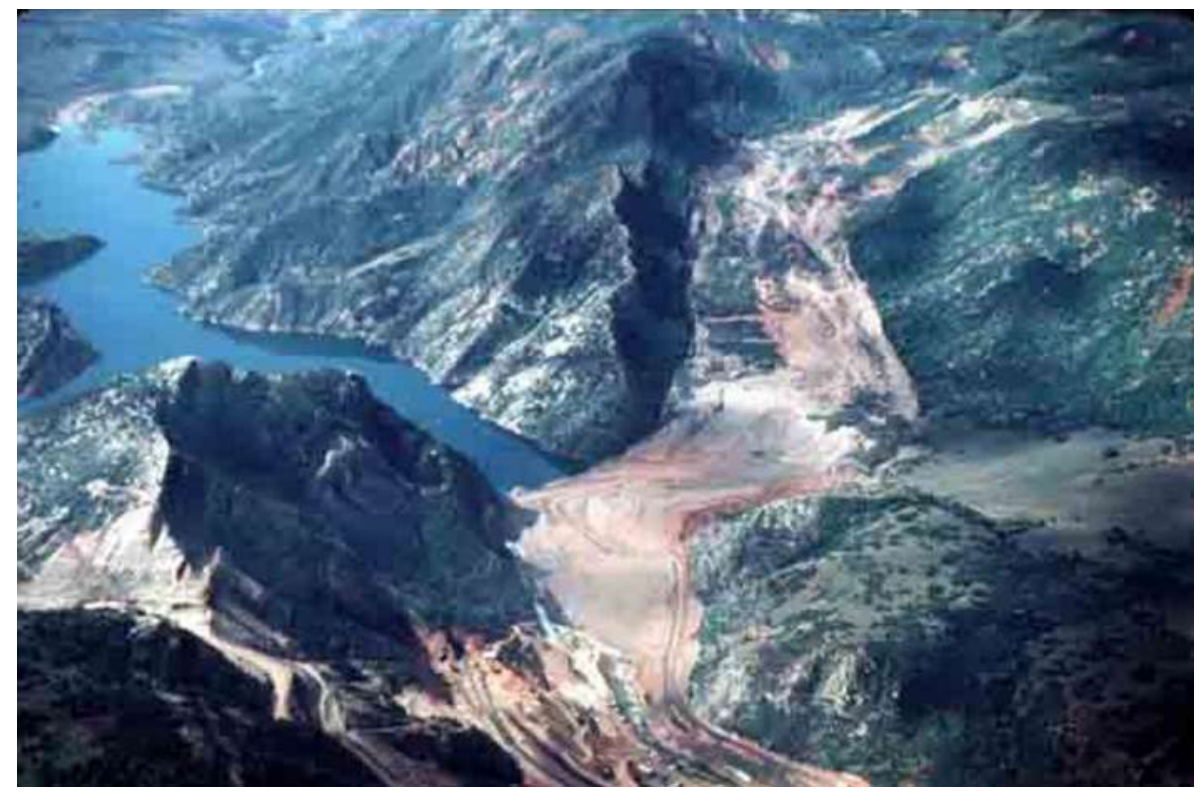

Foto 2. Vista aérea del represamiento del río Spanish Fork en Thistle. Tomada de: https://pubs.usgs.gov/of/2001/ofr-01-0276/

Otros eventos de flujos impactantes sucedieron en Europa, en la zona de los Alpes, como por ejemplo la avalancha de rocas de Val Pola (Foto 3), en la zona turística "La Valtellina" de los Alpes italianos (Lombardia, Italia), que en 1987 arrasaron los pueblos de Marignone y Aquilone con 29 muertos y pérdidas estimadas en US \$400 000000 (Crosta, Chen, \& Lee, 2004). Así también, los flujos de materiales volcanoclásticos 
procedentes de las laderas superiores de la montaña Pizzo d' Alvano (Foto 4), en 1998 causaron la muerte de 137 personas del municipio de Sarno en la región de Campania (Di Crescenzo \& Santo, 2005).

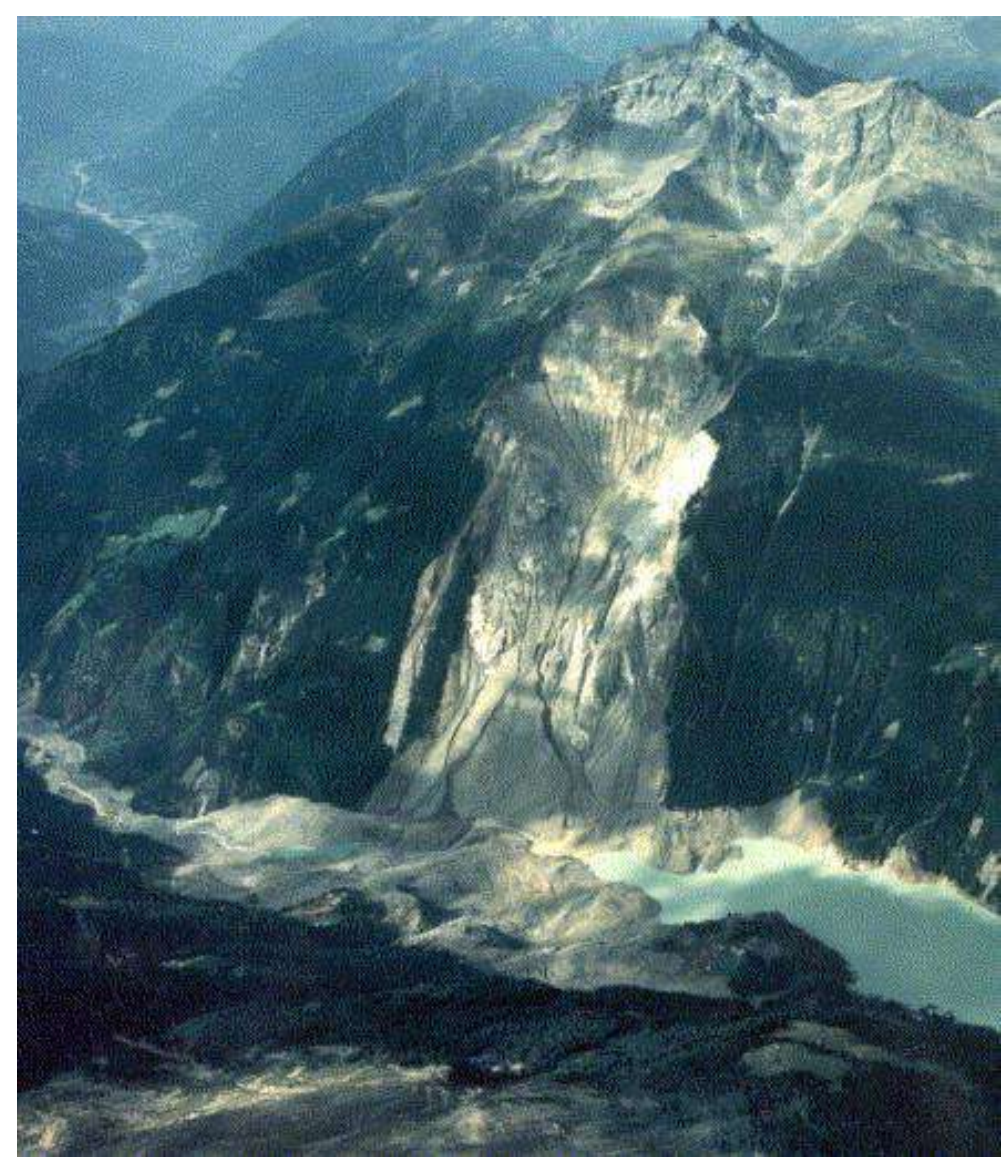

Foto 3. Fotografía de la avalancha de rocas del 28 de julio de 1987 en Val Pola (Valtellina, Alpes italianos) con el lago embalsado aguas abajo hacia la derecha. Tomado de Crosta et al. (2004). 


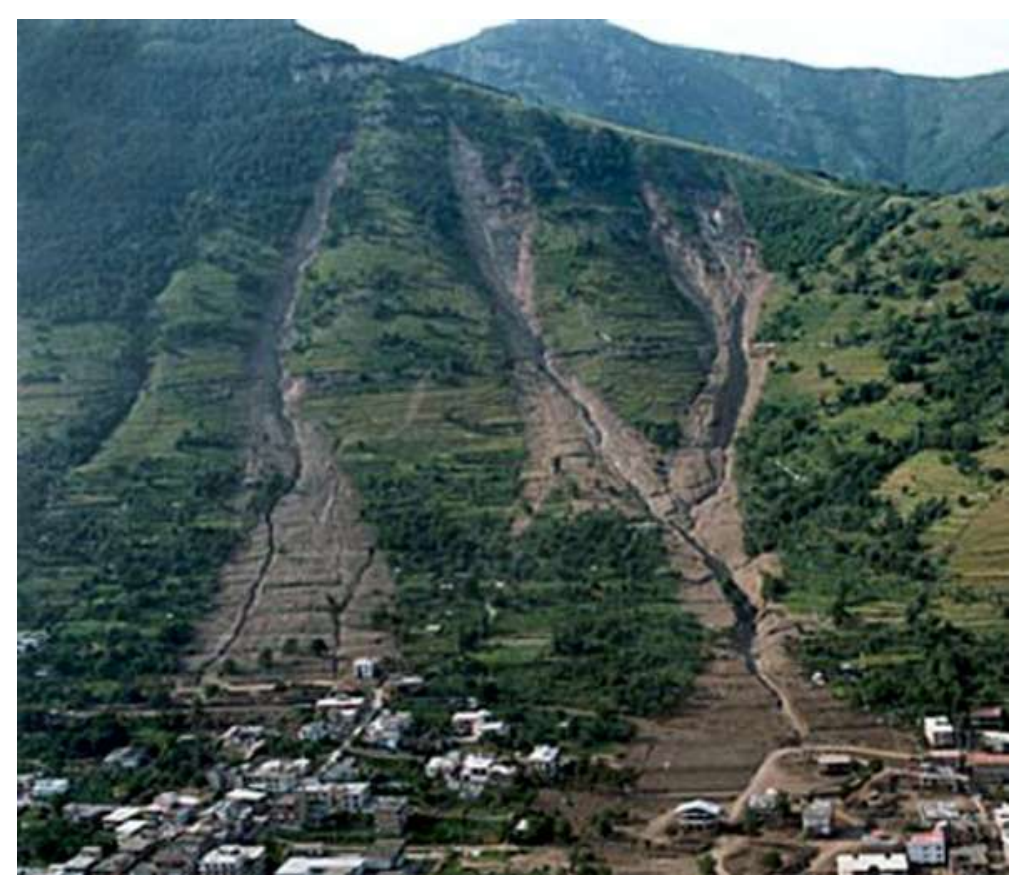

Foto 4. Flujos de detritos de Sarno (Italia). Tomado de: http://polaris.irpi.cnr.it/le-colate-rapidedi-sarno-del-maggio-1998/

En Suramérica, entre los debris flow más reconocidos se encuentran el aluvión de Yungay (descrito en esta memoria), los flujos de lahares en Armero (Colombia) a raíz de la erupción del volcán nevado del Ruiz de 1985, que causaron alrededor de 21700 muertos (Montero, 2007) y el flujo de detritos de Páez (Colombia) detonado por un sismo de magnitud 6.4 en la escala de Richter que en 1994 provocó la muerte de 221 personas y la destrucción del poblado de Páez (Foto 5) ((Wilches-Chaux, 2005). 


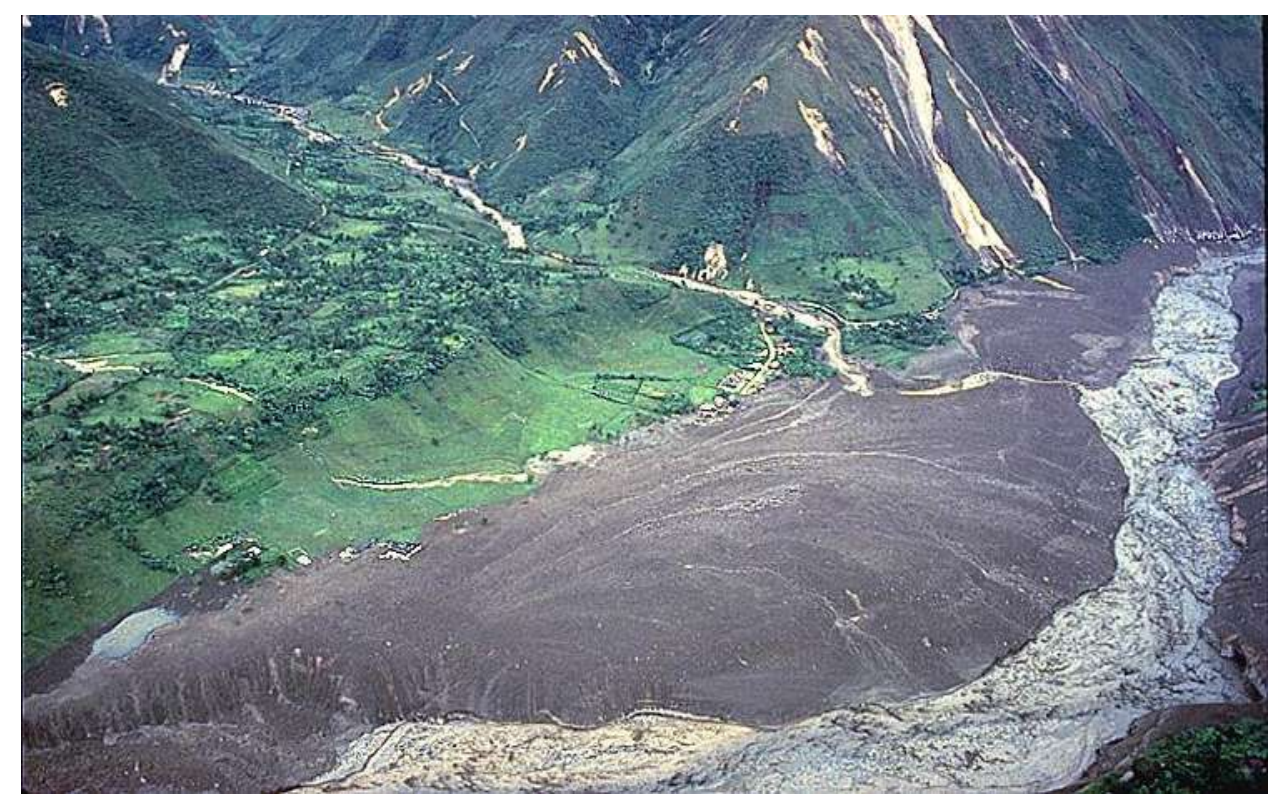

Foto 5. Vista aérea del flujo híper-concentrado de Páez (Colombia) en 1994. Tomado de: http://landslides.usgs.gov/learn/photos/largest_worldwide_landslides/1994_debris_flows_trigg ered_by_paez_colomibia_earthquake/paezearthquakelahar1994casadevall.jpg.

2.2.2.4 Flujos híper-concentrados y debris flow en el Perú

El evento más conocido internacionalmente es el conocido "aluvión de Yungay" (Ancash) en 1970, provocado por un terremoto de 7.7 grados de magnitud en la escala de Richter que ocasionó la caída de un fragmento del glaciar Huascarán, transformándose en una avalancha de detritos que recorrió el valle a velocidades cercanas a $270 \mathrm{~km} / \mathrm{h}$ (Foto 6). Este flujo rápido produjo alrededor de 7.000 muertos (Ericksen, Plafker, \& Concha, 1970; Evans et al., 2009); quedando sepultada debajo de 30 metros de lodo y fragmentos rocosos de diferentes tamaños (Foto 7). 


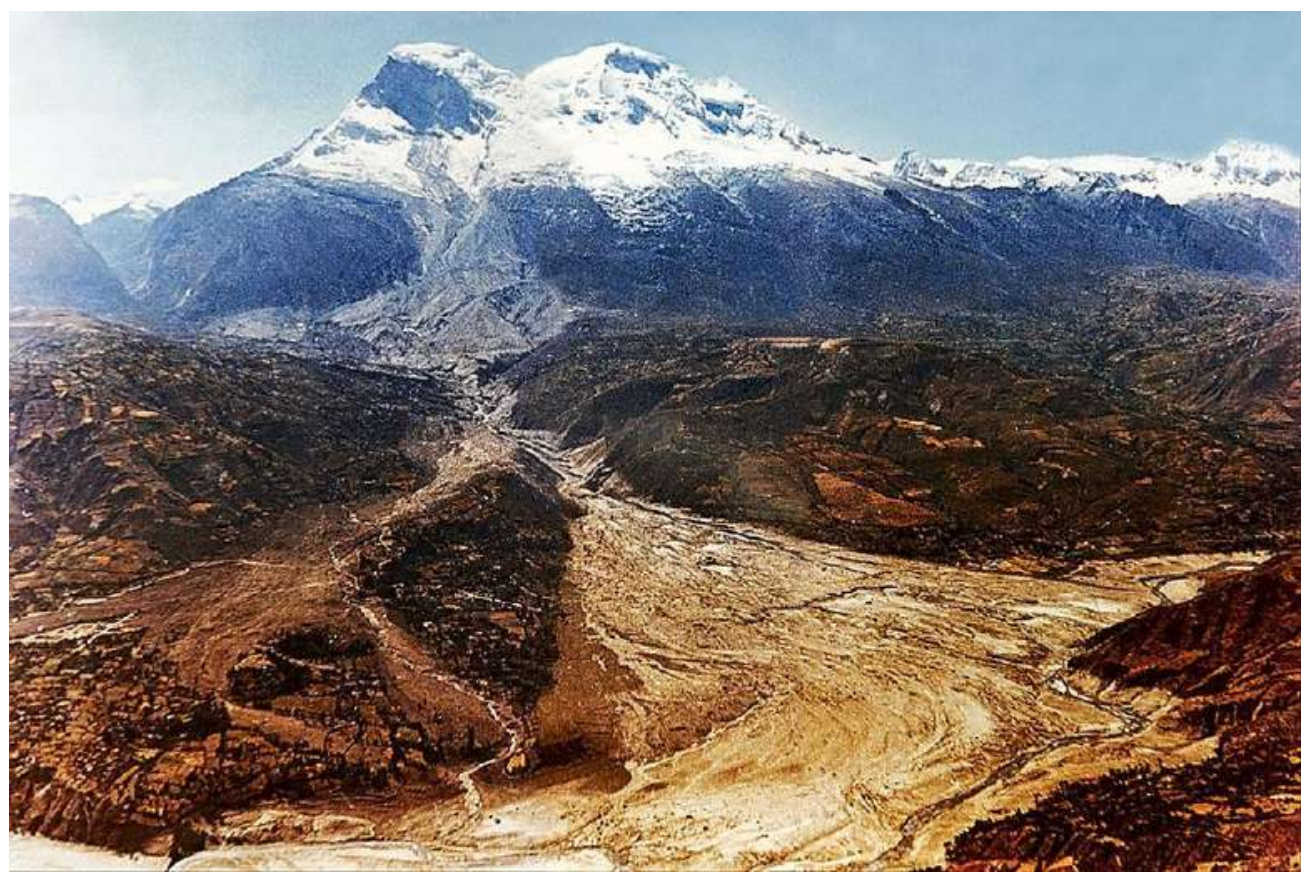

Foto 6. Vista aérea del aluvión que en 1970 enterró al poblado de Yungay y causó la muerte de 25000 personas. (tomado de: http://www.actualidadambiental.pe/?p=19482

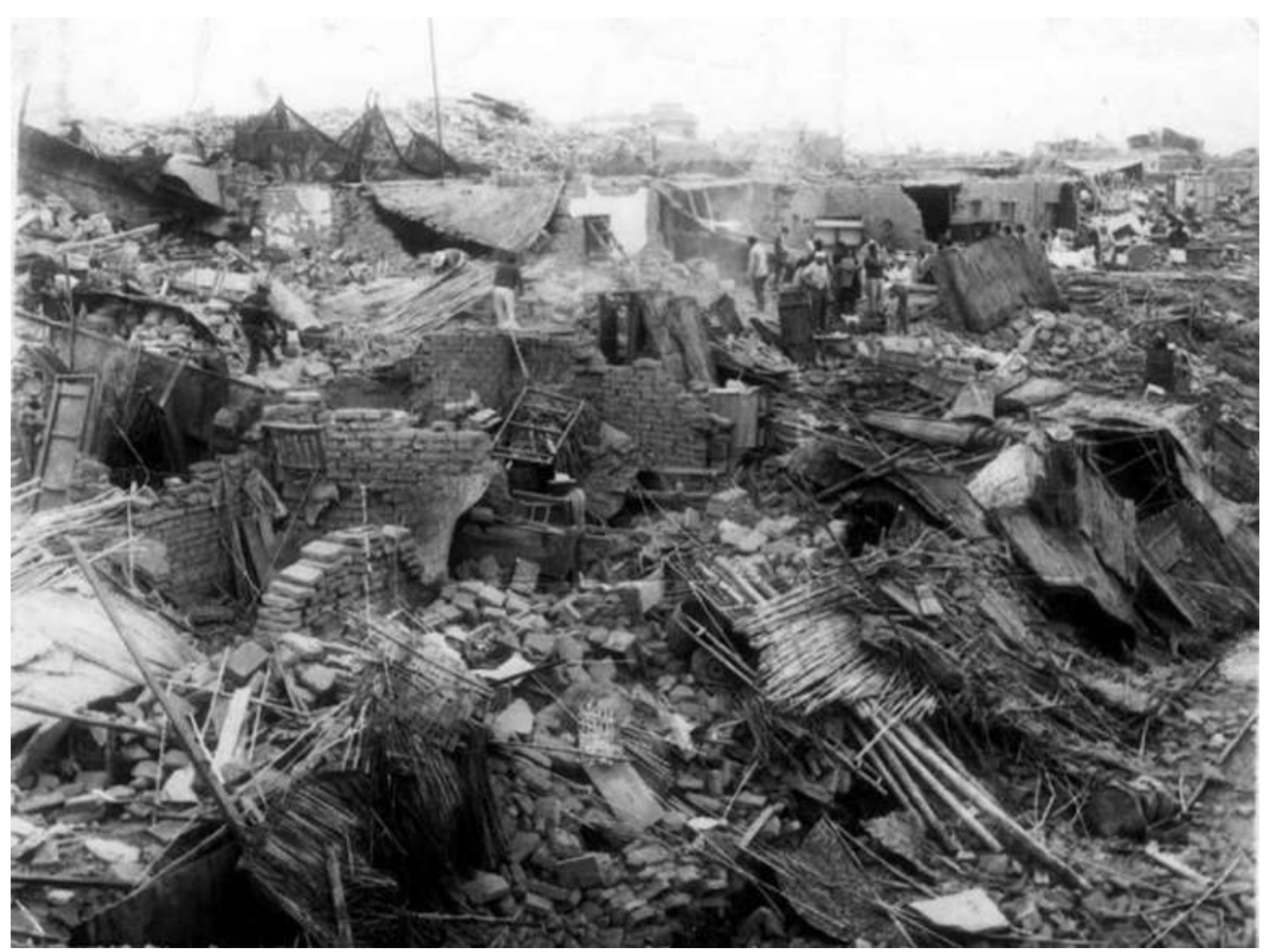

Foto 7. Vista de la población de Yungay (Ancash) tras el paso de la avalancha. Tomado de http://peru.com/actualidad/nacionales/ancash-asi-quedo-yungay-luego-terremoto-79-grados-yaluvion-fotos-noticia-142301-542528?foto $=1$ 
Otro ejemplo de flujos híper-concentrados y debris flows, es el de Aguas Calientes (Cuzco), que, en febrero del 2010 causó la destrucción de la carretera de acceso a Machupicchu por las intensas precipitaciones, la topografía abrupta y la fuerte meteorización de los afloramientos (Foto 8) (Vilímek et al., 2007).

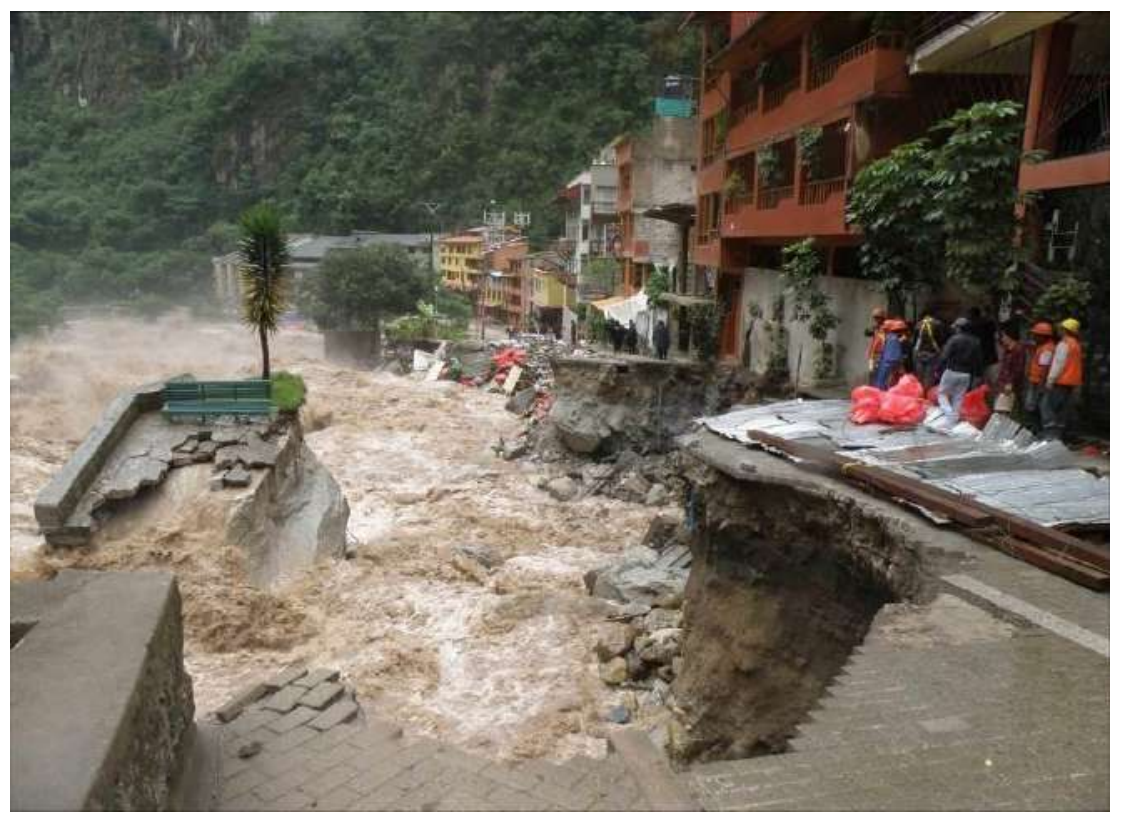

Foto 8. Vista de la destrucción causada por el flujo de detritos de Aguas Calientes en la entrada a Machupicchu (Cusco, Perú). Tomado de Villacorta, Fidel \& Zavala (2012).

\subsubsection{Erosión hídrica}

Se define como el desprendimiento y remoción de la capa de suelo principalmente por acción del agua. Las condiciones meteorológicas y el clima, preparan el material parental para la erosión, actuando la lluvia como agente detonante.

La cobertura vegetal, el tipo y características del suelo, la geomorfología, la geología y los usos del terreno, establecen el grado de propensión de aquel a ser afectado por los agentes generadores de la erosión (Flanagan \& Nearing, 1995).

La evaluación de la erosión se lleva a cabo mediante métodos directos o indirectos (modelos numéricos). Los primeros, usualmente recurren a: simuladores de lluvia; agujas de erosión y perfiles microtopográficos; cuencas y parcelas experimentales; medidas de aterramiento de embalses y medidas por Cesio $\left(\mathrm{Cs}^{137}\right)$. 
Los simuladores de lluvia (Pérez-Latorre, De Castro, \& Delgado, 2010; Navas, Alberto, Machín, \& Galán, 1990; Grierson \& Oades, 1977) calculan en qué medida un evento de lluvia de ciertas características puede desencadenar la erosión. Las agujas de erosión y los perfiles microtopográficos (Sirvent, Desir, Gutierrez, Sancho, \& Benito, 1997; Sancho, Benito, \& Gutiérrez, 1991) son técnicas complementarias que, en conjunto, permiten estimar las tasas de erosión y la evolución del microrelieve (Benito, Gutie, \& Sancho, 1992). Las cuencas experimentales se monitorean para evaluar la erosión hídrica en relación al proceso lluvia-escorrentía (Mathys, Klotz, Esteves, Descroix, \& Lapetite, 2005) mientras que las parcelas experimentales sirven para modelizar eventos de lluvia o evaluar las lluvias asociadas a flujos locales de agua (Wainwright, Parsons, \& Abrahams, 2000; Huang, Gascuel-Odoux, \& Cros-Cayot, 2002).

De otro lado, las medidas de aterramiento de un embalse sirven para analizar la tasa de degradación específica de la cuenca asociada (Verstraeten \& Poesen, 2002; Avendaño, Cobo, Gómez, \& Sanz, 1995). Finalmente, la obtención de medidas directas del radionucléido $\mathrm{Cs}^{137}$ permite determinar la erosión y depósito de sedimentos (Y. Li, Poesen, Yang, Fu, \& Zhang, 2003).

\subsubsection{Sucesiones sedimentarias en abanicos aluviales}

En los modelos sedimentarios de abanicos aluviales se reconocen tres facies sedimentarias asociadas a la distribución de los materiales que lo conforman: proximal, media y distal (Bull, 1964a; Blissenbach, 1954; Steel, 1974; McGowen, 1971, figura 7).

Las facies proximal y distal se localizan a través del estudio de los paleocanales. Los cambios en facies representan variaciones climáticas o tectónicas (Harvey, 1989) (Figura 8).

Zona proximal: el área más cercana a la salida de los materiales, es decir la parte más alta. Tiene mayor pendiente y los sedimentos, en esta área, son los más gruesos de todo el sistema de abanico.

Zona media: sus pendientes son menores que en la zona proximal y los canales se hacen más someros y difusos. La granulometría de los sedimentos es inferior a la zona proximal. La estratificación se desarrolla muy bien en esta zona. 
Zona distal: conocida como la "base del abanico", desarrolla las pendientes más bajas del sistema, el depósito sedimentario es de granulometría más fina y los canales están muy poco desarrollados. Es el área más amplia.

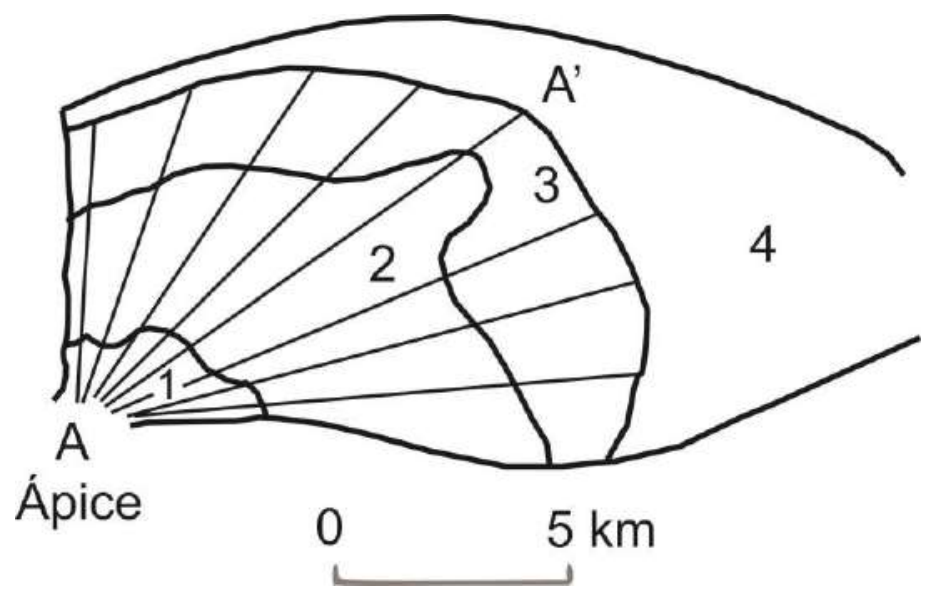

Figura 7. Sectores de un abanico aluvial 1. Zona proximal (ápice) 2. Zona media, 3 Zona distal y 4: Zona de coalescencia con otros abanicos (Bull, 1964a).

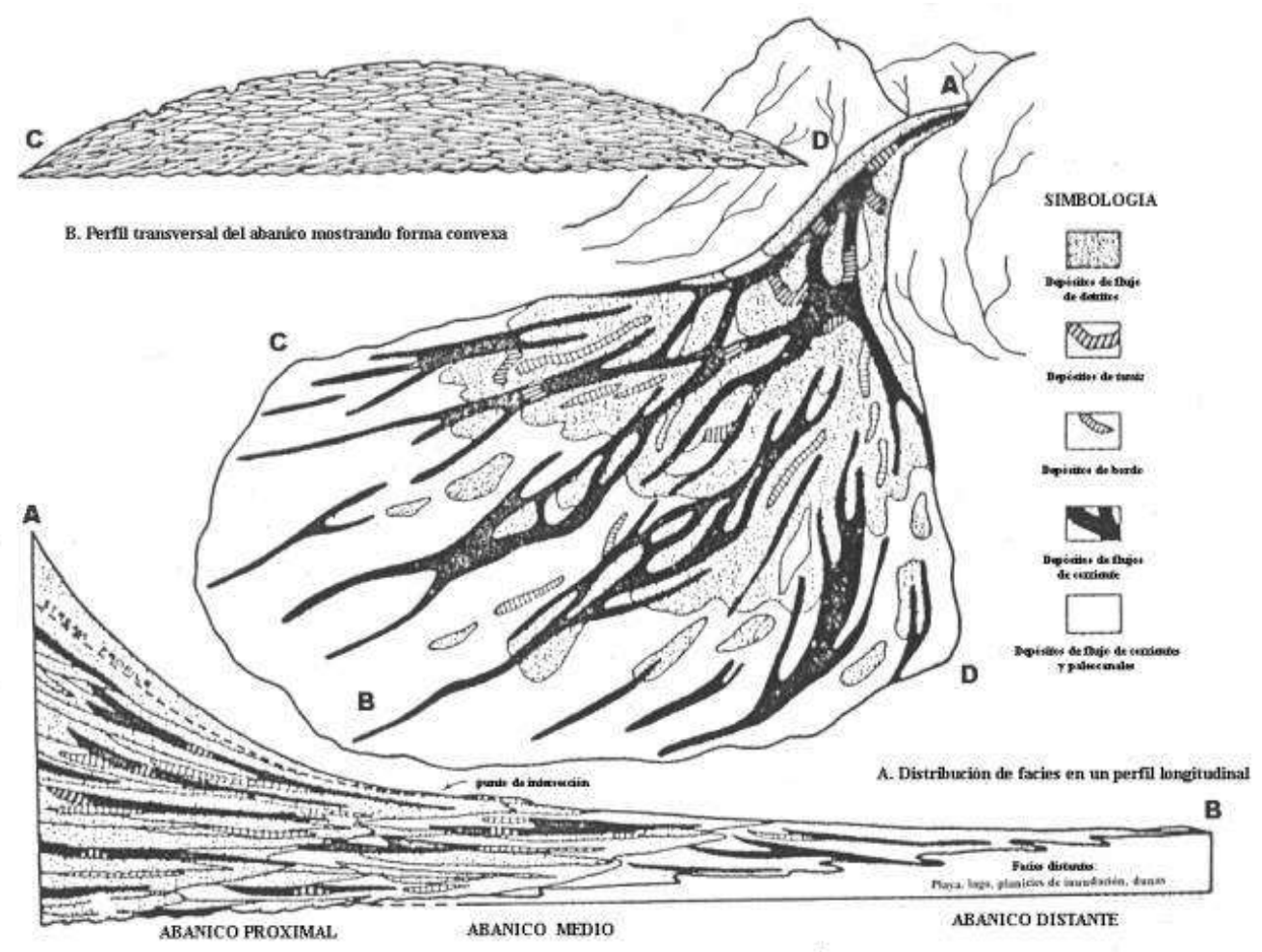

Figura 8. Distribución de facies en un abanico aluvial. El perfil se muestra cóncavo indicando a los sedimentos más gruesos en la zona proximal, los intermedios en el cuerpo medio y los más finos hacia la zona distal (McGowen, 1971). 


\subsection{ABANICOS ALUVIALES EN SURAMÉRICA Y EL CASO DE LIMA}

Se han hecho múltiples trabajos que han evaluado las condiciones geotectónicas que dieron lugar a las geoformas localizadas en la margen continental pacífica de Suramérica.

El postulado principal es que la evolución tectónica andina está relacionada con la subducción, para esta área, de la placa de Nazca bajo la Suramericana. Ello provoca que el levantamiento andino haya influido en los patrones de la precipitación y sedimentación de la vertiente pacífica de Suramérica (Le Roux, 2012; Somoza \& Ghidella, 2005; Hindle et al., 2002; Jordan et al., 2001). Las investigaciones actuales buscan encontrar las relaciones de la tectónica con el emplazamiento de los abanicos aluviales durante el Cuaternario usando como base la reconstrucción de eventos de flujos en la zona desértica suramericana, por lo que se han estudiado los sedimentos depositados, cómo y cuándo se han erosionado y sus posibles relaciones con la deglaciación (Haug et al., 2010; Steffen, Schlunegger, \& Preusser, 2010).

Otros investigadores han estudiado los depósitos de abanicos aluviales en la vertiente atlántica con evidencias de haber sufrido los efectos del cambio climático y actividad sísmica (González Díaz \& Di Tommaso, 2011; Suvires, 2013).

Se ha corroborado que la velocidad de acortamiento horizontal en los Andes Centrales de Suramérica fue mayor durante los últimos 10 Ma (Figura 9); lo que se interpreta como un mayor acoplamiento de las placas, subducción más joven de la litosfera e incremento de la tensión normal con efectos en la elevación y en la disminución de la producción de sedimentos (Hindle et al., 2002; Somoza \& Ghidella, 2005). 

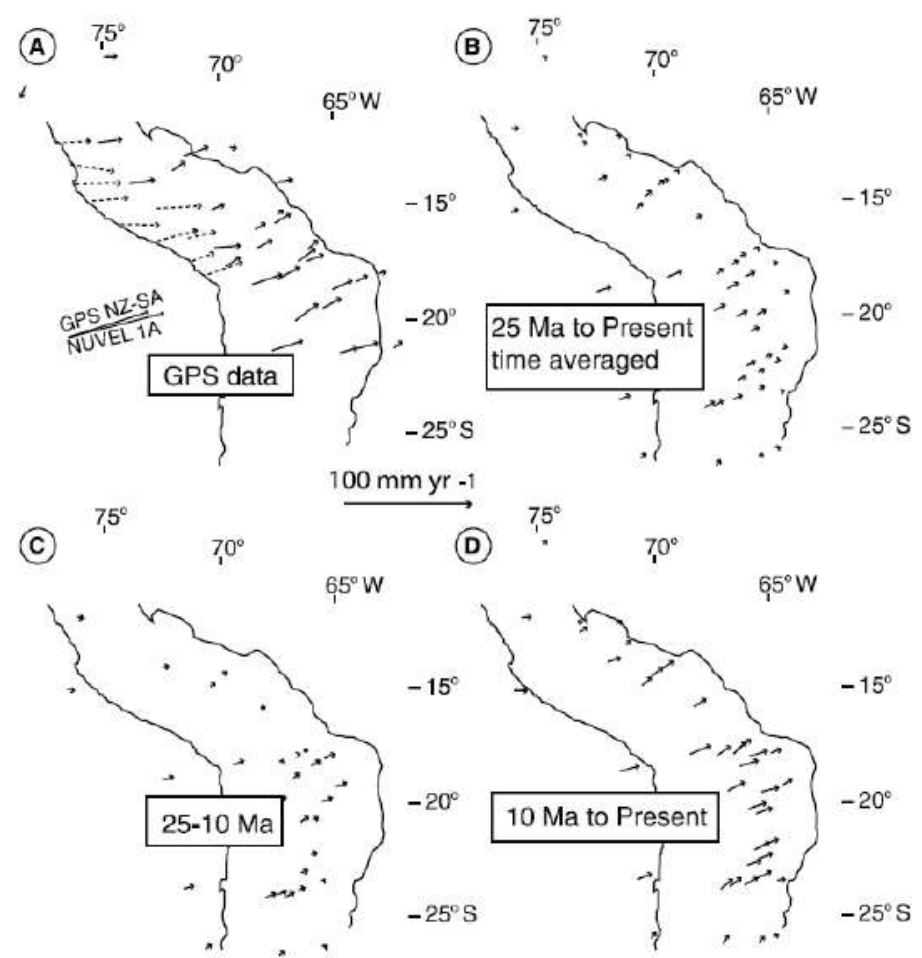

Figura 9 Comparación de vectores promedio de velocidad en los Andes Centrales de América del Sur. A) Velocidades GPS con respecto al interior estable de Suramérica y los vectores de convergencia para la placa de Nazca con respecto a Suramérica derivado de data GPS pronosticado por el modelo de movimiento de las placas mundial NUVEL-1A. Los vectores discontinuos son transitoriamente elásticamente cargados y no directamente comparable en magnitud a los datos geológicos (B) Promedio de las velocidades geológicas en los últimos $25 \mathrm{Ma}(C)$ y (D) muestran las velocidades promedio para un campo de desplazamientos en dos fases, 25 a 10 Ma y 10 Ma hasta el presente. (Hindle et al., 2002).

De acuerdo con Le Roux (2012) la evolución de la cordillera andina ha tenido una marcada influencia en los patrones climáticos de América del Sur y la Península Antártica. El autor señala que hasta el Mioceno medio el relieve era todavía lo suficientemente moderado como para permitir que las lluvias de verano llegasen al centro y centro-norte de Chile. Sin embargo, hace unos 14 Ma se levantó la cordillera con rapidez y desde entonces bloquea eficazmente el traslado de humedad proveniente del Océano Atlántico y la cuenca del Amazonas hacia el centro y centronorte de Chile.

En este momento el establecimiento de la corriente fría de Humboldt, junto con la formación de los Andes, ayudó a crear la "Diagonal Árida" de América del Sur localizada entre el sur del desierto de Atacama hasta las estepas secas de la 
Patagonia (Dunai, López, \& Juez-Larré, 2005; Rech, Currie, Michalski, \& Cowan, 2006), provocando el retroceso de los bosques subtropicales de centro-sur de Chile y la expansión de la vegetación esclerófila hasta el centro de Chile. Sin embargo, y al mismo tiempo que se interceptó más lluvia desde el noreste, causó el efecto del Monzón suramericano que se intensifica en el noroeste de Argentina y sur de Bolivia (Grimm, Vera, \& Mechoso, 2005).

El estudio de abanicos aluviales asociados a flujos de detritos en un área de condiciones híper-áridas, en las cercanías de lquique y Antofagasta, en el desierto de Atacama (Chile) ha permitido la reconstrucción de eventos a través del análisis de la escorrentía y el modelado hidrológico empleando datos climatológicos de aproximadamente 20 años. Los resultados sugieren la existencia de eventos de precipitación breves e intensos con periodos entre una y tres horas -con cerca de 4 $\mathrm{mm}$ de lluvia acumulada- que fueron capaces de producir flujos superficiales que movilizaron y transportaron grandes bloques a través de distancias significativas, datos que proporcionan evidencias de la magnitud de los eventos y, en particular, de la tasa de precipitación que puede activar eventos de este tipo en ambientes híperáridos (Haug et al., 2010).

Sobre la relación entre los sedimentos de agradación, la erosión y el clima, Steffen et al. (2010) estudiaron los abanicos aluviales en el valle de Majes (Arequipa, sur de Perú) datándolos por luminiscencia ópticamente estimulada. Los resultados mostraron una correlación, con intervalos de humedad en el Altiplano, lo que sugiere que se produjeron importantes períodos de agradación de $110-100, \sim 60-50$ y 12-8 ka Asimismo y analizando los patrones de precipitación, los autores encontraron que la elevada precipitación en la cuenca Majes produjo un aumento de erosión y transporte de sedimentos, llegando al punto en que la carga de sedimentos excedió la capacidad de transporte de dicho río y, como resultado, ocurrió la agradación en la parte baja del valle. La disminución de sedimentos de vertiente causó un relativo aumento en la capacidad de arrastre y transporte hacia el río principal, que contribuyó a su vez con la erosión de los sedimentos depositados.

Consecuentemente, aunque el cambio en los patrones de precipitación puede originar la acumulación de sedimentos, la posterior degradación se asociaría al desencadenamiento de una realimentación granocreciente secuencial asociada a los sistemas fluviales (Steffen et al., 2010). 
Gonzáles Díaz \& Di Tommaso (2011) estudiaron en la región del Chubut (Argentina) los depósitos aterrazados de un antiguo abanico aluvial con desembocadura en el Océano Atlántico y su evolución geomorfológica correspondería a una estructura de corte y relleno como resultado de reiterados procesos de captura fluvial. Los investigadores observaron una progresiva migración del paleo-drenaje hacia el sur a finales de la última glaciación.

Suvires (2013) estudió la evolución de abanicos aluviales en la Cordillera Oriental de la provincia de San Juan (Argentina), con desembocadura en la vertiente Atlántica, durante el Cuaternario. Registró las oscilaciones climáticas y la actividad sísmica que afectaron a la formación de las terrazas aluviales. Descubrió sucesivas fases de agradación y erosión que estarían promovidas por los cambios en el nivel del mar durante la última glaciación.

Investigaciones sobre el abanico de Lima

A pesar de su importancia como capital histórica en Suramérica, el área limeña no había sido objeto de estudio hasta iniciado el siglo XX, cuando el geólogo alemán Gustav Steinmann (1904) investigó por primera a vez los fósiles en el área de Lima y los describió en el texto titulado "Observaciones geológicas efectuadas desde Lima hasta Chanchamayo". Posteriormente Lissón (1907) presentó su colección de fósiles recolectados en esta zona, en su libro titulado "Contribución a la Geología de Lima y sus Alrededores" donde descubre un molar de Equus curvidens (Owen, 1845) de edad pleistocena, que desde ese entonces se asocia con la edad de la formación del abanico de Lima.

Posteriormente, y hasta mediado del siglo XX, especialmente a partir de la década de 1950, investigadores franceses y peruanos desarrollaron nuevas líneas de trabajo sobre el Cuaternario del Perú central, principalmente relacionados a la tectónica de los Andes de la parte central de Suramérica, tomando como referencia los estudios de: Petersen (1954), Dresch (1961), Dollfus (1966), Lecarpentier \& Motti (1968), Soulas (1978), Megard (1979), Sebrier \& Macharé (1980) Cobbing (1982). Los estudios geofísicos desarrollados por Arce (1984) ponen de manifiesto que el material acumulado por los principales cauces fluviales del abanico alcanza centenares de metros de espesor (Figura 10). 


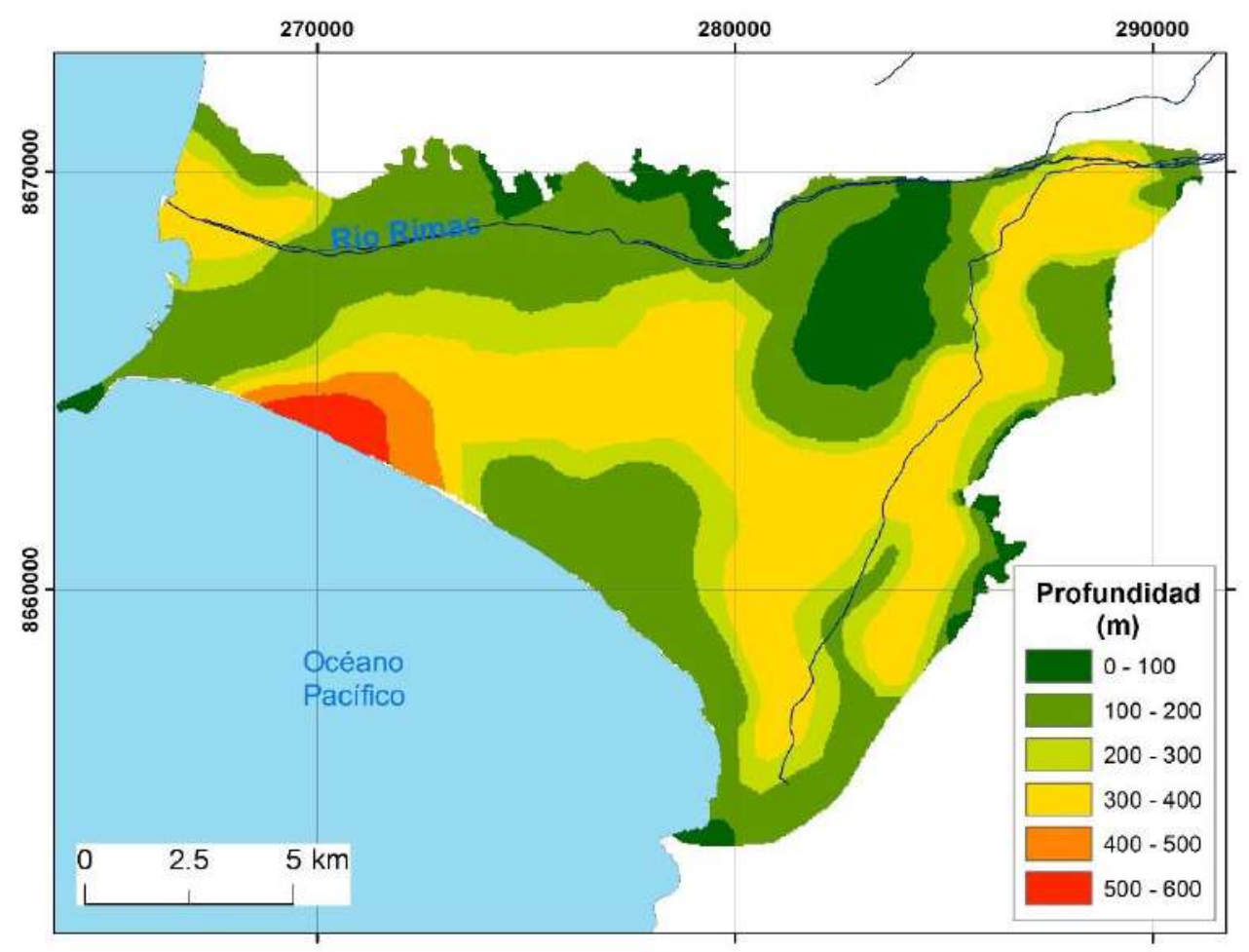

Figura 10 Isobatas del basamento rocoso en el área de Lima Metropolitana, deducidas del análisis de la conductividad eléctrica del terreno. Modificado de Arce (1984).

Le Roux et al. (2000) atribuyen al movimiento y subsidencia de la Placa de Nazca una consecuente transgresión marina durante el Pleistoceno (1.7 Ma), seguida por el depósito de gravas que representarían un posible retrabajamiento fluvial de morrenas glaciares.

Otros trabajos acerca del área del abanico de Lima, sobre todo de la exposición de sus sedimentos en la Costa Verde, abordan aspectos estructurales y sedimentológicos (Aleman et al., 2006). 


\subsection{CLIMA Y FENÓMENOS METEOROLÓGICOS}

Actualmente el clima preponderante en la costa limeña es híper-árido con temperaturas moderadas ( $15^{\circ}$ en invierno a $25^{\circ}$ en verano) pero con una humedad relativa elevada. La precipitación media anual es de aproximadamente $10 \mathrm{~mm} / \mathrm{año}$, con una variación de 1 o 2 mm/año (Instituto Metropolitano de Planificación, 2008). En este acápite se describen los factores que configuran este clima, los fenómenos meteorológicos asociados así como los cambios climáticos ocurridos en el pasado en la costa central del Perú.

\subsubsection{Factores que configuran el clima}

Entre las principales causas tienen especial incidencia: la temperatura de la superficie del mar; la nubosidad procedente de la cuenca del río Amazonas, topografía y altitud de la Cordillera de los Andes.

\subsubsection{Temperatura superficial del mar}

La temperatura de la superficie del mar en la costa del Océano Pacífico es casi $10^{\circ} \mathrm{C}$ menor a la de la costa atlántica, con referencia a la misma latitud. Esto se debe al efecto de la denominada "Corriente de Humboldt" que, impulsada por masas de aire alisios desde el sureste enfría las aguas marinas (Alfaro, Cid, \& Enfield, 1998) generando una inversión térmica (Vargas, Ortlieb, \& Rutllant, 2000); en un intervalo de altitud entre 850 y 1000 m (Rutllant, 1985). Sin embargo, otra corriente actúa por el norte peruano produciendo el efecto contrario, se trata de la corriente "El Niño". 


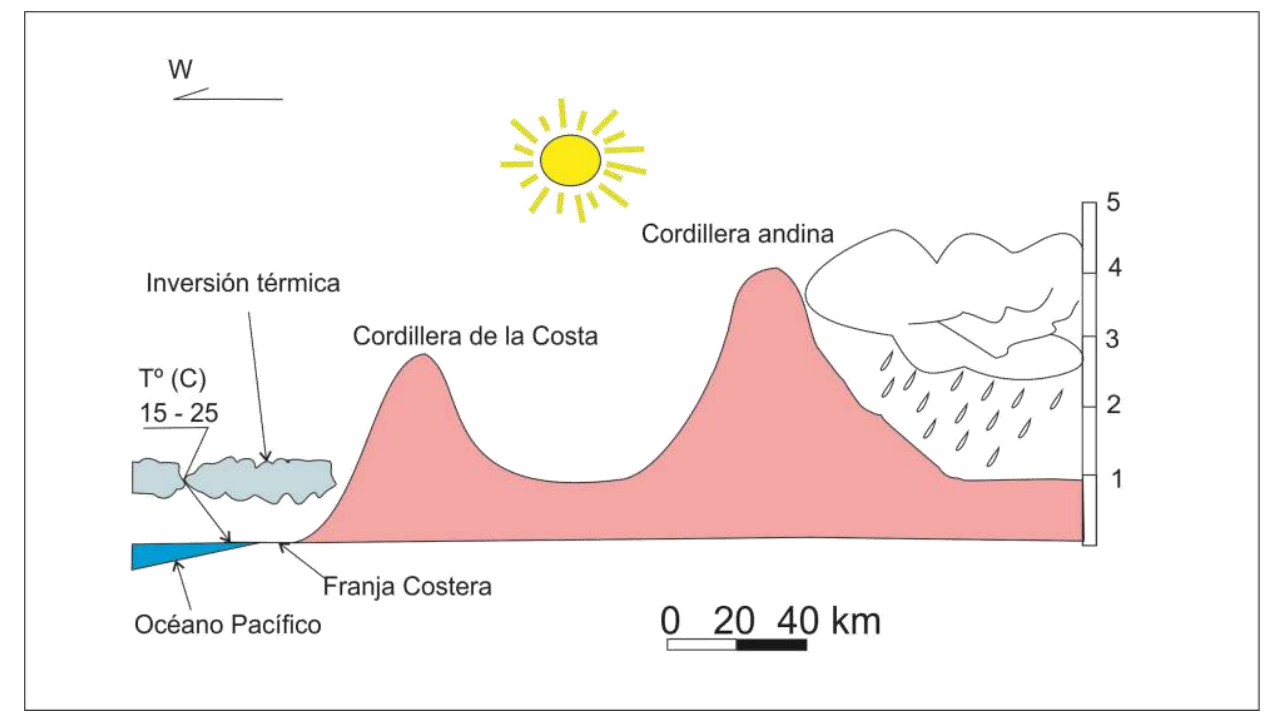

Figura 11. Esquema general del patrón climático en la vertiente occidental de la Cordillera de los Andes. Indica una distribución vertical aproximada de la temperatura en la costa y donde estaría ubicada la capa de inversión térmica. Modificado de: Vargas, Ortlieb \& Rutllant (2000).

\section{Las corrientes marinas}

La "Corriente de Humboldt" es producto del Anticiclón del Pacifico sur, masa de aire frio y seco que actúa como un remolino anti-horario e impulsa las aguas marinas superficiales permanentemente sobre el Pacífico generando una inversión térmica en un intervalo de altitud entre 850 y 1000 m (Rutllant, 1985) e impidiendo que ocurran precipitaciones importantes: en la costa de Lima lluvias de más de $10 \mathrm{~mm}$ se producen aproximadamente cada 30 a 50 años (Capel, 1999b), salvo una densa neblina casi permanente en esta parte de la costa peruana que al desintegrarse forma la "garúa" (Leonard, 2000; Lillo Carpio, 1999).

La corriente "EI Niño" se empezó a estudiar a fines del siglo XIX como un flujo de aguas cálidas procedente del golfo de Panamá. La denominación de "El Niño" se debe a que, suele ocurrir en la temporada de Navidad (Capel, 1999a; Enfield, 1989; Pezet, 1896). Lo más importante acerca de esta corriente de agua es que cada cierto tiempo produce una elevación anormal en las temperaturas del agua en las costas de Perú y Ecuador. Actualmente se ha reconocido que producen los siguientes efectos: sequías severas en el interior del país; pérdida de especies marinas por el cambio de temperatura; modificación en patrones de calor y humedad todo el año y lluvias excepcionales (con la consecuente generación de inundaciones, erosión fluvial y flujos de detritos, deslizamientos y otros procesos) (Lillo Carpio, 1999; Dracup \& Kahya, 1994; Mechoso \& Perez, 1992). Ya en el pasado, los eventos ENSO habrían afectado 
ruinas pre-incaicas sobretodo en la zona norte del Perú (Macharé \& Ortlieb, 1993). Así por ejemplo están los eventos "Chimu flood" (Nials, Deeds, \& Moseley, 1978) ocurrido cerca de 1100 d.C. posteriormente descrito por Craig y Shimada (1986) como "Ñaylamp flood" y luego identificado por sus daños a la estructura de la ciudadela de Chan-Chan, que se configura como la causa del abandono del sitio, entre 1300-1350 D.C. (Pozorski \& Pozorski, 2003; Vilchez \& Pari, 2012). Igualmente Uceda \& Canziani (1993) registraron 4 eventos de inundaciones que afectaron al templo de la Luna en el valle del rio Moche en Trujillo, uno de los cuales se asocia a un "Mega Niño" alrededor del año $600 \mathrm{~d}$. C. Posteriormente otros eventos ENSO habrían afectado otras ciudades peruanas, siendo los más importantes -por los daños causados-, los de los años 1720, 1728 y 1791, considerados como "muy fuertes" (Huertas, 2009) pues destruyeron extensas áreas del norte del país, como la ciudad de Saña (Capel, 1999a).

En 1966 el meteorólogo Bjerknes (1966) sugirió que El Niño está asociado a la Oscilación del Sur, proceso meteorológico que involucra la presencia de bajas presiones en el Pacífico oriental y las simultáneas altas presiones en su parte occidental (Hastenrath, 1990; Ortlieb, Macharé, Fournier, \& Woodman, 1989; Lockyer \& Lockyer, 1902; Walker, 1928). Rasmusson y Carpenter (1982) acoplan a "El Niño" y "La Niña” como ENSO “El Niño-Oscilación del Sur", refiriéndose a la anomalía producida durante varios meses en todo el Pacifico inter-tropical (DeVries, Ortlieb, Díaz, Wells, \& Hillaire-Marcel, 1997; Glantz, 1997; Keefer et al., 1998). Los últimos estudios sobre el evento ENSO ubican su aparición en el Holoceno (Gomez, Carter, Trustrum, Palmer, \& Roberts, 2004). Debido a que diversos estudios lo asocian con las anomalías de viento, de presión atmosférica y de la temperatura superficial del mar, a nivel internacional se le suele medir con el índice IOS (índice Oscilación del Sur) propuesto por Walker (1928), que se calcula como la diferencia normalizada de presión superficial entre la isla Tahití (Polinesia Francesa) y Darwin (Australia). El índice es positivo cuando las presiones son muy bajas en el sector occidental del Pacifico. Sin embargo, el mismo tiene limitaciones por lo cual se analiza también con otros tipos de índices (Capel, 1999a).

\section{Eventos super-ENSO y Mega ENSO}

En la década de los 80 en base al análisis de registros paleo-climáticos de América del Sur, se propuso la posible aparición de eventos "Súper-ENSO" (Martin et al., 1992; Mörner, 1985; Mörner, 1984a). Se trataría de eventos ENSO extremadamente fuertes, 
muchos de ellos precedidos por grandes sismos que modificaron fuertemente el paisaje causando "ciclos de alteración ambiental" (Moseley, Feldman, Moseley, \& Feldman, 1981). Tales eventos corresponderían con la redistribución de calor (masa y energía) lo cual se ha (registrado por el paleo-clima) y el cambio del nivel del mar) debido a la transferencia de momento angular entre la Tierra y la hidrosfera debido a que traen masas de agua caliente desde latitudes ecuatoriales hasta altas latitudes. Así por ejemplo en los años 1981/82, el aumento del nivel del mar a lo largo de las costas occidentales de América, fue del orden de $30 \mathrm{~cm}$ (Newell \& Hsiung, 1984).

Actualmente se sabe que la distribución global de las masas de agua oceánicas (y el nivel del mar) cambia con las deformaciones gravitatorias, así como con las variaciones en la circulación debido a la tasa de rotación de la Tierra. (Mörner, 1984b) propuso el intercambio del momento angular entre la Tierra y la hidrosfera y más tarde demostró los cambios climáticos-eustáticos registrados entre 13 y $10 \mathrm{Ka}$ BP (Mörner, 1993a) donde se ha reconocido cambios de altitud del mar que pueden representar eventos de Mega-ENSO. Durante las edades glaciales, se piensa que no se produjeron eventos ENSO dado que, en los registros de largo plazo, las huellas de eventos ENSO son breves y usualmente demasiado leves (Mörner, 1984a; Mörner, 1988; Mörner, 1993a).

Algunos eventos ENSO han sido reconocidos en la época medieval como lo indican datos de Europa, África Oriental, Antártica y Sudamérica (Mörner, 1993a; Mörner, 1993b). En el evento principal de Súper-ENSO el nivel del mar cayó alrededor de $1 \mathrm{~m}$ entre aproximadamente 950 y 1050 DC en la región Kattegatt-Báltico. Las playas del norte peruano parecen haberse formado en ese periodo de tiempo, que fue cuando se experimentó en América del Sur un calentamiento significativo debido al incremento del contenido atmosférico de $\mathrm{CO}_{2}$ en aproximadamente 30 ppm en 150 años alrededor de 1100-1200 DC. Los sucesos ENSO interpretados habrían sucedido alrededor de 950-1000 DC y siguen alrededor de 1200-1300 DC (Mörner, 1993a).

Durante el Holoceno, parece haber habido una serie de eventos Súper-ENSO cuya duración oscila entre algunas décadas hasta un siglo o un poco más. En el Atlántico Norte, alrededor de 16 eventos parecidos han ocurrido durante el Holoceno.

Sin embargo, debido a que la tasa de rotación se incrementó durante las edades glaciales, lo cual produjo la disminución del nivel del mar eustático glaciar y acortamiento del radio ecuatorial (que tiene que ser compensada por una aceleración 
del sistema total de la Tierra en correlación con el acortamiento en la distancia TierraLuna), el transporte de aguas superficiales calientes de este a oeste se incrementó fuertemente (lo cual está documentado en bases paleontológicas) dejando poco o ningún espacio para el reverso de este flujo, siendo probable que las edades glaciales se caractericen por la ausencia de eventos ENSO y Súper-ENSO (Mörner, 1993a).

En relación a su relación con eventos geo-hidrológicos en Perú, estos ocurren en las diferentes estaciones y las fases del ciclo ENSO. Durante la fase madura de El Niño (verano austral), tales eventos han sido reportados en enero de 1982 y 1998, mientras que en Austral invierno-primavera han ocurrido en julio de 1972, agosto-septiembre de 1965 y enero-marzo de 1998. Durante La Niña y en condiciones casi neutras, eventos de flujo de detritos e inundaciones se han reportado sólo en primavera austral (septiembre de 1961 y 1962, respectivamente).

2.4.1.2 Nubosidad procedente de la cuenca del río Amazonas, topografía y altitud de la Cordillera de los Andes

El clima de la costa peruana es además influenciado por las masas de aire húmedas procedentes de la cuenca del río Amazonas, las cuales se desintegran a medida que se alejan del área fuente. De tal forma, se reducen progresivamente sobre el altiplano y la cordillera andina (por influencia orográfica), barrera que impide el ingreso de las nubes (Figura 11). La topografía y altitud de la Cordillera de los Andes tiene influencia en el comportamiento de los vientos procedentes tanto del este como del oeste y configura los patrones de circulación de las nubes y precipitación (Magilligan, Goldstein, Fisher, Bostick, \& Manners, 2008).

La distribución estacional de la precipitación está vinculada con el régimen anual de la Zona de Convergencia Intertropical (Aceituno, 1998). Por ese motivo, en la franja comprendida entre la costa y el altiplano se localiza uno de los desiertos más áridos del planeta, y en el que, además las precipitaciones son casi inexistentes.

Otro fenómeno que afectaría al área, y aún no ha sido estudiado en el Perú, es la Depresión Aislada en Niveles Altos (DANA) o sistema "cut-off low", también conocido como "gota fría" (Hernández, 1999). Se trata de una depresión aislada en altura que se ha separado de la circulación del cinturón de vientos (polares o subtropicales) y gira en sentido anti-horario (no asociada al efecto Coriolis, por tanto); es decir de forma independiente al flujo que lo generó, pudiendo ser estacionaria y retrograda. 
Este sistema se desplaza lentamente y permanece a menudo sobre la misma región durante varios días; y, por lo tanto, pueden afectar de forma significativa las condiciones climáticas en la superficie (Martín León, 2003).

Se estima un diámetro entre 500 y 2000 km de diámetro de influencia y juega un papel importante en el equilibrio del ozono troposférico a través de la disipación y la mezcla de ozono estratosférico (Gimeno, Trigo, Ribera, \& Garcia, 2007; Langford, Masters, Proffitt, Hsie, \& Tuck, 1996; Ebel et al., 1991).

Por lo común se manifiesta desde latitudes medias $\left(30^{\circ}\right.$ a $45^{\circ}$ Norte y Sur) desde el Océano Atlántico, luego cruza la Cordillera de los Andes entre Chile y Argentina acercándose hacia la costa donde se producen las precipitaciones (Campetella \& Possia, 2007). A este fenómeno se le atribuyen fenómenos aislados que suceden en la costa y no debidos al evento ENSO, como los flujos de detritos de los años 2010 en Cuzco y los de 2012, 2015 y 2016 en Chosica (Lima).

\subsubsection{Cambios climáticos en el cuaternario en el Perú Central}

A partir de los años 70 se produjo un gran debate en relación a la ocurrencia de cambios climáticos en el Perú, durante el Cuaternario reciente, específicamente en el Holoceno temprano. Autores como Parsons (1970) y Craig (1985) en base a datos geológicos, geomorfológicos y paleoecológicos defendían la idea de que los cambios climáticos fueron menores y que la aridez actual ha permanecido durante la mayor parte del Cuaternario a lo largo de la costa peruana. Sin embargo, (Richardson, 1978); (Dollfus \& Lavallee, 1973) utilizando correlaciones con datos externos al desierto costero peruano (Suroeste ecuatoriano o Piedemonte andino) afirman que el clima había sido mucho más húmedo hacia el final del Pleistoceno y durante la primera mitad del Holoceno. Para (Ortlieb \& Macharé, 1989), las evidencias de climas más húmedos al actual, en áreas situadas a cierta altitud sobre el nivel del mar, pueden haber sido correctas, sin implicar por ello que el régimen climático haya sido muy diferente al actual.

La variabilidad del sistema climático sobre los Andes Centrales se ve afectada por la frecuencia y la intensidad de la Oscilación del Sur conocida como "El Niño" (ENSO, por sus siglas en inglés de "El Niño Southern Oscillation); por las temperaturas 
superficiales del Pacífico tropical y del Atlántico y según (Perry, Seimon, \& Kelly, 2014) también por otros factores que todavía son poco conocidos. La localización de los Andes Centrales dentro de sistemas de gran circulación explica su sensibilidad climática y hace que esta zona de montaña sea un sitio clave para la reconstrucción paleoclimática (Kanner, Burns, Cheng, Edwards, \& Vuille, 2013) ya que modula la circulación atmosférica a escalas mesoplanetarias y planetarias (Seluchi, Garreaud, Norte, \& Saulo, 2006). Los estudios más recientes se enfocan en determinar la presencia de eventos ENSO en los tiempos glacial y postglacial, así como la evolución de la Corriente Peruana de Humboldt (Liu, Reese, \& Thompson, 2007).

Algunos investigadores han asumido que, durante los periodos glaciales, la Corriente Peruana de Humboldt fue reforzada y se extendía más al norte que actualmente (Simpson, 1975; Simpson \& Haffer, 1978; S. D. Webb, 1978). Otros autores han propuesto que, durante el fin del Pleistoceno e inicio del Holoceno, esta corriente se debilitó y desvió hacia una posición más occidental y rneridional que la actual (Chauchat, 1987; Uceda, 1986). Según (DeVries, 1987) parece poco probable que el sistema de circulación del Pacífico oriental haya sufrido profundas modificaciones durante las últimas fluctuaciones climáticas. Los datos disponibles sobre la composición faunística de los "tablazos" del Noroeste peruano sugieren que el límite biogeográfico que se observa actualmente cerca a Paita ha permanecido por lo menos durante los estadios interglaciares del último millón de años. Sin embargo, no se puede descartar que la Corriente Peruana haya variado a través del tiempo, especialmente durante las transiciones glacial/interglacial (Ortlieb \& Macharé, 1989).

En relación a las glaciaciones, (Dollfus, 1964) describe tres glaciaciones cuaternarias en la Sierra del Perú Central, asociadas con terrazas fluviales.

(Sébrier \& Macharé, 1980) de acuerdo a sus estudios geomorfológicos en Asia y Cañete al sur de Lima y el rio Chillón al norte de Lima, ponen en evidencia cuatro niveles de terrazas aluviales que asocian a las deglaciaciones ocurridas en la zona central del Perú (Figura 12). 


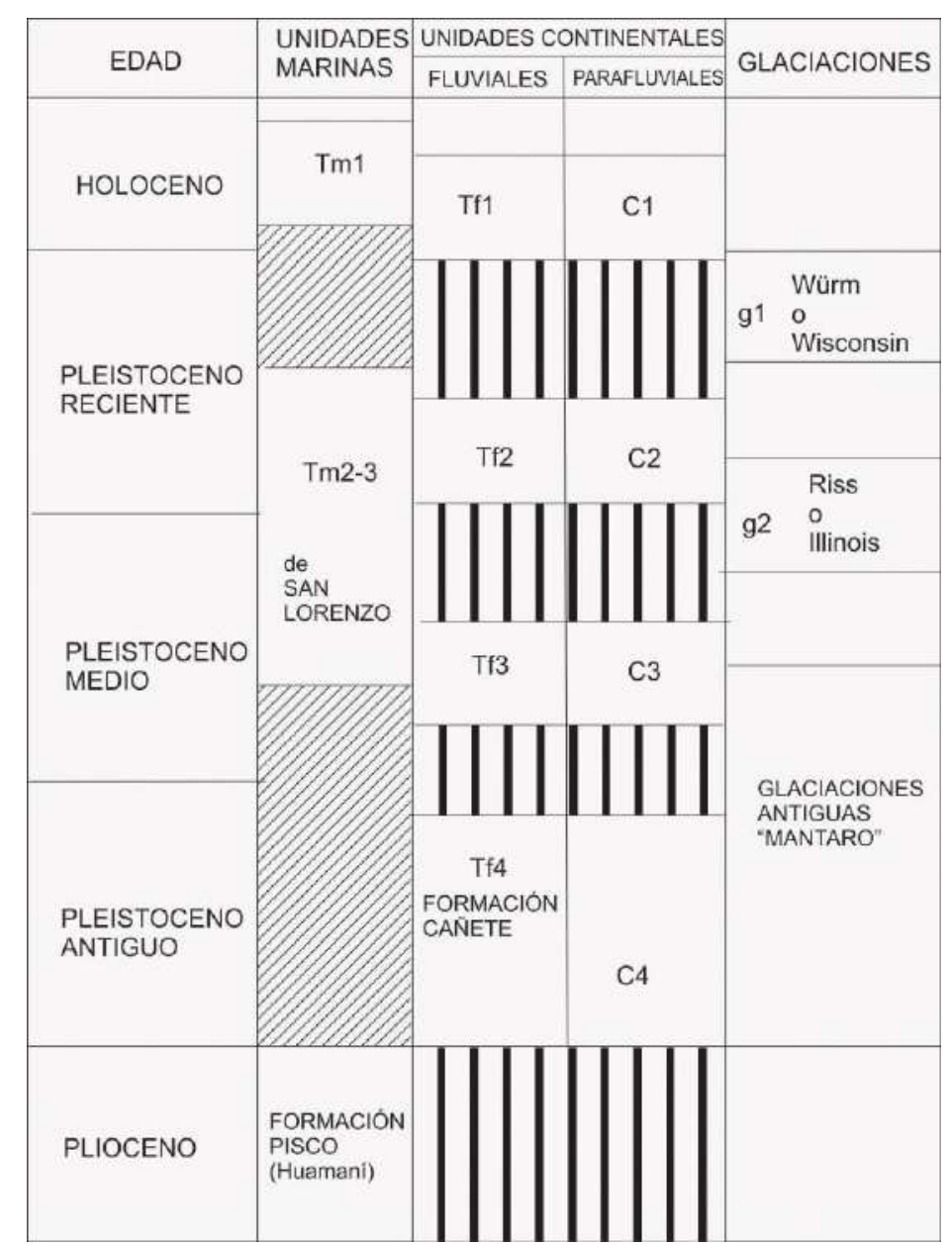

Figura 12. Esquema de las Glaciaciones del Perú Central en correlación con las glaciaciones conocidas en Europa y Norteamérica. Tm1 representa el conjunto de niveles marinos holocenos. Las terrazas fluviales (Tf) y las acumulaciones de flujos detríticos esporádicos (c) están numeradas de más reciente al más antiguo. Nótese que la terraza Tf1 se correlaciona con las morrenas de la última glaciación g1 y que existe una relación similar entre Tf2 y las morrenas de la penúltima glaciación. Tomado de: Sébrier y Macharé (1980).

Sébrier y Macharé (1980), señalan además que la presencia de formas eólicas en los conos de flujos detríticos esporádicos indica que, a pesar de un aumento de la pluviosidad, las condiciones eran en el momento de su ocurrencia las de un desierto árido. El estudio de los depósitos más antiguos sugiere una conclusión idéntica, es decir, la permanencia de las condiciones desérticas durante todo el Cuaternario con la ocurrencia de períodos lluviosos eventuales.

Durante las glaciaciones, cuando el nivel del mar era inferior al actual, se habrían producido las incisiones que determinaron los encajonamientos de los ríos de la costa peruana, como el Rímac (Le Roux et al., 2000). Sin embargo, para esta pluviosidad nunca dejó de ser la de un clima desértico árido (Sébrier \& Macharé, 1980). 
La Pequeña Edad de Hielo (LIA por sus siglas en inglés) es decir el periodo durante el que se produjo un aumento en los glaciares de las latitudes medias entre los siglos XVI y XVII (Matthes, 1939), se encuentra bastante documentada en el Hemisferio Norte, pero es aún poco estudiada en los Andes tropicales (Rabatel, Francou, Jomelli, Naveau, \& Grancher, 2008). (Clapperton, 1993) señala que los datos procedentes de otras regiones demuestran que las masas de hielo pueden haber estado presentes en los Andes Centrales al menos desde el Plioceno. En la mayoría de localidades, la evidencia disponible es aun preliminar y es considerable la variabilidad en la extensión y tiempo de los eventos relacionados a la expansión máxima de LIA identificada en la mayoría de áreas entre el siglo XVI y IX (Masiokas et al., 2009).

Para Engel et al. (2014), quienes basan sus hipótesis en los cambios climáticos registrados en la turba Distichia extraída del nevado Mismi (Arequipa, sur del Perú), las condiciones relativamente cálidas y húmedas en los Andes del sur del Perú prevalecieron de 4,3 a 3ka B.P. con un corto episodio seco más frío hace 3,8ka B.P. Los investigadores identificaron posteriores cambios climáticos entre los 3 y 2,8ka B.P. cuando el calentamiento inicial se convirtió en un enfriamiento rápido a temperaturas de por lo menos $2^{\circ} \mathrm{C}$ inferiores a la media para el Holoceno tardío. Así mismo señalan que en dicho periodo la humedad se incrementó hasta hace aproximadamente 800 años en que las condiciones se volvieron relativamente secas hasta que se produjo un período cálido y relativamente húmedo entre 640 y 155 años B.P.

Para Masiokas et al. (2009) los eventos de avance glaciar en Suramérica, durante la primera mitad del pasado milenio, fueron generalmente menos extensos que los pulsos máximos de LIA. A pesar de la ocurrencia de muchos avances nuevos post-LIA en los últimos 100-110 años, la mayoría de áreas glaciares en los Andes subtropicales áridos (Chile y Argentina) han experimentado un patrón general de recesión glaciar y pérdidas de masas de hielo significativas.

Para Rodbell et al. (Rodbell, Smith, \& Mark, 2009), los patrones espacio temporales de glaciación en el Holoceno muestran evidencias de avances de hielo desde el Holoceno temprano y medio en muchas regiones, pero no así en los Andes subtropicales áridos, donde los registros señalan que las morrenas se depositaron durante, o ligeramente antes de LIA marcando el máximo avance del Holoceno. 
(Seltzer, 1990) y Rodbell et al. (2009) en base a dataciones de morrenas entre Perú y Bolivia, señalan que existió un re-avance significativo de hielo en el inicio del Dryas reciente (Younger Dryas en inglés) evento de enfriamiento que tuvo lugar entre 12,700 y 11,500 años atrás (finales del Pleistoceno) en los Andes Centrales de Perú. Sin embargo, el hielo fue retirándose durante considerable parte del intervalo restante del Dryas reciente.

Relación con la actividad aluvial

De acuerdo a Ortlieb y Machare (1980), en el pasado para activar los conos aluviales desérticos se necesitaron lluvias más fuertes y más frecuentes que las que ocurren en la actualidad. Y debieron producirse entre la finalización de cada glaciación y el máximo transgresivo interglaciar. La temporada de deglaciación (paso del estado glaciar al interglaciar) representa una época de inestabilidad climática que favorece una debilitación de la zona anticiclónica del Pacífico y por lo tanto una ocurrencia de lluvias en el desierto. Este evento habría ocurrido entre 10,000 B.P. (final de 1a última glaciación) y 6,000 B.P. (máximo transgresivo del Holoceno).

Respecto al máximo transgresivo del Holoceno, en la Costa del Perú Central, (Dollfus, 1965) describe dos niveles marinos holocenos:

- El más antiguo corresponde a una transgresión de 4 o 5 m encima del nivel actual del mar;

- El más reciente corresponde a una estabilización del mar a 2 m encima de su nivel actual.

El más antiguo corresponde al máximo transgresivo posterior a la última glaciación, corresponde al Veguian inferior definido por (Paskoff, 1970) en el Norte de Chile y fechado a ,4000 años AC. En la Figura 12, el conjunto de los niveles holocenos está colocado como Tm1. Las huellas de esta trasgresión están representadas por: cordones litorales abandonados, acantilados, arrecifes y fósiles (Ortlieb y Machare, 1989).

El nivel marino holoceno más antiguo se correlaciona con la terraza fluvial Tfl. La desembocadura del rio Chillón (figuras 13 y 14) proporciona un ejemplo de dichas relaciones: se pueden observar varios cordones litorales Tm, estando el más antiguo en relación con los depósitos fluviales Tf 1 . No se conocen sedimentos marinos 
relacionados con las terrazas fluviales más antiguas que Tf1 (M. Siebrier y J. Macharé, 1980).

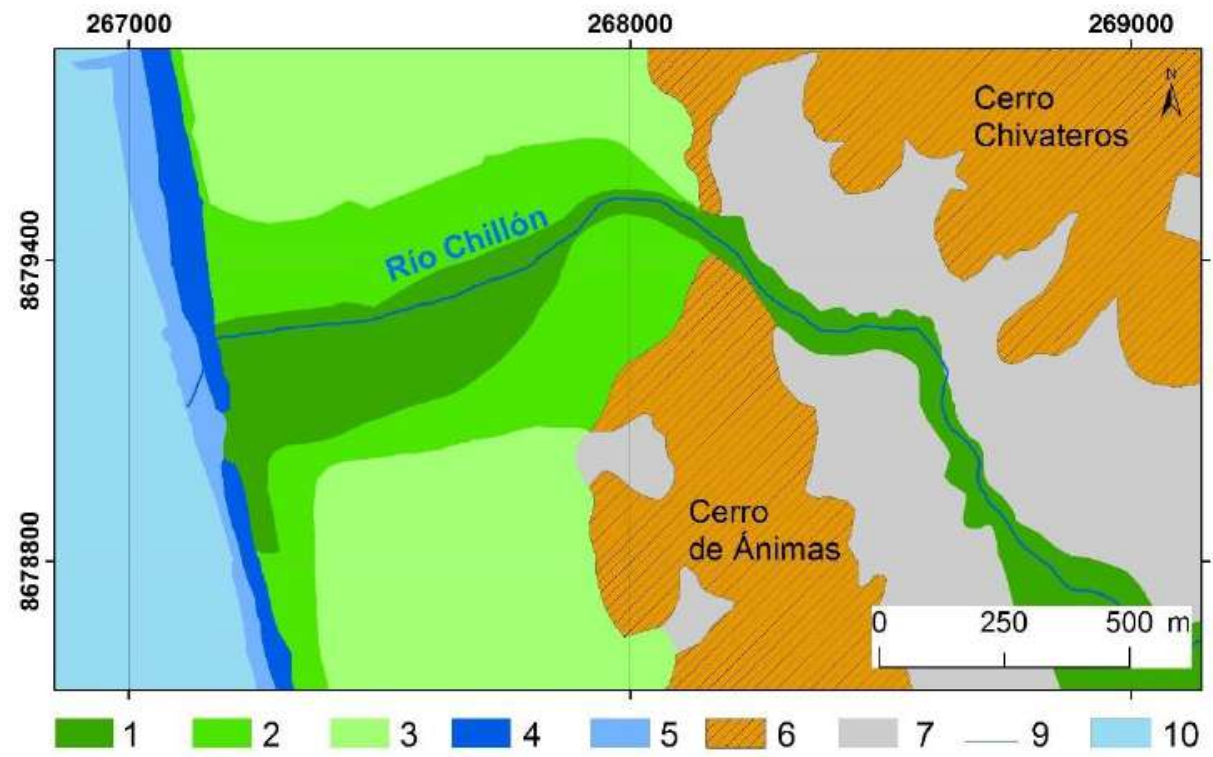

Figura 13. Esquema morfológico en la desembocadura del río Chillón. 1,2 y 3: terrazas fluviales. 4 y 5: cordones litorales holocenos. 6: substrato volcanosedimentario. 7: Flujos de detritos esporádicos. 8: Acumulaciones eólicas. 9: cauce actual. 10: océano Pacífico. Modificado de: Sebrier y Macharé (1980).

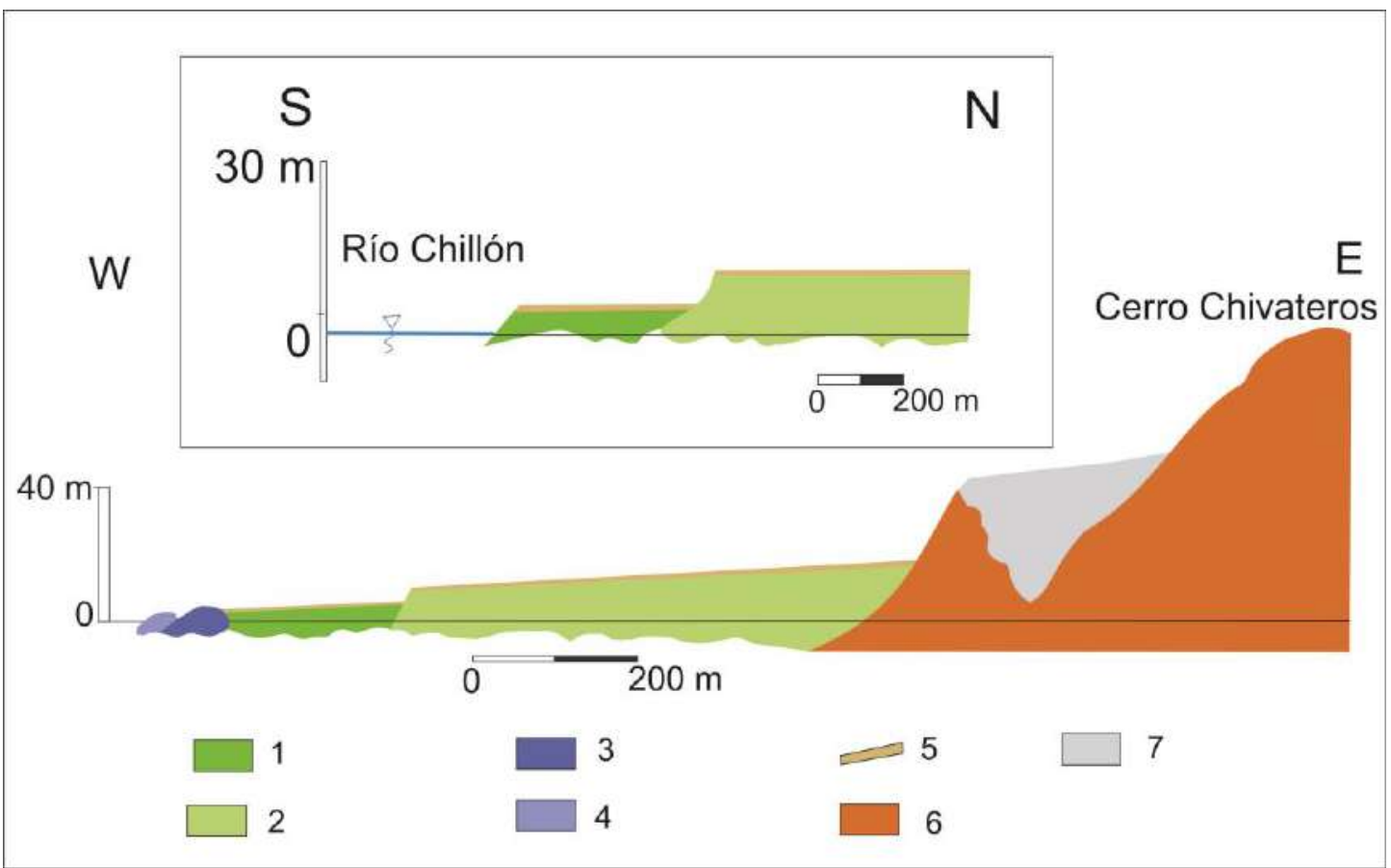

Figura 14. Perfiles de los niveles cuaternarios en la desembocadura del río Chillón. - 1 y 2 terrazas fluviales; 3 y 4 Cordones litorales; 5 Capa de limo que recubre las terrazas fluviales; 6 Substrato 
volcano-sedimentario cretáceo; 7 Material de flujos esporádicos. Tomado de: Sebrier y Macharé (1980). 


\subsection{MÉTODOS PARA EL ESTUDIO DE INUNDACIONES FLUVIALES}

De acuerdo a Diez (2004) se tiene cuatro grupos de estudios acerca de las inundaciones:

1) Análisis hidrológico-hidráulico en base a datos de las estaciones de aforo o meteorológicas.

2) Investigaciones sobre paleo-inundaciones.

3) Caracterización geomorfológica de los eventos.

4) Identificación de inundaciones repentinas o relámpago (flash flood).

Los modelos hidrológicos e hidráulicos permiten estimar el caudal asociado a una inundación en un área determinada (Garcia \& Conesa, 2011; Chow, Maidment, \& Mays, 1994; Témez, 1978). En los métodos hidrológicos, se analiza la transformación lluvia - escorrentía para estimar el caudal (Nash, 1957, Cunge, 1969, Kundzewicz \& Strupczewski, 1982; Cudworth, 1989) mientras que los métodos hidráulicos emplean los datos de aforo. Aunque los últimos son los más usuales para calcular caudales instantáneos, existe la creencia de que son más difíciles de aplicar por tener una gran cantidad de parámetros a evaluar (R. H. Webb \& Jarrett, 2002).

Ya sea que se obtengan indirectamente de la consideración de variables hidrológicas o directamente de las mediciones de descargas de ríos, estos datos son sólo muestras del comportamiento del río a través del tiempo (Shaw, Beven, Chappell, \& Lamb, 2010). Es pertinente entonces evaluar la representatividad de los datos durante el período para el cual se requiere la información, sobre todo cuando se realizan los modelos hidráulicos que están más relacionados al diseño de obras de ingeniería hidráulica (Rico, Benito, \& Barnolas, 2001). A continuación, se presenta un repaso de los métodos más empleados para generar escenarios de inundaciones.

\subsubsection{Modelamiento hidrológico}

Chow et al. (1994) clasifican los modelos hidrológicos en determinísticos y estocásticos (Figura 15). Los modelos determinísticos están basados en la física del fenómeno y los estocásticos en su comportamiento probabilístico (Fernández, Vela, \& Castaño, 1997; Llanos, Díaz, Garfias, Antigüedad, \& Llamas, 2004). 


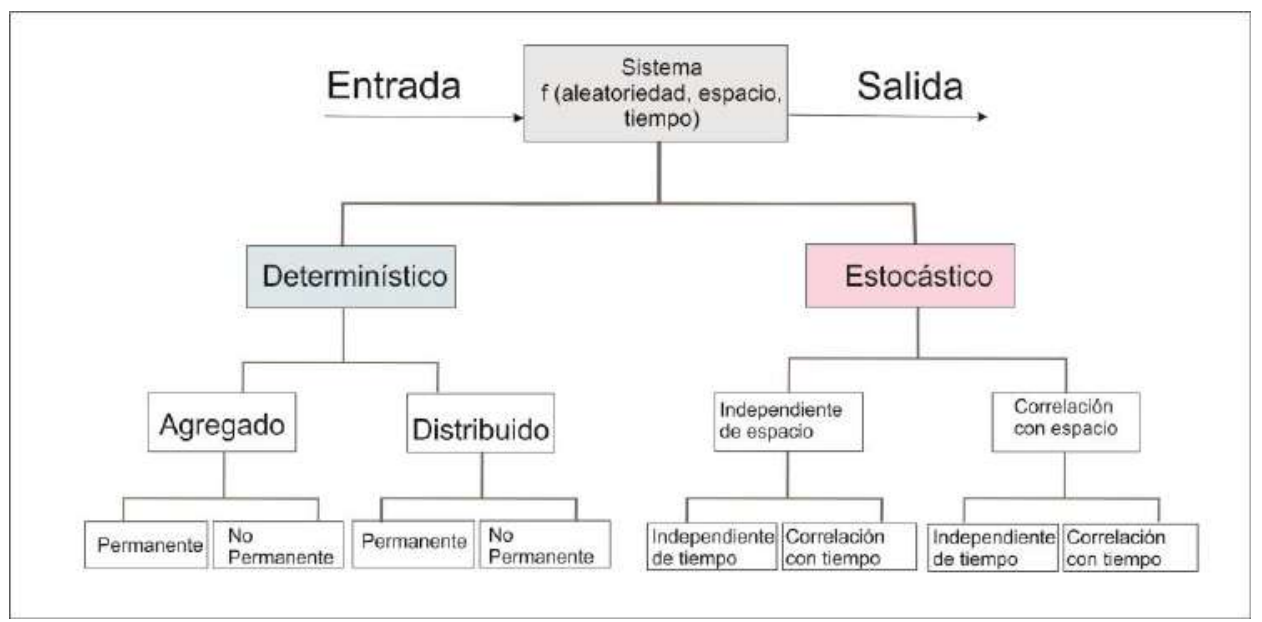

Figura 15.Clasificación de modelos hidrológicos. Tomado de: (Chow et al., 1994)

Los modelos hidrológicos se emplean para estimar caudales en base a información pluviométrica (Zanon et al., 2010; Bell \& Moore, 1998; Linsley, Kohler, \& Paulhus, 1975), sobre todo en cuencas pequeñas sin estaciones de medición (Témez, 1978).

Este análisis incluye la modelización del proceso lluvia-escorrentía de las cuencas hidrográficas, es decir la caracterización del sistema hidrológico de las áreas donde se inicia la escorrentía superficial (Dietrich \& Dunne, 1993). Parte de este trabajo se basa en analizar el registro de precipitaciones y aplicar modelos de transformación (Ferrer, 1993). La validez de los mismos requiere de calibración o contraste (Jarrett, 1987).

En el proceso de escorrentía superficial se pueden distinguir dos fases básicas: fase de ladera y fase de propagación-laminación por la red de drenaje. En la fase ladera predominan los procesos de arroyada y los flujos sub-superficiales. Su resolución exige complejos modelos matemáticos (Akan, 1993; Tayfur, Kavvas, Govindaraju, \& Storm, 1993). En la fase de propagación, los caudales entregados por las laderas pasan a la red de cauces propagándose y laminándose.

La lluvia que precipita sobre una cuenca sufre una serie de pérdidas relacionadas con la infiltración en el terreno, el almacenamiento en las depresiones del terreno, la intercepción por la vegetación y la evapotranspiración (Bodoque, 2007; Olivares, Gómez, Candela, \& Tamoh, 2009). De esta forma, la lluvia que no interviene en la escorrentía rápida, esta última compuesta por la arroyada superficial y flujo subsuperficial rápido, se le denomina con el concepto general de pérdidas. Las pérdidas 
dependen de la tipología de depósitos superficiales, litología de la cuenca (características físicas como la permeabilidad), tipo y uso de suelo y la pendiente (Aparicio, 1997).

Existen diferentes métodos para el cálculo de las pérdidas totales como el de abstracción inicial y uniforme, el del Número de Curva, o los modelos que solo calculan la infiltración como el de USDA-SCS (Mockus, 1972; Boughton, 1989) definido a través de las propiedades físicas del suelo, o el de Green \& Ampt (1911), entre otros.

\subsubsection{Métodos Determinísticos}

Representan al sistema hidrológico en base a una serie de registros y expresiones analíticas que simulan cómo se comportará el proceso evaluado en el futuro (DíezHerrero, 2004; Llanos et al., 2004; Fernández et al., 1997).

En muchos casos no se cuenta con todos los datos de entrada por lo que este tipo de modelos tiene muchas limitaciones, requiriendo de análisis secundarios o finalmente debe recurrirse a computadoras (ordenadores) de altas prestaciones poco accesibles por su costo.

Los modelos determinísticos se distinguen por su grado de agregación y distribución espacial (Fernández et al., 1997).

Los modelos agregados se basan en que las componentes se ponderan con el fin de definir un valor promedio, considerando con ello a la cuenca como una única unidad (Andreu, 1983; Cazenave, 2006). Este tipo de modelos al parecer presentarían inconvenientes debido a la escala (Beven, 1991; Wood, Sivapalan, Beven, \& Band, 1988).

Los modelos distribuidos, desarrollados a fines de los años sesenta, se diferencian de los agregados en que dividen la cuenca en subunidades (Freeze \& Harlan, 1969).

Se considera entonces, en la simulación, a todas las variables espaciales y características de cada subunidad de la cuenca (precipitación, conductividad hidráulica, pendiente, etc.). La respuesta de la cuenca sería el acumulativo de los 
valores de todas las subunidades. Uno de los más conocidos es el modelo SHE (Abbott, Bathurst, Cunge, O'Connell, \& Rasmussen, 1986).

Los modelos semi-distribuidos se consideran intermedios entre los anteriores. En ellos algunas variables o parámetros son globales. Por ejemplo, el modelo TOPMODEL (Beven \& Kirkby, 1979) donde la precipitación no es distribuida.

\subsubsection{Métodos Estocásticos}

Tratan de reproducir las características de procesos altamente aleatorios, como la precipitación y la escorrentía, basándose en los datos observados y en términos de la probabilidad. (Marco, 1993).

A mediados del siglo XIX se produce un incremento en el desarrollo de las construcciones y en pleno progreso de la Hidrología fluvial, se ensayaron los primeros métodos numéricos para el diseño de alcantarillados públicos. En ese período se formuló el método racional y se definió el concepto de tiempo de concentración (Mulvaney, 1851) como el tiempo que demora una gota de lluvia neta o efectiva, caída en el punto más alejado de la salida de la cuenca, en llegar a la desembocadura. Corresponde además al tiempo en que se alcanza el caudal de equilibrio o el tiempo base del hidrograma unitario menos la duración de la lluvia neta (Pernas, 2002; Ferrer, 1993; R. E. Horton, 1941).

A finales de los sesenta, el desarrollo tecnológico permitió acceder a la modelización estocástica de series temporales de datos la cual se empleó en el análisis de datos de caudales y lluvias (Box \& Jenkins, 1976). Es en esta época cuando se desarrolla la teoría de la respuesta hidrológica considerando parámetros morfométricos propios de la cuenca analizada (Rodríguez-Iturbe \& Valdes, 1979). A consecuencia de estos avances se incorporan nuevos parámetros que representan mejor el tiempo de recorrido del agua en la cuenca; su velocidad durante la crecida y el tiempo en la fase de ladera (Bras, 1990; Gupta, Waymire, \& Wang, 1980). Posteriormente, otros autores desarrollaron mejoras a los modelos naciendo así el hidrograma unitario geomorfológico basado en funciones de distribución tipo gamma; planteamiento que se adapta mucho mejor a las redes hidrológicas (Cudennec, Fouad, Sumarjo, \& Duchesne, 2004; Chang-Xing, 1992; Rodríguez-Iturbe \& Valdes, 1979) 
El método racional tuvo que modificarse por considerarse muy general y cuyos resultados se restringían a cuencas de limitada dimensión y con características específicas de lluvias (Ross, 1921; Díez-Herrero, 2004) con la incorporación de parámetros que contemplan la variación de la lluvia a través del tiempo, áreas mayores y la reconstrucción del hidrograma supuesto (Chow et al., 1994; Témez, 1978).

Desde la creación de los Sistemas de Información Geográfica (SIG) en los años 80, la variedad de métodos y software para el modelamiento hidrológico se ha incrementado (Triviño \& Ortiz, 2004). Las ventajas de esta algoritmia numérica radican en que permite el almacenamiento, la gestión, análisis y visualización de datos cartográficos (Clarke, 1997). En el caso de los SIG aplicados a modelización hidráulica, son de gran utilidad para el diseño de soluciones alternativas mitigadoras o paliativas (presas, diques, drenajes, etc.). permitiendo la rápida delimitación de las cuencas hidrográficas, de sus características morfométricas, así como la rápida obtención de parámetros como el Número de Curva (NC) o el Umbral de Escorrentía $\left(P_{0}\right)$ a partir de la combinación y reclasificación de diferentes capas (shapes) como las de usos del suelo, mapa de pendientes, litología y tipos de suelos.

\subsubsection{Análisis Pluviométrico}

La precipitación varía en el espacio y el tiempo de acuerdo con el patrón general de circulación atmosférica y con factores locales (Chow et al., 1994). Existen diferentes tipos de precipitación como la orográfica, ciclónica y convectiva (Wiesner, 1970). El análisis pluviométrico se inicia con el tratamiento de una serie de datos para determinar la frecuencia o probabilidad de alcanzar o superar un valor (Linsley et al., 1975). En el caso de no contar con series de datos completas se suele realizar el proceso de regionalización (Chow et al., 1994; Zalina, Desa, Nguyen, \& Kassim, 2002). Autores como Fontaine y Potter (1989) y Bras (1990) indican que es necesario conocer no solo la cantidad de las precipitaciones por evento registrado, sino analizar la intensidad, duración y frecuencia de cada lluvia en relación a un determinado periodo de retorno.

\subsubsection{Ajuste de la probabilidad muestral a una función}

Para estimar la probabilidad de ocurrencia de valores extremos de lluvias, se seleccionan los máximos anuales registrados y se ajustan a funciones de probabilidad. Como existen muchas funciones de distribución de probabilidad teóricas es necesario 
escoger la que se adapte mejor a los datos analizados. Entre las funciones de distribución de probabilidad especializadas en valores extremos destacan: Normal., Log Normal, Pearson III, Gumbel, Pearson III, SQRT-ET max, etc. (Chow, 1964; Bobee \& Robitaille, 1977; Koutsoyiannis, 2004; Llorente, 2014).

\subsubsection{Análisis de frecuencia}

Lo que se busca con este análisis es encontrar un modelo matemático de la distribución de la probabilidad que represente la variable considerada, por ejemplo la precipitación diaria máxima o los caudales máximos instantáneos (Chow, 1964; Kite, 1977). Para ello se considera que los registros describen la variable como un evento aleatorio, y que los procesos naturales significan eventos independientes representados por modelos probabilísticos que no varían en el tiempo (A. Bradley \& Zhao, 1997; A. A. Bradley, 1998).

\section{Periodo de retorno}

Corresponde al tiempo que en promedio transcurre entre dos sucesos, dada una serie de sucesos suficientemente larga (Llorente, 2014; Chow et al., 1994; Fuller, 1914). También es llamado intervalo de recurrencia o frecuencia. Suele asociarse con la frecuencia por la siguiente fórmula (Mélice \& Reason, 2007):

$\operatorname{Tr}=1 / f$

Para los modelos hidrológicos se prefiere emplear los periodos de retorno en lugar de la probabilidad pues es más ventajoso en relación a su comprensión y suele relacionarse a la vida útil de las obras de infraestructura como diques o presas (Aparicio, 1997).

\subsubsection{Regionalización}

Con frecuencia es difícil obtener una serie de datos larga y completa, pues suele suceder que las estaciones no son suficientes en un área. Para superar esa problemática, es posible emplear la estadística para extrapolar los datos de estaciones circundantes. Para ello se requiere de un análisis regional (Chow et al., 1994; Stedinger, 1993) que permite encontrar un área homogénea donde los cuartiles estimados no difieran grandemente del factor específico relacionado al lugar evaluado, es decir que no alteren la serie de datos empleada (A. Bradley \& Zhao, 1997). 


\subsubsection{Cálculo hidrológico del Caudal máximo}

Cuando se dispone de datos de caudales máximos diarios tomados de estaciones de aforos ubicadas en la cuenca evaluada, estos se analizan de manera similar al análisis estadístico de frecuencias de las precipitaciones diaria máximas. Se concluye el análisis de los datos con el de una probabilidad de frecuencia o un valor de diseño (Chow et al., 1994). En general una avenida de diseño se proyecta a partir de los máximos anuales registrados y se refiere a un caudal pico Qmax. Cuando no se cuenta con esta información se realiza un cálculo basado en la transformación en escorrentía de las precipitaciones que ocurren en una cuenca.

Permite hallar el caudal máximo proporcional a la intensidad de la lluvia y al área de la cuenca (Benito et al., 2004). Según el método racional dicho valor de caudal se ve corregido por un coeficiente de escorrentía cuyo valor está comprendido entre 0 y 1 ; y que representa el agua de lluvia retenida en la cuenca en su camino a la desembocadura; así como la que se evapora antes o durante su tránsito.

La fórmula general del método racional es:

$$
Q_{\max }=C I_{T c} A
$$

Dónde:

$Q_{\max }$ es el caudal máximo o pico.

C es el coeficiente de escorrentía, el cual se calcula a partir del Número de curva

$I_{T c}$ es la máxima intensidad de la lluvia durante un periodo igual al tiempo de concentración de la cuenca.

$A \quad$ es el área de la cuenca.

Esta fórmula se ha modificado incluyendo $\mathrm{K}$ y dividiendo entre 3.6 para su empleo en el sistema métrico internacional:

$$
Q_{\max }=\text { C.I. A. K/ } 3.6
$$

Cálculo de coeficiente de escorrentía

Dentro de los métodos utilizados para estimar el coeficiente de escorrentía, el Número de Curva (CN por sus siglas en inglés) es el de mayor difusión (Ferrer, 1993; Kottegoda, Natale, \& Raiteri, 2000; Garen \& Moore, 2005; Gaspari \& Senisterra, 2006). El método se basa en que las combinaciones de características semejantes de suelo (a partir de su grupo hidrológico) y tipo de cobertura vegetal responden de manera análoga bajo el efecto de una tormenta de intensidad variable. 
En el Perú este método es poco conocido y es aun escasamente empleado y la elección de $\mathrm{CN}$ incurre en el uso de tablas y de la experiencia, al no ser posible la calibración por aforos. Así por ejemplo valores mayores a 80 corresponderían en el Perú, a cuencas de las regiones costa y sierra (Bernabé, 2010).

Para estimar el volumen mínimo de precipitación que pueda producir escorrentía superficial el método racional modificado propone el parámetro umbral de escorrentía $\left(\mathrm{P}_{0}\right)$, el cual está relacionado con CN mediante la ecuación (Mockus, 1972; Boughton, 1989):

$C N=1000\left(10+0,2 P_{0}\right)$

Cálculo de la Intensidad de las precipitaciones

La caracterización de la intensidad de la precipitación se basa en las mediciones de pluviógrafos para concluir un patrón de comportamiento en una zona. Sin embargo, no siempre se dispone de estos para precipitaciones máximas de corta duración, por lo que es común el uso de registros pluviométricos para estimar las intensidades por medio de ecuaciones (Del Ángel \& Domínguez, 2013).

Las curvas de Intensidad-Duración-Frecuencia (IDF) se elaboran mediante la interpolación de datos representativos de la intensidad media de precipitación para diferentes períodos de retorno (Témez, 1978). La metodología tradicional usada para su cálculo consiste en analizar la frecuencia de cada una de las series de valores máximos de precipitación obtenidas para cada duración.

Aunque no existe aún un consenso acerca del tipo de serie de datos a emplear en el cálculo de las curvas IDF, en muchos casos se emplean las series máximas anuales (Chow, 1964). Una vez seleccionada la serie de máximos el siguiente paso consiste en establecer el rango de duraciones para el cual se estimarán las curvas IDF. Algunos autores consideran que en un sitio específico puede estimarse una sola familia de curvas para un amplio rango de duraciones, por ejemplo, entre 5 minutos y 24 horas, mientras que otros emplean en cada sitio dos familias de curvas una para las duraciones más cortas, entre 5 y 60 o 120 minutos y otra entre 60 o 120 minutos hasta 24 horas. Diversos autores consideran que esta subdivisión se debe a las diferentes características físicas muy diferentes en las lluvias de corta duración, entre 
0 y 1 o 2 horas, las cuales se asocian a fenómenos convectivos, y las de larga duración, mayores a dos horas (Bonacci, 1984).

Existen varias fórmulas para representar las curvas IDF en forma regionalizada (Froehlich, 1995; Vargas, 1998; y Varas, 2000) (Froehlich, 1995; Varas \& Farías de Reyes, 2000).

Froehlich (1995) empleo ecuaciones adimensionales para representar las curvas IDF en regiones de los Estados Unidos:

Tabla 1. Ecuaciones IDF de Froehlich (Froehlich, 1995)

\begin{tabular}{|l|l|l|}
\hline $\begin{array}{l}\text { Tipo de } \\
\text { ecuación }\end{array}$ & Expresión & $\begin{array}{l}\text { Parámetros de la } \\
\text { ecuación }\end{array}$ \\
\hline I & $i=a 1 /(t+b 1)$ & $a 1, b 1$ \\
\hline II & $i=a 2 / t^{D 2}$ & $a 2, b 2$ \\
\hline III & $i=a 3 /(t+b 3)^{c 3}$ & $a 3, b 3, c 3$ \\
\hline IV & $i=a 4 /\left(t^{c 4}+b 4\right)$ & $a 4, b 4, c 4$ \\
\hline
\end{tabular}

Los parámetros de estas ecuaciones se hallan minimizando la suma de los cuadrados de los errores para los datos considerados (Vélez et al., 2002).

Otra metodología que se usa para la representación de curvas IDF se basa en un derivado de la ecuación de Témez modificada (1991):

La cual es ampliamente utilizada en España y es recomendada por la Instrucción de Drenaje Superficial, dependencia del Ministerio de Obras Públicas de España. En esta, $\mathrm{PD}(\mathrm{Tr})$ es la precipitación máxima diaria, I1/ID es la relación entre la intensidad máxima de una hora con la intensidad de 24 horas, también llamada coeficiente de torrencialidad.

En el Perú se emplea la ecuación anterior asignándosele un valor de 11 a la relación: I1/ld lo cual está señalado en el Manual de carreteras de Perú: Hidrología, Hidráulica y Drenaje (Ministerio de Transportes y Comunicaciones, 2014).

Donde: P es la precipitación y Tc es el tiempo de concentración. 


\subsubsection{Parametrización de un hidrograma adimensional}

Se suele emplear el método racional o se reconstruye un hidrograma que representa los caudales de un río en relación al tiempo (Aparicio, 1997; J. C. Manning, 1997). El concepto del hidrograma unitario apareció en el siglo pasado referido al hidrograma de $1 \mathrm{~mm}$ de lluvia distribuido de forma uniforme sobre un área con una duración determinada (Chow, 1964; R. E. Horton, 1933; Sherman, 1932). Pronto este concepto deviene en el hidrograma unitario sintético elaborado por la USDA-SCS (Snyder, 1938; Mockus, 1972; Boughton, 1989) teoría aplicada en cuencas con tamaños entre $30 \mathrm{~km}^{2}$ y $30.000 \mathrm{~km}^{2}$ estudiadas en los Apalaches norteamericanos. Este método consiste en calcular un hidrograma unitario a partir de las características físicas de la cuenca y un perfil de precipitación efectiva, generando un hidrograma compuesto de la avenida.

Posteriormente otros investigadores propusieron, en base al análisis de una gran cantidad de datos de cuencas en Norteamérica, un nuevo tipo de hidrograma unitario sintético: el Hidrograma Unitario Adimensional, en el que el caudal viene dado por la relación existente entre el caudal $Q_{t}$ instantáneo y el máximo $Q_{\max }$, y el tiempo por la razón entre el tiempo t desde el inicio de la lluvia y el tiempo hasta la obtención del caudal pico $t_{p}$, (Wu, 1963; James, Winsor, \& Williams, 1987).

El método de las Curvas Envolventes de Creager, aplica a la relación:

$$
Q_{\max }=\left(C_{1}+C_{2}\right) * \log (T) * A^{m A^{-n}}
$$

Donde, C1, C2, m y $\mathrm{n}$ son coeficientes adimensionales para diferentes regiones del Perú. En la Tabla 2 se muestra los valores de los coeficientes para cada región del Perú, según los cuales el ámbito de estudio se ubica en las regiones 4 y 6 .

Tabla 2. Valores de los coeficientes según región del Perú. Tomado de (Ministerio de Transportes y Comunicaciones (2014)

\begin{tabular}{|c|c|c|c|c|c|c|}
\hline № & Región & Cuencas & C1 & C2 & $\mathrm{m}$ & $\mathrm{n}$ \\
\hline 1 & $\begin{array}{c}\text { Costa Norte } \\
\text { (frontera) }\end{array}$ & Tumbes a Piura & 1.01 & 4.37 & 1.02 & 0.04 \\
\hline 2 & Costa Norte & Cascajal o Santa & 0.10 & 1.28 & 1.02 & 0.04 \\
\hline 3 & Sierra Norte & Alto Marañón & 0.27 & 1.48 & 1.02 & 0.04 \\
\hline 4 & $\begin{array}{c}\text { Costa } \\
\text { Central }\end{array}$ & $\begin{array}{c}\text { Locramarca o Camaná- } \\
\text { Majes }\end{array}$ & 0.09 & 0.36 & 1.24 & 0.04 \\
\hline 5 & Costa Sur & Quilca o Caplina & 0.11 & 0.26 & 1.24 & 0.04 \\
\cline { 2 - 6 } & Titicaca & Titicaca & 0.18 & 0.31 & 1.24 & 0.04 \\
\hline 6 & $\begin{array}{c}\text { Sierra } \\
\text { Central Sur }\end{array}$ & $\begin{array}{c}\text { Mantaro, Apurímac y } \\
\text { Urubamba }\end{array}$ & 0.18 & \\
\hline
\end{tabular}




\begin{tabular}{|c|c|c|c|c|c|c|}
\hline 7 & Selva & $\begin{array}{c}\text { Ucayali, Bajo Marañón, } \\
\text { Madre de Dios y Amazonas }\end{array}$ & 0.22 & 0.37 & 1.24 & 0.04 \\
\hline
\end{tabular}

\subsubsection{Modelamiento hidráulico}

\subsubsection{Cálculo hidráulico del caudal en una sección tipo}

Para este cálculo se puede tomar en cuenta la ecuación de Manning (1890), que ha derivado de la de Chézy empleada en el cálculo de la velocidad del agua en canales abiertos y tuberías.

$$
Q=\frac{1}{n} A \mathrm{R}^{2 / 3} \mathrm{~S}^{1 / 2}
$$

Donde:

$Q$ es el caudal, " $n$ " es el coeficiente de rugosidad de Manning, A es el área de la sección, $\mathrm{R}$ es el radio hidráulico, $\mathrm{S}$ es la pendiente del cauce.

Para efectuarlo se emplean perfiles calculados in situ en base a un levantamiento topográfico a detalle con el fin de obtener curvas de nivel a cada metro y secciones transversales al menos una por cada 20 metros en el cauce evaluado donde se establece un perímetro húmedo a analizar. Teniendo en cuenta las alturas o tirantes alcanzados en eventos extraordinarios y calcular de esta manera el área inundada de la sección transversal. En relación al coeficiente de rugosidad, la selección del mismo se basa en la experiencia (Benson \& Dalrymple, 1967).

\subsubsection{Simulación numérica de caudal sólido}

Cuando el fondo de valle contiene material particulado heterométrico, se dice que su lecho tiene carácter granular, mientras que si ocurre lo contrario es cohesivo. En el último de los casos, es mayor la resistencia a la erosión; sin embargo, los mejor estudiados son los lechos granulares (Martín-Vide, 2007).

Una partícula de un lecho granular, que soporta la circulación de una corriente de agua, se verá en algún momento desplazada por la fuerza del arrastre del agua. Al límite de esta resistencia se le conoce como umbral o condición crítica del arrastre del fondo. Shields (1936) lo estudió en laboratorio principalmente con arenas tamizadas obteniendo un parámetro que relaciona la tensión de corte crítica con el peso sumergido de los granos y con su tamaño: $\Theta c={ }^{t} / g\left(\rho_{s}-\rho\right) D$ (siendo g la gravedad, $\rho_{s}$ la densidad del sedimento, $\rho$ la densidad del agua y $\mathrm{D}$, el tamaño de grano). La tensión 
de corte también varía con la rugosidad del substrato, por lo cual Shields (1936) relacionó las tensiones críticas observadas con el número de Raynolds que involucra la rugosidad de frontera (Figura 16).

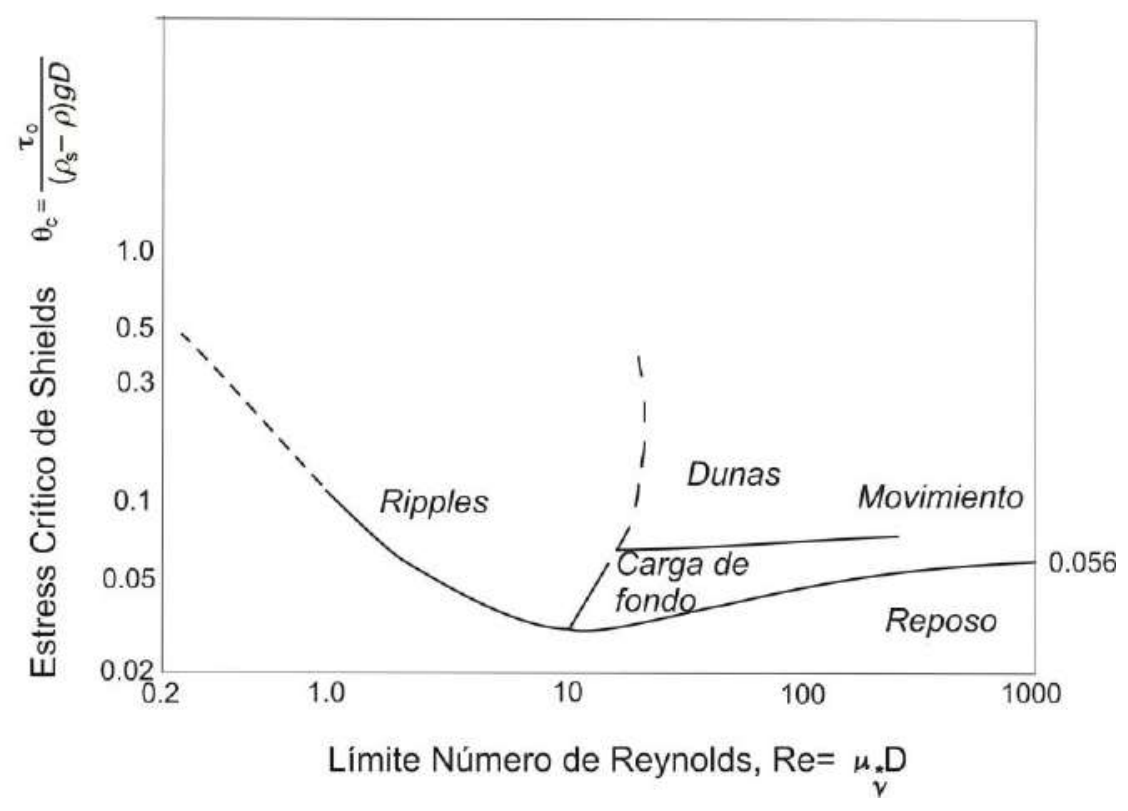

Figura 16. Diagrama de Shield. Tomado de: Martín-Vide (2007)

Al ser turbulento el flujo de agua en una corriente natural, solo en el lecho se produce movimiento laminar y las tensiones totales siguen una ley lineal. Esta distribución de tensiones a lo largo de la columna de agua refleja la acción de la gravedad por unidad de volumen en la dirección del movimiento (Martín-Vide, 2007).

\subsubsection{Caudal solido}

Como un río no solo transporta agua sino también sedimentos, cuando se habla de caudal, normalmente se entiende por caudal líquido, sin embargo, en el análisis del transporte de sedimentos es necesario definir además el caudal sólido, Qs, que representa el volumen por unidad de tiempo que cruza una sección transversal y definir el correspondiente caudal sólido unitario, q, por unidad de anchura. No es fácil, pues el peso específico de1 sedimento varía con el tiempo por consolidación y depende también de la granulometría (Martín-Vide, 2007).

En el estudio de los desbordes producidos por avenidas (cuando el origen está en un lugar distinto del que se registran sus efectos) y crecidas (cuando el agua crece desde un nivel inicial bajo, Díez-Herrero, 2014); una parte importante se dedica al estudio del transporte de sólidos, los cuales no pueden separarse del flujo de agua (Martín-Vide, 
2007). Cuando el flujo transporta sólidos, el calado (altura alcanzada por el agua) puede ser mucho mayor que en un flujo solo de agua del mismo caudal (Graf, 1998).

Según Martín-Vide (2007) se pueden distinguir dos tipos de fenómenos torrenciales: el flujo hiper-concentrado y las lavas torrenciales. Para los fines de este estudio nos vamos a referir solo al primero.

\subsubsection{Propiedades de los flujos de detritos}

Siendo una mezcla de fases, estos materiales presentan características que lo definen: porosidad, grado de saturación, densidad; así como los coeficientes de compresibilidad, de dilatación volumétrica, tensiones efectivas, y viscosidad (Darcy, 1856).

\subsubsection{Física de su movimiento}

El comportamiento de los flujos de detritos se ha abordado habitualmente en función de dos principios:

Conservación de la masa:

$\frac{\partial h}{\partial t}+\frac{\partial h_{u}}{\partial x}+\frac{\partial h_{v}}{\partial y}=0$

Conservación de la cantidad de movimiento o momentum:

$$
\begin{aligned}
& \frac{\partial h_{u}}{\partial t}+\frac{\partial\left(h_{u}^{2}+g \frac{h^{2}}{2}\right)}{\partial x}+\frac{\partial h_{u v}}{\partial y}=g h\left(S_{0}-S_{f}\right)_{x} \\
& \frac{\partial h_{v}}{\partial t}+\frac{\partial\left(h_{v}^{2}+g \frac{h^{2}}{2}\right)}{\partial y}+\frac{\partial h_{u v}}{\partial x}=g h\left(S_{0}-S_{f}\right)_{y}
\end{aligned}
$$

Donde la variable $h$ es la profundidad hidráulica en sus distintas proyecciones ( $u$ y $v$ ), $S_{0}$ corresponde a la pendiente topográfica y $S_{f}$ es el gradiente de energía.

La aplicación práctica de estos principios al estudio del movimiento de un fluido queda materializada en las ecuaciones de Saint-Venant.(Saint-Venant, 1871) Han sido modificadas para adaptarse a las características de los flujos con alta carga de sedimentos, a partir de las siguientes hipótesis:

- Alta pendiente, considera que la hipótesis modifica dos términos de las ecuaciones anteriores, 
- El parámetro gravedad, corrigiendo su valor en proporción al ángulo entre la fuerza gravitatoria y la presión del material movilizado.

- Se añade el término de fuerza centrípeta como variable obtenida del relieve cuya acción corrige los valores de la presión sobre el terreno y la procedente del fluido.

- Fenómeno granular y presión de poro (intersticial y porosidad abierta) según los cuales la existencia de una presión de poro en material de tipo granular modifica la correspondiente presión efectiva sobre el terreno disminuyéndola y activando su movilización.

- Reología, que supone un determinado comportamiento de acuerdo al tipo de material y se incorpora ajustando la presión de la mezcla.

Con estos ajustes y teniendo en cuenta un volumen de control determinado, la resolución del problema queda limitada al siguiente esquema numérico diferencial:

$U_{i j}^{n+1}=U_{i j}^{n}+\frac{\Delta t}{\Delta x}\left(F_{i-1 / 2 j}-F_{i+1 / 2 j}\right)+\frac{\Delta t}{\Delta y}\left(G_{j i-1 / 2}-G_{j i+1 / 2}\right)+S_{i j} \Delta t$

Donde los subíndices indican la posición del nodo de la malla bidimensional, los superíndices indican el tiempo, $U_{i j}$ son los valores promediados de ganancia o pérdida hidráulica en el interior de las celdas, $F_{i j}$, los valores de flujo que entra o sale a través de las caras izquierda y derecha de las celdas, respectivamente, $G_{i j}$ los valores de flujo de entrada o salida a través de las caras superior e inferior de las celdas y $S_{i j}$ las pendientes motrices, también llamadas gradientes de energía para cada celda.

La resolución de esta ecuación diferencial en cada celda de cálculo aporta los datos necesarios para caracterizar el movimiento y la dinámica de los flujos detríticos.

\subsubsection{Reología de los flujos de detritos}

La reología estudia la respuesta de un material ante una tensión aplicada sobre él, así como la deformación resultante producida por dicha fuerza (Lavigne \& Suwa, 2004).

La característica reológica de la mayor parte de fluidos densos es la coexistencia de fuerzas viscosas y turbulentas en un mismo material y la posibilidad de existencia de un umbral de esfuerzo por debajo del cual no hay deformación. Se pueden utilizar modelos reológicos contrastados en función de la naturaleza del material movilizado. Todos ellos expresan genéricamente en la ecuación de cálculo tensional siguiente:

$\tau=\tau_{0}+\mu_{m} \frac{d v}{d z}+\delta\left(\frac{d v}{d z}\right)^{2}$ 
Donde $\tau$ corresponde a las tensiones totales, $\tau_{0}$ es la tensión umbral por debajo de la cual no se produce movimiento ni deformación, $\mu_{m}$ es la viscosidad, $\delta$ el coeficiente de turbulencia, $v$ la velocidad local del fluido y $d v / d z$ la velocidad o gradiente de deformación o de velocidad en la dirección $z$.

Según las características del material movilizado, la presión intersticial de fluido, la naturaleza del material y su comportamiento ante las fuerzas, se definen principalmente:

- Reología granular. Intervienen las fuerzas de fricción inter-granular que configura el material transportado y las fuerzas del propio fluido inter-poroso.

- Reología granular turbulenta. El comportamiento granular del material (con la aparición del término de fricción inter-granular) es modificado por las fuerzas turbulentas del fluido que preponderan sobre las viscosas.

- Reología visco-elástica. Aparecen esfuerzos normales o difusivos que controlan y modifican el movimiento del flujo.

- Reología plástica. Es la permanencia, y adaptación de las deformaciones producidas sobre el material y la posible existencia de un umbral de esfuerzo por debajo del cual no se genera movimiento.

En la realidad los flujos detríticos muestran comportamientos que pueden ser sucesivamente elásticos, plásticos, granulares o viscosos en el tiempo, en función de la fuerza aplicada.

\subsubsection{Modelización hidráulica}

La modelización de un sistema hídrico que permita reflejar de forma cercana la realidad del comportamiento hidráulico del tramo de río modelizado requiere de (Bladé, Sánchez-Juny, Sánchez, Niñerola, \& Gómez, 2009):

(1) Software especializado

(2) información detallada de la topografía del cauce y sus riberas

(3) Estimaciones realistas de muchos parámetros

(4) Datos suficientes para una adecuada calibración y validación

(5) Mucho tiempo, esfuerzo y dinero

En este sentido, para escoger el mejor modelo numérico que permita resolver el problema de hidráulica fluvial al que se enfrenta el especialista, tienen que ver mucho las características del área evaluada y los datos disponibles; los cuales ayudan a 
escoger una solución con la precisión requerida (Llorente, 2014; Bladé et al., 2009; Graf, 1998).

Como las simulaciones naturales rara vez son solo de agua, cuando se desea modelizar con carga sólida, los modelos aplicados consideran las características reológicas de los flujos. Los más antiguos se basan en las ecuaciones de Euler, mientras que los actuales emplean las de Lagrange o una combinación de ambas ( $\mathrm{T}$. Takahashi, 1981; Haddad, 2007). Es así que se conocen tres modelos que simplifican el comportamiento de los flujos para estudiarlos (Costa, 1984; Hungr, Morgan, \& Kellerhals, 1984): flujo newtoniano (en el régimen turbulento o laminar), no newtoniano (Bagnold, 1954; Bingham, 1922; Bingham \& Green, 1919), y el flujo visco-elástico (Del Río \& López de Haro, 1990; Fortin \& Fortin, 1989). Los modelos de flujos no newtoniamos se han desarrollado en laboratorios con el uso de reómetros (O'Brien \& Julien, 1988; Coussot \& Piau, 1994; Wang et al., 1994; Whipple \& Dunne, 1992). Específicamente los modelos de Bingham y Bagnold se basan en relaciones empíricas muy simples por lo que hasta la actualidad son bastante empleados (Naef, Rickenmann, Rutschmann, \& McArdell, 2006). Sin embargo el modelo de Bingham no es aplicable a la mezcla de agua y suelo (Coussot \& Meunier, 1996) pues no considera la tensión superficial entre las partículas al momento de la movilización del flujo, siendo la mínima a superar para que este se produzca (Coussot, Leonov, \& Piau, 1993; McEwen \& Pratt, 1957). Para modelizar fluidos no-newtonianos, autores como Johnson \& Rodine (1984) y Hutchinson (1986) aplicaron modelos simplificados teniendo en cuenta un "enfoque continuo" basado en la ecuación de Coulomb.

Posteriormente, los modelos se adaptaron incluyendo parámetros de velocidad, profundidad como los que estudian la forma de acumulación. Muchos de ellos emplean soluciones de una fase simple y definen la fuerza de fricción que actúa en la interfaz entre el flujo y la trayectoria del lecho fluvial (Kowalski \& McElwaine, 2013; Pastor et al., 2002; Iverson \& Denlinger, 2001; T. Takahashi, 1983; T. Takahashi, 1978).

Sin embargo, la elección del modelo reológico y la calibración de sus peculiares parámetros siguen siendo problemáticos y cuestionables, no existiendo aun en la actualidad ninguna ecuación que pueda describir el comportamiento real de los flujos considerando sus esfuerzos, propagación y teniendo en cuenta que cuando se fluidifican los suelos, el comportamiento es diferente al mostrado en el inicio del movimiento (Iverson, 1997). Es por ello que se necesita una gran cantidad de 
parámetros de amplia variabilidad que requieren validación sistemática y calibración. Los datos de campo a gran escala son cruciales, pero la falta de reproducibilidad y control de las condiciones de contorno y de partida hacen difícil su obtención. Para abordar dicha problemática es de gran utilidad el desarrollo de modelos físicos a escala mediante el uso de fluido equivalente, cuyas propiedades reológicas se aproxima el comportamiento que se espera de la mezcla real. Estas simulaciones, aunque no pueden satisfacer una similitud completa, reproducen características detalladas que permiten la estimación de la dinámica de los flujos (Turnbull et al., 2015). Mediante la integración de estas dos fuentes de datos se corrigen los métodos en la evaluación de la dinámica de los flujos (Luna, Remaître, Van Asch, Malet, \& Van Westen, 2012).

\subsubsection{Software de modelización}

Existe una gran variedad de software para la simulación numérica de flujos, los cuales permiten estimar cómo funcionan estos procesos, así como los daños asociados. Con la finalidad de mostrar diferentes aspectos de la dinámica de los mismos, se comentan a continuación algunos de los existentes a la actualidad.

\section{FLO-2D}

Este modelo bidimensional de elementos finitos simula fluidos no-newtonianos en topografías complejas y se ha aplicado extensamente para diferentes tipologías de flujos (barro, de detritos y similares) y en una variedad de condiciones como áreas urbanizadas (O'brien, Julien, \& Fullerton, 1993).

La información base es de tipo topográfico (se requiere modelos de elevación digital de alta resolución), datos hidrológicos y, sobre todo, de carácter reológico del material movilizado. Estos últimos son determinantes sobre los resultados obtenidos por lo que es necesario calibrar el modelo, de preferencia con ensayos de campo. Como resultados más importantes se destacan la obtención de la altura y velocidad alcanzada por el flujo.

La más reciente versión incluye una secuencia de aplicaciones libres que permite interactuar con los SIG obteniendo nuevas variables representadas en mapas ilustrativos (Figura 17). 

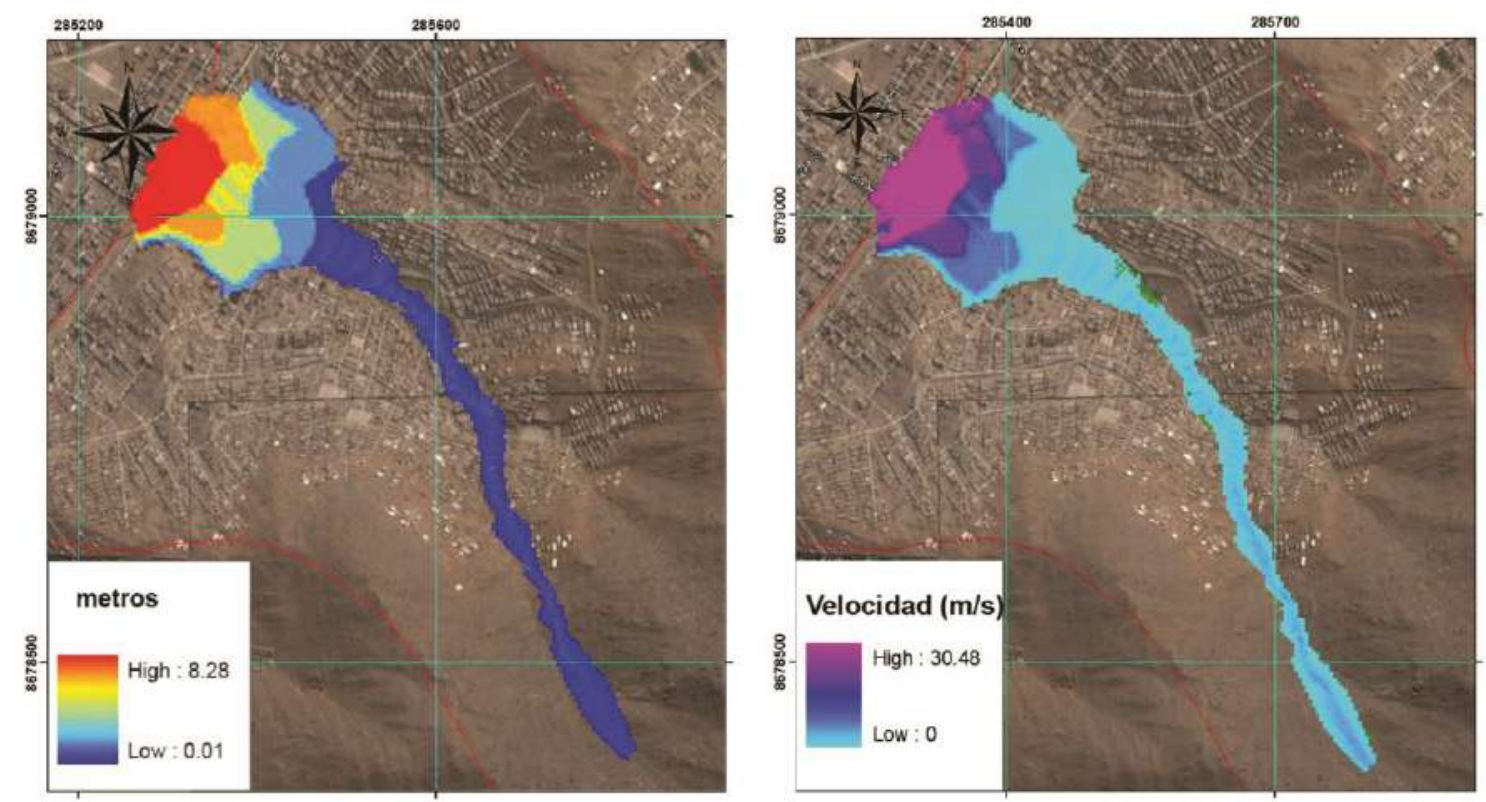

Figura 17. Salida del programa flo2d. a) Elevación máxima del flujo y b) velocidad del flujo en la quebrada Cerro Negro (San Juan de Lurigancho, Lima) para un periodo de retorno de 500 años

DAN

El programa DAN (Hungr, 1995), se basa en una aproximación desarrollada específicamente para simular el movimiento de los flujos, deslizamientos pseudo-flujos y avalanchas. Reduce el complejo y heterogéneo problema tridimensional a una formula sencilla, que hace posible la elección entre las diferentes reologías, algunas de las cuales son particularmente simples. Trata la masa deslizante como un "fluido equivalente", un material hipotético gobernado por relaciones sus propiedades de densidad, viscosidad y concentración de sedimentos (Figura 18). 
Es un programa que se sustenta en Windows e implementa una solución de Lagrange para las ecuaciones de movimiento de una masa de material terroso que parte de una configuración estática prescrita y fluye de acuerdo con una de las posibles relaciones reológicas.

Esta ecuación se deriva mediante la aplicación de una función de balance de impulso a las delgadas láminas de masa que fluyen y que, asume, son perpendiculares a la base del flujo. Estos "bloques frontera" dividen la masa deslizante en "n elementos" de masas de volumen constante.

La fórmula resultante para la fuerza impulsora neta que actúa sobre cada bloque límite i es:

$F=\rho{ }^{*} g^{*} \mathrm{Hi}^{*} d s^{*} \mathrm{Bi}^{*} \sin \vartheta-\mathrm{T}-\mathrm{P}$

Donde $\mathrm{Hi}$ es la profundidad de un i-elemento considerado en el que la masa puede ser dividida en partes, $F$ es la fuerza impulsora neta igual a $F=\rho \cdot H \cdots d s B(d v / d t)$, donde $\rho$ es la densidad aparente del material de flujo, $\mathrm{H}$ es la profundidad de flujo normal a la base, B es la anchura del canal, ds es la longitud infinitesimal del bloque límite, $\theta$ es el ángulo de la base desde la horizontal, $T$ es la fuerza de resistencia al corte que actúa en la base, $\mathrm{P}$ es la presión tangencial interna y $\mathrm{V}$ es la velocidad media de flujo. 


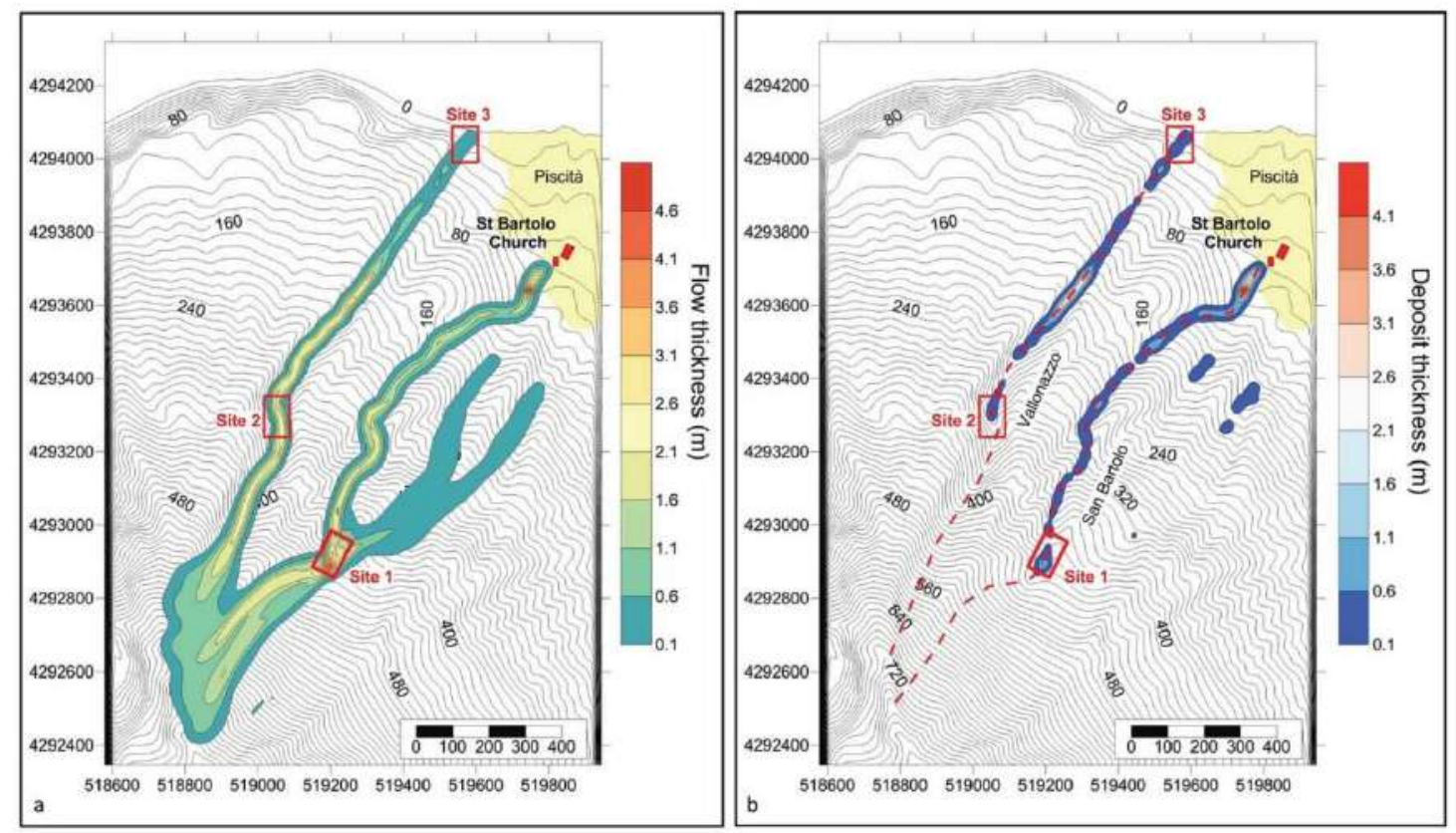

Figura 18. Salidas de simulación en el programa $D A N-3 D$. a) Espesor del flujo y b) espesor del depósito para un sector de Italia. Tomado de Morelli et al. (2016).

\section{FLAT Model}

Es un modelo bidimensional desarrollado por el Grupo de Investigación en Transporte de Sedimentos de la Universidad Politécnica de Cataluña para la simulación de flujos de agua de poca profundidad con correcciones y modificaciones que le permiten representar el comportamiento de un flujo de detritos. Basado en el esquema de Godunov (Godunov, 1959), emplea elementos finitos y las diferentes leyes de resistencia incluyendo las fórmulas de Bingham, Herschel, Bukley y Voellmy (Bateman, Medina, Hürlimann, \& Velasco, 2007).

FlaT Model trabaja con una entrada y salida de datos realizada desde el entorno SIG Arcview. Se alimenta de varias mallas de información con celdas de geometría rectangular, como topografía, condiciones iniciales, condiciones de contorno, rugosidad, profundidad máxima erosionable, entre otros.

Los resultados se representan también mediante mallas, con lo que su visualización es inmediata con las herramientas propias del SIG (Figura 19). 

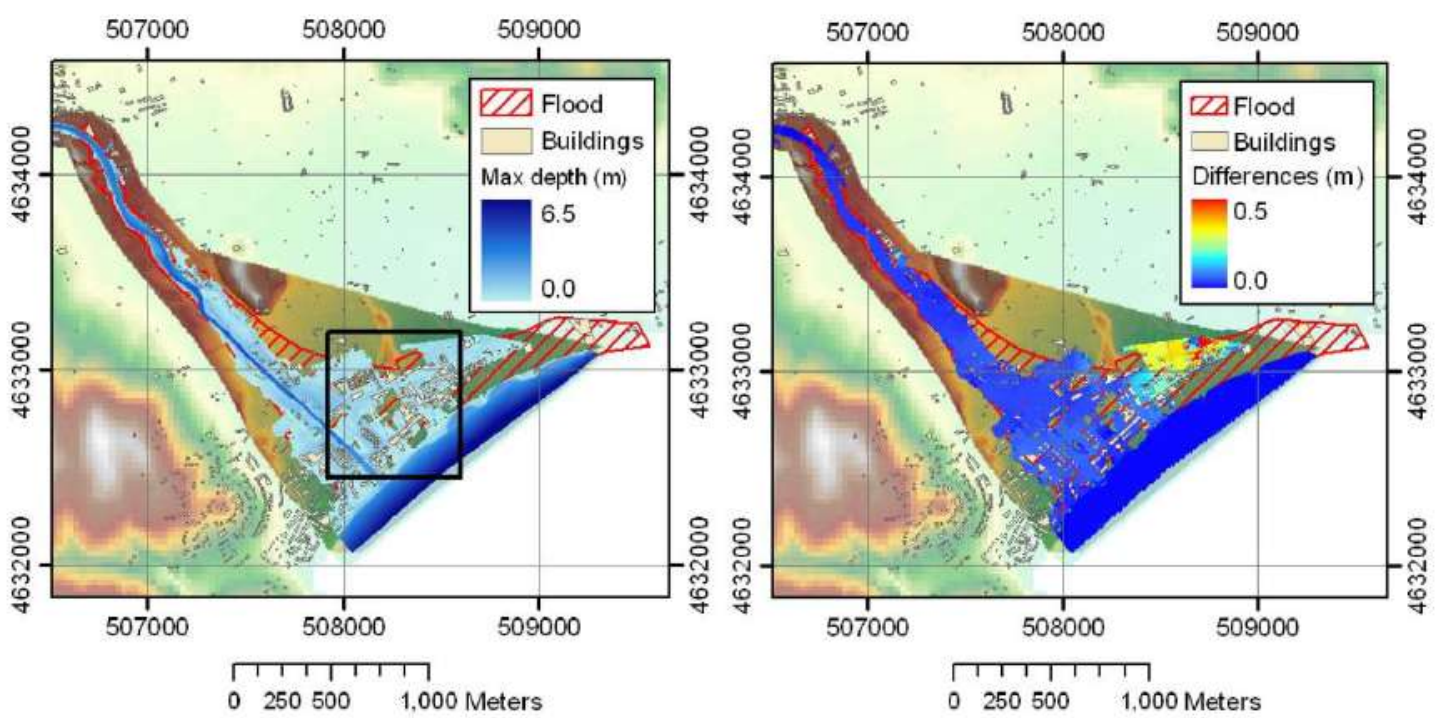

Figura 19. Salida del modelo FLAT MODEL. Tomado de (Bateman, Medina, \& Velasco, 2010)

\section{KANAKO}

Desarrollado por el Instituto de Investigación de Tecnología Sabo y el Laboratorio de Control de Erosión, División de Biomasa y Ciencia Forestal de la Escuela Superior de Agricultura de la Universidad de Kyoto.

Produce simulaciones de flujo de detritos en una y dos dimensiones y se basa en un modelo de integración que emplea simulaciones unidimensionales de las zonas de quebradas y simulaciones bidimensionales de áreas de abanicos aluviales. Considera además las influencias mutuas en las zonas limítrofes entre quebradas y conos de deyección.

Posee una interfaz gráfica de usuario sencilla (Figura 20) en comparación con otros paquetes informáticos. Los usuarios pueden ver las imágenes visualizadas en tiempo real de un flujo de detritos durante una simulación. La interfaz permite a los usuarios ejecutar una simulación de flujo de detritos sin conocimiento experto del modelo. Es usado mayoritariamente en Japón para determinar los posibles efectos de las presas de la ingeniería SABO (tecnología de presas desarrollada en Japón).

Se ha desarrollado utilizando MS Visual Basic.NET para funcionar en Windows, útil por su fácil uso y porque proporciona un alto rendimiento. Además, dado que la plataforma es tan ampliamente utilizado y fácil de aprender, los usuarios pueden fácilmente modificar y ampliar el sistema (Nakatani, Satofuka, \& Mizuyama, 2007). 

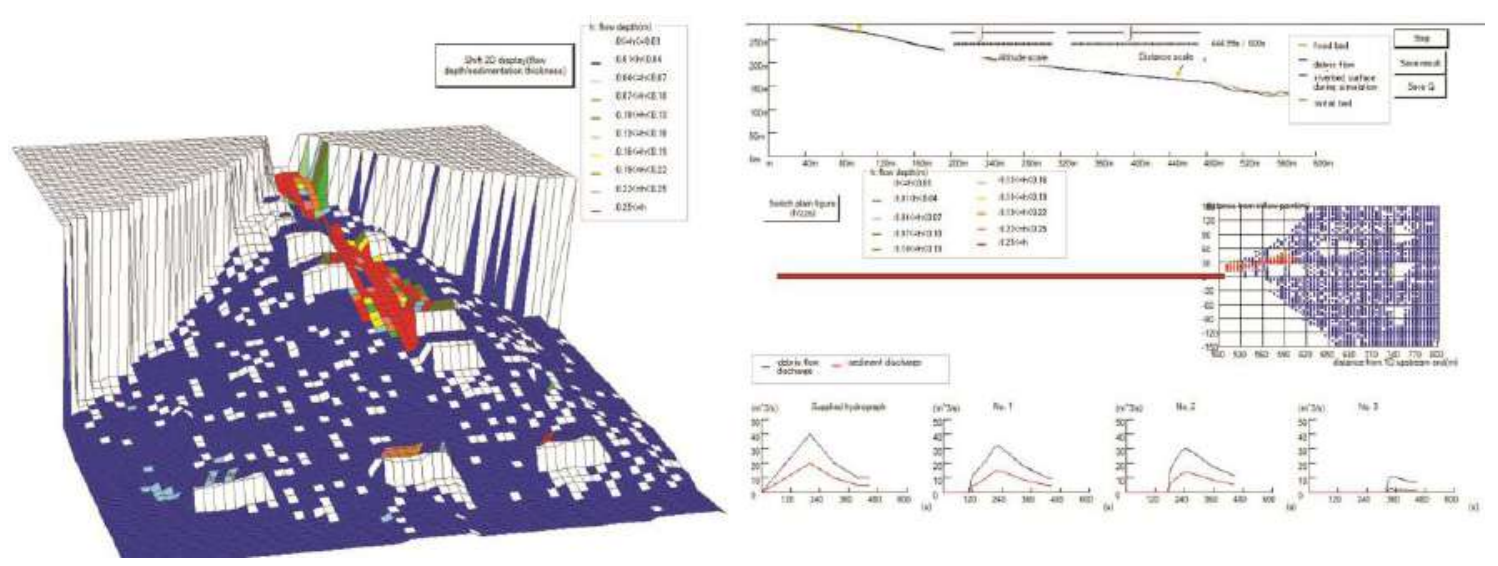

Figura 20. Salida de simulación bidimensional en el software KANAKO (mostrando la profundidad de flujo). Tomado de Nakatani et al. (2007).

\subsubsection{Métodos Geomorfológicos e históricos}

Según Díez-Herrero (2004) se ha demostrado desde hace unas décadas la utilidad de los métodos geomorfológicos e históricos para una mejor comprensión del comportamiento real de los procesos hidrológicos y en la optimización de los modelos matemáticos que intentan representarlos.

\subsubsection{Modelos geomorfológicos}

Se considera en la actualidad que los métodos geomorfológicos proveen de información fiable que permite validar los modelos hidrológicos ((Brázdil, Kundzewicz, \& Benito, 2006; Díez-Herrero, 2004; Ruiz-Villanueva, 2013). Por ejemplo, la información sobre las características del drenaje y de la cuenca se incorpora en el cálculo de los parámetros hidrológicos (Ponce, 1989; Saurral, Barros, \& Lettenmaier, 2008).

Los métodos geomorfológicos se basan principalmente en la caracterización de geoformas y depósitos de paleoinundaciones al detalle para identificar áreas susceptibles a ser inundadas (Murcia \& Macías, 2009; G. P. Williams \& Costa, 1988). Para ello extraen información base del análisis multi-temporal de fotos e imágenes de satélite (Gaume, Livet, Desbordes, \& Villeneuve, 2004; Klemes, 1988). Esta información se contrasta con datos de campo como por ejemplo marcas del depósito y erosión causadas por el agua que se correlacionan con datos de la geometría del cauce (Díez-Herrero, 2004; Wohl, 1995; J. E. O'Connor, Webb, \& Baker, 1986). 
Los materiales que constituyen las paloterrazas de crecidas históricas (Figura 21) permiten estimar la velocidad y fuerza de los flujos que las originaron. Estas técnicas se aproximan mejor a la tendencia natural de evolución de los cursos hídricos y son especialmente útiles en el caso de aquellos que cambian drásticamente en un periodo corto de tiempo.

Para asignar una probabilidad de ocurrencia a las paleoinundaciones que se pueda incorporar a la modelización hidráulica, se emplea además la datación de los depósitos (acápite 2.7) por diferentes técnicas como las paleontológicas, dendrocronológicas radiométricas entre otras (Díez-Herrero, 2004).

\subsubsection{Métodos históricos}

Información muy relevante es la que proviene de la revisión de documentos históricos sobre todo cuando no se cuenta con datos de eventos registrados instrumentalmente (Benito et al., 2004; Díez-Herrero, 2004; Ruiz-Villanueva, 2013). Principalmente corresponde a información sobre las fechas, causas de las inundaciones, la caracterización de los eventos y sus daños; que procede de municipalidades, iglesias, bibliotecas nacionales, diarios pasados, entre otros (Tabla 3). Para que este tipo de datos se puedan integrar en los modelos paleohidrológicos, debe ser transformada en datos cuantitativos (Brázdil et al., 2006; Díez-Herrero, 2004; Glaser, 2001). Cuando la información se procesa adecuadamente permite incluso reducir los intervalos de error en las estimación de escenarios de inundación (Gaume et al., 2009; Payrastre, Gaume, \& Andrieu, 2005; Benito et al., 2004).

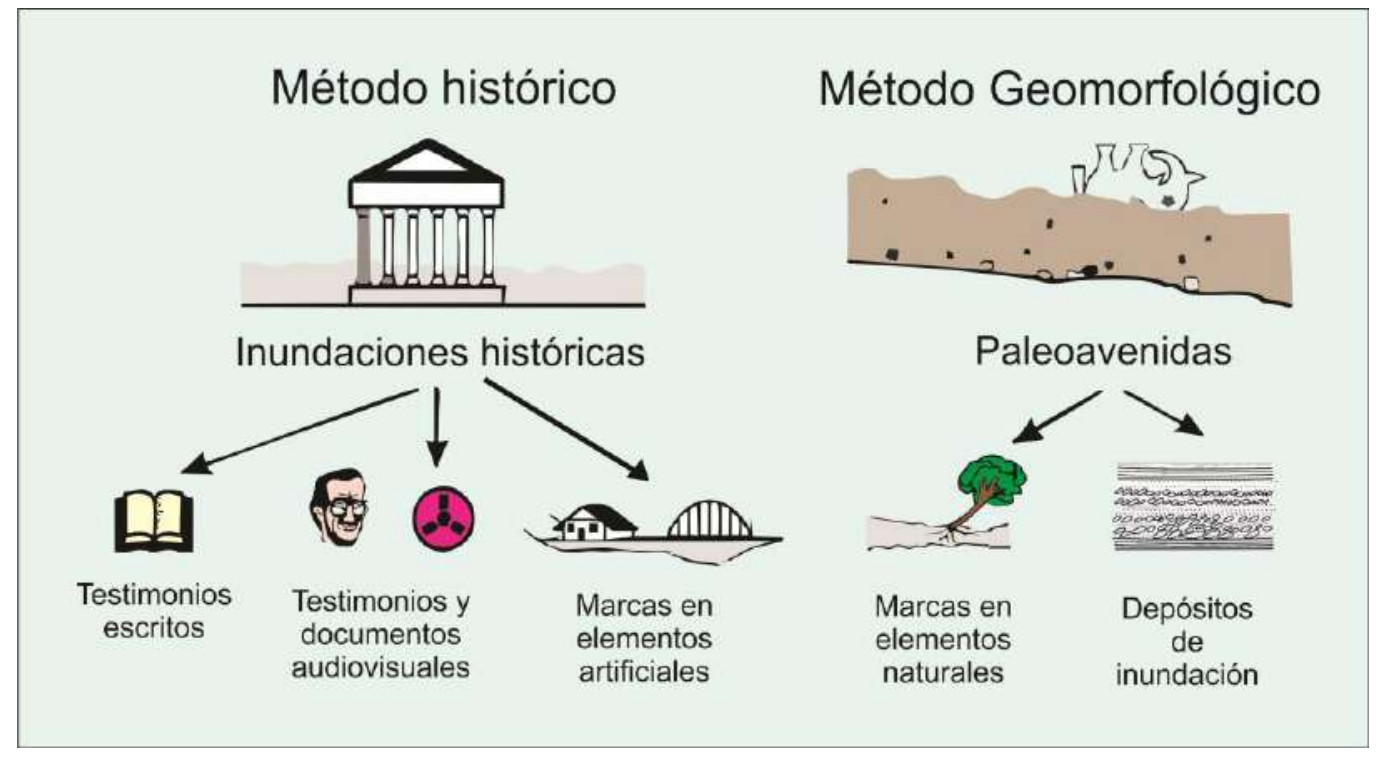

Figura 21. Fuentes de datos en los métodos históricos y geomorfológicos (Díez-Herrero, 2004) 


\subsection{REGISTRO DE PALEOINUNDACIONES EN LIMA METROPOLITANA}

Como ya se ha mencionado antes, la revisión de información de eventos históricos es de gran importancia en el análisis de paleoinundaciones ya que permite incorporar en el análisis de frecuencia, datos de inundaciones pasadas no registradas instrumentalmente (Díez-Herrero, 2004).

\subsubsection{Análisis de eventos históricos}

En este trabajo de Tesis se ha revisado estudios pasados sobre eventos geohidrológicos en Lima Metropolitana (Abad, 2009; Mogrovejo \& Makowsky, 1999; H. O'Connor, 1988; Hocquenghem \& Ortlieb, 1992), se recopiló la información de archivos históricos municipales asi como datos de estudios de la Autoridad Nacional del Agua (ANA) y el el Servicio Nacional de Meteorología e Hidrología del Perú (SENAMHI), donde se analizó las series de lluvias y de caudales máximos de aforo (ANA, 2012a; ANA, 2012b; Apaclla, 2010; Bernabé, 2010). Se consultó la Base de datos nacional de peligros geológicos y geohidrológicos administrada por INGEMMET y visualizada a través de su portal web GEOCATMIN (Villacorta et al., 2012), asi como de los estudios geodinámicos y de informes técnicos sobre peligros geológicos realizados por dicha institución, del Álbum de Mapas de Zonificación de Riesgos Fisiográficos y Climatológicos del Perú (INGEMMET, 1997), reportes de estadísticas de las emergencias anuales en el Perú elaborados por el Instituto Nacional de Defensa Civil - INDECI (1995 al 2017); tesis y datos del Proyecto GA 11: Geología Geomorfología, Peligros Geológicos y Características Ingeniero-geológicas del área de Lima (Villacorta et al., 2015), noticias de inundaciones de las hemerotecas digitales de diversos periódicos nacionales como El Comercio, La República, y otras publicaciones.

De acuerdo a las bases de datos revisadas, entre los años 1907 y 2017 los eventos registrados de flujos que causaron daños y perjuicios a la población Limeña se ha elaborado una síntesis que se muestra en la tabla 3. Asimsimo, se tiene una estadística resumida (Figura 22), donde se observa una mayor frecuencia de eventos de flujos de detritos (73\%). En menor porcentaje se han registrado inundaciones $(12 \%)$, avalanchas (9\%) y flujos de lodo (6\%). 
Tabla 3. Eventos históricos de flujos e inundaciones en Lima Metropolitana (modificado de:

(Zavala, Vílchez, \& Nuñez, 2012; Villacorta, Nuñez, \& Huarez, 2015)

\begin{tabular}{|c|c|}
\hline Año & Eventos ocurridos \\
\hline Pre inca & $\begin{array}{l}\text { Estudios arqueológicos revelan la ocurrencia de flujos de detritos que afectaron } \\
\text { las ciudadelas pre-incas de Pachacamac, Cajamarquilla y Catalina Huanca, } \\
\text { relacionados al fenómeno de El Niño (Mogrovejo \& Makowsky, 1999). }\end{array}$ \\
\hline $\begin{array}{l}\text { Época } \\
\text { colonial y } \\
\text { republicana }\end{array}$ & $\begin{array}{l}\text { En los primeros años de la época colonial y republicana, las crónicas de los } \\
\text { años } 1552,1578,1607,1671,1687,1696,1803,1872 \text {, mencionan el efecto } \\
\text { destructivo de flujos e inundaciones en las riberas del río Rímac, debido a que } \\
\text { los barrios de Lima estaban más cerca del río en aquella época (Hocquenghem } \\
\text { \& Ortlieb, 1992) }\end{array}$ \\
\hline 1907 & $\begin{array}{l}\text { Se activaron las quebradas Quirio, San Antonio y otras, en relación con el } \\
\text { evento ENSO (Abad, 2009) }\end{array}$ \\
\hline 1925 & $\begin{array}{l}\text { Se activaron las quebradas Quirio, San Antonio y otras, en relación con e } \\
\text { evento ENSO. }\end{array}$ \\
\hline 1965 & Santa Eulalia fue afectada por flujos de detritos. \\
\hline 1978 & Santa Eulalia fue afectada por flujos de detritos. \\
\hline 1970 & $\begin{array}{l}\text { Se activaron las quebradas Quirio y San Antonio y se produjeron flujos de } \\
\text { detritos. }\end{array}$ \\
\hline 1976 & $\begin{array}{l}\text { Se activaron las quebradas Quirio y San Antonio activándose flujos de detritos e } \\
\text { inundaciones. }\end{array}$ \\
\hline 1981 & $\begin{array}{l}\text { Se generaron flujos, deslizamientos y desbordes del río Rímac por fuertes } \\
\text { lluvias. }\end{array}$ \\
\hline 1983 & $\begin{array}{l}\text { Se activaron flujos de detritos en las quebradas Cashahuacra, San José de } \\
\text { Palle, Las Kiskas y la Trinchera ( } 70 \text { viviendas afectadas). }\end{array}$ \\
\hline 1987 & $\begin{array}{l}\text { Se activaron las quebradas Pedregal, Corrales, Quirio, Carossio, Rayos de sol y } \\
\text { Cashahuacra. }\end{array}$ \\
\hline 1994 & $\begin{array}{l}\text { Los sectores de Gambeta y Castilla (El Callao) fueron severamente afectados } \\
\text { por inundaciones del río Rímac. } 10754 \text { damnificados, } 1096 \text { viviendas afectadas } \\
\text { (de las cuales } 427 \text { viviendas se destruyeron) y cuantiosas pérdidas materiales. }\end{array}$ \\
\hline 1998 & $\begin{array}{l}\text { Las lluvias producidas anegaron carreteras importantes en Lima Metropolitana y } \\
\text { El Callao, como la Vía Expresa y la Costanera. Se produjeron desprendimientos } \\
\text { de rocas, flujos de detritos en Huaycán, San Juan de Lurigancho y Chosica } \\
\text { (quebradas Quirio, Pedregal, Santo Domingo y La Cantuta) e inundación por } \\
\text { desborde del río Rímac en Chosica, Chaclacayo y Naña; asimismo se produjo } \\
\text { una inundación ocasionada por el desborde del río Huaycoloro que afectó los } \\
\text { distritos de San Juan de Lurigancho y Rímac, al este de Lima. También fue } \\
\text { afectado el distrito de San Martin (San Diego) por el desborde del río Chillón. }\end{array}$ \\
\hline 2000 & Iebrada Media Luna afectó el Anexo 22 de Jicamarca. \\
\hline
\end{tabular}




\begin{tabular}{|c|l|}
\hline 2001 & $\begin{array}{l}\text { Desborde del río Chillón en el sector de San Diego (San Martín de Porres) } \\
\text { inundó } 388 \text { viviendas y dejó más de 1940 damnificados. }\end{array}$ \\
\hline 2009 & $\begin{array}{l}\text { Flujos de detrito y lodo en las quebradas Quirio y La Cantuta. Grandes } \\
\text { cantidades de lodo y piedras bloquearon la Carretera Central a la altura del km } \\
33 .\end{array}$ \\
\hline 2010 & $\begin{array}{l}\text { Flujos de lodo en el sector de Collique (Comas) afectó viviendas, calles y } \\
\text { bloquearon la Av. Túpac Amaru. }\end{array}$ \\
\hline 2012 & $\begin{array}{l}\text { Se activaron el río Huaycoloro y las quebradas La Ronda, Dos Barrios, Santo } \\
\text { Domingo, La Cantuta, California, Coricancha y Los Cóndores. 26000 } \\
\text { damnificados }\end{array}$ \\
\hline 2016 & $\begin{array}{l}\text { Se activaron las quebradas Pedregal, Corrales, Quirio, Carossio, Rayos de sol, } \\
\text { Cashahuacra. 9 muertos, 400 metros de la carretera central fueron bloqueados, } \\
\text { a más de 200 vivienda dañadas. }\end{array}$ \\
\hline $\begin{array}{l}\text { Flujos de detritos y desborde del río Rímac afectaron la carretera central a la } \\
\text { altura del kilómetro 80.5 }\end{array}$ \\
\hline
\end{tabular}

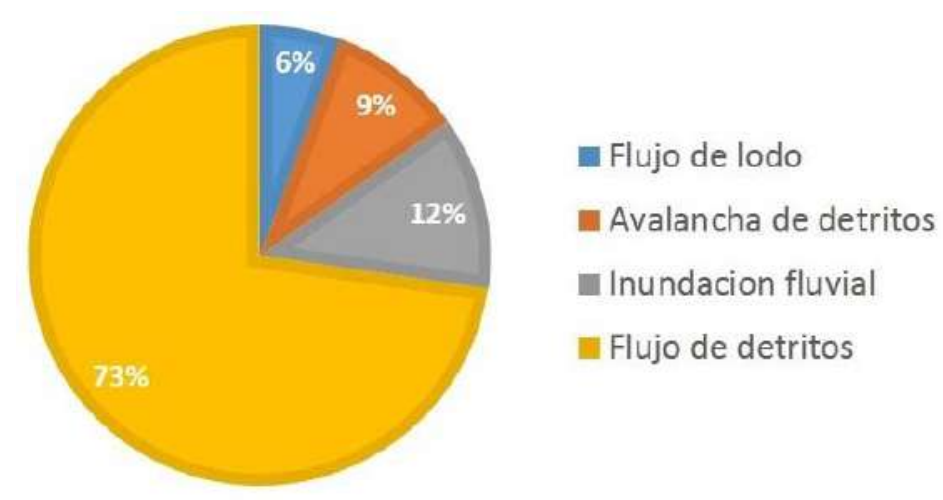

Figura 22. Gráfico que representa los eventos hidrometeorológicos registrados por el INGEMMET en la región de Lima Metropolitana.

Los eventos más destacables por los daños producidos o por su mayor dimensión en la región de Lima Metropolitana han sido: los flujos de detritos de Chosica en 1986, los de 1998, los de Chosica y Chaclacayo en el 2012 y Chosica en el 2015. Todos ellos han ocurrido en los primeros meses del verano austral.

\subsubsection{Flujos de detritos de Chosica en 1986}

Uno de principales eventos de flujos que afectó la ciudad de Lima (y el distrito de Chosica) ocurrió el 09 de marzo de 1987. Este proceso comprendió, depósitos coluvioresiduales que se movilizaron debido a la sobresaturación por agua de los materiales 
depositados en las partes altas de las laderas y generaron flujos que se desplazaron por las quebradas Quirio, Pedregal, Santo Domingo y La Cantuta (Figura 23), Ilegando hasta la zona urbana: 120 personas perdieron la vida y 1200 viviendas fueron afectadas (Abad, 2009).

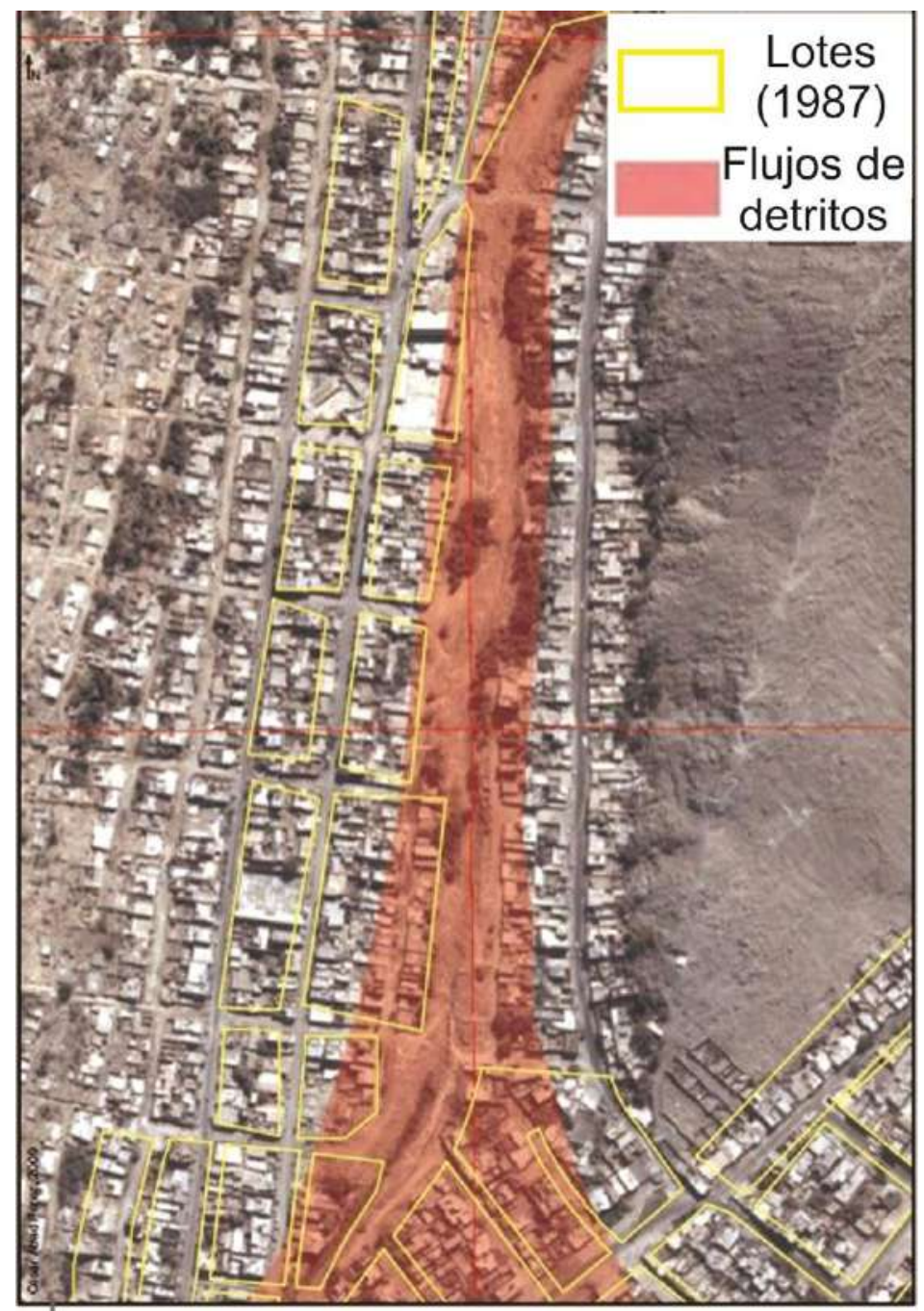

Figura 23. Sectores urbanos afectados por los huaycos de 1987 en San Antonio de Pedregal (Chosica) sobre imagen de la plataforma Google Earth del año 2000. Tomado de:(Abad, 2009)

\subsubsection{Flujos de detritos de 1998}

El detonante de los flujos ocurridos en febrero de 1998 fueron las lluvias anómalas: en 48 horas se registraron sobre Lima $2.7 \mathrm{~mm}$ de precipitación (casi el 40\% de la lluvia anual acumulada). Provocó además desprendimientos de rocas y flujos de detritos en Huaycán, San Juan de Lurigancho y Chosica; e inundaciones asociadas al incremento de caudales y desborde de los ríos Chillón y Rímac con mayor incidencia en las 
poblaciones de Chosica y Chaclacayo en la cuenca del río Rímac y San Diego en la cuenca del río Chillón. Asimismo, se produjo una sorprendente inundación ocasionada por el desborde del río Huaycoloro que afectó los distritos de San Juan de Lurigancho y El Rímac, al este de Lima. Se anegaron carreteras importantes en Lima Metropolitana y EI Callao, como la Vía Expresa y la Costanera, debido a los procesos descritos.

\subsubsection{Flujos de detritos del río Huaycoloro del 2012}

El río Huaycoloro es un curso tributario del Río Rímac, que tiene una extensión aproximada de $36 \mathrm{~km}$ localizados en su mayor parte en el Distrito San Antonio (provincia de Huarochirí). Ha sido escenario de flujos de detritos de gran magnitud asociados al fenómeno "El Niño" que ocasionaron inundaciones en asentamientos humanos construidos en su cauce y alrededores, próximos a su desembocadura en el Río Rímac.

Tras el conocido evento de 1998, en marzo del 2012 se produjo otro evento de flujos en el río Huaycoloro, esta vez afectando a 2700 personas, 150 casas, animales muertos y campos de cultivo arrasados. El desborde de la quebrada se debió a las fuertes precipitaciones, el estrechamiento del cauce (para ganar terreno y ser aprovechado para construir edificaciones y viviendas) y la acumulación de desmonte y basura.

Los sectores afectados por estos desbordes se ubican a lo largo de seis kilómetros del río Huaycoloro (Santa Rosa, Pampa Chiri, Las Riberas, Villa Leticia, Valle del Mantaro, Los Huertos de Cajamarquilla, San Miguel, Los Claveles, Residencial y Cajamarquilla) (ANA, 2012b).

\subsubsection{Flujos de detritos de Chaclacayo y Chosica en el 2012}

En abril del 2012 se produjeron flujos en las quebradas La Ronda, Dos Barrios, Santo Domingo, La Cantuta, California, Coricancha y Los Cóndores; de la margen izquierda del río Rímac.

Los registros diarios de lluvias entre el 16 y el 25 de marzo del 2012, indican que las lluvias fueron inferiores a $2 \mathrm{~mm}$ los días previos, con un pico el jueves 5 de abril, día de la ocurrencia de los flujos, de $28 \mathrm{~mm}$. Producto de ello se contabilizaron 26000 damnificados (Zavala et al., 2012). 


\subsubsection{Flujos de Chosica del 2015}

Los eventos de flujos ocurridos el 23 de marzo del 2015 en las quebradas: Quirio, Pedregal, La Libertad, Carossio, Rayos de Sol y Cashahuacra (Figura 24), se produjeron debido a la acumulación de depósitos coluviales en las cabeceras de las quebradas secundarias con incorporación de material proveniente de las vertientes aledañas a los cauces. Los diques construidos luego de los eventos de 1986 en las quebradas La Libertad, Carossio y Rayos de Sol, estaban completamente colmatados y se destruyeron en su gran mayoría. A causa de los flujos murieron 09 personas, se destruyeron 400 metros de la carretera central y se registraron daños en más de 200 vivienda (Villacorta et al., 2015).

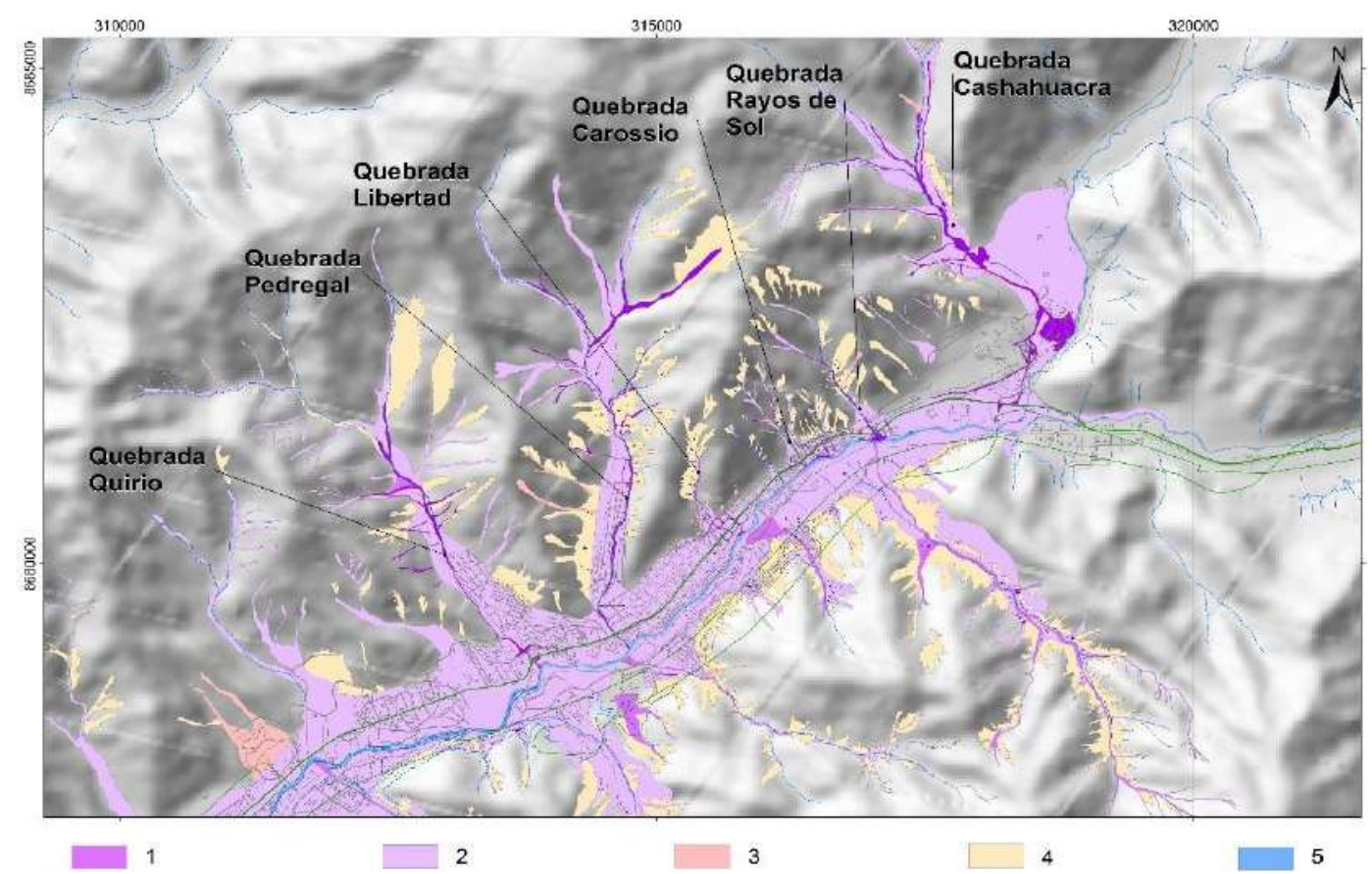

Figura 24. Eventos ocurridos en eel 2015 en Chosica (Villacorta et al., 2015). 1: Flujos del 23-03-15, 2: Flujos antiguos, 3: Avalanchas de detritos, 4: Depósitos coluvio-deluviales, 5: Río Rímac.

Análisis hidrológicos previos

Existen algunos antecedentes del modelamiento hidrológico en el área de la cuenca del río Rímac.

Sarango et al. (2014) hicieron una simulación para la cuenca Rímac-Santa Eulalia donde se incluye al proyecto de central hidroeléctrica (C.H.) del distrito de Huanza (ubicado a 130 kilómetros de Lima, en la provincia de Huarochirí). Según los autores el modelo es aceptable porque garantiza un caudal medio multianual de $12.51 \mathrm{~m}^{3} / \mathrm{s}$ en la 
C.H. de Huinco ubicada a $63.5 \mathrm{~km}$ al este de Lima en el Distrito de San Pedro de Casta (provincia de Huarochirí).

(ANA, 2012b) tomando datos desde 1912 hasta el año 1964 (naturales) y de 1965 al 2009 (regulados), calculó los caudales máximos para diferentes periodos de retorno en la estación de Chosica y obtuvo para un periodo de retorno de 200 años $429.5 \mathrm{~m}^{3} / \mathrm{s}$ y para 500 años $497.4 \mathrm{~m}^{3} / \mathrm{s}$.

En el estudio de Bernabé (2010) se evaluó el comportamiento pluviométrico de la cuenca Rímac, basándose en datos pluviométricos del período 1964 a 2009. Con la información de precipitaciones máximas obtenidas para las subcuentas de interés: Rio blanco, Alto río Rímac quebrada Párac y Río Santa Eulalia y los parámetros geomorfológicos, el autor calculó las máximas avenidas de diseño para diferentes períodos de retorno, aplicando el método del hidrograma unitario sintético (SCS). Así por ejemplo el caudal máximo instantáneo hallado para un periodo de retorno de 500 años es de $108.00 \mathrm{~m}^{3} / \mathrm{s}$ para la subcuenca del Rio blanco, $147.00 \mathrm{~m}^{3} / \mathrm{s}$ para la subcuenca del Alto río Rímac $108.00 \mathrm{~m}^{3} / \mathrm{s}$ para la subcuenca de la quebrada Párac y de $399.20 \mathrm{~m} 3 / \mathrm{s}$ para la subcuenca del río Santa Eulalia.

Otros datos obtenidos son los de Apaclla (2010), que en base al análisis de datos pluviométricos del período 1984 a 2009 obtuvo una precipitación máxima en 24 horas para un periodo de retorno de 200 años en la cuenca Santa Eulalia de $36.77 \mathrm{~mm}$; en la cuenca La Cantuta de: $40.79 \mathrm{~mm}$ y en la cuenca de la quebrada Canto Grande de: $13.68 \mathrm{~mm}$. Asimismo tomando como punto de salida la estación Chosica para un periodo de retorno de 200 años, el caudal para la cuenca alta Rímac es de 264.20 $\mathrm{m}^{3} / \mathrm{s}$ y para la cuenca baja es de $145.37 \mathrm{~m}^{3} / \mathrm{s}$.

\subsection{DATACIONES}

La datación por luminiscencia es un método de datación de sedimentos depositados en períodos largos de tiempo, debido a que el material empleado (cuarzo y feldespatos) tiene capacidad para acumular radiación ionizante del entorno (producida por las partículas subatómicas que provienen de los rayos cósmicos) y emitir luminiscencia cuando los electrones libres, atrapados en los niveles de energía 
metaestables de las estructuras minerales son expuestos a la luz (Molodkov, 2007; Prescott \& Hutton, 1994).

Fue propuesta por primera vez por Grogler, Houtermans, \& Stauffe (1960) quienes la emplearon para datar materiales arqueológicos. Posteriormente Huntley, GodfreySmith, \& Thewalt (1985) la utilizaron para datar sedimentos y desde que Hütt, Jaek, \& Tchonka (1988) la emplearon con feldespatos la luminiscencia ha crecido en multitud de aplicaciones.

El rango de edad de luminiscencia es del orden de varios cientos de mil años, lo cual está relacionado a las propiedades luminiscentes de la muestra (Wallinga, 2002).

La técnica permite calcular el tiempo transcurrido desde la última vez que un grano estuvo expuesto a la luz solar. Este tiempo es atribuido a la depositación en un nivel de sedimentación. Desde ese momento y debido a la radiación del entorno, en la muestra se acumula energía nuevamente; por ello se dice que la edad está relacionada con el tamaño de la lesión por radiación (Stokes, 1999). Se emplea para sedimentos eólicos, fluviales y lacustres.

Como toda técnica, tiene limitaciones en relación con la exposición limitada de los granos de sedimento a la luz del día durante el corto y rápido transporte de muchos depósitos de abanicos y también asociados a la sensibilidad del cuarzo en muchos ambientes de alta montaña (Stokes, 1999; Lang, 2013).

\subsubsection{Conceptos asociados}

Las técnicas de datación por luminiscencia se subdividen de acuerdo con el tipo de energía suministrada para la estimulación. Así se tiene la termoluminiscencia (TL) que es la emisión de luz debida a estimulación por calor, luminiscencia ópticamente estimulada (OSL) es la emisión de luz debido a estimulación óptica (luz en el rango visible con luz azul o luz verde) y luminiscencia estimulada por infrarrojo (IRSL o IROSL), es la emisión de luz debido a estimulación por luz en el rango de infrarrojo. A menudo dataciones por OSL y IRSL se refieren como "dataciones ópticas'.

La OSL es un tipo de datación basada en la emisión de luz de materiales semiconductores. La energía acumulada por el grano, desde su tiempo de formación, 
es borrada por la continua exposición a la luz solar, hasta el momento en el que queda completamente cubierta por los sedimentos que se depositan encima. A partir de ese momento, comienza nuevamente la acumulación de energía ionizante en el grano debido a su entorno (Figura 25). Toda esta energía acumulada se mide en el laboratorio y es conocida como dosis equivalente, correspondiendo a la relación de la energía ionizante por unidad de masa. Para completar el proceso de datación por OSL, es necesario conocer cómo la muestra acumula la energía por año. Esto se conoce como tasa de dosis o dosis anual y depende de las emisiones de partículas alfa, beta y gamma de la muestra misma, así como las emisiones gamma de la radiación cósmica del lugar en el que se deposita. La radiación cósmica depende de la profundidad del depósito, así como de las coordenadas geográficas (Molodkov, 2007).

Mientras mayor sea el tiempo de exposición a los rayos cósmicos, mayor será el número de electrones atrapados. Por tanto, la intensidad de la señal de luminiscencia está relacionada con la cantidad de isotopos radioactivos existentes y con el tiempo de exposición (Aitken, 1985). Esto permite que se puedan utilizar para estimar el tiempo de estancia como parte de un depósito.

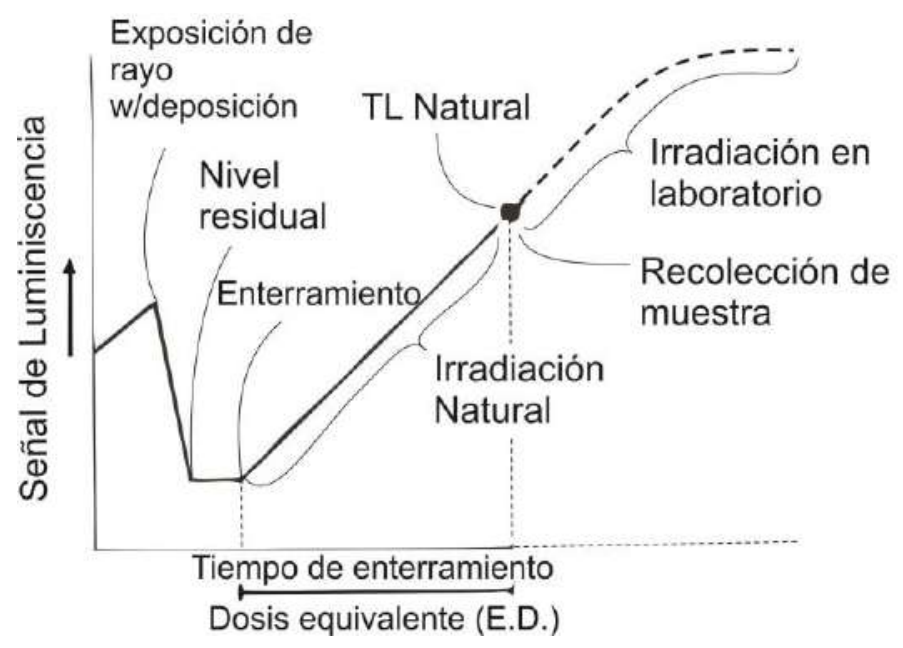

Figura 25. Representación esquemática del ciclo geológico TL. La exposición a la luz reduce la señal $T L$ de sedimentos a un bajo nivel definible. Después del entierro de sedimentos la radiación ionizante imparte progresivamente una señal $T L$. La señal de $T L$ en el momento de la recolección se denomina la $T L$ natural. La dosis beta añadida a la señal de $T L$ natural define una función, que a menudo es la base para determinar la dosis equivalente. Modificado de (Wintle \& Huntley, 1982). 


\subsubsection{Edades posibles}

Con esta técnica se datan depósitos recientes de menos de 500 años, al igual que los antiguos de más de 400000 años. Se aplicó con buenos resultados al datar diferentes tipos de sedimentos de origen eólico, fluvial y fluvio-glacial.

Mahan, Noe, \& McCalpin (2009) señalan que el margen de tolerancia analítica varía entre 5 y $25 \%$. Por ello se puede decir que el mejor método es aplicar la edad mínima de múltiples granos singulares (muestreo estadístico multivariante). 


\subsubsection{Procedimiento de la Datación por OSL}

La edad de las muestras se determina según la relación:

Edad (años) $=$ Dosis equivalente (Gy)/Tasa de dosis (Gy/año)

La tasa de dosis se calcula a partir de las concentraciones de los isotopos de ${ }^{238} \mathrm{U}$, ${ }^{232} \mathrm{Th},{ }^{40} \mathrm{~K}$ y ${ }^{87} \mathrm{Rb}$ medidas a partir de diferentes métodos, entre ellos espectrometría gamma de alta resolución, conteos de emisiones alfa por centelleo en discos de SZn:Ag, activación neutrónica, entre otros; sin embargo, estos métodos son considerados indirectos. Una forma directa de medir la tasa de dosis anual es dejar enterrados dosímetros en el lugar del muestreo, la desventaja de este método es que se necesitan tiempos largos de medición, alrededor de un año. La contribución de la radiación cósmica se calcula en función de la profundidad de muestreo. Los valores medidos de dosis anual o tasa de dosis necesitan de correcciones debido al contenido de humedad de la muestra al momento del muestreo (Stokes, 1999). 


\section{GENERALIDADES SOBRE LA ZONA DE ESTUDIO}

En este capítulo se describen los aspectos más relevantes acerca del abanico de Lima Metropolitana, en especial sobre sus condiciones geográficas, características geomorfológicas y geológicas.

\subsection{UBICACIÓN DEL ÁREA DE ESTUDIO, GEOGRAFÍA E HIDROGRAFÍA}

El abanico de Lima se localiza en la región de Lima Metropolitana y la provincia constitucional de El Callao donde se centraliza casi el $31 \%$ de la población del Perú (Instituto Nacional de Estadística e Informática, 2014). El área de estudio se circunscribe a la cuenca del río Rímac (en cuya desembocadura se ha depositado el material que lo constituye. Las nacientes del río Rímac están en las cumbres más altas de la Cordillera Occidental de los Andes centrales peruanos (Figura 26) aproximadamente a 5000 m.s.n.m., que atraviesa después de recorrer unos $160 \mathrm{~km}$ y desemboca en el Océano Pacifico.

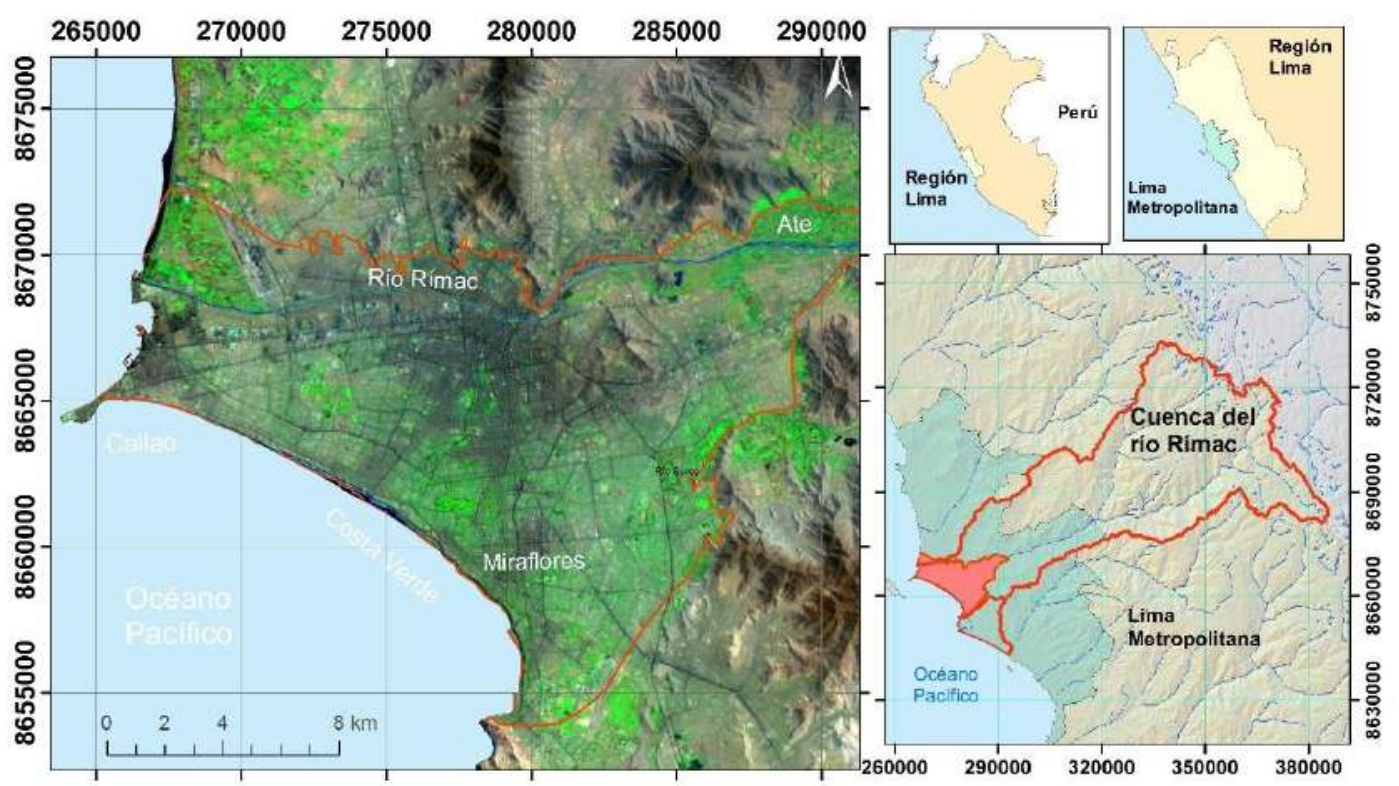

Figura 26. Ubicación del área evaluada en la cuenca del río Rímac

La cuenca del río Rímac está regulada y tiene aproximadamente $3400 \mathrm{~km}^{2}$ (ANA, 2012b). Su sistema hidrográfico está conformado por los ríos Santa Eulalia y San Mateo. El primero de ellos nace en la laguna Pacococha (Huanza) alrededor de 4400 m.s.n.m. y el segundo en los ex nevados Uco y Ticlio; cerros Volcan Mines y Meiggs; 
quebrada Antaccasa y laguna Yanacocha; las cuales se unen en la localidad de Ricardo Palma, desde donde toma el nombre de río Rímac hasta su desembocadura en el Océano Pacífico.

En su recorrido abarca gran cantidad de proyectos mineros y de abastecimiento de agua para el consumo humano, así como hidroeléctrico para producir energía para la ciudad capital. En total contiene 191 lagunas, algunas de ellas reguladas como Marcapomacocha y las de la cuenca Santa Eulalia. Asimismo, tiene un área de humedales en la parte baja y restos de glaciares en las nacientes (Apaclla, 2010). Sus aguas son aprovechadas para el funcionamiento de 5 centrales hidroeléctricas: Huampaní, Matucana, Huinco, Barbiblanca y Juan Carossio (Bernabé, 2010).

En la cuenca del río Rímac los cambios de pendiente a lo largo del cauce son importantes en relación a su capacidad de transporte. Así, en el tramo más alto, la pendiente varía entre 5 y 15 grados, posibilitando el transporte de los bloques de mayor tamaño. En la cuenca media, su pendiente está entre 5 y 2 grados y en la cuenca baja, menor a 2 grados.

\subsection{COBERTURA VEGETAL, TIPO Y USO DE SUELOS}

La información descrita aquí ha sido tomada Mapa Nacional de Cobertura Vegetal (Ministerio del Ambiente, 2015), complementada con datos de campo y de la interpretación de imágenes de la plataforma online Google Earth.

\subsubsection{Cobertura vegetal}

En la cuenca del río Rímac, en general la vegetación natural se considera muy escasa, existiendo pocos cultivos agrícolas (Figura 27. Un gran porcentaje de la cuenca baja es ocupada por construcciones humanas (área urbana) y en el porcentaje restante la vegetación es mínima, considerándose inexistente (Asociación Louis Berger International -Tropical. Research - ECSA Ingenieros, 1998). Las unidades identificadas por el MINAM (2015) son las siguientes: 


\subsubsection{Agricultura costera y andina}

Corresponde al área donde se desarrollan los cultivos agropecuarios sobre todo en zonas de valles costeros e interandinos y que limitan en este último con el pajonal altoandino. Comprenden los cultivos bajo riego y en secano, tanto anuales como permanentes, además de incluir la vegetación natural ribereña que se extienden como angostas e interrumpidas franjas a lo largo de los cauces de los ríos y quebradas, como por ejemplo en la zona costera y las porciones inferiores andinas donde es frecuente las especies Salix humboldtiana "sauce", Acacia macracantha "huarango" y Shinus molle "molle".

\subsubsection{2 Área urbana.}

El área ocupada por las viviendas y construcciones. Se centra principalmente en el valle (parte baja de la cuenca del río Rímac) y en las capitales de distritos (parte alta de la cuenca).

\subsubsection{Bofedal}

Corresponde a un área de las zonas altoandinas permanentemente húmedas por el aporte de flujos subterráneos. Normalmente se aprecia sobre los $3800 \mathrm{msnm}$. También se le conoce como "oconal" por su raíz quechua "oco" que significa mojado.

\subsubsection{Bosque relicto alto andino.}

Es un bosque que se desarrolla en zonas montañosas con pendientes mayores a los $30^{\circ}$ en forma espaciada (no continua). La altura a la que se desarrolla oscila entre los 3500 y 4900 m. s. n. m.

\subsubsection{Matorral arbustivo}

Recaen en esta nomenclatura matorrales influenciados por las condiciones climáticas: marorrales de piso bajo que crecen entre 1500 y 2500 m.sn.m. (Jatropha sp. ("huanarpo"), Cnidoscolus sp.; Ortopterigium huasango ("huancoy"), Carica candicans ("mito"), Heliotropium arborescens, Mutisia sp., Tecoma arequipensis, Fourcroya andina ("maguey"), Grindelia sp., Ambrosia artemisioides, Balbisia sp., etc. Asi mismo matorrales de piso medio, entre 2500 a 3800 m.s.n.m. correspondiente a las comunidades arbustivas caducifolias y perennifolias entre las que destacan: Dodonea viscosa ("chamana"), Kageneckia lenceolata ("Iloque"), Mutisia acuminata ("chinchilcuma"), Barnadesia dombeyana ("yauli"), Agave americana ("maguey azul”), Tecoma sambucifolia ("huaranhuay"), Ophryosporus peruvianus ("arenilla"), Ambrosia arborescens entre otras. 


\subsubsection{Pajonal altoandino}

Está conformado mayormente por herbazales ubicados entre los 3800 y 4800 m.s.n.m. En la cuenca Rímac se desarrolla sobre terrenos empinados cercanos al área el ex nevado Ticlio.

Comprende a su vez a los pajonales (hierbas en forma de manojos de hasta $80 \mathrm{~cm}$ de alto) y césped (hierbas de porte bajo hasta de $15 \mathrm{~cm}$ de alto). Entre las primeras se identifica a las siguientes asociaciones: Asociación Calamagrostis - Stipa (representada por especies como Calamagrostis rigida, Stipa hans-meyeri, Pycnophyllum molle, Parastrephia phylicaeformis, Loricaria graveolens, entre otras; la Asociación Festuca-Stipa, donde predominan las especies Festuca weberbaueri, Stipa inconspicua, Calamagrostis amoena y la Asociación Stipa - Margiricarpus, que está constituida por especies como Stipa ichu, Margyricarpus strictus y Aciachne pulvinata. De las segundas se puede mencionar a especies de porte rastrero o almohadillado como Azorella sp. y Picnophyllum sp.

\subsubsection{7 Áreas sin vegetación:}

Pertenecen a esta clase, los afloramientos rocosos sin vegetación (roca desnuda) ubicados en niveles altitudinales superiores a los 4800 m.s.n.m. y áreas con cárcavas que han perdido su cobertura debido a remoción dejando áreas con suelos.

\subsubsection{Glaciar/Arroyo/lago}

Corresponde a zonas frías de morrenas, bofedales, lagos y lagunas. 


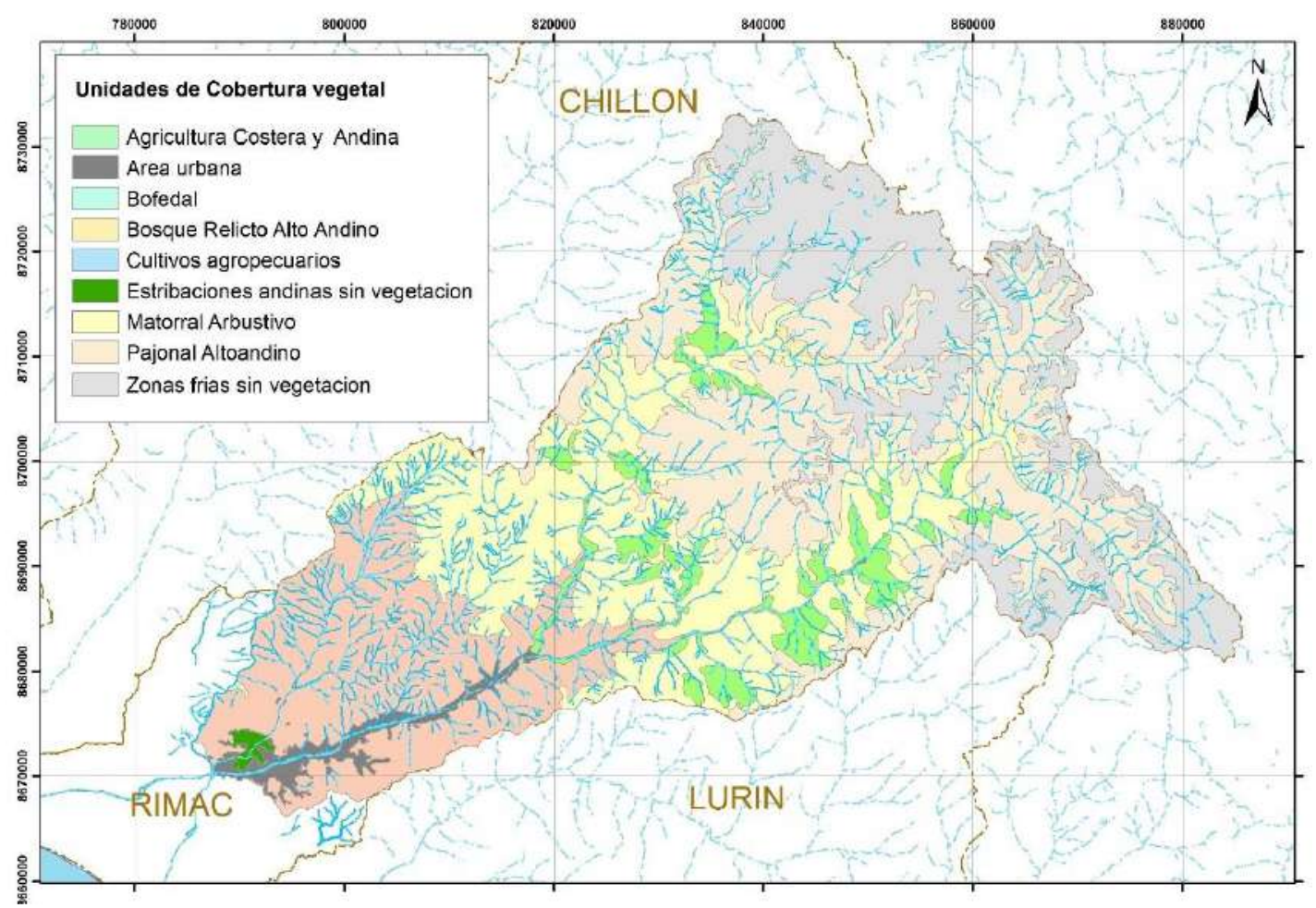

Figura 27. Unidades de cobertura vegetal del área a evaluar en la cuenca Rímac. Recorte extraído de Ministerio del Ambiente (2015).

\subsubsection{Tipos y usos de suelo}

De acuerdo al estudio de la Asociación Louis Berger International -Tropical. Research - ECSA Ingenieros (1998), el escenario edáfico en la cuenca del río Rímac está conformado por suelos de textura variable, entre gruesos a finos, en algunos casos con señales de cementaciones cálcicas. Durante los trabajos de campo se observó en diferentes sectores un incipiente horizonte $A$ superficial y contenido de materia orgánica muy bajo a nulo (Foto 9).

Los datos presentados aquí sirvieron para asignar los grupos hidrológicos de suelo en la cuenca, según la denominación del United States Department of Agriculture, Soil Conservation Service - USDA-SCS (Mockus, 1972; Boughton, 1989) donde se establece una capacidad de infiltración en relación a la textura, estructura y posición en el terreno de los materiales evaluados (Tabla 4). Según esto se procedió a agrupar las unidades de tipos de suelos en los grupos hidrológicos de acuerdo a las clases $A$, B, C y D, del SCS (Figura 28). 


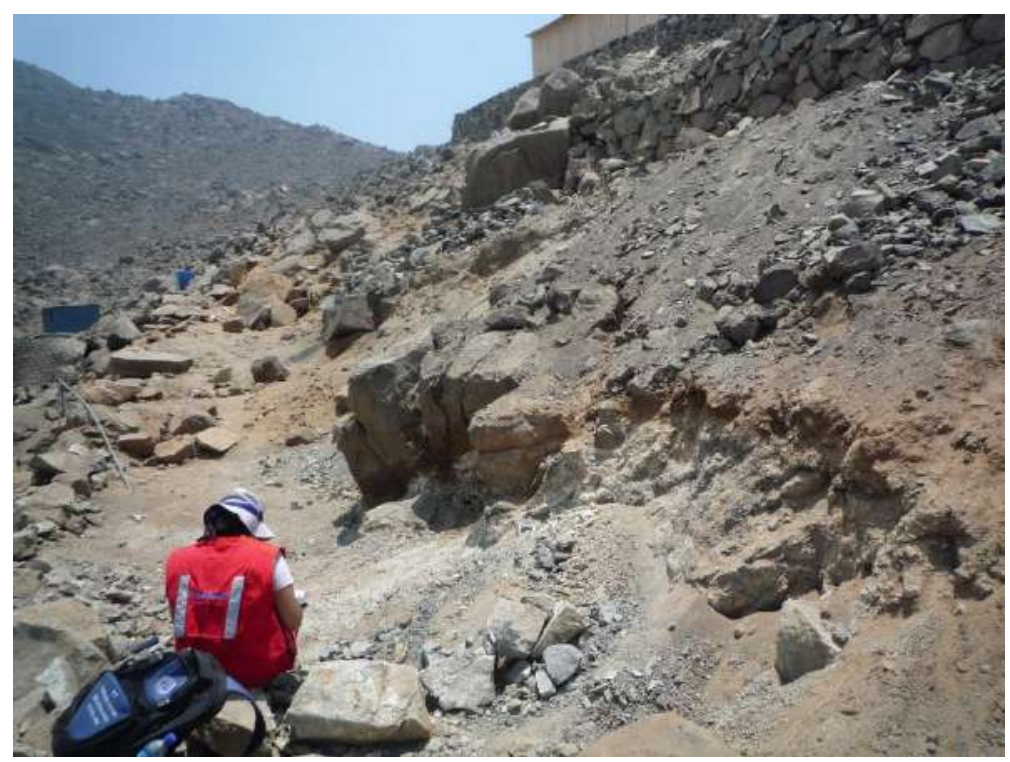

Foto 9. Incipientes cementaciones cálcicas por aparente alteración de feldespatos de la granodiorita que conforma el substrato. A.H. Hacia El Desarrollo (San Juan de Lurigancho).

Tabla 4. Descripción de los Grupos hidrológicos de suelos de la USDA-SCS (Mockus, 1972;

Boughton, 1989) Traducido por: Ferrer, Rodríguez, \& Estrela (1995)

\begin{tabular}{|l|l|l|}
\hline $\begin{array}{l}\text { Grupo } \\
\text { de } \\
\text { Suelo }\end{array}$ & \multicolumn{1}{|c|}{ Descripción } & $\begin{array}{l}\text { Grado de } \\
\text { infiltración } \\
\text { (mm/hr) }\end{array}$ \\
\hline A & $\begin{array}{l}\text { En ellos el agua se infiltra rápidamente, aun cuando estén muy } \\
\text { húmedos. Profundos y de texturas gruesas (arenosas o areno- } \\
\text { limosas), están excesivamente drenados. }\end{array}$ & $8-12$ \\
\hline B & $\begin{array}{l}\text { Cuando están muy húmedos tienen una capacidad de infiltración } \\
\text { moderada. La profundidad de suelo es de media a profunda y su } \\
\text { textura es franco-arenosa, franca, francoarcillosa o franco-limosa. } \\
\text { Están bien o moderadamente drenados. }\end{array}$ & $4-8$ \\
\hline C & $\begin{array}{l}\text { Cuando están muy húmedos la infiltración es lenta. La profundidad } \\
\text { de suelo es inferior a la media y su textura es franco-arcillosa, } \\
\text { francoarcillo-limosa o arcillo-arenosa. Son suelos imperfectamente } \\
\text { drenados. }\end{array}$ & $1-4$ \\
\hline D & $\begin{array}{l}\text { Cuando están muy húmedos la infiltración es muy lenta. Tienen } \\
\text { horizontes de arcilla en la superficie o próximos a ella y están } \\
\text { pobremente o muy pobremente drenados. También se incluyen } \\
\text { aquí los terrenos con nivel freático permanentemente alto y suelos } \\
\text { de poco espesor (litosuelos). }\end{array}$ & $0-1$ \\
\hline
\end{tabular}




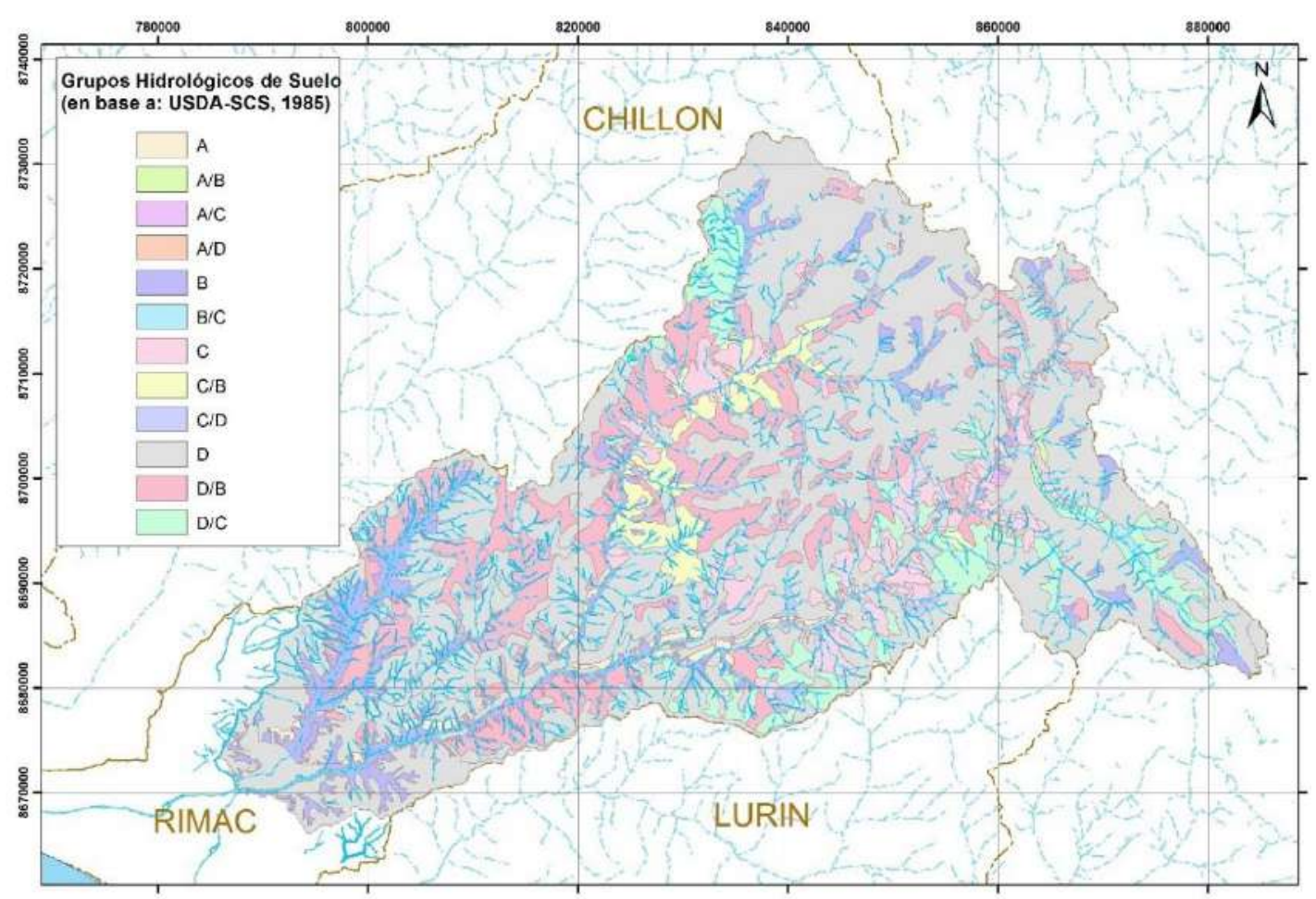

Figura 28. Grupos hidrológicos de suelos en la cuenca del río Rímac. Elaborado en base a; Mockus, 1972; Boughton, 1989; Asociación Louis Berger International -Tropical. Research - ECSA Ingenieros, 1998.

En la Tabla 5 se pueden ver los usos del suelo en la cuenca del rio Rímac (Figura 29), información que se ha tomado como base para la determinación del Número de Curva (capitulo 3, ítem Análisis hidrológico). De manera general las áreas arbustivas como el pajonal andino es una fuente de forraje importante para la ganadería de llamas, alpacas y ovejas. Cabe mencionar que muchas de las áreas actualmente se encuentran en proceso de degradación por sobrepastoreo y quema de pastos para ampliar las áreas de cutlivo, del mismo modo el incremento del área urbana mayor crecimiento poblacional que vuelve impermeable los terrenos.

Tabla 5. Usos de suelo en el área de la quebrada cuenca del río Rímac

\begin{tabular}{|l|l|c|r|}
\hline Clasificación SCS & unidad del mapa & Área (km2) & \multicolumn{1}{l|}{} \\
\hline Andenes de cultivo & Agricultura andina & 242.5418822 & 7.95 \\
\hline Tierra de cultivo de valle & $\begin{array}{l}\text { Agricultura Costera y } \\
\text { Andina }\end{array}$ & 97.34391233 & 3.19 \\
\hline Bosques y arbustos & Bosque Relicto Alto Andino & 1.772859584 & 0.06 \\
\hline Minas, canteras y otros & Campamento minero & 50.29955158 & 1.65 \\
\hline Glaciar / Arroyo/lago & Glaciar & 58.60874905 & 1.92 \\
\hline Matorrales/ Malezas tundra & Matorral Arbustivo & 40.41227978 & 1.33 \\
\hline
\end{tabular}




\begin{tabular}{|c|c|c|c|}
\hline Glaciar / Arroyo/lago & Oconal & 12.26099663 & 0.40 \\
\hline Bosques y arbustos & Pajonal Alto-andino & 169.5424892 & 5.56 \\
\hline Reservorio & Reservorio & 0.659287474 & 0.02 \\
\hline Roca expuesta & Sin Uso & 2230.348325 & 73.15 \\
\hline Residencial & Urbano & 110.9387844 & 3.64 \\
\hline \multirow[t]{2}{*}{ Vías pavimentadas } & Vía & 34.42175709 & 1.13 \\
\hline & TOTAL & 3049.150874 & 100.00 \\
\hline
\end{tabular}

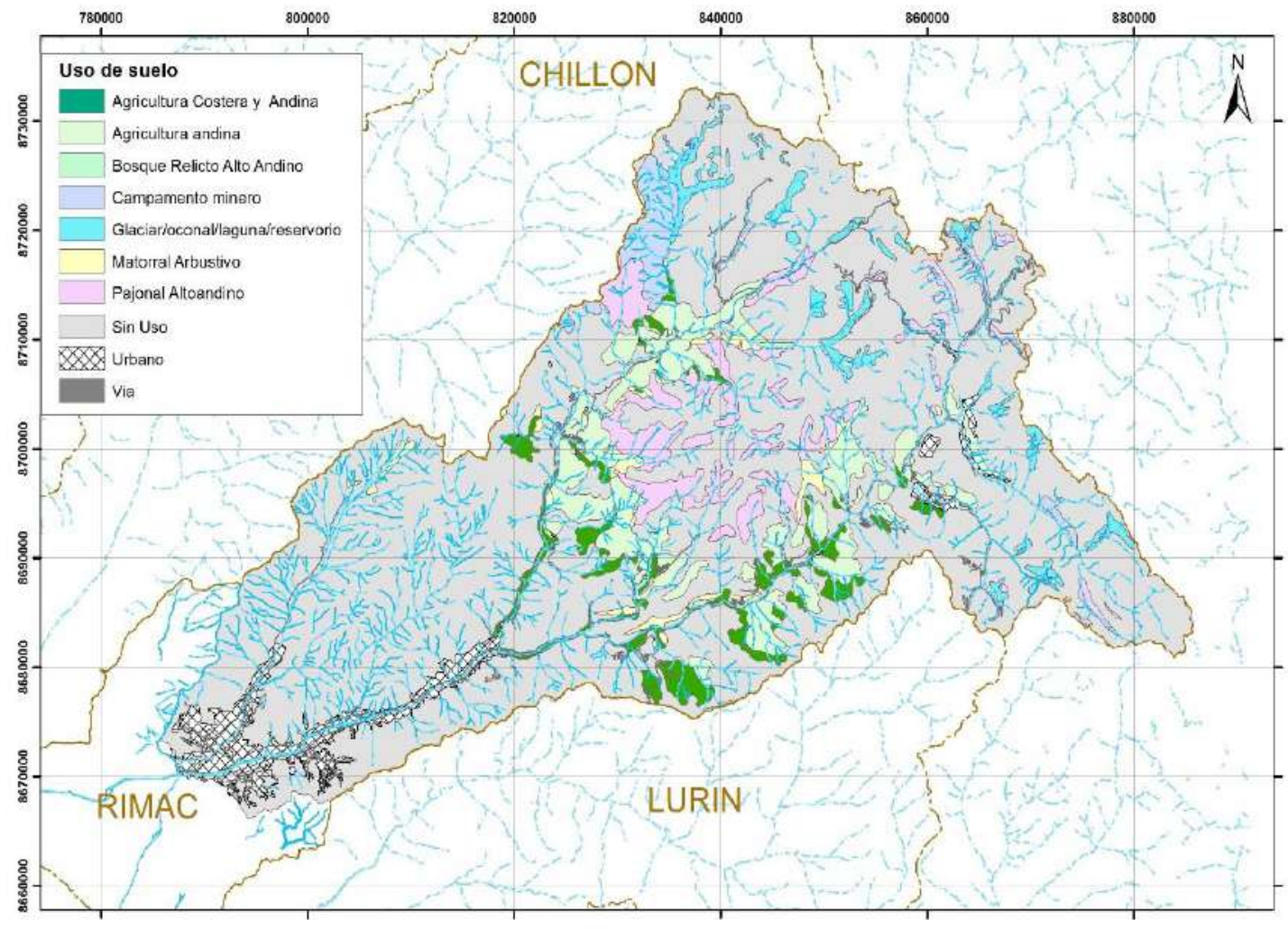

Figura 29. Usos de suelo en la cuenca del rio Rímac. Modificado de: Asociación Louis Berger International -Tropical. Research - ECSA Ingenieros (1998).

\subsection{GEOMORFOLOGÍA}

La cuenca del río Rímac está enmarcada en el flanco Occidental de los Andes peruanos la cual se generó a partir de intrusiones magmáticas con edades comprendidas entre 84 y 102 Ma (Pitcher, 1978), como consecuencia de la subducción del fondo del Océano Pacífico por debajo de la placa de Suramérica (Benavides-Cáceres, 1999; Mégard, 1979); Figura 30). Posteriormente otros procesos de deformación tectónica permitieron que la Cordillera Occidental alcanzara su actual elevación (Dalmayrac, Laubacher, \& Marocco, 1988). 
La importante cantidad de sedimentos no consolidados originados en las partes altas de la cuenca del río Rímac, transportados y modelados en el transcurso de su recorrido se han acumulado en la parte inferior de la cuenca dando origen al abanico aluvial, que abarca un área de aproximadamente $216 \mathrm{~km}^{2}$ con una característica forma triangular asimétrica (Figura 31;Error! No se encuentra el origen de la referencia.).

El área ocupada por el abanico limeño se caracteriza por la presencia de paleo cauces colmatados, correspondiéndose a depósitos de glacis y abanicos coalescentes que alcanzan centenares de metros de espesor (600 m en su parte más profunda según Arce, 1984), sobre todo en el cauce y la desembocadura del río Rímac. Algunos autores infieren por esta causa (asimetría) que la migración del rio Rímac se habría producido por el basculamiento relacionado con la subducción de la dorsal de Nazca bajo la placa Suramericana (Hampel, 2002; Macharé \& Ortlieb, 1992).

Alrededor del abanico existen formas de relieve heredadas originadas por procesos para-fluviales y las de origen aluvial, gravitacional, eólico, marino; estas diferencias pueden establecerse por sus frecuencias e intensidades y por el ámbito de sus acciones (Villacorta et al., 2015).
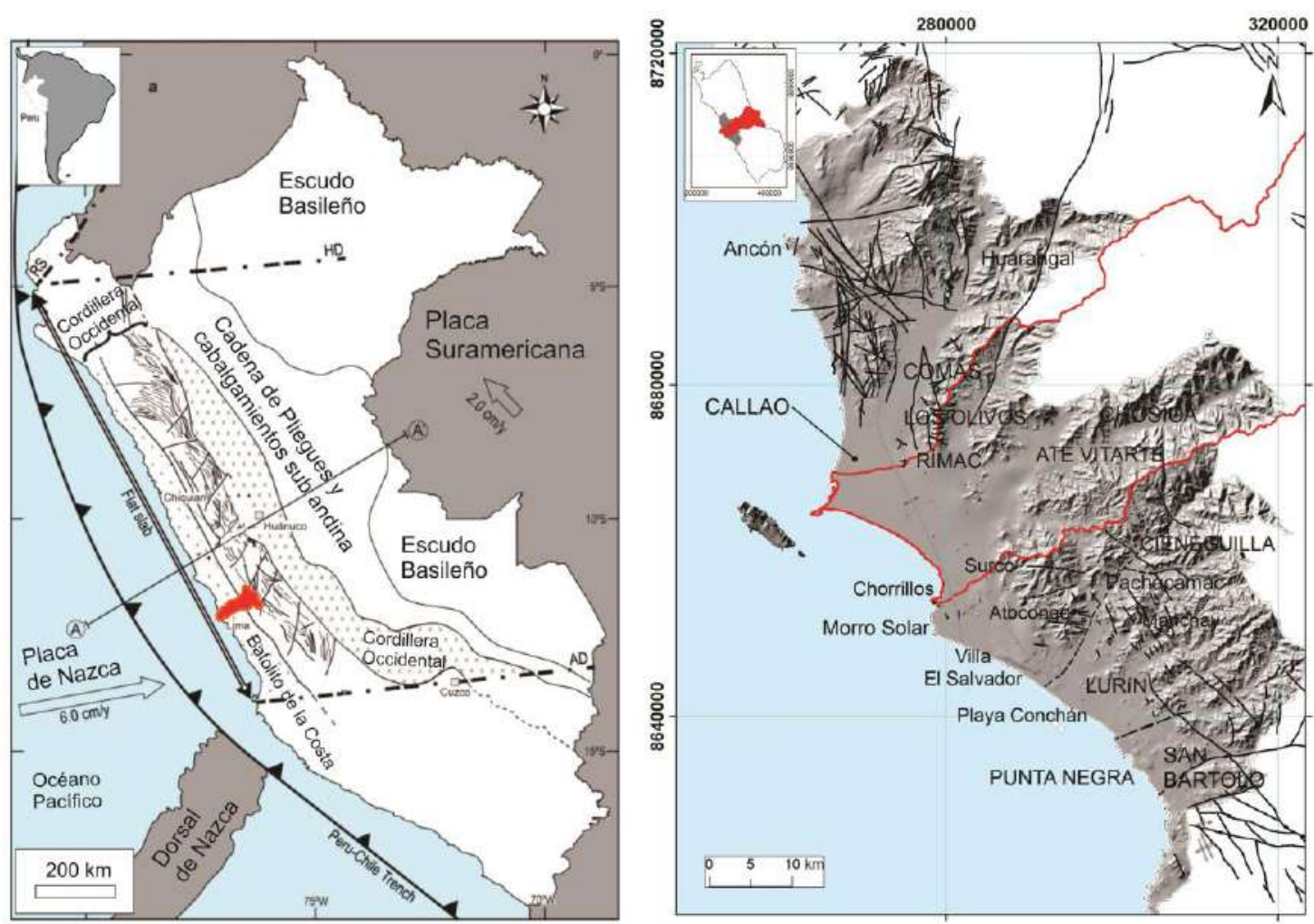

Cuenca del rio Rimac

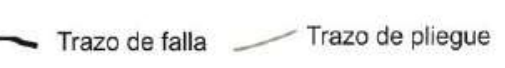

Granitoide al. (2000); Macharé et al. (2009); Scherrenberg et al (2014) y Villacorta et al. (2015). 
El ápice del abanico del río Rímac está localizado en las primeras estribaciones andinas de la Cordillera Occidental, en la localidad de Ate (Figura 31), dista unos 16 a $21 \mathrm{~km}$ de la costa, que marca su límite frontal. La zona distal está cortada dando lugar al acantilado de la Costa Verde (Figura 31 y Foto 10), que cuenta con un ancho de aproximadamente $21 \mathrm{~km}$ a lo largo de la franja costera de dicho sector y con altitudes de hasta 80-100m en su zona central (área de Miraflores y el centro comercial Larcomar, foto 10).

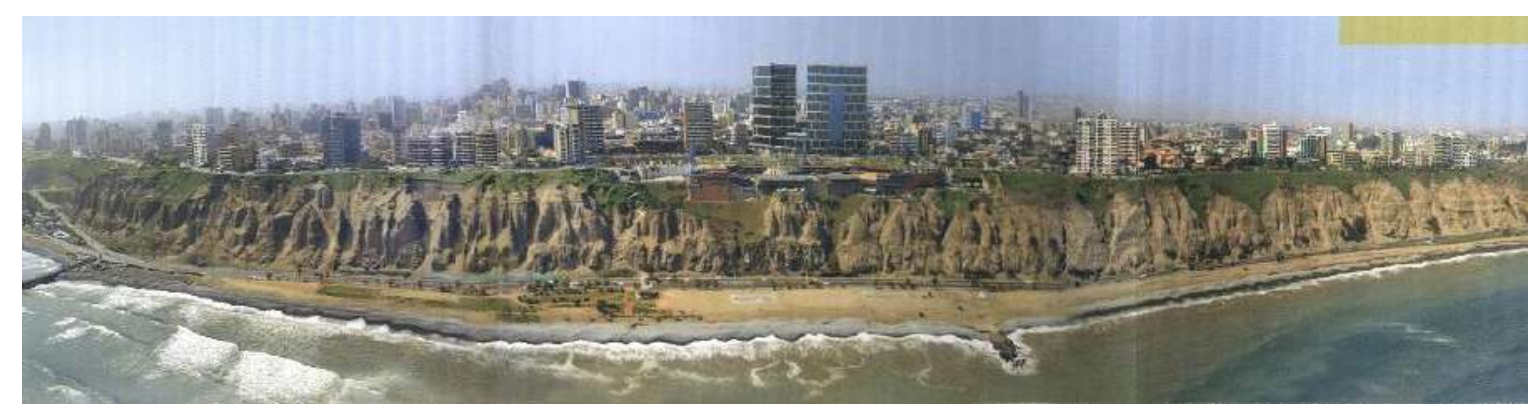

Foto 10. Vista panorámica de La Costa Verde a la altura de Miraflores (tomado de: (Mixmade S.A.C., 2008)

\subsection{GEOLOGÍA}

Este acápite se dividirá en una descripción general de los materiales localizados, la historia geológica del área, la geología estructural y la edad geológica del Abanico de Lima.

\subsubsection{Sedimentología}

El registro sedimentario de la sección transversal expuesta en los acantilados permite interpretar el desarrollo y evolución del depósito que conforma el abanico de Lima, que se compone básicamente de facies de flujos aluviales rellenando paleo-cauces, depósitos de arroyada en manto y travertinos post-sedimentarios. Estos materiales (gravas, arenas y arcillas) varían en tamaño y distribución, tanto en la vertical como en la horizontal (figura 32). 


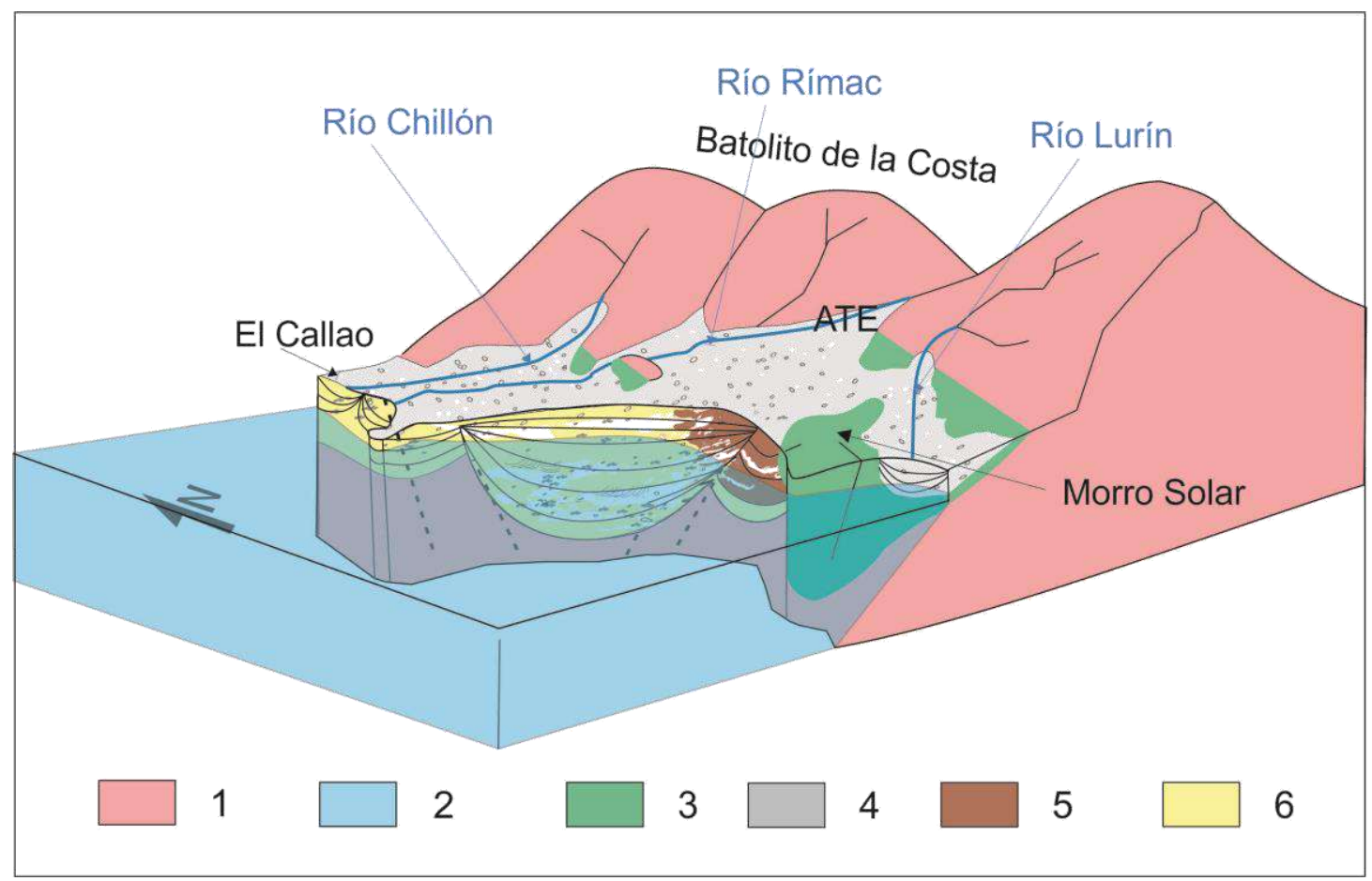

Figura 31. Bloque diagrama esquemático del área evaluada y alrededores. 1: Intrusivos ecocenomiocenos exhumados. 2: Océano Pacífico. 3: Afloramientos Jurásico-cretácicos. 4: sedimentos cuaternarios. 5: Arcillas. 6: Arenas y gravas. No a escala.

De acuerdo con Giles, Moroco \& Jacay (2002), en la Costa Verde los ciclos menores presentan secuencias grano-decrecientes, con dominio de gravas que, a su vez, se agrupan en secuencias grano-crecientes, típicas de la progradación de abanicos aluviales (Sébrier \& Macharé, 1980; Le Roux et al., 2000; Palacios, Caldas, \& Vela, 1992; Cobbing, 1973; Lecarpentier \& Motti, 1968).

Los conglomerados tienen bases erosivas y gradan a areniscas, limolitas y lodolitas según secuencias con grano-selección positiva. Estos se interrumpen por horizontes de caliche que se asocian a episodios de no depósito y evidencian condiciones de intensa aridez.

Las areniscas se presentan a menudo colmatando paleocanales y cuerpos lenticulares con estratificación cruzada que dan cuenta del pasado sistema fluvial trenzado que conformaron. Las facies descritas han sido identificadas por estudios anteriores entre Miraflores y Chorrillos (Villacorta et al., 2015; figura 32). 


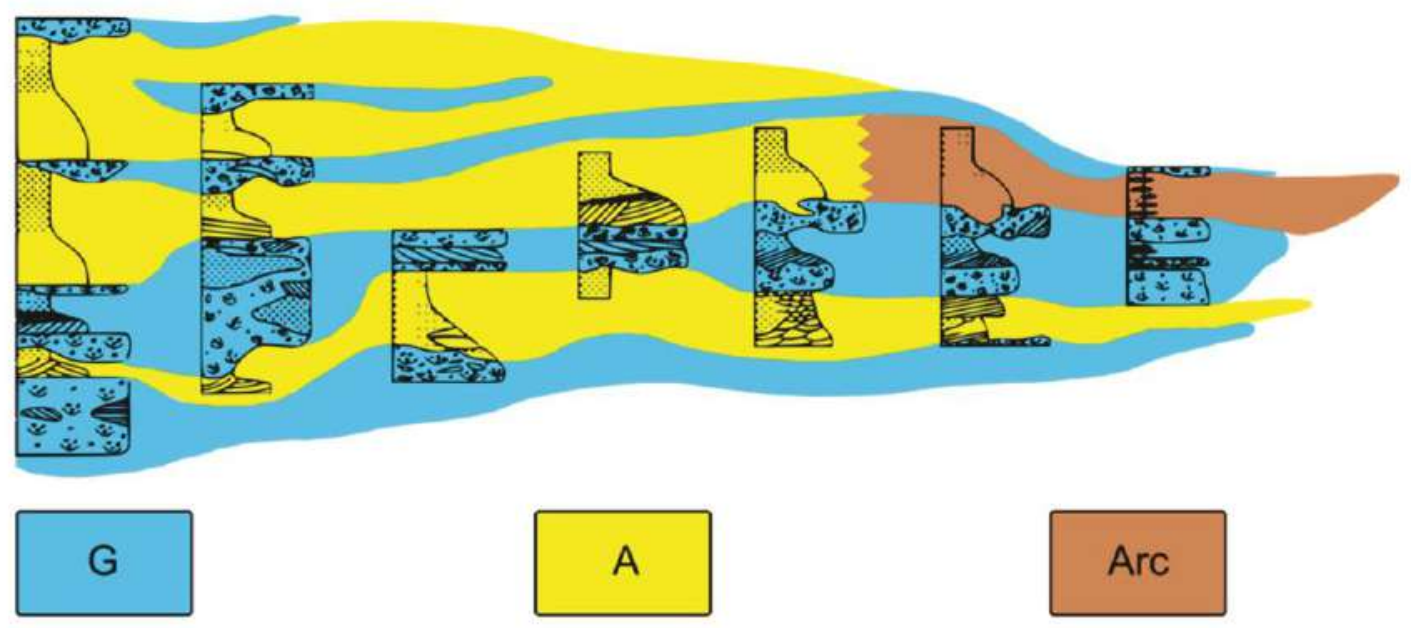

Figura 32. Esquema de cómo están distribuidas las facies sedimentarias en la Costa Verde (entre Miraflores y Chorrillos). G: Gravas correspondientes a canales tractivos, A: Arenas de canales rellenados, Arc: Arcillas y limos correspondientes a llanuras de inundación. No a escala. Modificado de: Villacorta et al. (2015).

\subsubsection{Litología}

El área del abanico está limitada por afloramientos remanentes que pertenecen a asociaciones mayores agrupadas por sus características litológicas en Grupos. De esta forma se tiene en la base de la columna estratigráfica a las rocas piroclásticas, brechas volcánicas y lavas de los grupos Puente Piedra y Casma; areniscas cuarzosas y lutitas del Grupo Morro Solar; así como calizas, margas y limolitas calcáreas del Grupo Lima, sobre las cuales se encuentran rocas de la Formación Chilca que en conjunto representan el intervalo crono-estratigráfico del Jurásico Superior-Cretáceo Superior; concluyendo con derrames andesíticos de la Formación Quilmaná de edad Paleógena. Todos estos remanentes están intruídos por rocas graníticas del Batolito de la Costa (Ramos \& Aleman, 2000; Scherrenberg et al., 2014).

Entre los distritos limeños de La Victoria y El Agustino, el abanico está interrumpido por relieves de rocas intrusivas de granodiorita y diorita de la Súper Unidad Santa Rosa que cortan a los remanentes jurásico-cretácicos como se observa en los cerros El Agustino, El Pino y La Atarjea, ubicados en su zona media (figura 31).

Los sedimentos del abanico lo conforman depósitos aluviales, eólicos y coluviales del Plioceno/Pleistoceno (Sébrier \& Macharé, 1980). La cuenca marina preexistente se 
colmató por depósitos continentales entre el final del Mioceno y comienzo del Plioceno (Palacios et al., 1992).

Los depósitos aluviales predominan y se han desarrollado en ambas márgenes del río Rímac, centrándose y focalizándose en su curso principal. Así, también, tanto en las quebradas alimentadoras como en el abanico, estos materiales conforman un relleno potente (Foto 11), aunque la acumulación debió producirse solo en la época de avenidas. Precisamente por el gran espesor del relleno aluvial (Arce, 1984) se infiere que esta sucesión de avenidas debió haber sido frecuente en el pasado histórico, o que pudo corresponder a un hundimiento de los bloques fallados (Aleman et al., 2006; Cobbing, 1982).

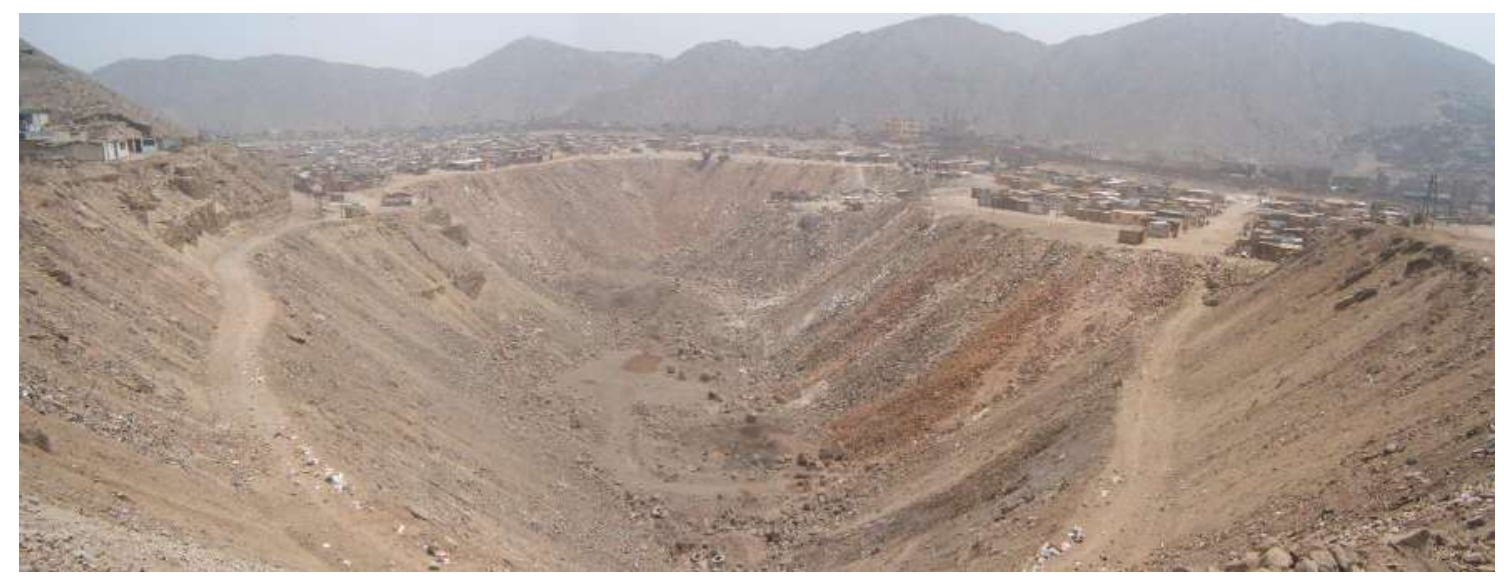

Foto 11. Cantera abandonada, rellenada con desmonte y basura en quebrada tributaria al río Rímac (sector Las Américas-Ate Vitarte). Tomado de Villacorta et al. (2015).

\subsubsection{Geología estructural}

En el área de Lima Metropolitana se han registrado una serie de fallas normales con componente de rumbo y bloques rotados, en su mayor parte ocultos por sedimentos más recientes y por la densidad de fracturamiento (Figura 33). La falla más importante cartografiada en el área tiene una dirección NE-SO y ha sido observada al este de Comas. El resto de estructuras de deformación son de menores dimensiones, destacando alineaciones paralelas NO-SE al este de Villa El Salvador y hacia Manchay (Macharé et al., 2009). Aparecen otras estructuras con direcciones predominantes NO-SE, E-O y N-S entre Ancón y Lima, entre Pachacamác y Lurín y en San Bartolo (Villacorta et al., 2015). 


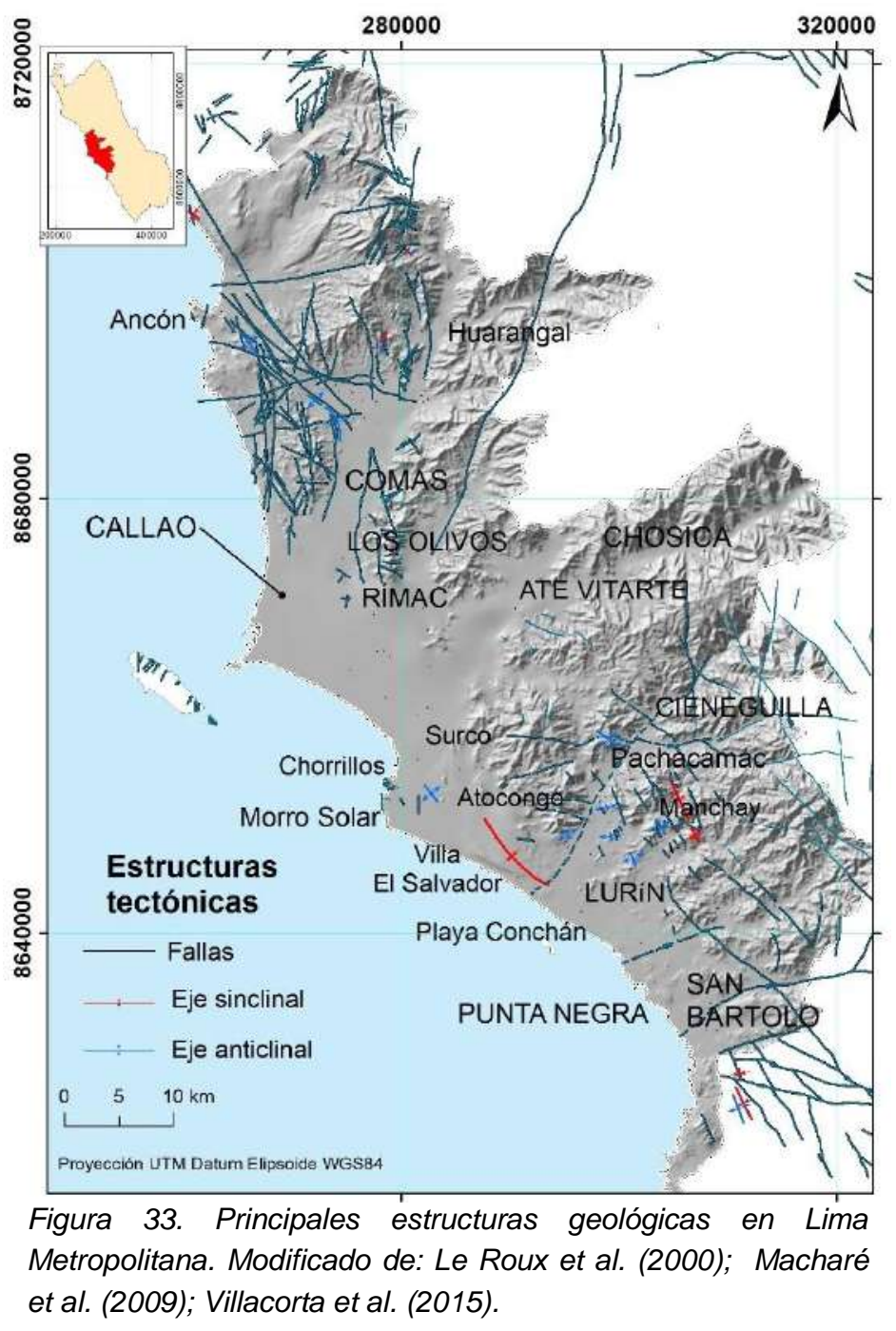

Cobbing (1982) infiere que la zona central, donde se ubica el abanico, se formó por el hundimiento de bloques fallados. No obstante, no se han encontrado aún evidencias suficientes para confirmar esta hipótesis.

Jacay et al. (2000) y Jacay (2013) postulan que podría existir una reactivación por sismicidad en esta parte de la costa peruana por la aparente deformación de los materiales arcillosos evidenciada con las estructuras de carga observadas en la columna de sedimentos expuesta en el sector sur de los acantilados.

El denominado "Anticlinal de Lima" (Figura 34), cuyo eje tendría una dirección NO-SE y cuya extensión iría desde Ancón hasta la altura de la playa Conchán en Villa El 
Salvador (Lisson, 1907) fue cuestionado por nuevas interpretaciones de los buzamientos divergentes, como bloques fallados y rotados (Figura 35) que se asociarían a una tectónica transtensional debido a la subducción (Aleman et al., 2006). Ejemplo de esa tectónica se encuentra al sur del abanico de Lima, en la formación Ventanilla (Foto 12).

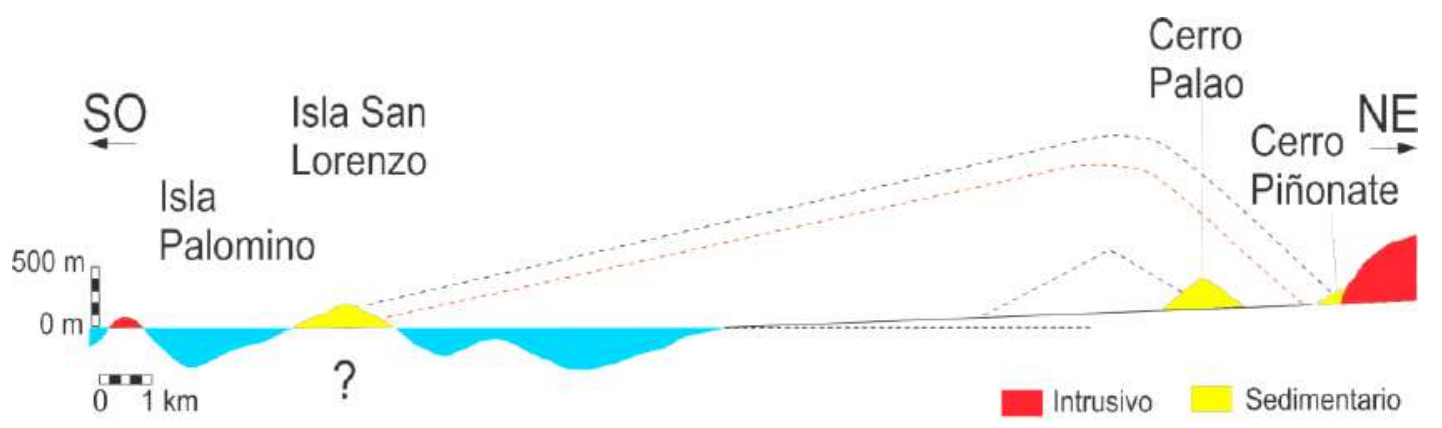

Figura 34. Anticlinal de Lima inferido por Lisson. Modificado de Lisson (1907)

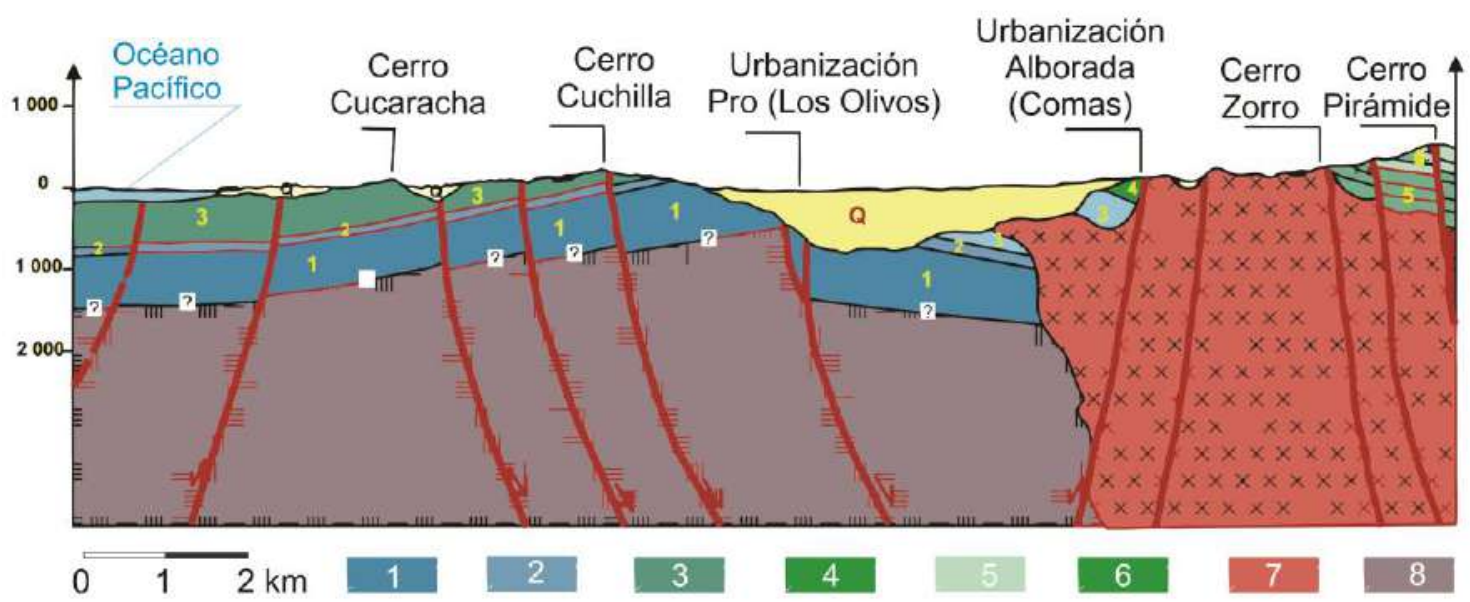

Figura 35. Sección playa Márquez - cerro Pirámide (Comas). Fallas normales habrían causado la rotación de bloques que pueden dar una interpretación de un anticlinal fallado sin serlo. Modificado de Aleman et al. (2006). 1. Fm. Tambo Inga, 2. Puente Inga, 3. Ventanilla, 4. La Herradura, 5. Chilca, 6. Quilmaná, 7. Batolito de la Costa, 8. Basamento desconocido. 


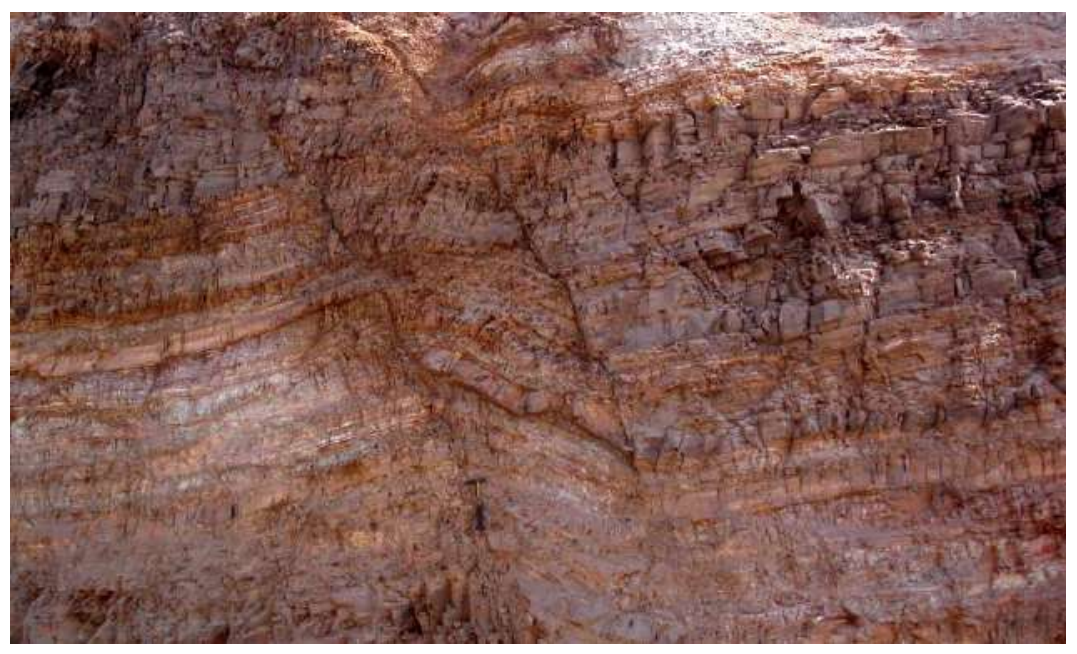

Foto 12. Bloques rotados a causa de set de fallas normales asociadas que aparentan un anticlinal fallado. Tomado de: (Aleman et al., 2006).

\subsubsection{Edad del Abanico de Lima}

Como se había mencionado en el apartado 2.2, la primera referencia de datación del abanico es la de Lisson (1907), que habría descubierto en el techo de la estructura geomorfológica, un molar de Equus curvidens Owen, 1895 de edad pleistocena.

Según Le Roux et al. (2000), los depósitos expuestos en la Costa Verde corresponden a la migración del cauce del río Rímac desde su posición original hacia el SE de su ubicación actual. Señala que esto debió producirse durante el Mioceno tardío-Plioceno (entre 10 y $5.3 \mathrm{Ma}$ ) y que estaría asociado a la actividad de la Dorsal de Nazca.

De otro lado Noble, Wise, Zanetti, Vidal, \& McKee (2009) dataron mediante Ar-Ar niveles volcánicos, dentro de los depósitos aluviales en Mala (80 km al sur de Lima) entre los $8 \mathrm{Ma}$ y $7 \mathrm{Ma}$ (finales del Mioceno) y propusieron que el abanico de Lima podría ser de la misma edad. Aunque Teves (1975) y Aleman et al. (2006) señalan que, por sus características sedimentológicas, es posible que sea más joven.

Viveen et al. (2016) en sus recientes investigaciones han datado por Luminiscencia Òpticamente Estimulada (OSL) arenas de la parte distal del abanico, en el distrito de Barranco, cerca del "Club de Regatas". Las edades calculadas son 0.9 a 0.1 ka, 3.8 a 1.2 ka y 3.9 a 0.5 ka lo que ubicaría geocronológicamente estos materiales en el Holoceno tardío. 


\section{METODOLOGÍA Y DESARROLLO}

Para alcanzar los objetivos planteados en esta investigación, se ha desarrollado una metodología (Figura 36) que ha incluido desde trabajos en laboratorio, hasta la recolección de información en campo. Se ha incluido como parte importante de los métodos aplicados, el análisis hidrológico-hidráulico mediante SIG que incluye la modelización numérica de flujos de detritos en el área urbana del río Rímac (abanico de Lima).

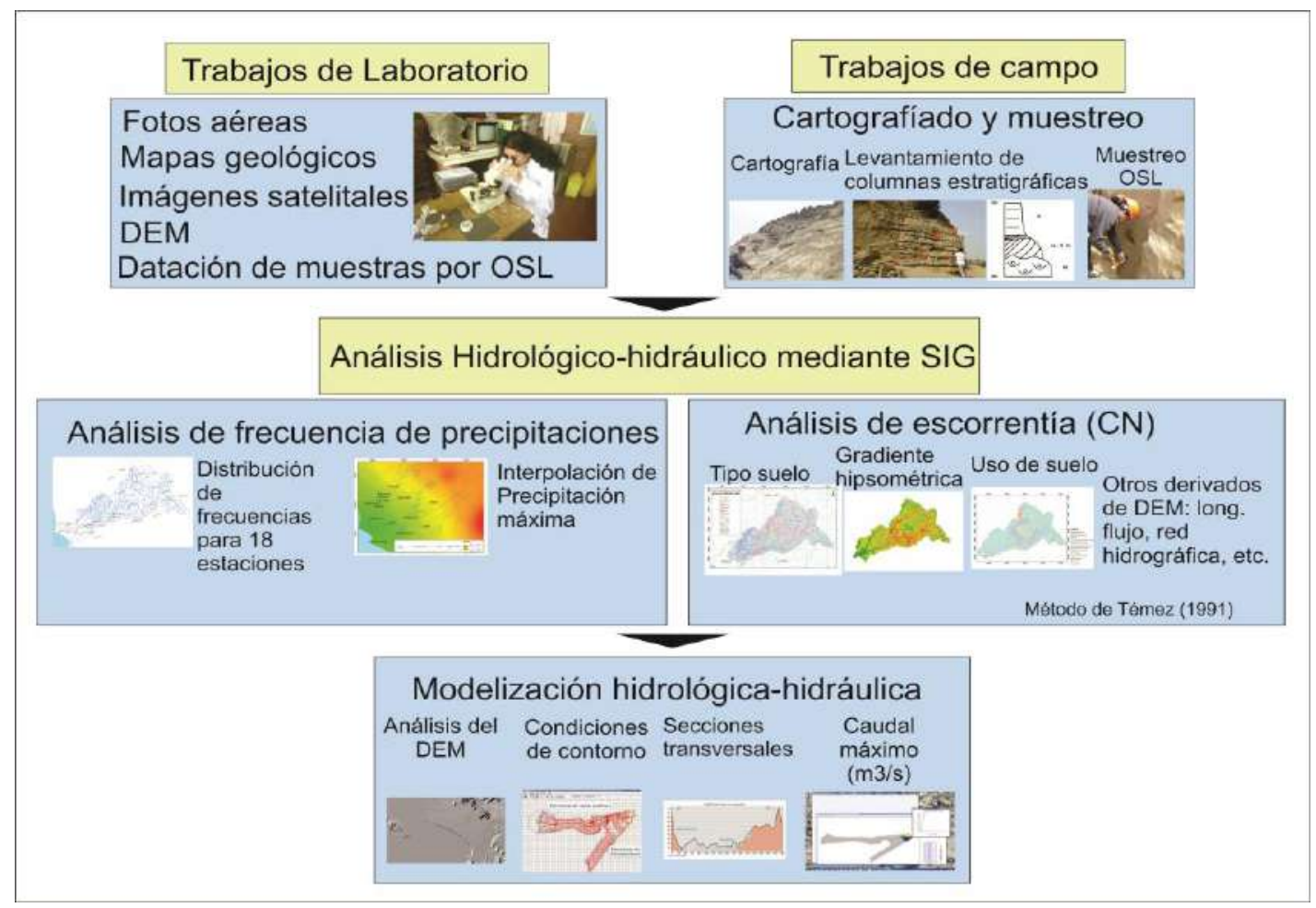

Figura 36. Esquema metodológico seguido en este estudio. Modificado de: Llorente (2014)

\subsection{TRABAJOS DE LABORATORIO}

Incluye la recopilación de información, interpretación de imágenes de satélite y fotos aéreas; el tratamiento de muestras para dataciones, análisis de los resultados de gabinete y laboratorio, así como la sistematización de la información integrada con ayuda de un entorno operativo SIG. 


\subsubsection{Recopilación de información}

Incluye la integración, análisis y sistematización de toda la información existente en diferentes instituciones, bibliotecas, archivos técnicos, etc. entre otros. Entre los documentos analizados hay información cartográfica, fotográfica y documental sobre el tema de investigación y de la zona de estudio en especial.

Se recurrió a las bases de datos de bibliotecas especializadas (facultades de Geología y Geografía de la Universidad Nacional Mayor de San Marcos, Universidad Nacional de Ingeniería, Pontificia Universidad Católica del Perú, INGEMMET, entre otras.

Se ha investigado en las publicaciones periódicas de revistas especializadas en Geomorfología, Geología del Cuaternario en las bases de datos Scientific Electronic Library Online (SciELO), Scopus, ScienceDirect y Web of Science; y a nivel nacional de la Sociedad Geológica del Perú, Instituto de geografía de la PUCP, Revista geológica de la universidad san Marcos y ALICIA (Concytec).

Esta información constituye la base de datos de partida para esta investigación la cual se incluye en las referencias bibliográficas.

\subsubsection{Interpretación de imágenes satelitales y fotos aéreas}

En esta labor se ha contado con fotos áreas USAF de los años 1956/1957 en escala de grises y las de la plataforma "Google Earth" de espectro color desde el 2000 al 2015. Con ayuda de las fotos USAF verticales se interpretó detalladamente el área del abanico, desembocadura y cauce del río Rímac en el área metropolitana de Lima; información que ha sido fundamental para definir sus terrazas. Este trabajo ha permitido visualizar el área antes de su antropización, lo que no es posible en la actualidad. Con las imágenes de la plataforma "Google Earth" de diferentes años se interpretó la evolución multi-temporal del área influenciada debido a la creciente actividad poblacional.

Para estudiar las fotos aéreas e identificar las geoformas fluviales se usaron las conocidas técnicas de fotointerpretación de pares estereoscopios. Se tomó como base la cartográfica geológica proporcionada por la Dirección de Geología Regional del INGEMMET (inédita) y la cartografía geomorfológica del estudio: "Peligros Geológicos 
en Lima Metropolitana y la región Callao" a escala 1:25 000; datos que se actualizaron a una escala adecuada para este estudio (1: 5000).

La simbología empleada ha sido la utilizada por el INGEMMET en la cartografía geomorfológica a nivel nacional, la cual recoge elementos del Instituto de Levantamientos Aeroespaciales y Ciencias de la Tierra-ITC (Verstappen, Zuidam, Meijerink, \& Nossin, 1991), y la "Guía para la elaboración del Mapa Geomorfológico de España a escala 1:50 000 (Martín-Serrano, 2004) con una revisión de las geoformas identificadas en Perú realizada por Medina et al. (2014). Para su caracterización se tuvo en cuenta los aspectos morfométricos e interpretativos desde la perspectiva genética de los depósitos y formas de relieve.

La información obtenida se reclasificó en relación a su origen y evolución, estableciéndose con las dataciones las cronologías respectivas. Se realizó un análisis de la morfología actual de manera sistemática: se midieron anomalías de deformación con respecto a la morfología original, que se considera pre-deformacional. Para ello se emplearon perfiles transversales (Figura 39, 40 y 41), los cuales se generaron con la herramienta "perfil" del ArGIS 10.3.

\subsubsection{Dataciones}

Para conocer la edad de los depósitos fluvio-aluviales que forman al abanico de Lima, (proto-río Rímac) se tomaron muestras de los materiales que lo constituyen en diferentes sectores. También se aprovechó para extraer muestras de la paleo-duna "Lomo de Corvina" exclusivamente para analizar posibles cambios climáticos que hayan dado origen a la aridez en Lima. Todos ellos se analizaron por OSL.

Los análisis se realizaron en los laboratorios del Servicio Geológico de Estados Unidos (Denver, Colorado) y de La Facultad de Ciencias de la Universidad Nacional de Ingeniería, Perú. La estimulación se hizo en el espectro electromagnético del azul y en el del infrarrojo. Se aplicó el método regenerativo (Single Aliquot Regenerative Method, SAR-Method) siguiendo los protocolos de Bøtter-Jensen (2000). 


\subsubsection{Recolección de muestras para datación}

La metodología adoptada ha seguido el protocolo propuesto por Aitken (1985) que indica que las muestras para la datación por luminiscencia deben elegirse de perfiles representativos en el área de muestreo. Estos perfiles, ya sea a partir de exposiciones naturales o de núcleos, deben limpiarse extrayendo al menos $5-10 \mathrm{~cm}$ de material externo, ya que este sedimento se habrá expuesto a la luz solar y por lo tanto se ha blanqueado la señal de luminiscencia. Luego se toman muestras a distintas profundidades (o niveles de terrazas) generalmente a través de tubos o cubiertas metálicas que protegen las muestras de la luz del sol durante su transferencia al laboratorio. Posteriormente las muestras se estimulan utilizando un lector de OSL (Figura 37).

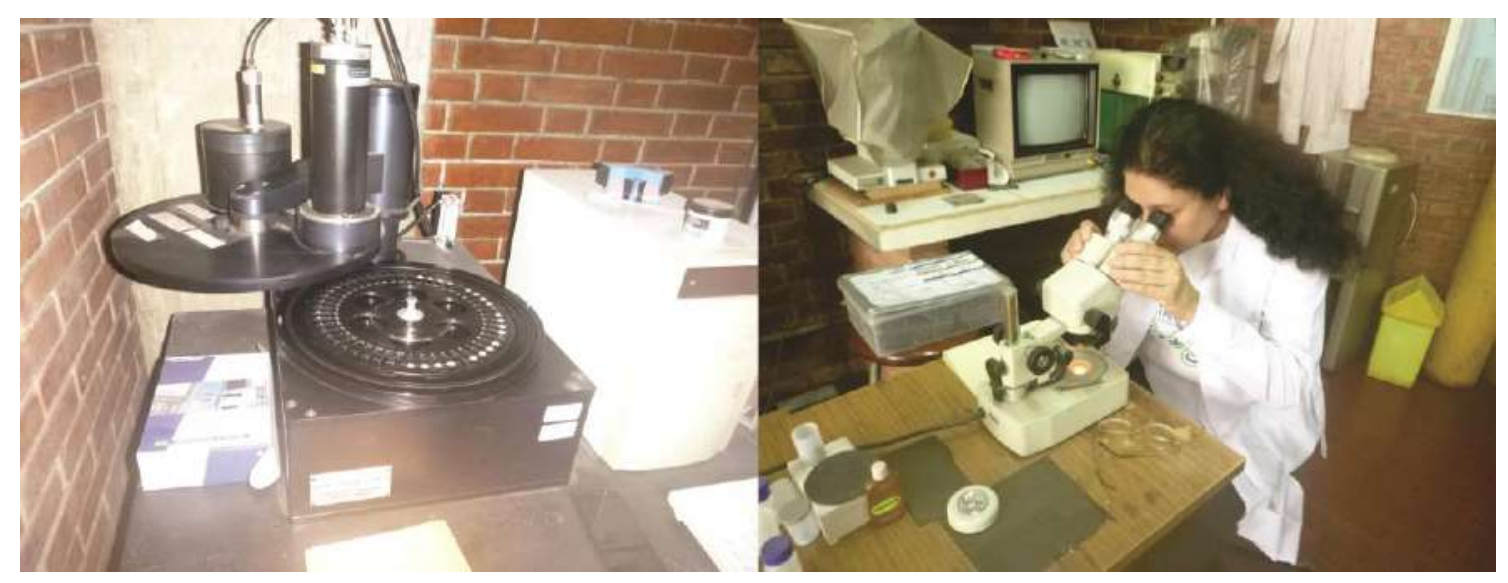

Figura 37. A) Equipo empleado en la datación por OSL (Sistema automatizado lector de termoluminiscencia y de luminiscencia ópticamente estimulada marca Risø) en el Laboratorio de Dataciones de la Facultad de Física de la Universidad Nacional de Ingeniería (Perú). B) Análisis en microscopio las muestras de cuarzo a ser analizadas por OSL.

Para las muestras tomadas en los perfiles representativos evaluados se obtuvieron las muestras en tubos de $19 \mathrm{~cm}$ de longitud y $2 \mathrm{~cm}$ de diámetro aproximadamente (Foto 13). Las arenas extraídas se emplearon para la medición de la señal luminiscente según los protocolos normalizados de Bøtter-Jensen (2000). 


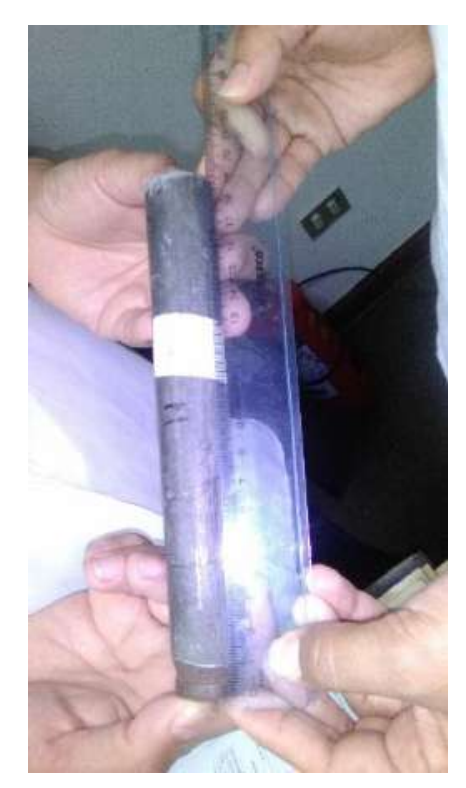

Foto 13. Tubos para muestreo por OSL diseñado por la Dra.

Susana Petrick del IPEN (Perú)

Se extrajeron muestras en Lomo de Corvina (03 en el flanco norte y 03 en el flanco sur a distintas profundidades, Foto 14), en la zona distal del abanico (Costa Verde), en el área de influencia del río Huaycoloro (Huachipa) y en el cauce del río Rímac (a la altura de la central de la empresa de Servicio de Agua Potable y Alcantarillado de Lima - SEDAPAL), cerca de la zona del ápice del abanico de Lima.

\subsubsection{Preparación de la muestra y datos de medición}

Para cada muestra, se obtuvo una alícuota de $2 \mathrm{~g}$ de material para material para observar bajo microscopio óptico. El resto del sedimento, se tamizó bajo luz roja en el laboratorio, reservándose la fracción de tamaño comprendido entre 100 y 150 micrones, que fueron posteriormente atacados en $\mathrm{HCl}$ por 90 minutos, luego se enjuagó la muestra con agua destilada para después ponerla nuevamente en remojó en peróxido de hidrógeno, a 50 volúmenes por tres días. Luego se enjuagó y se realizaron ataques sucesivos con $\mathrm{HF}$ al $40 \%$ por $60 \min$ y con $\mathrm{HCl}(1 \mathrm{~N})$ por 45 minutos en agitador magnético. El material obtenido se secó en estufa a $30{ }^{\circ} \mathrm{C}$.

Además, en una bolsa se recogieron alrededor de $2000 \mathrm{~g}$ de la arena que circundaba al tubo en el área donde se tomaron las muestras 4 y 5 Lomo de Corvina, con la finalidad de utilizar este material para estimar la tasa de dosis o dosis anual en el laboratorio. 


\subsubsection{Equipo de laboratorio utilizado}

Los granos de cuarzo tratados y secos se midieron en el sistema RIS $\varnothing$ modelo TL/OSL-DA-15 (Figura 37A), en ambiente de nitrógeno UHP. Esta unidad tiene una fuente de radiación beta90Sr. La fuente de radiación esta almacenada en una cámara de vacío y cuenta con un intercambiador de muestras automático que evita la irradiación de otras muestras dentro del equipo. El equipo es de acero y está recubierto de plomo para mantener el nivel de radiación externo al mínimo. El equipo cuenta con un software pre-programado que hace más eficiente el diseño de las secuencias de experimentación.

Las lecturas de termoluminiscencia se hacen por medio de una resistencia formada de la aleación de níquel y cantal que logra alcanzar temperaturas de hasta $700^{\circ} \mathrm{C}$, con

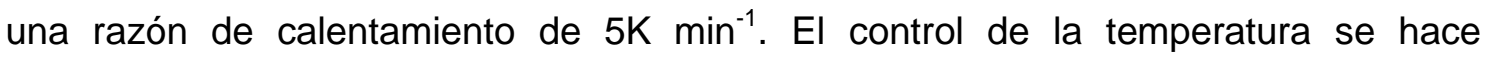
mediante un termopar soldado a la resistencia de $0.5 \mathrm{~mm}$ de diámetro y las placas de calentamiento se enfrié rápidamente (aprox. 2 min.) sin necesidad de un sistema de enfriamiento.

La estimulación óptica en este equipo para obtener la lectura OSL puede realizarse utilizando infrarrojo o por diodos emisores de luz azul (LED, por sus siglas en inglés). La estimulación con el diodo láser infrarrojo consiste en unos diodos de aproximadamente $0.36 \mathrm{~W} \mathrm{~cm}^{-2}$ y emite a $830 \mathrm{~nm}$, el arreglo óptico se basa en unos 30 - 40 diodos de IR que se sitúan entre 10 a 20 mm de distancia respecto a la posición de la muestra y que proveen un área de iluminación uniforme de aproximadamente 1 $\mathrm{cm}^{2}$.

La estimulación óptica con los diodos emisores de luz azules tiene su pico de emisión a $470 \mathrm{~mm}$ y un máximo de $24 \mathrm{~mW} \mathrm{~cm}^{-2}$ liberados a la muestra que se encuentra a 30 $\mathrm{mm}$ de distancia al momento de la lectura dosimétrica. Esta fuente de estimulación óptica consiste de un total de 42 diodos arreglados en un anillo situado entre el sistema de calentamiento y el tubo fotomultiplicador.

La fuente de luz utilizada fue en el rango de luz azul $(470 \mathrm{~nm})$ por 35 segundos al 90 $\%$ de la potencia máxima.

Los cálculos se realizaron con el programa Analyst V 3.04b.

Todas las irradiaciones se realizaron con fuente beta de $90 \mathrm{Sr}$, de 0,125 Gy/s. 
La dosis anual se calculó por conteo alfa de muestra gruesa sobre centellador de SZn:Ag. Se consideró una concentración de potasio de 1,5\%.

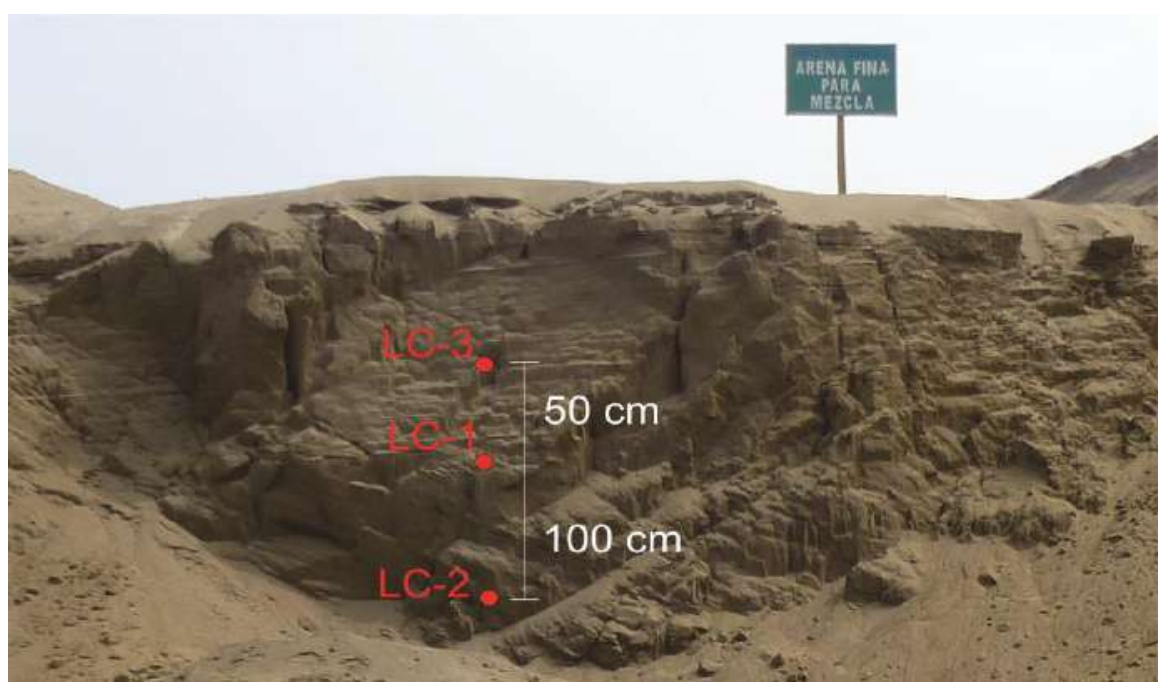

Foto 14. Perfil vertical sobre el afloramiento de arenas de la duna Lomo de Corvina. En la foto se indican las elevaciones sobre la base del perfil donde se extrajo la arena (muestras LC 1, 2 y 3) en tubos de acero galvanizado para realizar los análisis de OSL.

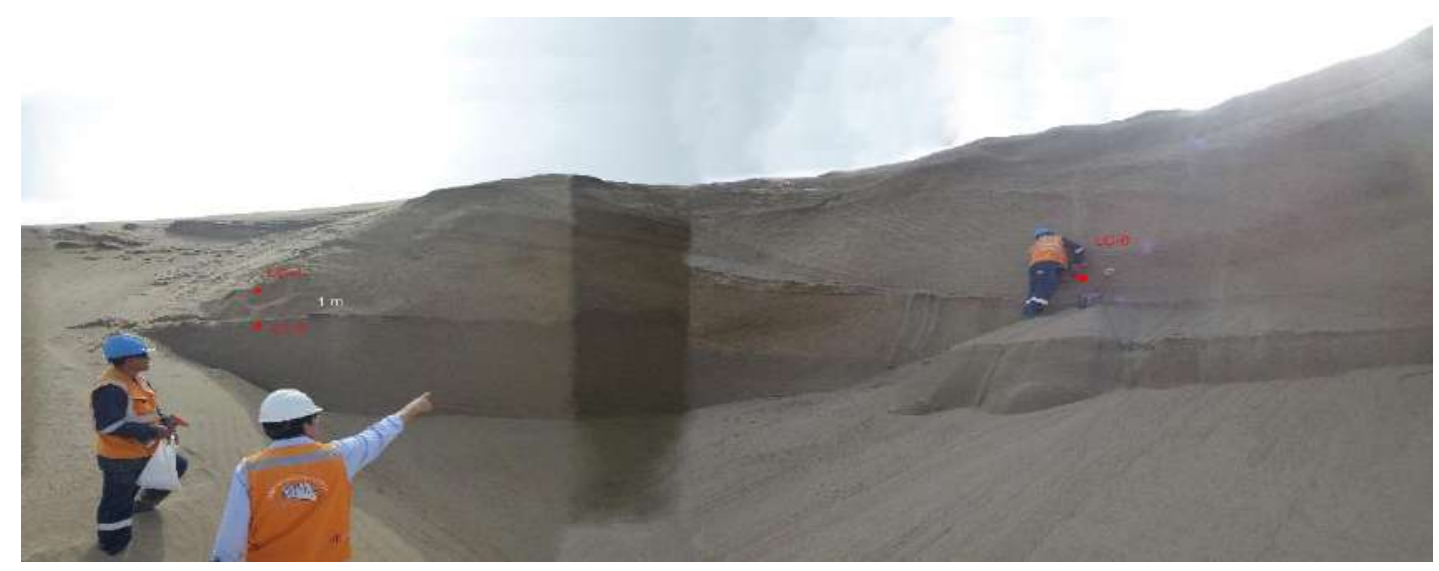

Foto 15. Área de la duna Lomo de Corvina donde se extrajeron las muestras $L C 4,5$ y 6.

En la estación Magdalena (Foto 16) se tomaron dos muestras casi a la misma altura y que correspondían a un nivel arenoso entre depósitos de gravas. Para cada muestra, se obtuvo una alícuota de 2 gramos de material para analizar la luminiscencia. Se siguió el procedimiento descrito anteriormente. 


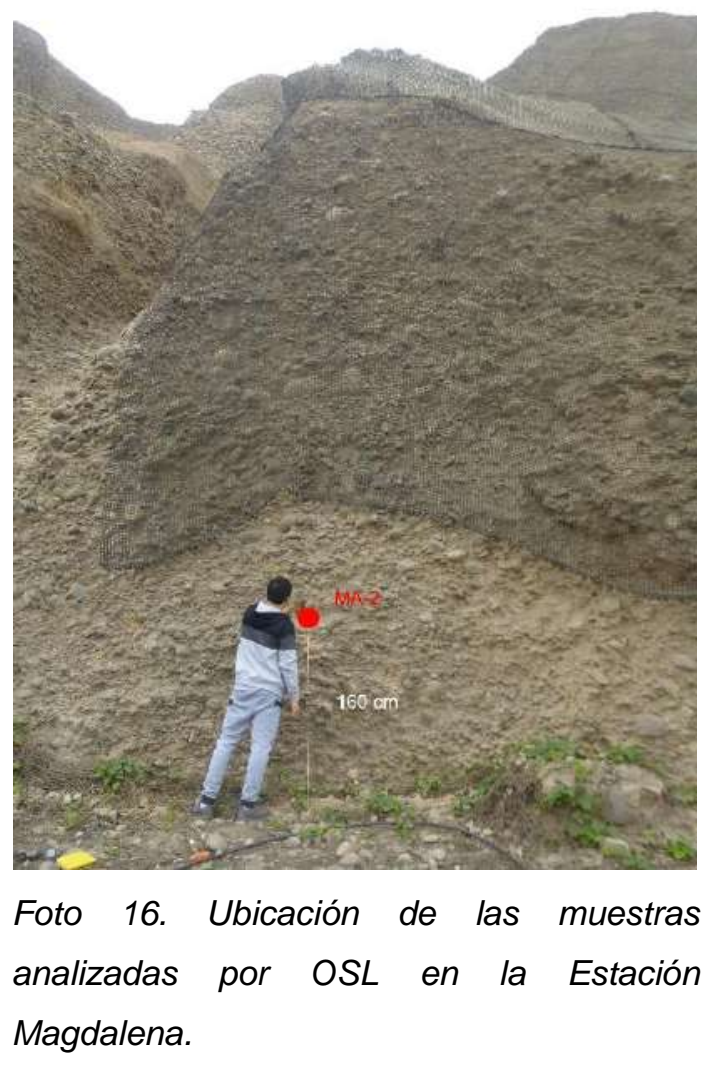

En la estación Regatas (Foto 17) se tomaron tres muestras (R1, R2 y $R 3$ ) la primera se tomó de un nivel arenoso y la segunda un metro más arriba que correspondía a otro nivel areno-limoso. Se siguió el procedimiento descrito anteriormente.

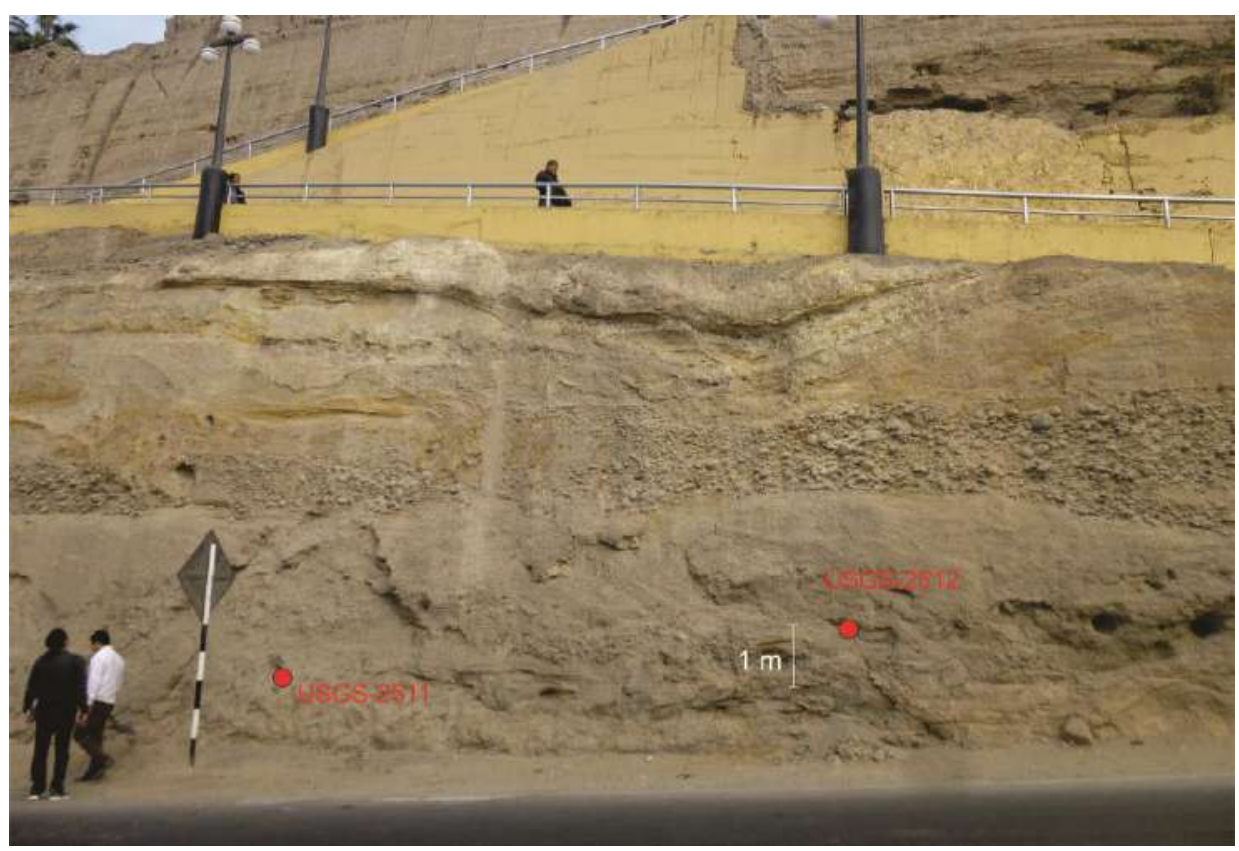

Foto 17. Ubicación de las muestras analizadas por OSL en la Estación Regatas 


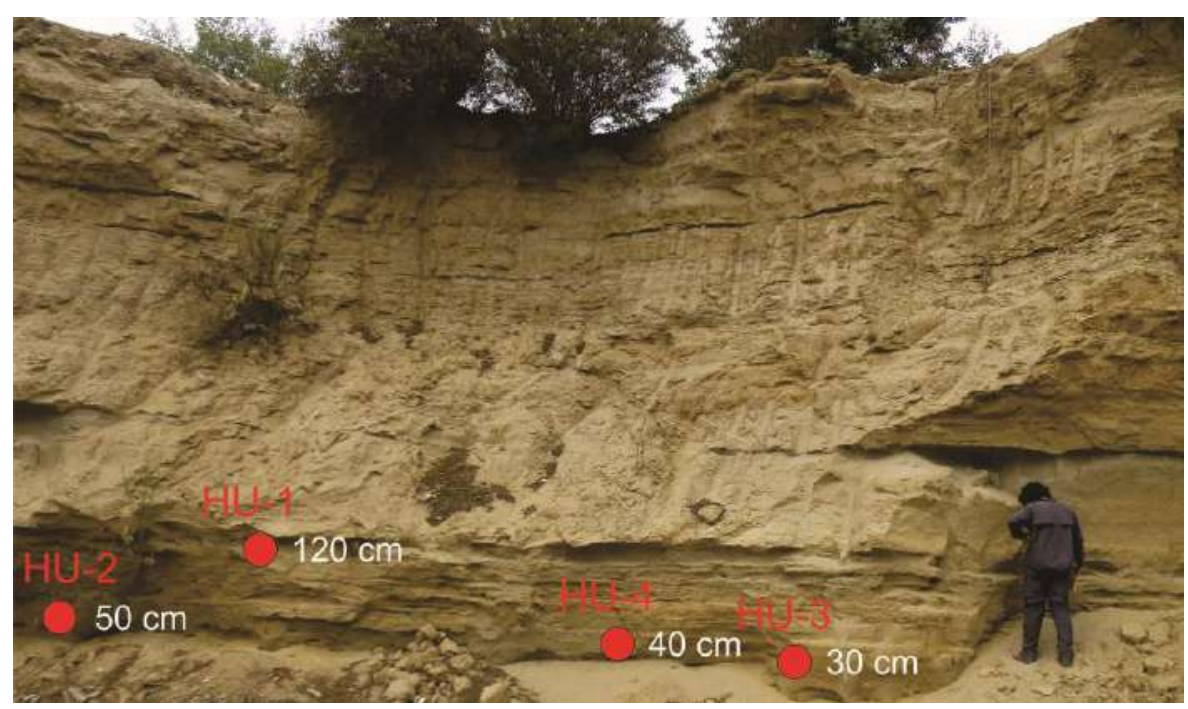

Foto 18. Ubicación de las muestras extraídas en Huachipa para su análisis por OSL.

\subsubsection{Sistematización de la información}

Se analizó la base cartográfica a escala 1:5000 proporcionada por la Municipalidad de Lima y posteriormente a 1:1000 del área a modelizar proporcionada por la Comisión Nacional de Investigación y Desarrollo Aeroespacial (CONIDA) para este estudio. Como se mencionó anteriormente la cartografía geomorfológica base proviene del INGEMMET y ha sido modificada y ampliada.

A fin de restituir la morfología original sin deformación del valle se elaboraron diferentes perfiles topográficos (Figura 38) en áreas donde no se había podido identificar estructuras tectónicas recientes, empleando ArcGIS 10.3.

Para la generación de los Modelos de Elevación Digital (DEM) se recurrió a las imágenes estereoscópicas del satélite Pléiades $1 \mathrm{~A} / \mathrm{B}$ correspondientes al área de estudio. Este tipo de imágenes poseen una resolución espacial de 0.5 metros en su banda pancromática y una cobertura de escena de 20 ×20 km.

Para el procesamiento de estas imágenes ha sido necesario realizar trabajos previos de identificación de los puntos GCP (Ground Control Points) y su correspondiente medición con GPS diferencial que permite realizar la corrección geométrica a nivel Orto (corrección en 3 dimensiones). 
Una vez realizados los trabajos de campo y post procesamiento de los puntos GCP se procedió a realizar la corrección geométrica mediante el software PCl Geomática 2016 a través de su módulo Ortho Engine, el cual tiene la capacidad de realizar esta corrección de imágenes estereoscópicas llegando obtener un ppeki cuadrático medio (RMS por sus siglas en inglés) de 0.7 adecuado para este tipo de estudios.

Como resultado se obtuvo el DSM (Modelo Digital de Superficie) el cual presenta no solo la morfología natural sino también la parte antrópica (cosntrucciones). En los perfiles se pudo identificar los niveles de terrazas y su continuidad al otro borde del abanico cuando no existía la erosión y deformación.

La reconstrucción de la superficie se efectuó empleando una función polinómica de bajo grado (herramienta DEM Editing del software PCI Geomática) con el fin de extraer las tendencias de las terrazas. Esto ha permitido tener una referencia de la altura máxima de la superficie siendo posible reconstruir las formas erosionadas, según lo indicado por García-Tortosa et al. (2008) y García-Tortosa et al. (2011); De esta forma, se reconstruyó la morfología en los sectores erosionados no deformados. Las coberturas se extrapolaron para ser comparadas con las zonas deformadas. Para reducir los efectos de ruido del DEM se realizó un filtrado espacial de paso bajo en una ventana de $3 \times 3$ píxeles.

Interpretando los DEMs ha sido posible: detectar la deformación en el área del abanico e identificar qué estructuras se produjeron.

Los perfiles se han ubicado en donde se observaron los mayores alineamientos (figuras 39 a 43). Se generaron varios perfiles en los que la superficie del abanico estuvo representada a ambos lados de la falla. En todas las posibles estructuras de deformación, el mayor desplazamiento disminuye hacia el extremo del abanico. Se definen hacie el norte y sur estructuras que posibilitarían el relleno aluvial en el área evaluada.

En la zona distal del abanico, la erosión hace que sea difícil para generar la superficie alta, por lo cual se debieron generar varias superficies que asumen posiciones predeformacionales. Según este procedimiento, la superficie del abanico al pie del talud generalmente coincide con la pre-deformacional. 


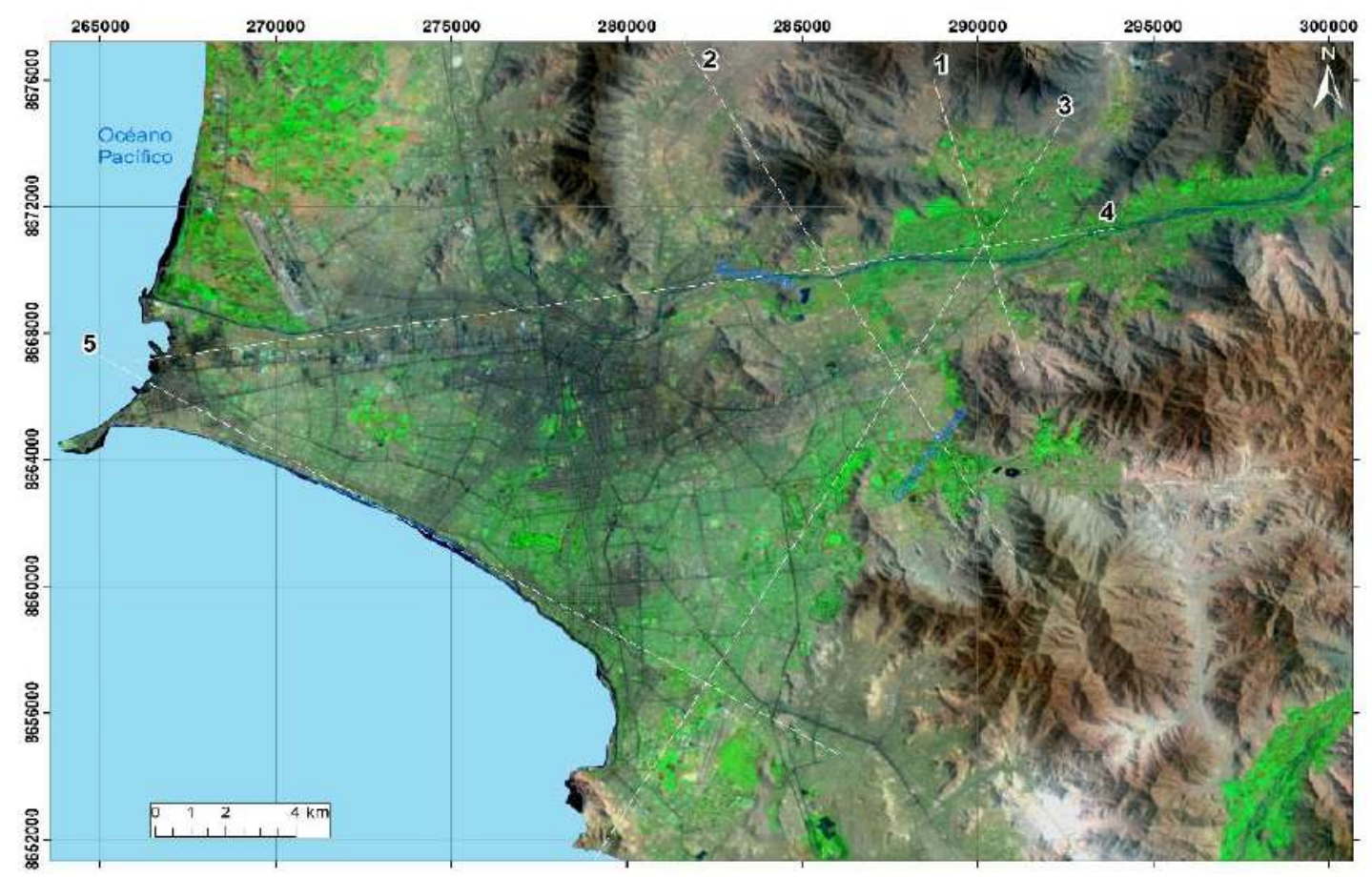

Figura 38. Vista de planta del área donde se trazaron los perfiles del análisis geomorfológico.

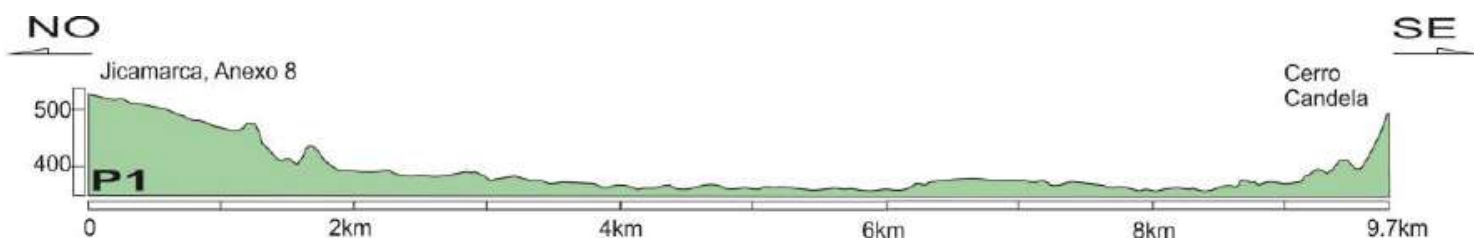

Figura 39. Perfil Jicamarca-Cerro Candela

NO

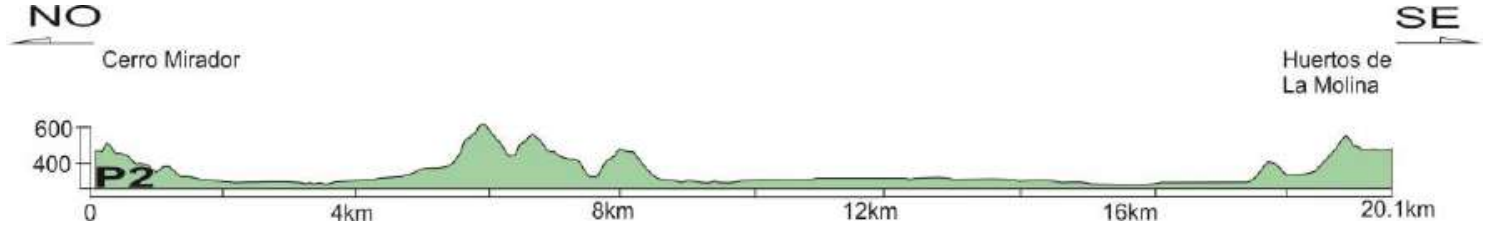

Figura 40. Perfil Cerro Mirador-Huertos de La Molina

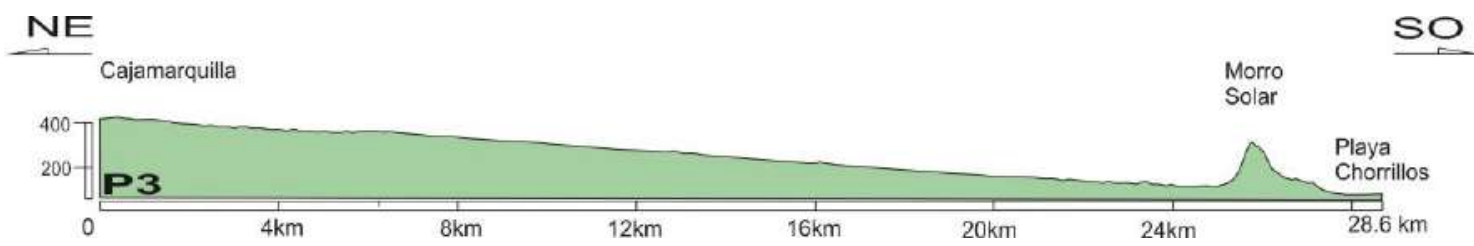

Figura 41. Perfil Cajamarquilla-Playa Chorrillos

NE

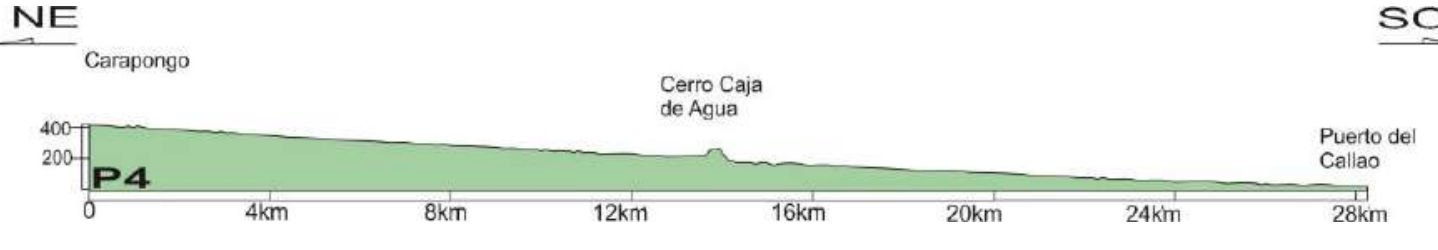

Figura 42. Perfil Carapongo-Puerto del Callao 


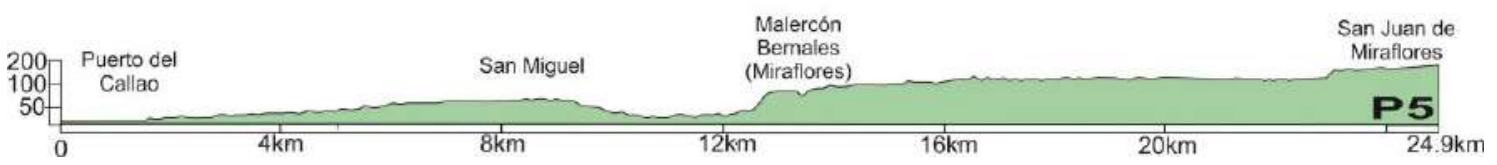

Figura 43. Perfil Puerto del Callao-San Juan de Miraflores 


\subsection{TRABAJO DE CAMPO}

\subsubsection{Validación de la cartografía geomorfológica.}

Se confirmaron In situ las geoformas identificadas en las fotos e imágenes correspondientes a la zona del abanico y alrededores. Se corroboraron diferentes niveles de terrazas fluviales, aluviales y coluviales.

Se ha recorrido desde el ápice hasta la desembocadura del río Rímac, pudiendo comprobarse la reducción de su ancho aproximadamente a la cuarta parte de su cauce natural, entre 1940 y la actualidad (Figura 44). En unas vistas tomadas en el propio cauce, a la altura de la desembocadura del rio Huaycoloro (Figura 45) se puede observar el tamaño métrico de las gravas que se encuentran en ese sector.

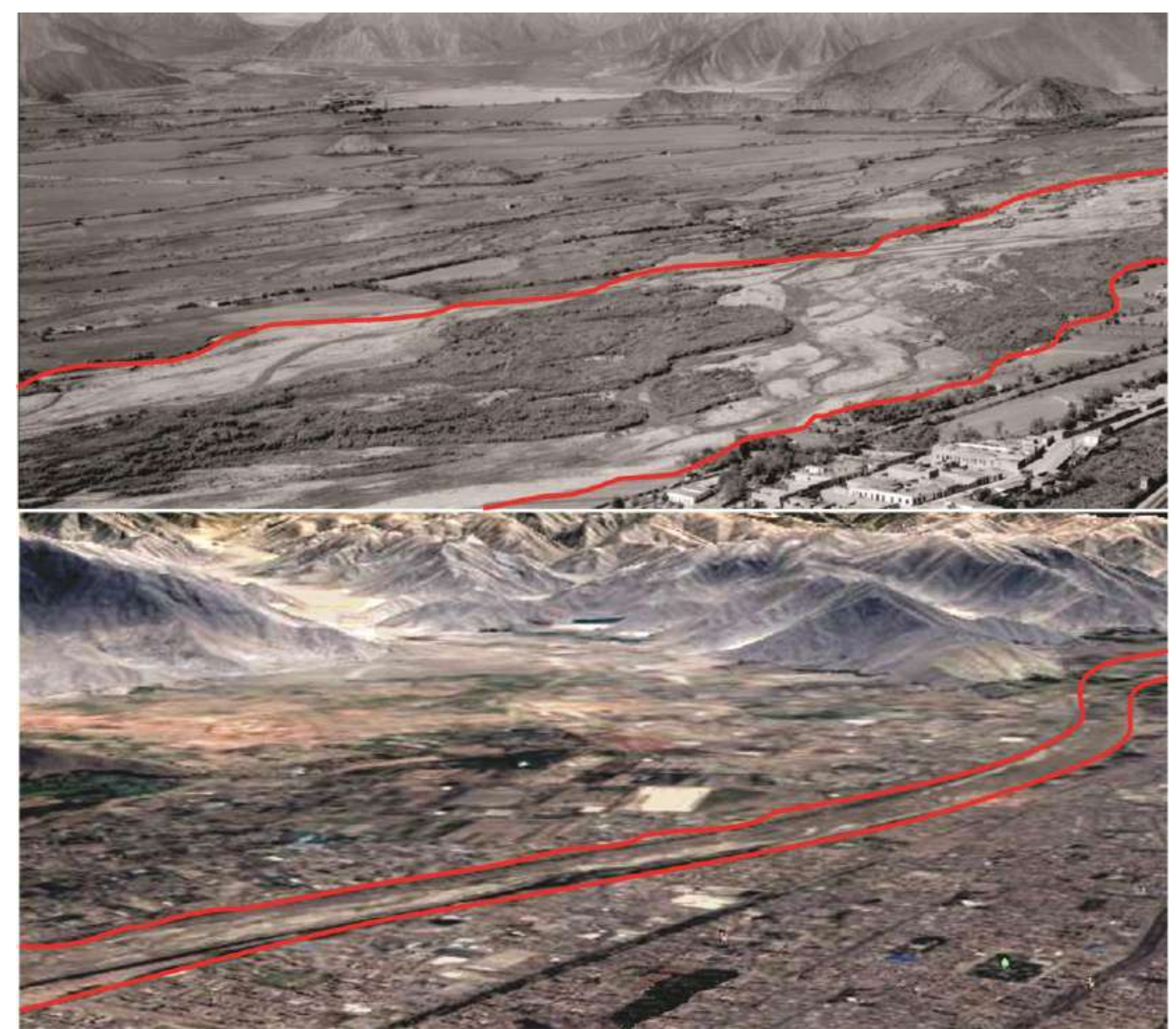

Figura 44. Reducción del ancho de cauce del río Rímac. Foto superiror: C, Wisse (1940); Abajo: imagen de Google Earth (2016). 

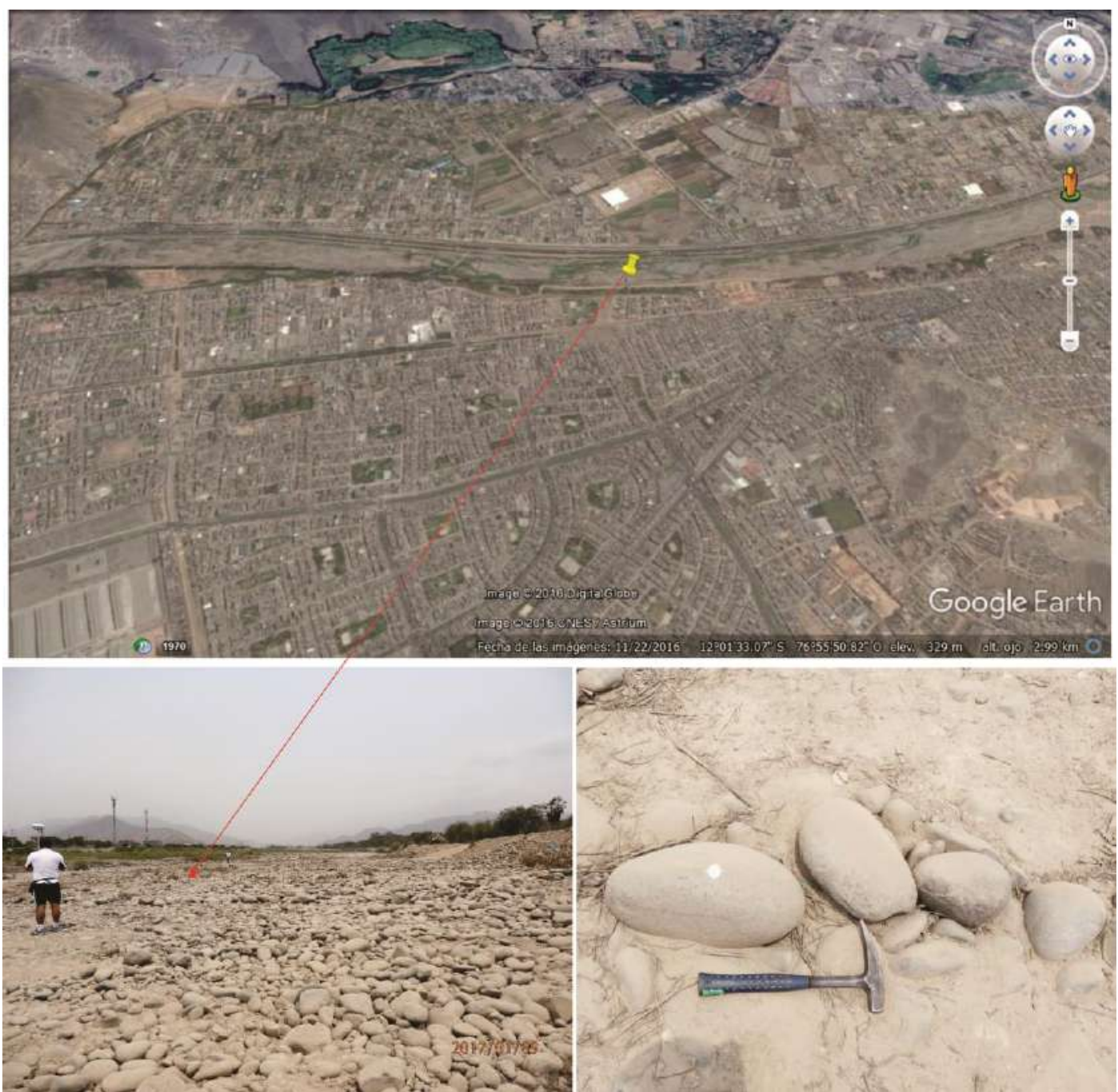

Figura 45. Material en el cauce del río Rímac a la altura del ápice (Ate)

\subsubsection{Cartografía estructural, tectónica y sedimentaria.}

Se realizó una interpretación de las imágenes satelitales, modelos de elevación digital y fotografías aéreas en relación a la identificación de alineamientos, así como formas de relieve en los alrededores del abanico de Lima. Dicha cartografía se verificó en campo para redefinir la información geomorfológica base.

De esta forma se pueden inferir algunos alineamientos que actualmente están cubiertos por depósitos recientes, poco visibles en campo debido a la expansión urbana, no observándose evidencias de los desplazamientos. Los alineamientos NOSE se identificaron hacia la zona norte del abanico por El Callao y cruzarían el río Rímac hacia San Miguel. Las montañas que rodean al abanico por el norte se cortan bruscamente y la dirección de las capas en las sedimentarias parecen algo rotadas 
con respecto a las capas en los cerros relictos en el centro del abanico y hacia al sur. Hacia el este, por la zona del ápice del abanico se identificó lineamientos NO-SE de menor ángulo (por ejemplo, a la altura de Barbadillo en ATE) (Foto 19). Otros alineamientos se extenderían con orientación NE-SO paralelos a los cursos alimentadores al río Rímac (quebrada Canto Grande y río Huaycoloro) y flanquearían al abanico por el este; y un alineamiento N-S habría condicionado la modificación del río Rímac haciendo que cambie de dirección a la altura de San Juan de Lurigancho (Zarate).

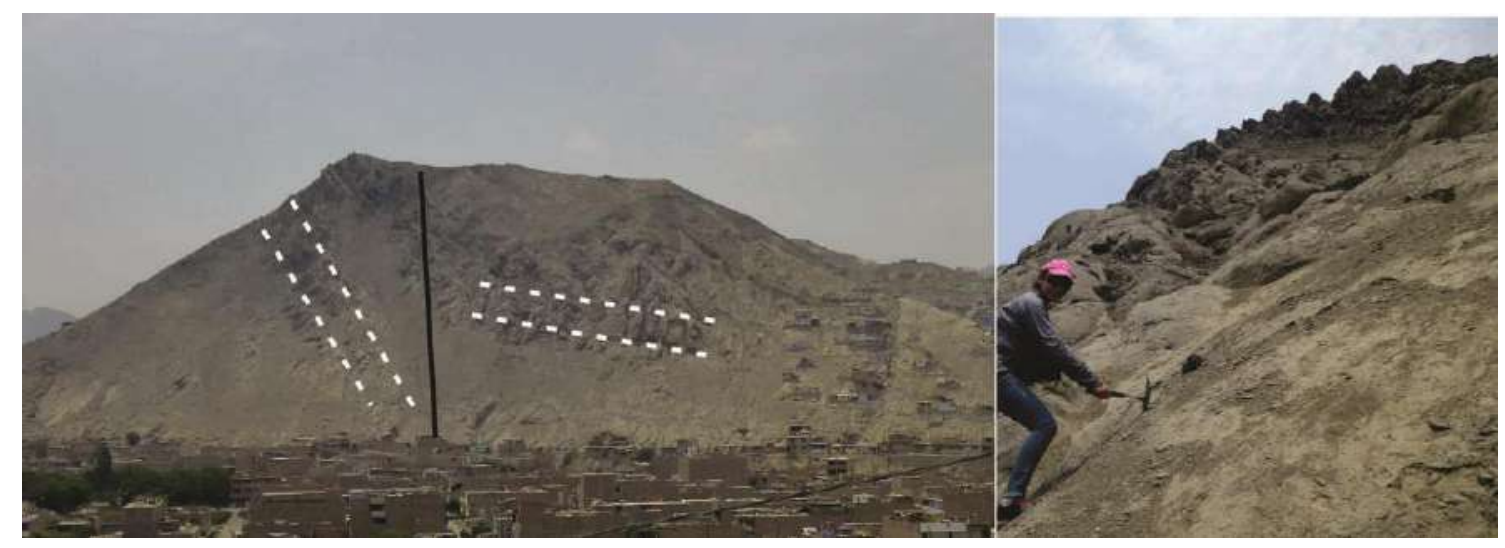

Foto 19. A) Falla en el sector Barbadillo (Ate) que corta intrusivos de la unidad Santa Rosa. B)

Plano de falla: Rumbo: $N$ 96 $\mathrm{Buz}: 61^{\circ} \mathrm{SW}$.

\subsubsection{Levantamiento de columnas estratigráficas}

Las columnas estratigráficas levantadas (anexo 5) han permitido identificar los procesos físicos que dieron lugar a los depósitos de paleo-eventos asociados al río Rímac. Esta información ha constituido la base para reconstruir la evolución geomorfológica del valle del río Rímac en el área de Lima Metropolitana. El levantamiento estratigráfico se efectuó en el área del acantilado de la Costa Verde, en el río Rímac a la altura de SEDAPAL, río Huaycoloro y la quebrada Melgarejo (La Molina).

Las estaciones evaluadas en la Costa Verde se ubicaron en Magdalena, Miraflores y Chorrillos.

La estación localizada en Chorrillos, zona sur del abanico, es adyacente a los afloramientos rocosos del Morro Solar. El perfil tiene unos 15 metros de altura (Figura 46). Allí se pudo observar una intercalación de gravas imbricadas y arenas dispuestas 
en capas estratificadas con algunos lentes arcillosos. Las gravas están compuestas por cantos redondeados semi-aplanados con formas pseudo-esféricas. La fábrica tiene soporte de clastos bien clasificados, que a su vez se hallan superpuestos en laminaciones cóncavas. Las arenas son gruesas con laminación horizontal, en forma de un tazón oblicuo. Igualmente, las arcillas muestran grietas de desecación (mud cracks) de hasta $1 \mathrm{~cm}$ de espesor y se hallan intercaladas con las facies arenosas.

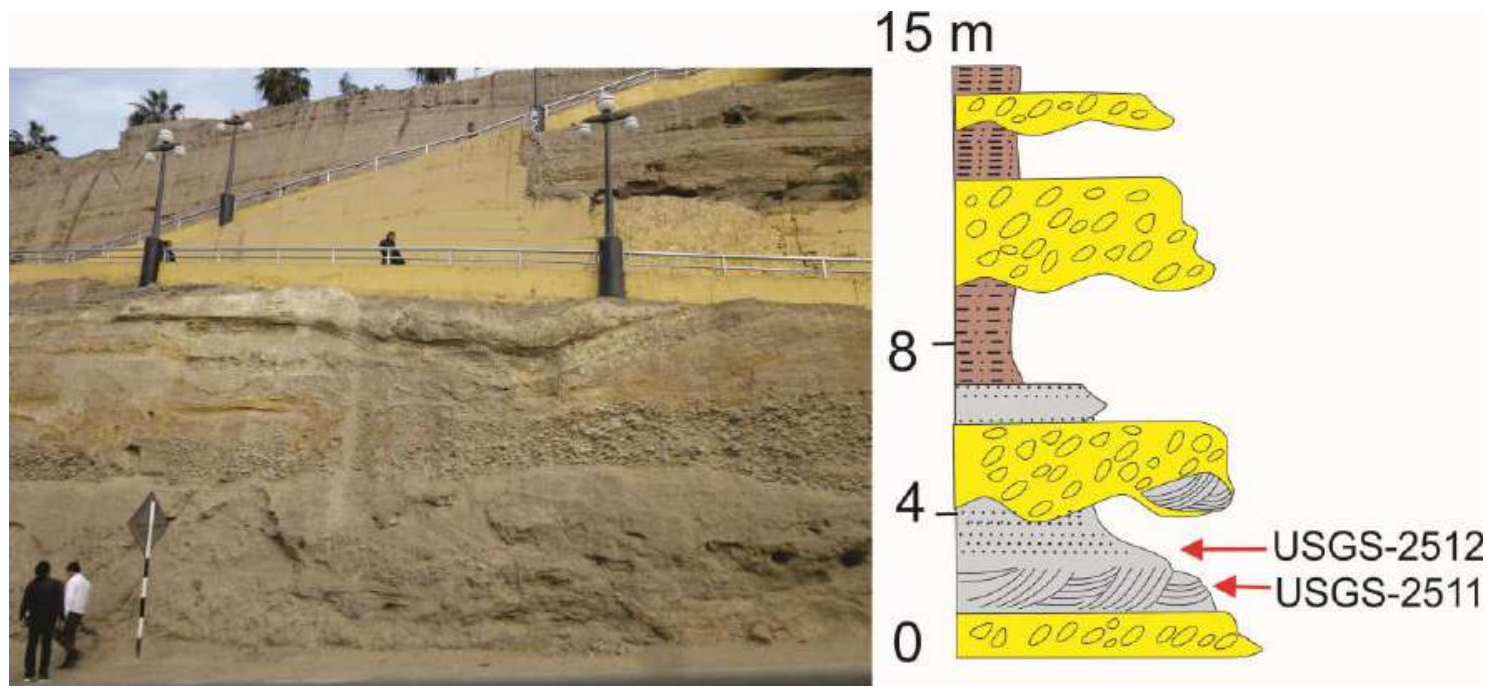

Figura 46. Sucesión observada en el club Regatas (Chorrillos). Se observa en la columna levantada las diferentes facies. grava (amarillo), arena (gris claro), arcilla (marrón).

En el área del río Huaycoloro se pudo observar materiales aluviales depositados por sucesivos episodios de flujos de detritos formando terrazas aluviales (Foto 20). La potencia estimada del material sedimentado es de 80 metros, visible en las canteras ubicadas en diferentes partes de la quebrada. El cauce principal recibe aporte de múltiples quebradas tributarias de menor longitud. 


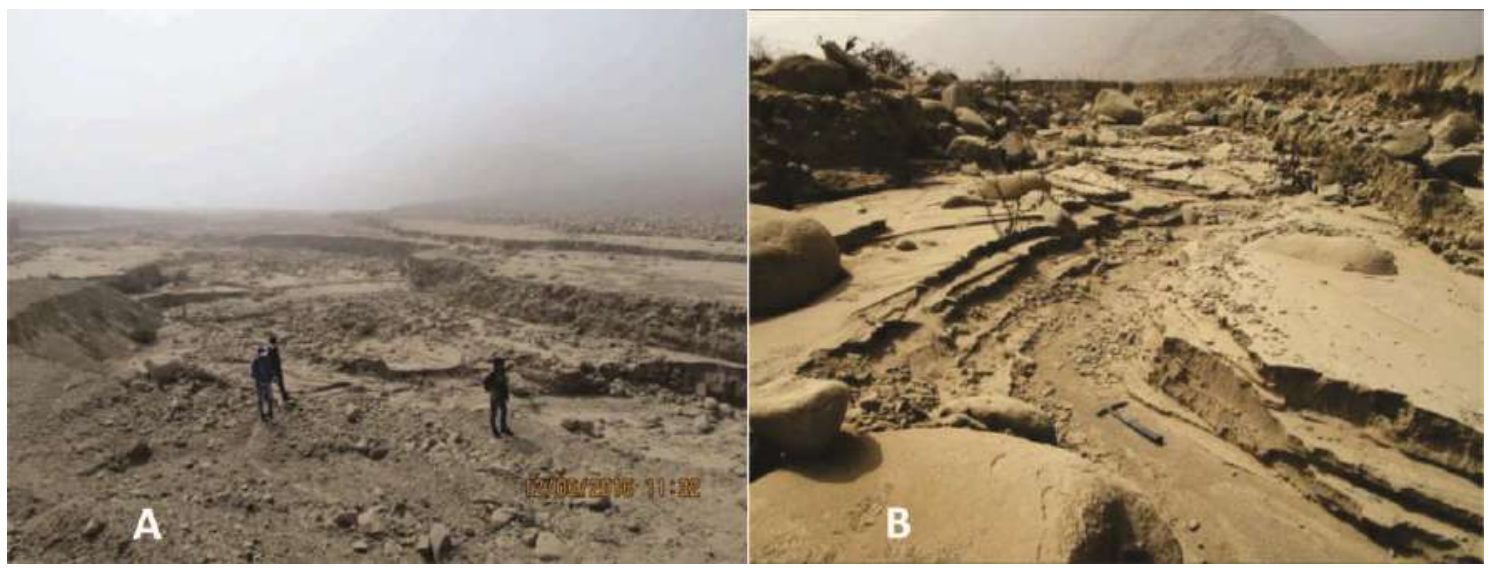

Foto 20. A, B. Terrazas depositadas en el área del río Huaycoloro como producto de diferentes episodios de flujos de detritos. Foto: Manrique, 2016.

La litología de los fragmentos incluidos en los depósitos aluviales del río Huaycoloro, son en su mayoría intrusivos y volcánicos.

Los fragmentos intrusivos son mayormente heterométricos, de formas semiesféricas $u$ ovaladas y con tendencia a la arenización por descascaramiento. Los bloques volcánicos observados suelen ser angulosos o sub-angulosos (Foto 21). El conjunto depositado ha originado estructuras sedimentarias definidas por la variada dinámica hidráulica y flujos sucesivos de huaycos.

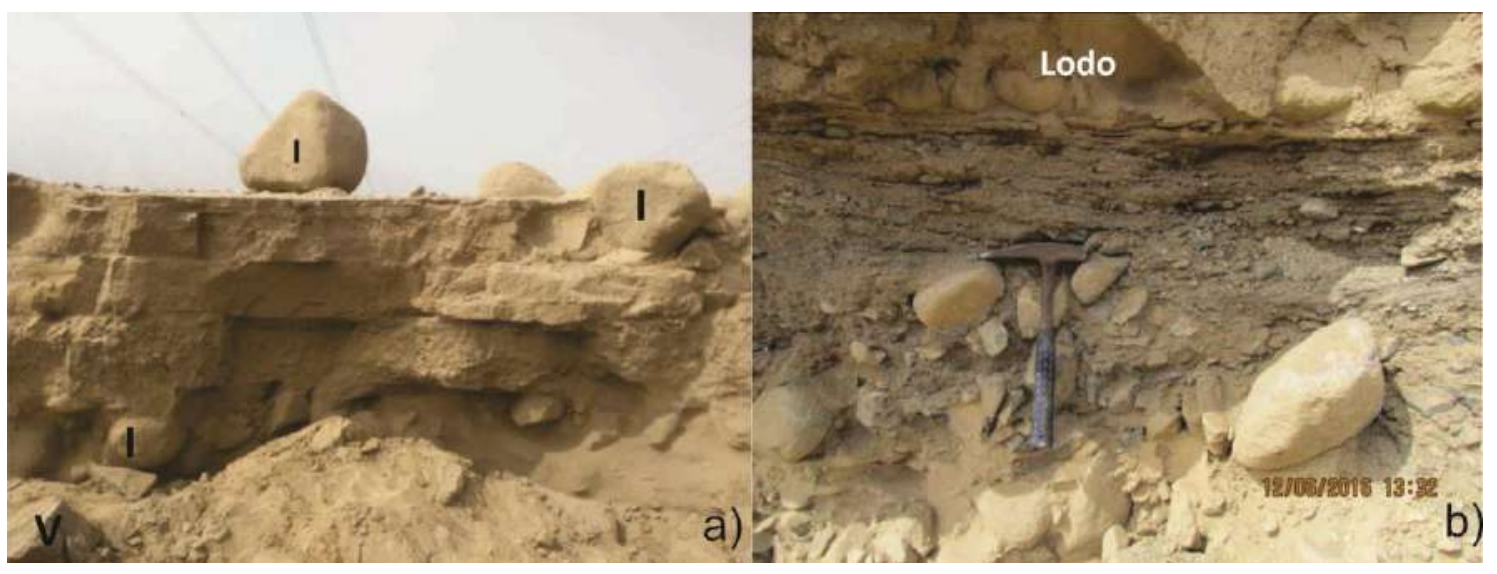

Foto 21. a) Flujos de detritos polimíctico que engloba bloques, bolones, detritos, arena, limos y arcillas. b) Predominan los clastos intrusivos (I) y volcánicos (v). Foto: Manrique, 2016.

Los flujos de material grueso se intercalan con capas delgadas de lodo que al secarse se quiebran dando formas poligonales debido a las grietas de desecación (Foto 22). Las grietas tienen forma de "V" y profundizan hasta la base de cada capa. 


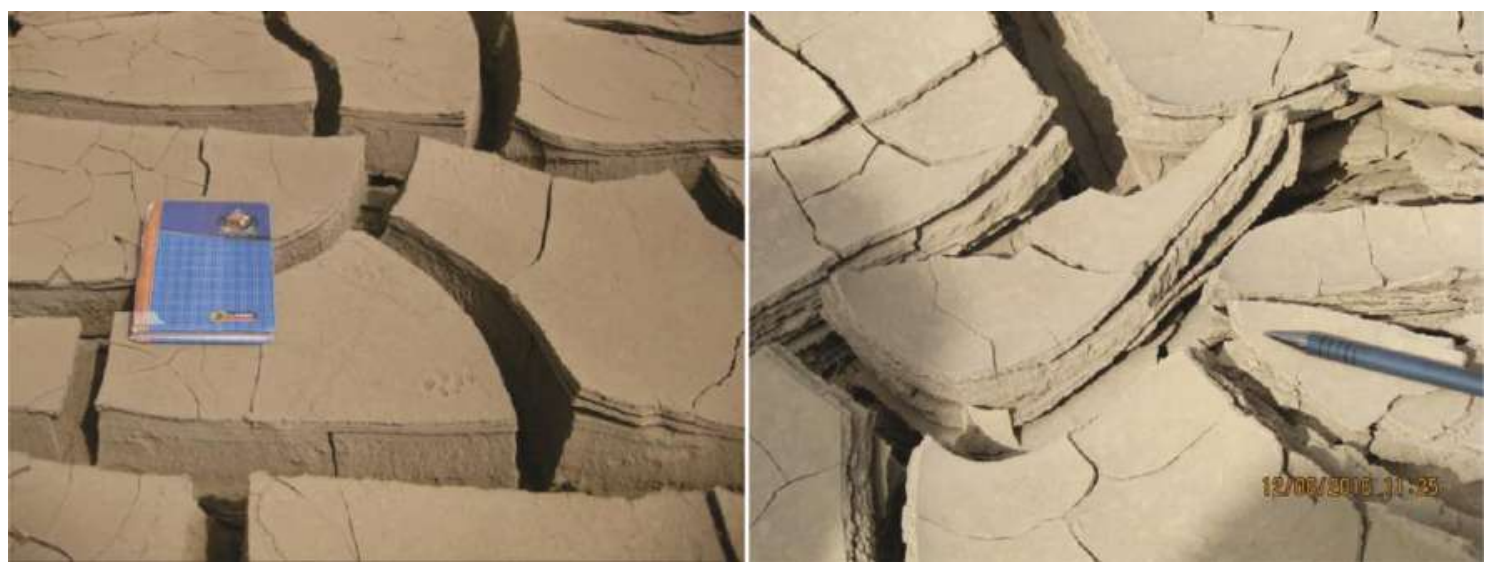

Foto 22. A, B. Capas de lodo transportadas por aguas turbias, sedimentadas en capas en ambientes de calma. En este tipo de materiales se producen las grietas de desecación. Foto: Manrique, 2016.

\subsection{CÁLCULOS HIDROLÓGICOS E HIDRÁULICOS}

Para el caso analizado en esta investigación, considerando la información disponible y las características del problema evaluado, se ha optado por emplear para el análisis hidrológico (Figura 47), el método racional modificado (Témez, 1991). En el estudio hidráulico se utilizó el software FLO2D.

Para el análisis hidrológico se recurrió en primer lugar a los datos históricos de lluvias proporcionados por el SENAMHI, así como a información de informes técnicos publicados por la ANA. 


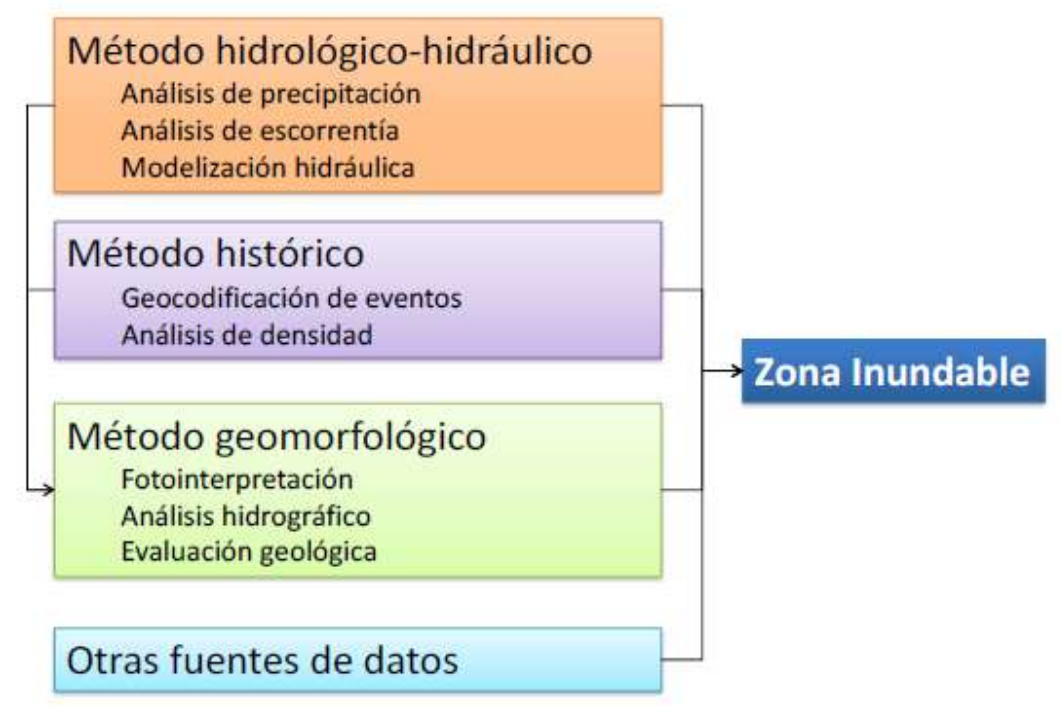

Figura 47. Esquema metodológico para el análisis de zonas inundables. Tomado de: Llorente (2014)

\subsubsection{Análisis de precipitaciones}

La información empleada fue la serie histórica de precipitaciones diarias registradas en 18 estaciones pluviométricas (Figura 48) que contaban con más de 10 años de datos continuos de acuerdo a lo recomendado por Llorente (2014). De las estaciones empleadas, 13 pertenecen a la cuenca del río Rímac, 03 en la cuenca del rio Chillón y 02 a la cuenca del río Lurín. Los datos (Anexo 1) corresponden al período comprendido entre los años 1979 y 2009 extraídos de ANA (2010) y los datos entre 2010 y 2015 proporcionados por el SENAMHI.

El análisis de la base de datos de lluvias se realizó mediante una hoja de cálculo Excel y luego se empleó el software Hydrognomon versión 4.0 y ArcGIS/ArcINFO en su versión 10.2.

De la base de datos completa de lluvias se extrajo el valor máximo en $24 \mathrm{~h}$ de cada mes que permitió calcular el dato máximo anual que se analizó en el software Hydrognomon versión 4.0.

\subsubsection{Análisis de la serie de datos de precipitación}

Para conocer en qué condiciones se encontraba de la serie de datos, en primer lugar, ha sido necesario la obtención de los momentos estadísticos de la serie de datos 
evaluada: media, desviación estándar, sesgo, varianza, máximo, mínimo, los cuales se pueden ver en el anexo 1. El promedio de los valores máximos de la serie completa empleada es de $40 \mathrm{~mm}$ y el de los mínimos de $6 \mathrm{~mm}$.

El análisis estadístico de las condiciones de la serie permitió filtrar las estaciones descartando las no fiables por sus inconsistencias. Debido a que las 18 estaciones elegidas no cubrían el área total de la cuenca del río Rímac en su totalidad. se procedió a buscar datos de apoyo adicionales, para lo cual se empleó el Modelo internacional ERA-Interim Reanalysis generado por el European Centre for Medium Range Weather Forecasts-ECMWF (Dee et al., 2011) que no alteró significativamente el resultado (no cambiaron los momentos estadísticos representativos).

Los datos de re-análisis han demostrado ser útiles para completar información climática basada en el modelamiento y diagnóstico, así como estudios sinópticos (Andres, Vegas, Lavado, \& Zappa, 2014; Olave, 2015). En este trabajo, los datos de lluvias diarias derivados del modelo internacional ERA-Interim cubren el periodo desde 1979 hasta la actualidad y corresponden a una resolución temporal de 24 horas. Se eligió una malla espacial de $0,4 \times 0,4^{\circ}$.

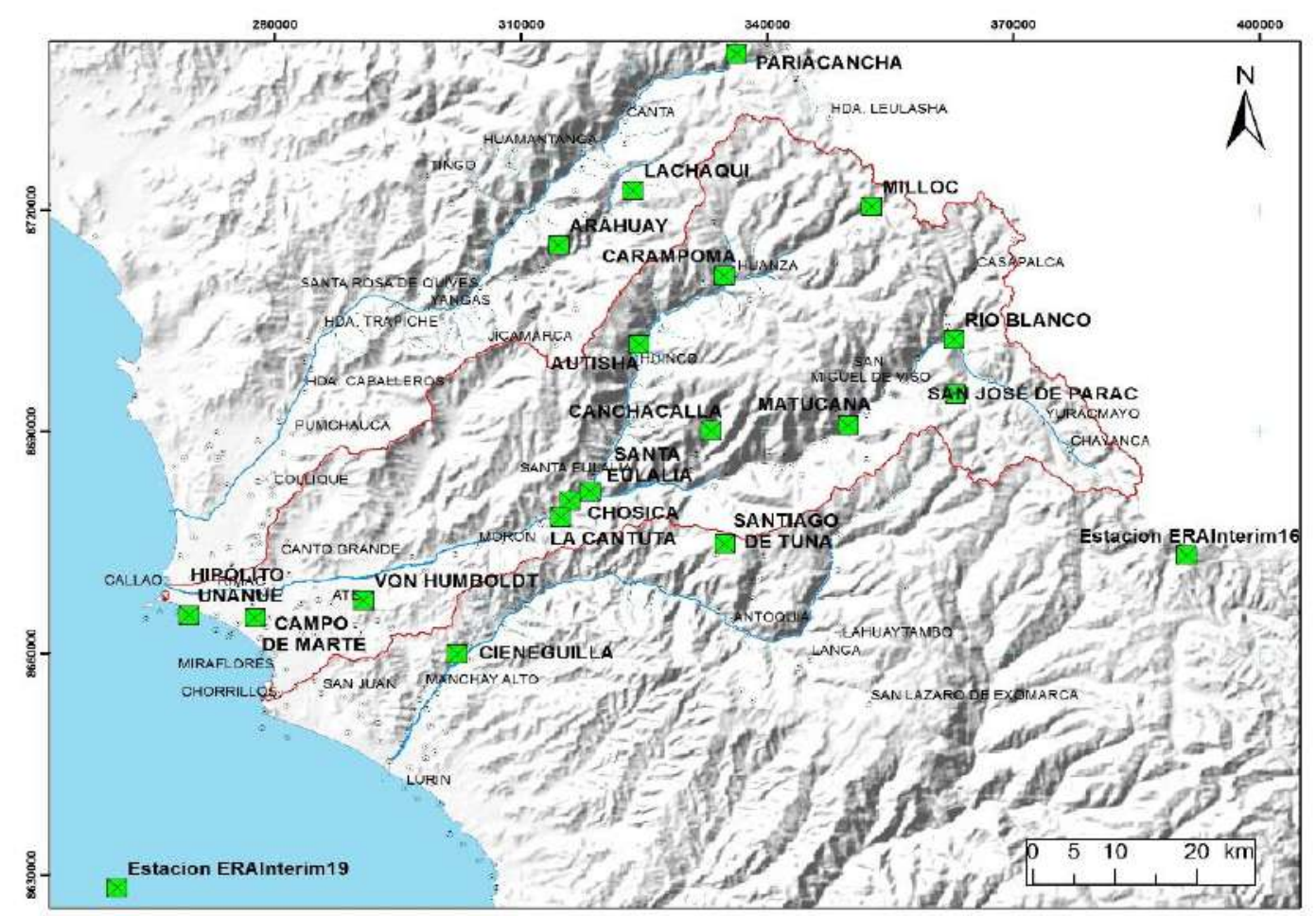

Figura 48. Ubicación de las estaciones meteorológicas empleadas en este estudio. 
4.3.1.2 Ajuste de la probabilidad muestral a una función

A continuación, se procedió con la aproximación numérica a una función para obtener valores fuera del rango muestreal. Para esto se empleó el software Hydrognomon versión 4.0 (Kozanis, Christoforides, \& Efstratiadis, 2010). La información de la precipitación máxima diaria se sometió al test kolmogorov-smirnov para evaluar cuáles eran las funciones de probabilidad (curvas de ajuste, Tabla 6) más adecuadas para obtener valores fuera de la serie y calcular escenarios de precipitaciones máximas en diferentes periodos de retorno en el área de la cuenca del río Rímac.

Tabla 6. Funciones de ajuste empleadas para cada estación evaluada en la cuenca del río Rímac

\begin{tabular}{|l|l|}
\hline Estación & Función de ajuste \\
\hline Campo de Marte & GEV Min (L-moments) \\
\hline Von Humboldt & GEV Max (L-moments) \\
\hline Hipólito Unanue & GEV Max (L-moments) \\
\hline Cieneguilla & Log Pearson III \\
\hline Chosica & $\begin{array}{l}\text { GEV MAX (kappa specified, L- } \\
\text { moments) }\end{array}$ \\
\hline La Cantuta & Log Pearson III \\
\hline Santa Eulalia & Exponential (L-moments) \\
\hline Canchacalla & Exponential (L-moments) \\
\hline Matucana & GEV Min (L-moments) \\
\hline Arahuay & GEV Min (L-moments) \\
\hline Río Blanco & EV2-Max \\
\hline Pariacancha & GEV Min (L-moments) \\
\hline Autisha & GEV Min \\
\hline Lachaqui & EV2-Max (L-moments) \\
\hline Carampoma & EV1-Max (Gumbel, L-moments) \\
\hline Santiago de Tuna & Gamma \\
\hline San José de Parac & EV3-Min (Weibull, L-moments) \\
\hline Milloc & $\begin{array}{l}\text { GEV MAX (kappa specified, L- } \\
\text { moments) }\end{array}$ \\
\hline
\end{tabular}

\subsubsection{Regionalización}

En este caso, se efectuó una primera aproximación interpolando con ArcGis módulo 3D analysis IDW y se obtuvieron modelos de precipitaciones máximas diarias para periodos de retorno eligiéndose como período de retorno 500 (Figura 49) por ser el más empleado para el análisis de peligrosidad por inundaciones. Sin embargo al detectar algunas inconsistencias en los datos (picos inciertos), se procedió a la 
revisión de anomalías y se empleó cokriging, intentando una mejora en los modelos resultantes empleando las variables precipitación y altura (Figura 50). Al incluir las altutitudes se obtuvo un modelo más realista pues la precipitación y la altitud están relacionadas proporcionalmente.

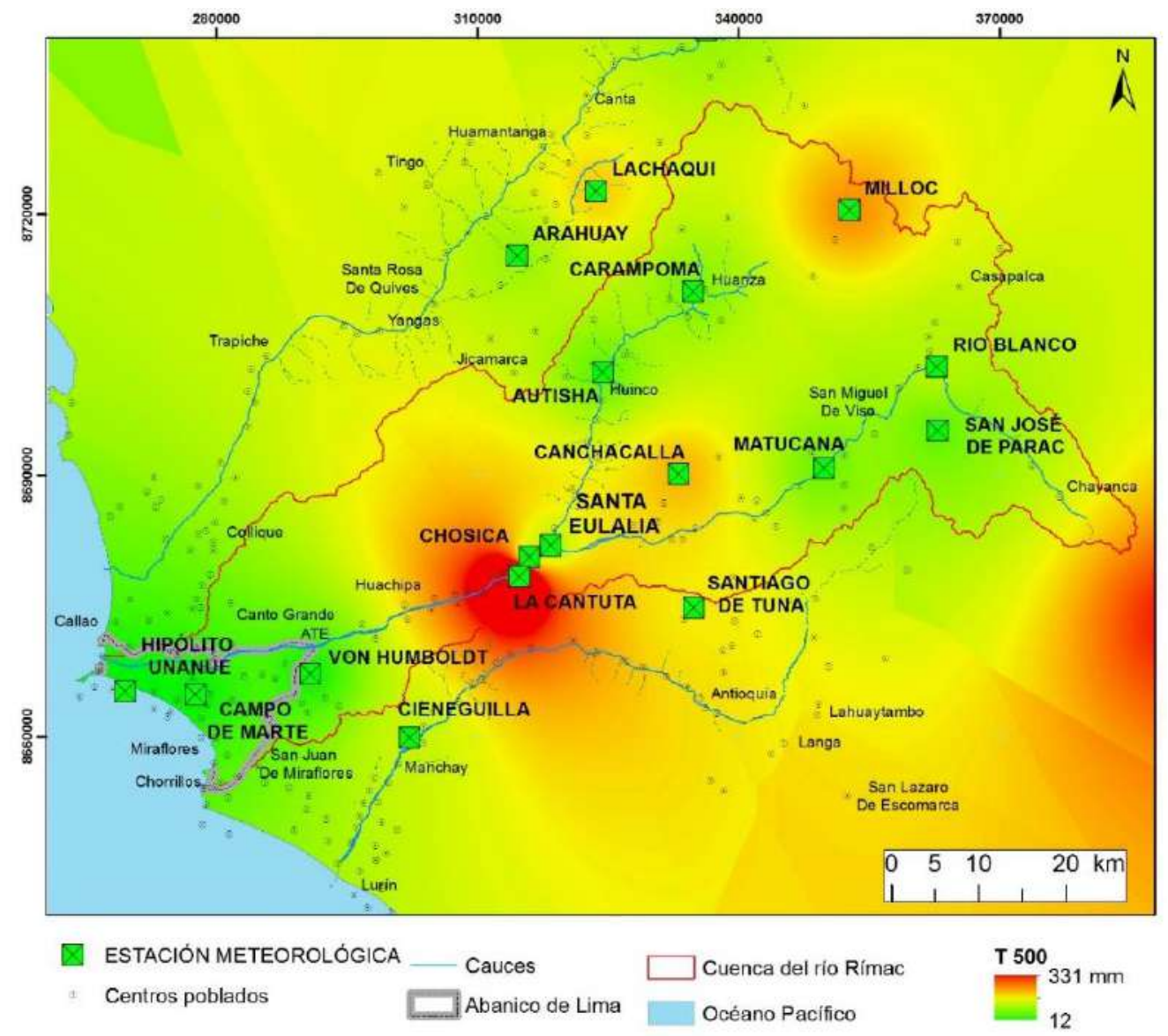

Figura 49. Estimación con IDW de la precipitación máxima diaria para un periodo de retorno de 500 años en el área de cuenca del río Rímac 


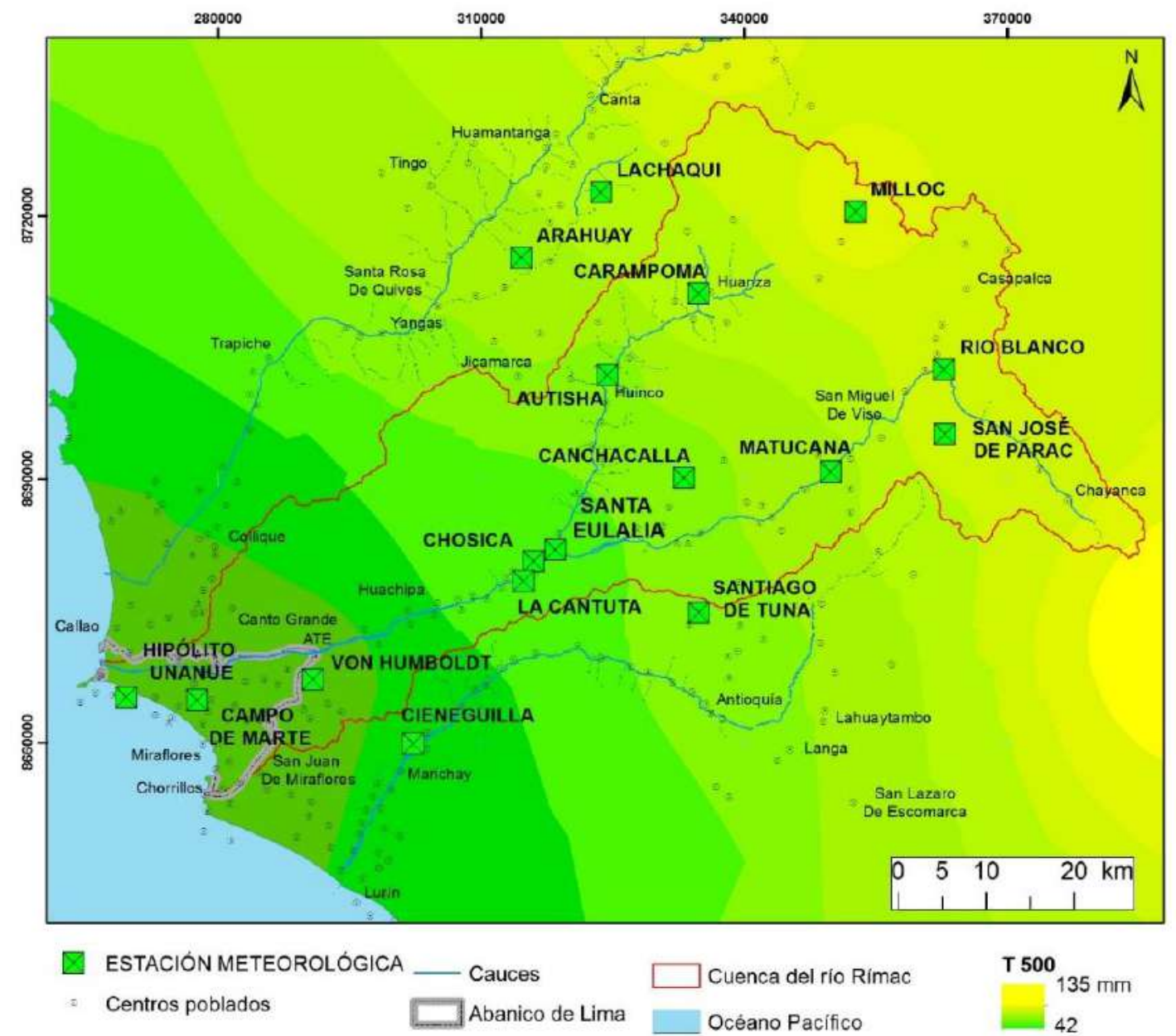

Figura 50. Modelo de precipitación máxima diaria para un periodo de retorno de 500 años en el área de la cuenca del río Rímac empleando cokrigeado precipitación-altitud.

\subsubsection{Intensidad de las precipitaciones}

Con el tratamiento de los datos de precipitación señalados anteriormente se obtuvieron las curvas IDF, una estimación de lluvias correspondiente a otros intervalos. Se ha corroborado el resultado tomando en cuenta lo publicado al respecto en el Manual de carreteras de Perú: Hidrología, Hidráulica y Drenaje (Ministerio de Transportes y Comunicaciones, 2014).

\subsubsection{Cálculo del CN}

Para calcular el CN del área de estudio se ha empleado el software ArcGis versión 10.3 y la siguiente información:

- Mapa de pendientes reclasificado (pendientes mayores al 3\% y el resto) 
- Características hidrológicas de los materiales de cobertura (descritas en el acápite 3.3.2, Figura 28).

- Tipos y usos de suelo. A las subclases del mapa de uso del suelo (Figura 29) intersectado con los grupos hidrológicos de suelo se le asignaron los valores de la tabla 7 que corresponden al umbral de escorrentía para condiciones medias de humedad (Mockus, 1972; Boughton, 1989; Mishra, Takara \& Tachikawa, 2008).

Se observa en el mapa resultante (Figura 51) que los valores de CN varían entre 0 (zonas que no generan escorrentía) y 98 (áreas con roca en superficie y vegetación nula).

Tabla 7. Valores del umbral de escorrentía para condiciones medias de humedad- asociación con grupo hidrológico y cobertura del terreno empleados para la cuenca Rímac (modificado de (Mockus, 1972; Boughton, 1989; Mishra et al., 2008)

\begin{tabular}{|r|l|r|r|r|r|}
\hline Uso de Suelo & \multicolumn{4}{l|}{ Grupo hidrológico } \\
\hline LUValue & Descripción & A & B & C & D \\
\hline 1 & Bosques y arbustos & 43 & 65 & 76 & 82 \\
\hline 2 & Residencial & 68 & 80 & 88 & 94 \\
\hline 3 & Tierra de cultivo de valle & 49 & 69 & 79 & 84 \\
\hline 4 & Andenes de cultivo & 65 & 74 & 82 & 86 \\
\hline 5 & Matorrales/Malezas tundra & 48 & 67 & 0 & 83 \\
\hline 6 & Glaciar/Arroyo/lago & 0 & 0 & 0 & 0 \\
\hline 7 & Reservorio & 98 & 98 & 98 & 0 \\
\hline 8 & Roca expuesta & 98 & 98 & 98 & 98 \\
\hline 9 & Vias pavimentadas & 77 & 86 & 91 & 98 \\
\hline 10 & Minas, canteras y otros & & 0 & 98 \\
\hline
\end{tabular}




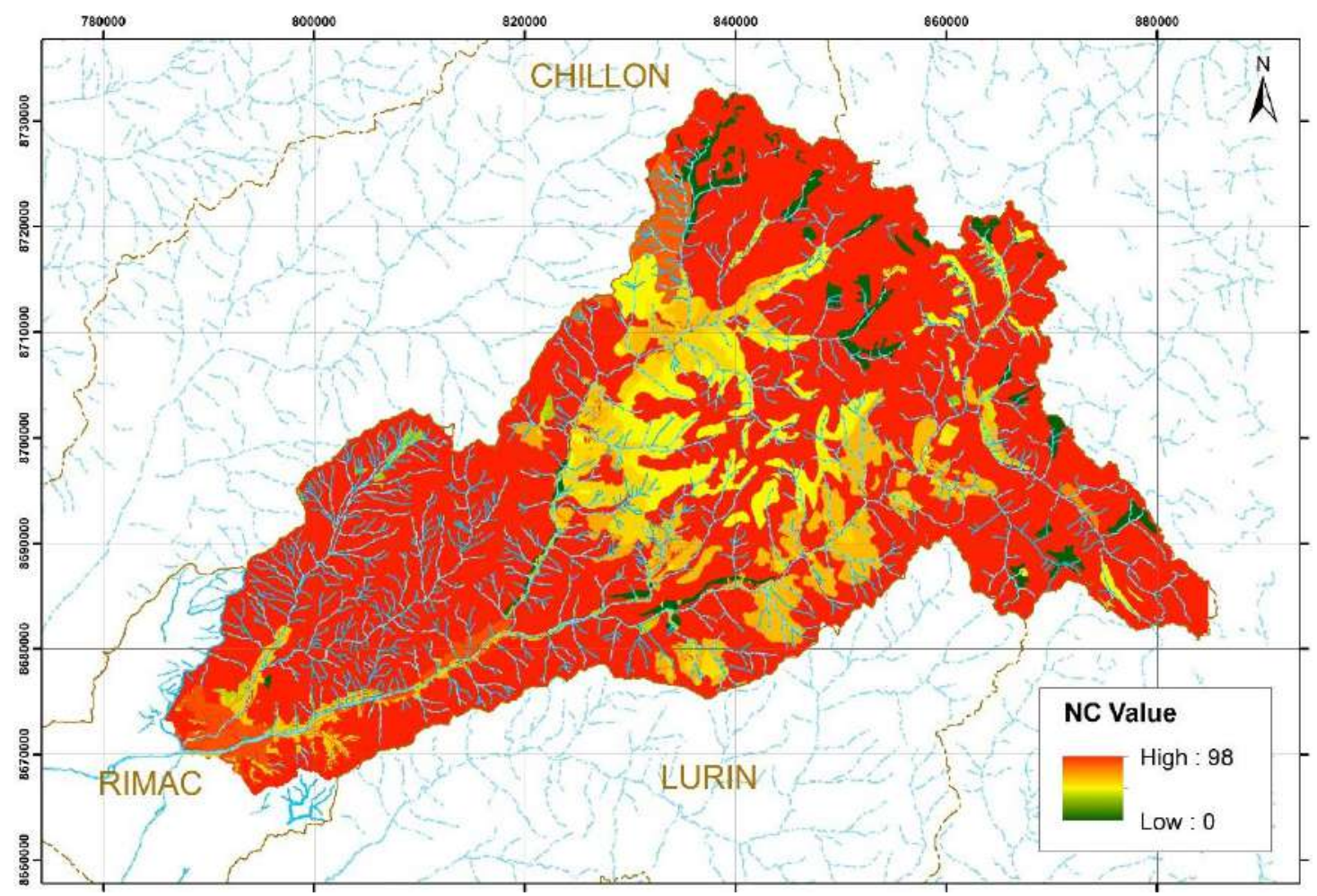

Figura 51. Numero de curva para la cuenca del río Rímac

De acuerdo a esto, en promedio para la cuenca a evaluar con desfoguen en el ápice del abanico se obtuvo un valor de $\mathrm{CN}$ de 85, lo cual es consistente con los datos empleados por otros estudios en Perú (Bernabé, 2010; Ministerio de Transportes y Comunicaciones, 2014).

\subsubsection{Análisis hidrológico-hidráulico}

Con el objeto de reconstruir los aspectos hidrológicos de una paleo-inundación en la cuenca del río Rímac, tales como el caudal asociado al flujo de material que dio origen a las terrazas aluviales observadas en campo; se realizó la modelización hidráulica del cauce. Ante la ausencia de estaciones de aforo, pues únicamente existe una estación de caudales en Chosica (fuera del área del abanico de Lima), se optó por emplear el modelo hidrológico de cálculo de caudales máximos diarios para un periodo de retorno de 500 años el cual se contrastó con el caudal obtenido empleando el método hidráulico (fórmula de Manning). 
4.3.5.1 Cálculo hidrológico del Caudal para un periodo de retorno de 500 años

Para el caculo del caudal hidrológico para un periodo de retorno de 500 años se empleó el método racional y los datos de la Tabla 8 . El caudal pico ha resultado en $583.9 \mathrm{~m}^{3}$ y ha permitido construir el hidrograma de la Figura 52.

Tabla 8. Datos empleados para calcular el caudal máximo para un periodo de retorno de 500 años mediante el método hidrológico

\begin{tabular}{|c|c|c|}
\hline \multicolumn{3}{|l|}{ Datos de entrada } \\
\hline Long cauce & 253 & $\mathrm{~km}$. \\
\hline Cota max & 5575 & $\mathrm{M}$ \\
\hline Cota min & 325 & $\mathrm{M}$ \\
\hline Superficie & 3051 & $\mathrm{~km}^{2}$ \\
\hline Precipitación & 24,1 & $\mathrm{Mm}$ \\
\hline Duración P neta & 2 & $\mathrm{H}$ \\
\hline Caudal pico & \multicolumn{2}{|c|}{$583,9 \mathrm{~m}^{3} / \mathrm{s}$} \\
\hline
\end{tabular}

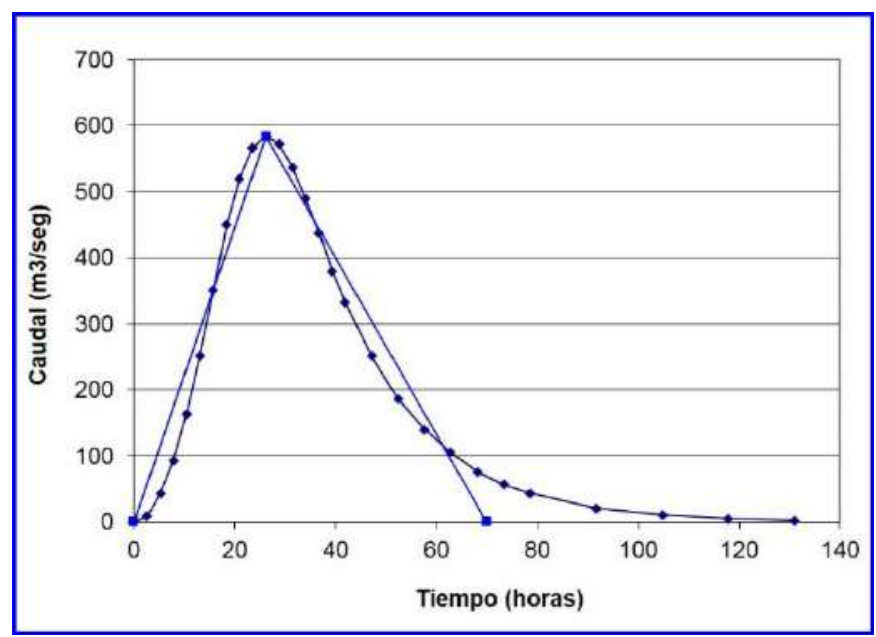

Figura 52. Hidrograma líquido de la sección en el punto Tokio y Los Laureles para un periodo de retorno de 500 años en la cuenca del río Rímac.

Cabe mencionar que la Autoridad Nacional del Agua, (2012) tomando datos desde el año 1912 hasta 1964 y de 1965 al 2009 calculó los caudales máximos para diferentes periodos de retorno en la estación de Chosica y obtuvo para un periodo de retorno de 500 años $497.4 \mathrm{~m}^{3} / \mathrm{s}$.

Asimismo, en el estudio de Bernabé (Bernabé, 2010)(2010) se hallaron los siguientes caudales máximos para un periodo de retorno de 500 años: $108.00 \mathrm{~m}^{3} / \mathrm{s}$ para la 
subcuenca del rio Blanco, $147.00 \mathrm{~m}^{3} / \mathrm{s}$ para la subcuenca Alto río Rímac, $108.00 \mathrm{~m}^{3} / \mathrm{s}$ para la subcuenca de la quebrada Párac y de $399.20 \mathrm{~m}^{3} / \mathrm{s}$ para la subcuenca del río Santa Eulalia.

Otro dato relevante ha sido obtenido por Apaclla (2010) quien, en base al análisis de datos pluviométricos del período 1984 a 2009, obtuvo caudal para un periodo de retorno de 200 años, de 145,37 m³/s (estación Chosica).

Finalmente, revisando los valores de la serie histórica de caudales en la estación Chosica entre 1920 y 2012 se observa que el máximo histórico recojido en aforos es de $325 \mathrm{~m}^{3} / \mathrm{s}$.

\subsubsection{Cálculo hidráulico del Caudal en una sección tipo}

Para este cálculo se tomó en cuenta la ecuación de Manning y se empleó un perfil representativo, el cual se midió en el campo con GPS diferencial. Se estableció el perímetro húmedo del perfil a analizar relacionado a las terrazas aluviales más elevadas. Para elegir los perfiles de control se ha tomado en cuenta datos de referencia a inundaciones en este sector del río Rímac (Villacorta et al., 2015). De esta forma, se eligió el sector de Tokio y Los Laureles (Huachipa-ATE, Figura 53) donde se reconocieron desbordes en febrero de 1998. El punto es cercano al área del ápice del abanico y muestra evidencias de materiales fluviales nos datados correspondientes a desbordes que habrían sucedido en el pasado. Asimismo, se reconoce allí el contacto entre los aluviales del río Huaycoloro y los fluviales del río Rímac (Figura 54) sobre un lecho rocoso (no móvil). Las alturas máximas alcanzadas por el agua se establecieron con datos proporcionados por la población que declaró se habría alcanzado 2 a $3 \mathrm{~m}$

sobre el cauce actual en 1998 En la 
Tabla 9 se muestran los datos de entrada para el análisis efectuado.

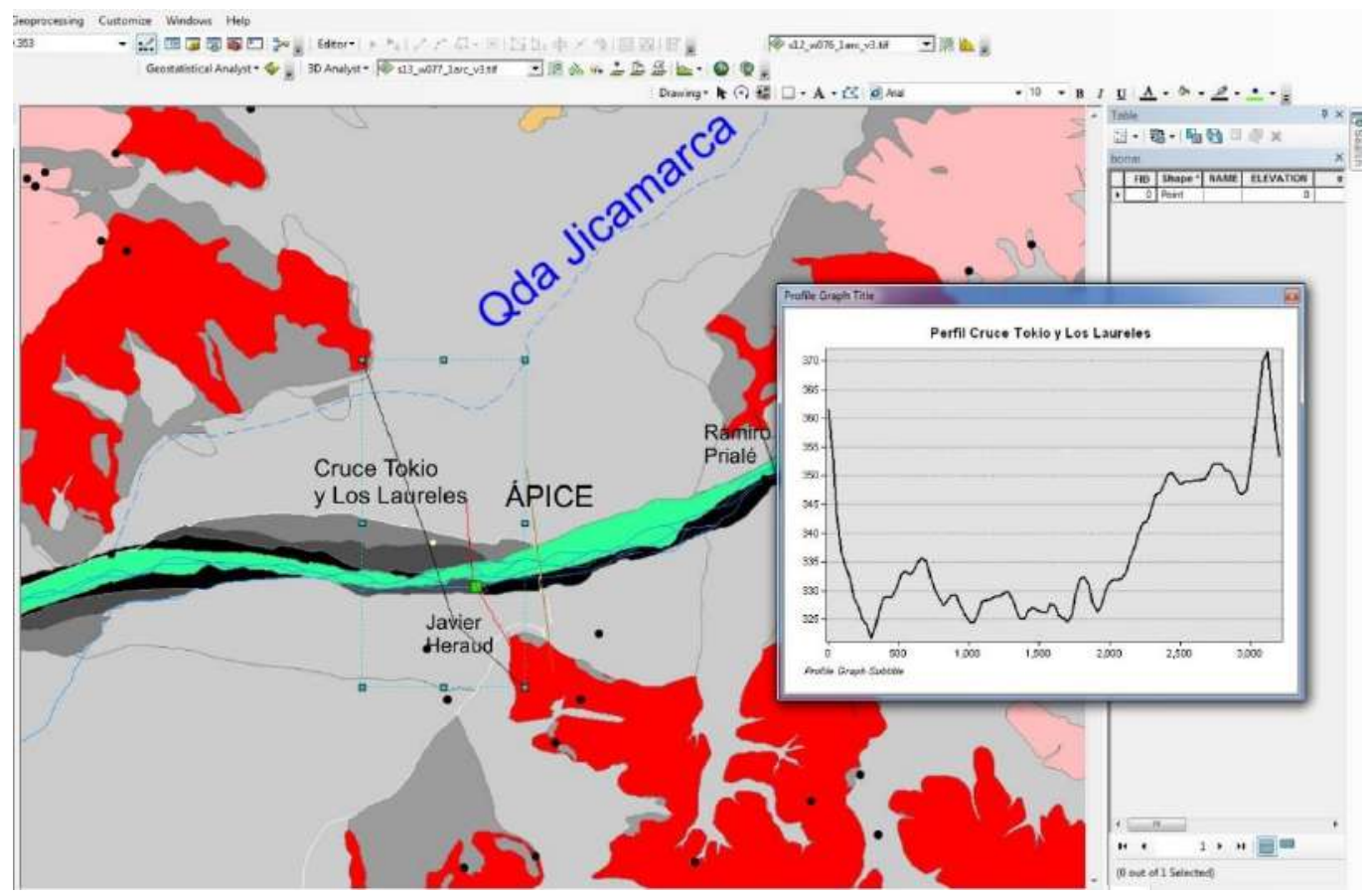

Figura 53. Localización del perfil representativo Sector denominado Tokio y Los Laureles.

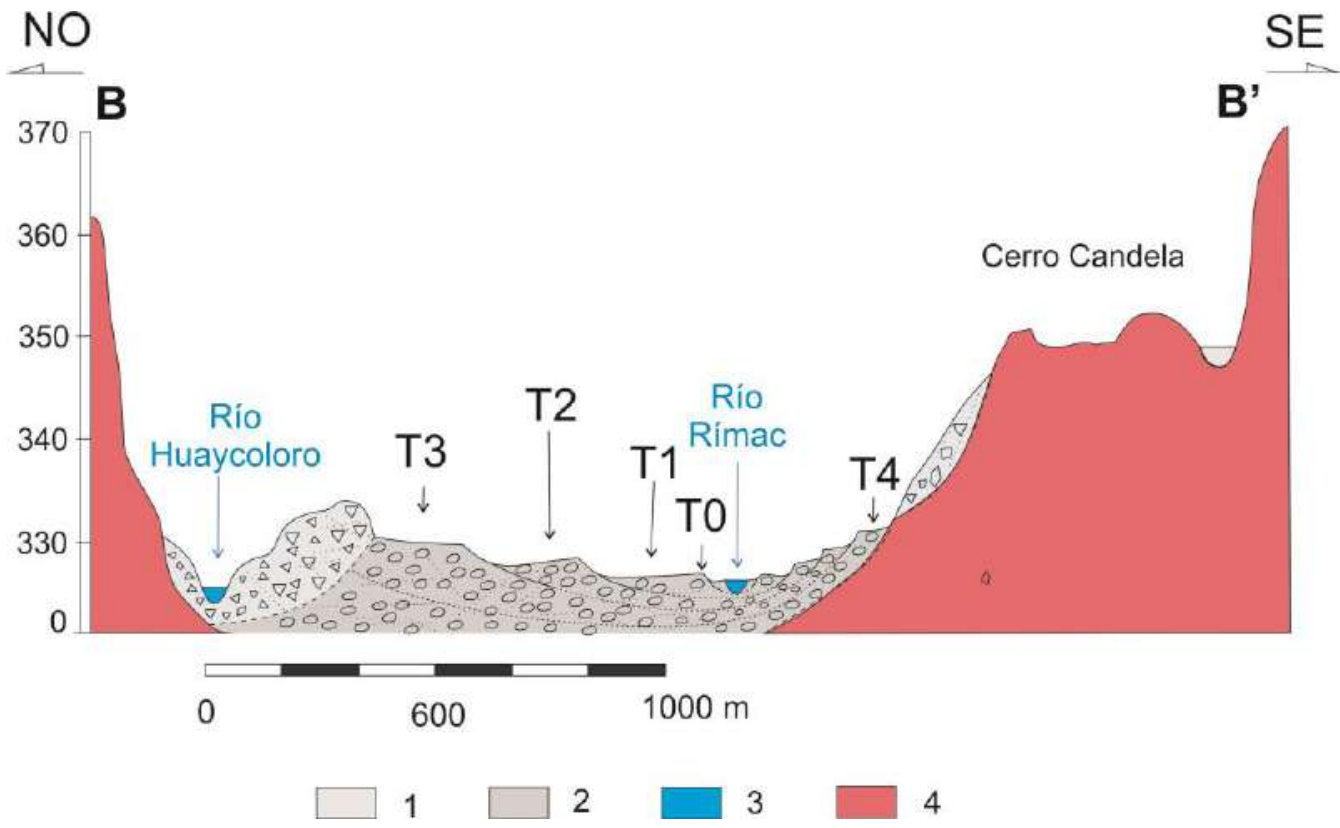

Figura 54. Sección transversal esquemática del sector Tokio y Los Laureles (a la altura del cerro Candela, ATE). 1. Depósitos aluviales, 2. Depósitos fluviales, 3. Cauce actual,4. Substrato intrusivo 
Tabla 9. Datos de entrada para calcular el caudal crític en el sector

Tokio y Los Laureles (modelo hidráulico)

\begin{tabular}{|l|l|}
\hline Rugosidad & 0,175 \\
\hline Pendiente promedio (cauce principal) $\mathrm{m}$ & 0,048 \\
\hline Area de la cuenca hasta confluencia $\left(\mathrm{km}^{2}\right)$ & 3051 \\
\hline Área de la sección $\left(\mathrm{m}^{2}\right)$ & 7894 \\
\hline Perímetro mojado $(\mathrm{m})$ & 1404,6 \\
\hline Rádio hidráulico $(\mathrm{m})$ & 5,6201 \\
\hline Longitud cauce $(\mathrm{km})$ & 112 \\
\hline Tc (tiempo de concentración) h & 19,28 \\
\hline
\end{tabular}

\subsubsection{Simulación numérica de flujos híper-concentrados e inundaciones}

Con la información anterior se establecieron las condiciones de contorno para efectuar la modelización numérica por flujos de detritos en el río Rímac desde el ápice hasta la desembocadura. Después de evaluar varios software se eligió el FLO2D, el cual cuenta con buena experiencia de calibración en Perú y Suramérica (Castillo Navarro, 2006; Gamión \& Jhon, 2014; Lacho \& Rodríguez, 2016; Ore, 2016)

Algunos datos incorporados al modelo efectuado, como los parámetros de resistencia laminar del lecho, han sido tomados de anteriores simulaciones por flujos de detritos en FLO2D efectuados en Lima Metropolitana (Lacho \& Rodríguez, 2016).

\subsubsection{Descripción del proceso de simulación}

El primer paso para la simulación por flujos de detritos fue procesar la topografía existente mediante SIG, para luego exportarla al pre-procesador del FLO2D: Grid Developer System (Figura 55). El área fue delimitada con ayuda del MDT e imágenes satelitales. Se empleó un node spacing de $10 \times 10$. 


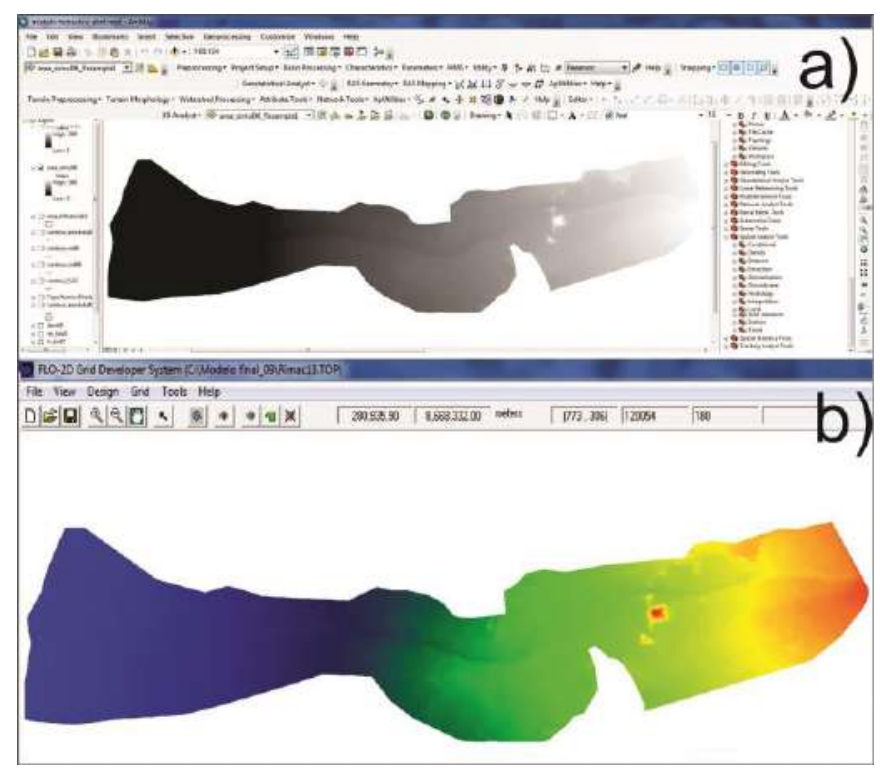

Figura 55. MDT exportado desde ArcGIS (a) al GDS del FLO-2D (b).

A continuación se definieron las condiciones de contorno aguas arriba y aguas abajo (figura 56), donde se ingresó el hidrograma calculado (Figura 57).

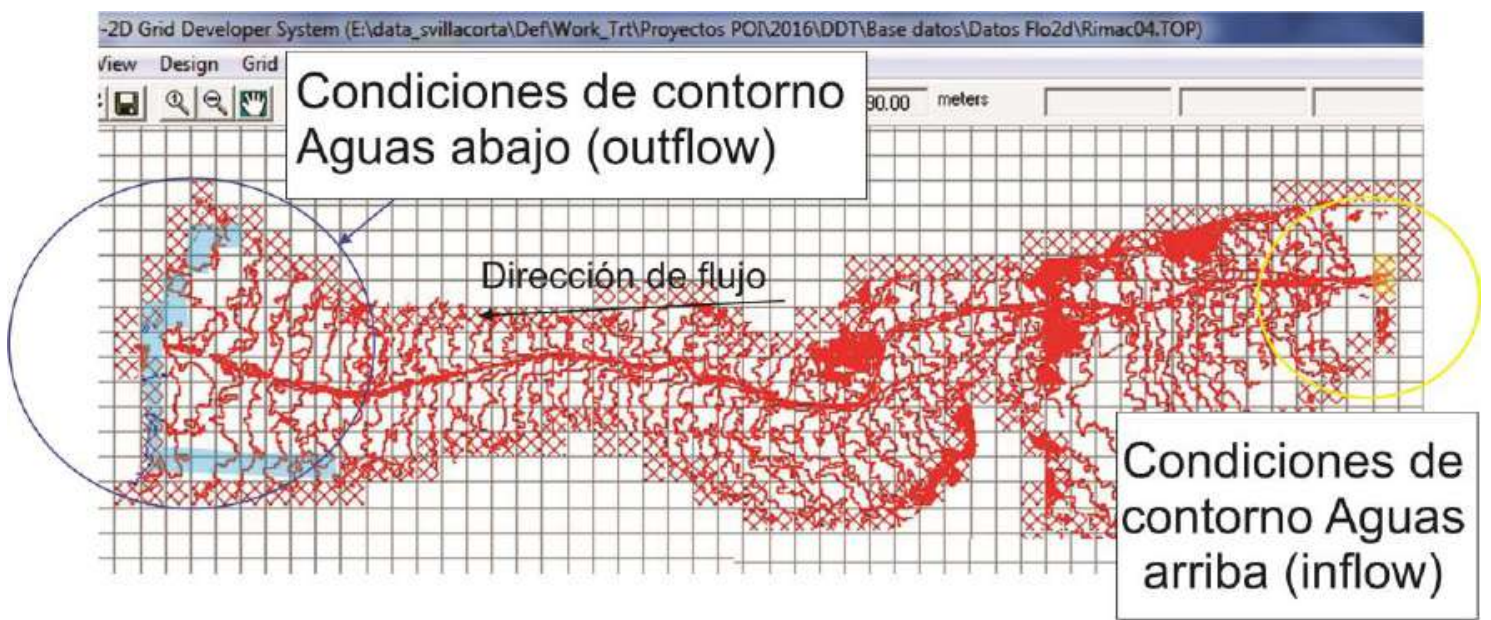

Figura 56. En el círculo verde se observan las condiciones de contorno de de entrada (inflow) con los datos del hidrograma.y en el circulo rojo lascondiciones de contorno de salida (outflow). 


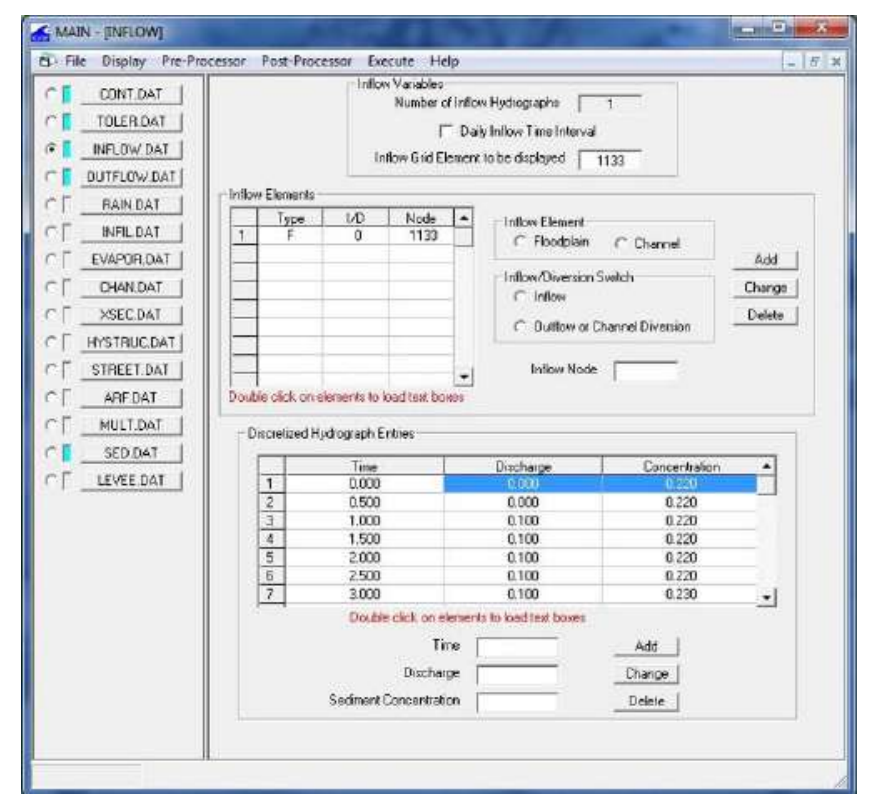

Figura 57. Ventana de dialogo en flo2d para ingresar los datos del hidrograma empleado en la modelización numérica.

Una vez ingresados los datos de input se procedió a generar la simulación (Figura 58). La zona gris es el área correspondiente a la simulación del flujo. La ventana pequeña es la expresión gráfica del hidrograma de avenida para un $\mathrm{T}=500$ años y la leyenda inferior muestra las alturas que el flujo va desarrollando conforme transcurre por el cauce de la quebrada.

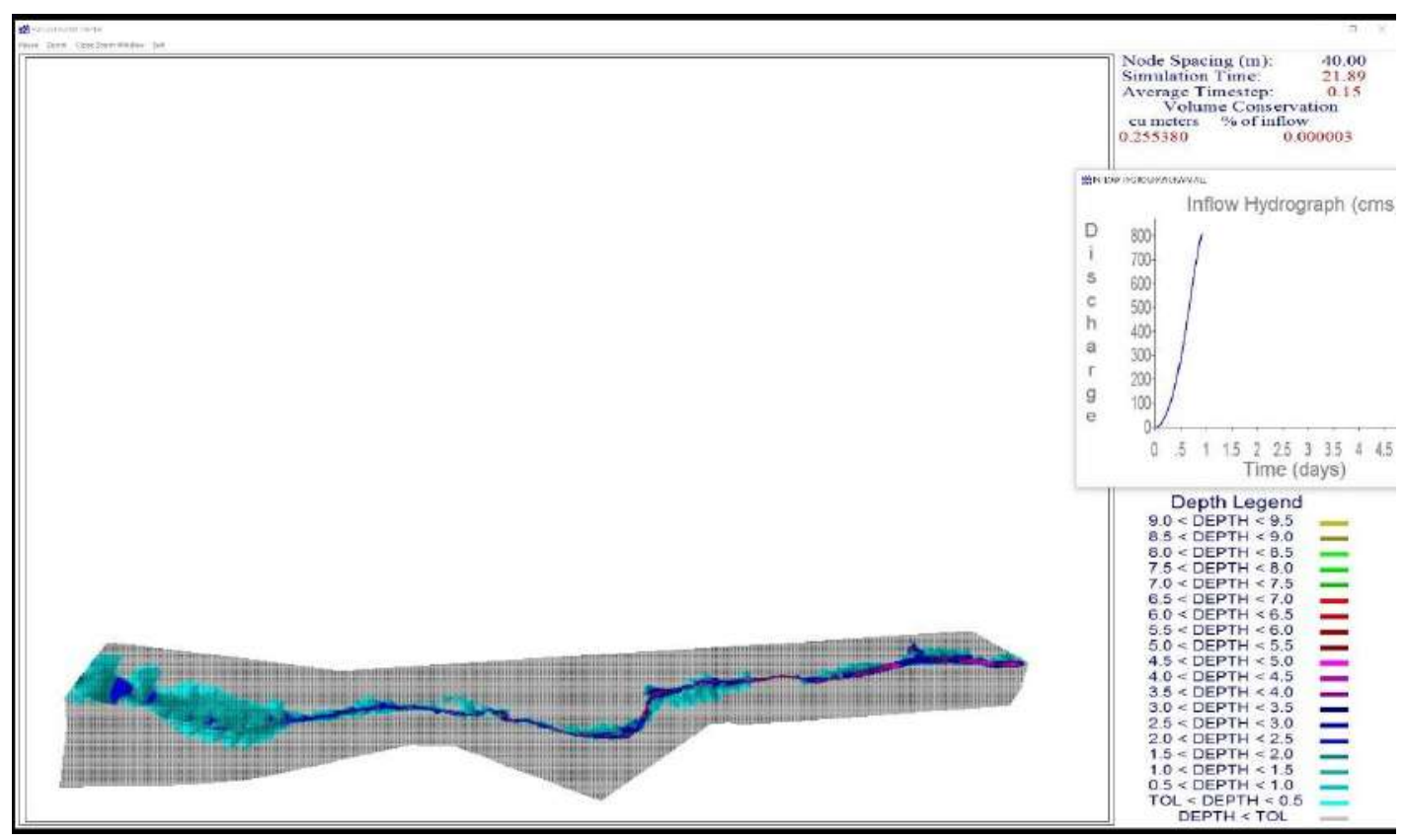

Figura 58. Vista de la simulación por flujo de detritos en el río Rímac en FLO 2D. 
Para este caso se empleó el hidrograma sintético que se obtuvo con los datos de la cuenca para un periodo de retorno de 500 años (Figura 59). Bajo estas condiciones, se emplearon los datos señalados en la Tabla 10, los cuales fueron obtenidos a partir del cálculo del caudal líquido y sólido en el sector Tokio y Los Laureles para simular un posible flujo de detritos que discurriese por el área del río Rímac desde ese punto aguas abajo.

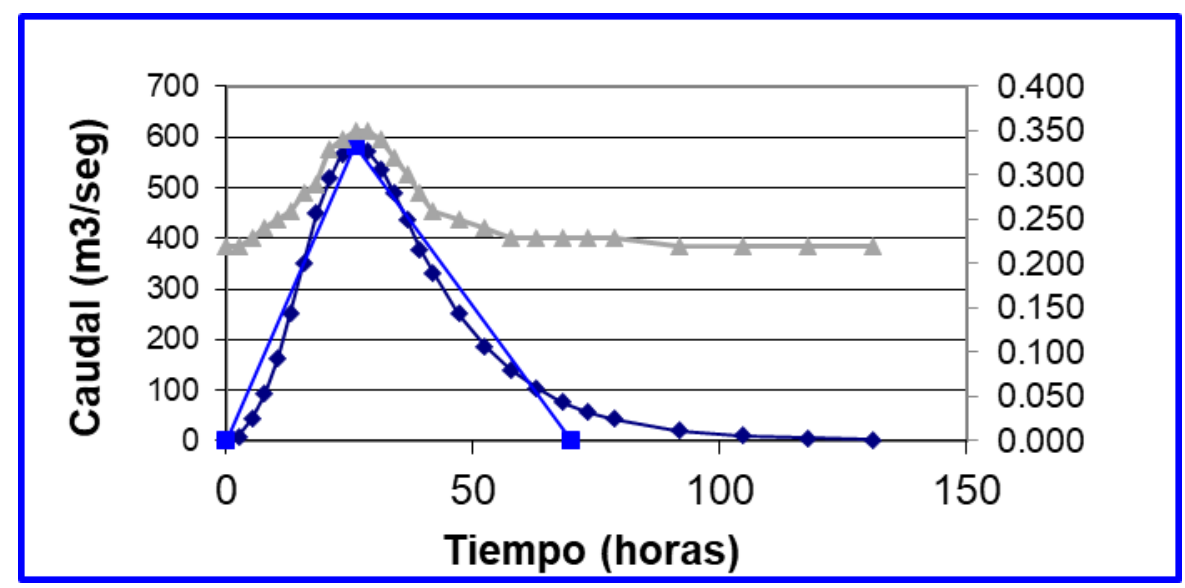

Figura 59. Hidrograma sólido de entrada para la simulación de un flujo de detritos en el abanico del río Rímac con periodo de retorno de 500 años

Tabla 10. Datos de entrada para la simulación de flujo de detritos en el río Rímac con periodo de retorno de 500 años en flo2d

\begin{tabular}{|l|l|}
\hline Tiempo de simulación & $131 \mathrm{hrs}$. \\
\hline Intervalo de generación de resultados & $2.6 \mathrm{hrs}$. \\
\hline Coeficiente de viscosidad "n" de flujo & 0.1 \\
\hline Rugosidad promedio del cauce & 0.150 \\
\hline Rugosidad Ilanuras urbanas & 0.3 \\
\hline Gravedad específica & 2.65 \\
\hline Coeficiente de "Wave celerity" & 0.02 \\
\hline Coeficiente "Laminar Flow resistence" & 2480 \\
\hline
\end{tabular}




\section{RESULTADOS}

En los siguientes ítems se describen los resultados de la aplicación de la metodología descrita: se presentará primero la cartografía geomorfológica del abanico limeño y luego los resultados de la modelización hidrológica-hidráulica. Los esclarecimientos se acompañan de, esquemas, modelos, fotografías y mapas mostrando los datos recopilados durante los trabajos de campo.

\subsection{TRABAJO DE LABORATORIO}

En el caso del estudio de dataciones de los depósitos del abanico de Lima, los resultados de OSL (Tabla 11 y Figura 60) en la estimulación en azul e infrarrojo señalan una tendencia de incremento de la luminiscencia desde la base del perfil hacia la superficie. Una respuesta similar en el comportamiento de la luminiscencia ha sido observada en depósitos de flujos de detritos que provienen de lahares en el área de Majes, Arequipa (Steffen, Preusser, \& Schlunegger, 2009; Steffen et al., 2010). El patrón de señales luminosas con una tendencia hacia a la verticalidad en función de la profundidad; lo cual es característico para los flujos torrenciales y puede explicarse por la movilización de un material masivo durante la génesis del flujo. Las edades obtenidas oscilan en el rango de 110.000 a 1.500 a años (Pleistoceno-Holoceno).

Tabla 11. Edad estimada y parámetros de datación OSL

\begin{tabular}{|l|l|r|l|l|l|}
\hline \multicolumn{1}{|c|}{ Código } & Localidad & $\begin{array}{c}\text { Profundidad } \\
\text { (metros) }\end{array}$ & $\begin{array}{c}\text { Dosis Total } \\
\text { DR } \\
(\mathrm{Gy} / \mathrm{ka})^{\mathrm{c}}\end{array}$ & $\begin{array}{c}\text { Dosis } \\
\text { Equivalente } \\
(\mathrm{Gy})\end{array}$ & \multicolumn{1}{|c|}{ Edad (ka) } \\
\hline USGS-2511 & Regatas & 15.6 & $3.97 \pm 0.16$ & $302 \pm 14$ & $76.070 \pm 5.13$ \\
\hline USGS-2512 & Regatas & 14.6 & $4.61 \pm 0.15$ & $305 \pm 21$ & $66.160 \pm 4.110$ \\
\hline MA1 & Magdalena & 8.5 & $3.05 \pm 0.45$ & $189 \pm 12$ & $44.580 \pm 3.190$ \\
\hline MA2 & Magdalena & 8.6 & $3.02 \pm 0.26$ & $263 \pm 20$ & $55.370 \pm 4.50$ \\
\hline M11 & Miraflores & 9.6 & $2.97 \pm 0.07$ & $315 \pm 35$ & $106.060 \pm 12,090$ \\
\hline M12 & Miraflores & 11.5 & $2.79 \pm 0.11$ & $304 \pm 20$ & $108.960 \pm 7,900$ \\
\hline HU1 & Huachipa & 12.5 & $3.02 \pm 0.27$ & $2.83 \pm 0.03$ & $45.02 \pm 0.28$ \\
\hline SE 1 & Sedapal & 4.5 & $4.91 \pm 0.14$ & $66.3 \pm 3.3$ & $13.500 \pm 780$ \\
\hline SE 2 & Sedapal & 4.5 & $4.47 \pm 0.14$ & $77.8 \pm 3.9$ & $20.310 \pm 1,880$ \\
\hline USGS-2516 & Sedapal & 1.5 & $5.04 \pm 0.12$ & $7.71 \pm 4.0$ & $1.530 \pm 800$ \\
\hline
\end{tabular}




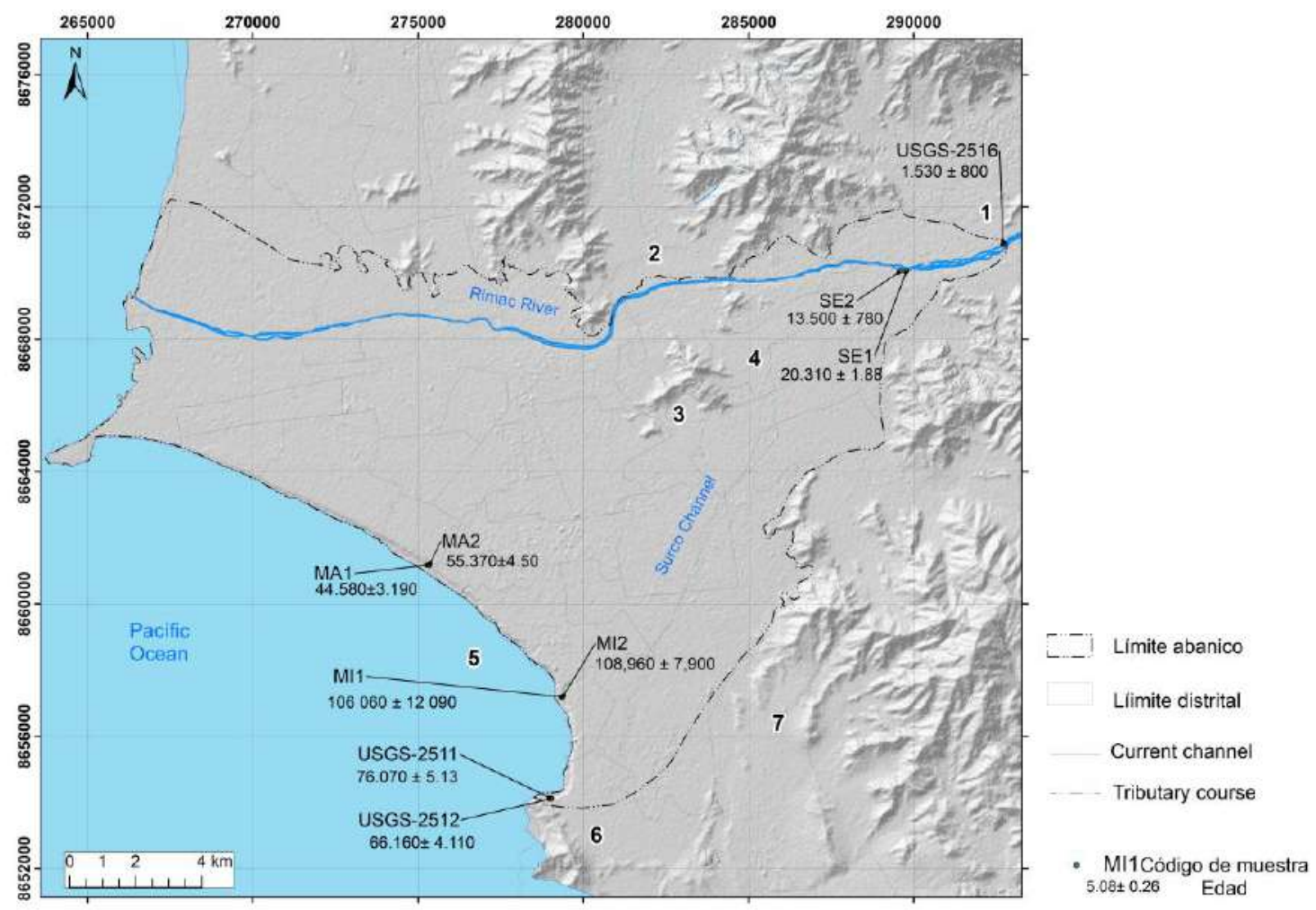

Figura 60. Ubicación de las muestras analizadas por OSL en este estudio.

\subsection{CARTOGRAFÍA}

En el área de la Costa Verde se puede observar que la mayoría de las columnas estratigráficas son grano-decrecientes y están cortadas, lo cual sería indicador de que el basculamiento tectónico ha sido muy importante en este sector.

Las diferencias sedimentológicas encontradas de norte a sur del abanico indican que hacia el sur existían cauces más jóvenes y donde se evidencia una incisión mayor. Esto es notable en las facies observadas en el sector Club Regatas (figura 46;Error! No se encuentra el origen de la referencia.) donde desde la base hasta el techo, los depósitos forman un sistema fluvial del tipo trenzado. Se identifican hasta cuatro intervalos grano-crecientes con gravas en la base que se interpretan como canales tractivos ocurridos durante la reactivación de eventos fluviales. Las arenas con laminación cruzada denotan un dominio fluvial.

El basculamiento, evidenciado por la diferencia de altura de los acantilados (menores hacia el norte), así como los lineamientos identificados (al norte y sur del abanico), que causaron notables cambios de dirección del río Rímac -desde su ápice hacia aguas 
abajo- demuestran el entramado tectónico subyacente en ese sector. El mismo, provocó que el río Rímac, y el río Chillón formen dos sistemas imbricados de abanicos aluviales truncados por la erosión marina, como costa emergente y que haría que se formen unos frentes casi verticales de materiales poco consolidados y con abanicos aluviales secundarios.

Los paleo-cauces identificados están cubiertos por sedimentos que fueron rellenando cauces menores que discurrían sobre un sustrato de gravas pre-existente. Dichos rellenos de canal migran a planicies de inundación que es donde prevalece la arcilla (evidencia de energía baja). Además, también se observa en distintos sectores como los paleo-cauces del río Rímac fueron cambiando de posición.

En otros sectores de la Costa Verde (hacia la zona central) predomina en las columnas la grava frente a las arenas y algunas formas lenticulares de arcilla, siendo los espesores de estas facies muy diferentes a medida que nos acercamos al sector norte del abanico. Si nos aproximamos hacia la zona norte del abanico, las columnas van ganando más porcentaje de gravas y contienen cuerpos de arenas de diferentes formas (Figura 61), por lo que se puede señalar que, a grandes rasgos, los depósitos forman una serie discontinua.
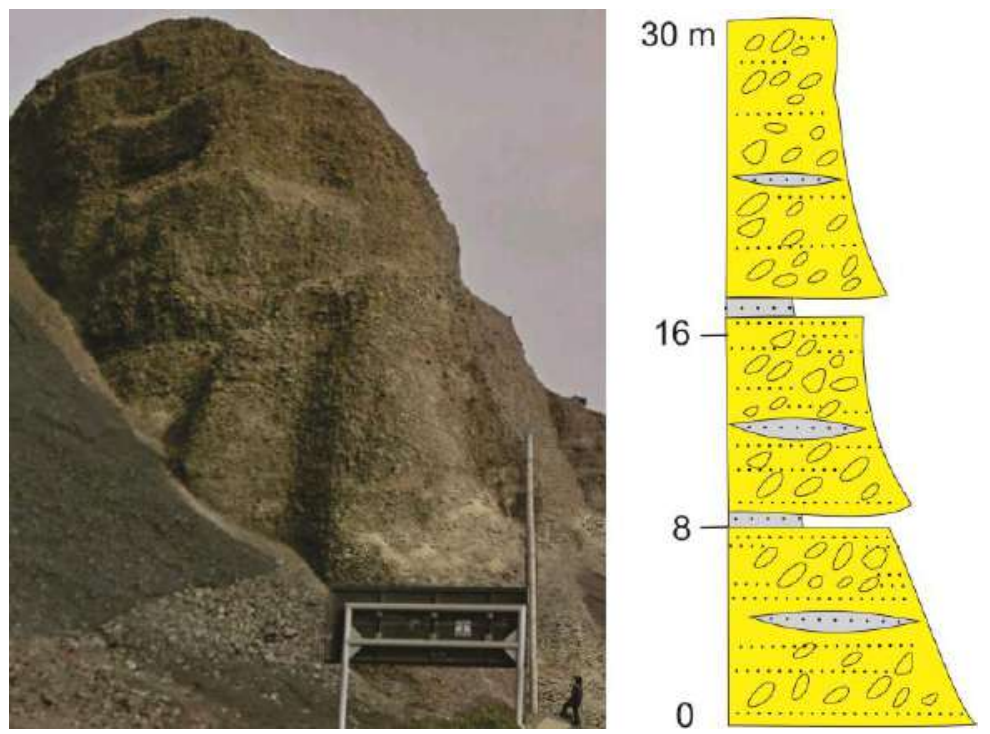

Figura 61. Interpretación de las secuencias observadas en la parte central del abanico a la altura del museo de la memoria (Miraflores). 

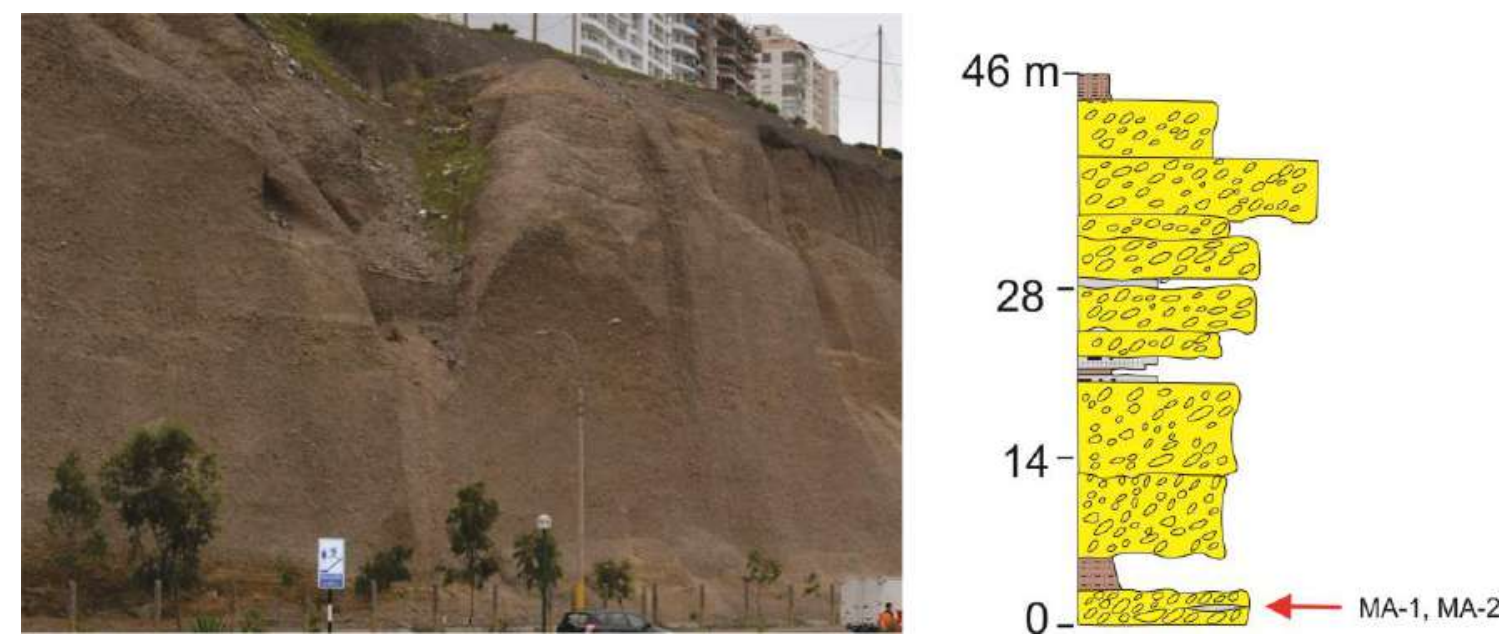

Figura 62. Columna levantada en el sector Magdalena, zona norte del abanico de Lima

Asimismo, a la altura de la quebrada de Armendáriz (Barranco) se identificaron estructuras sedimentarias en los cuerpos de arena de forma lenticular que indican niveles de transgresión. Las facies descritas están intercaladas con depósitos fluviales por lo que se observa que el sector correspondería a una zona de desembocadura con influencia de procesos fluviales y marinos.

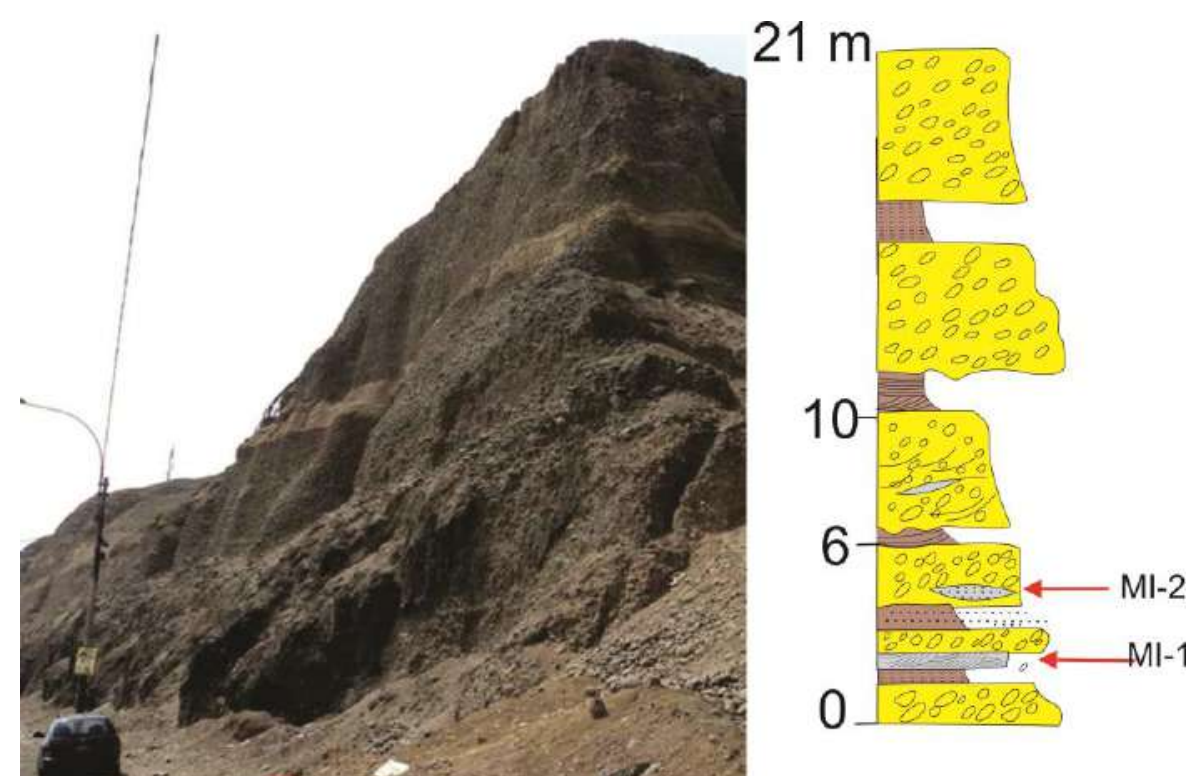

Figura 63. Columna levantada en el sector quebrada de Armendariz (Barranco)

En las columnas levantadas en el sector de Huachipa (río Huaycoloro) se observa que los materiales arrastrados por los flujos contienen gran cantidad de material fino en capas delgadas intercaladas con otros de materiales mucho más gruesos que los cubren en algunos casos en discordancias. Las diferentes estructuras sedimentarias 
identificadas permiten señalar que sucedieron eventos de diferentes magnitudes, algunas de ellas más violentas. En las columnas respectivas se observaron discordancias y diferentes estructuras sedimentarias (Figura 64).
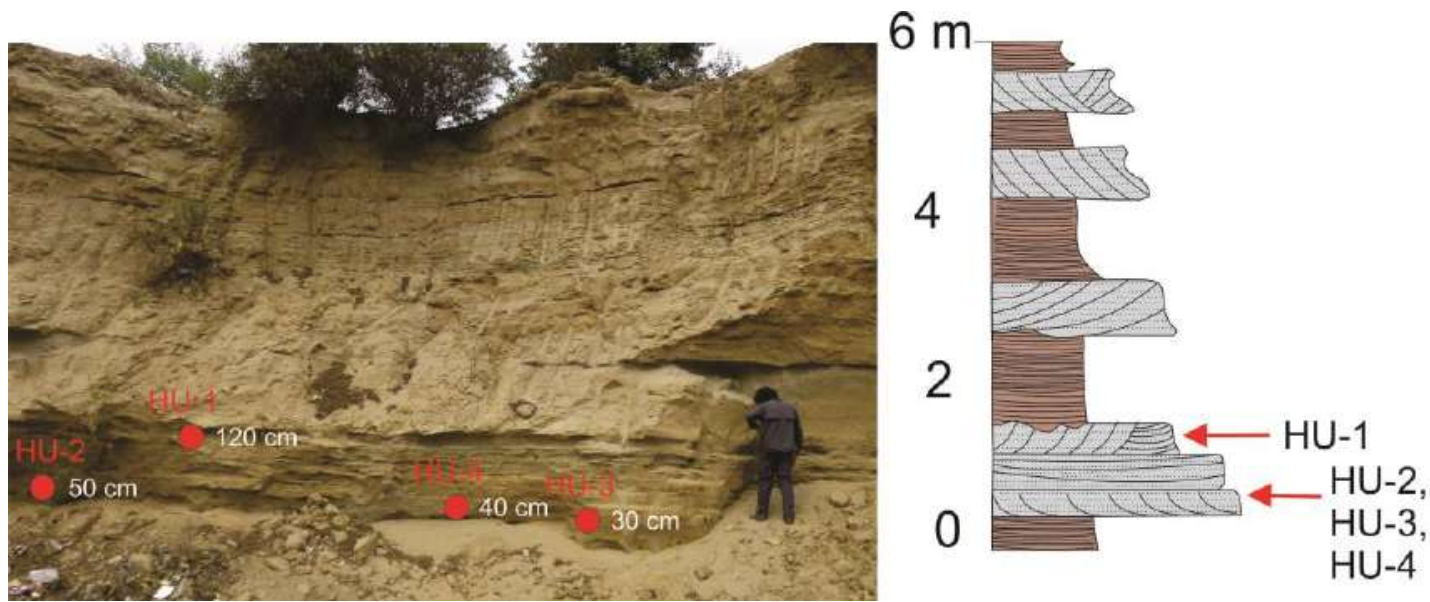

Figura 64. Secuencias fluviales y aluviales observadas en Huachipa (río Huaycoloro, uno de los principales afluentes del río Rímac).

Se han identificado 07 niveles de terrazas aluviales. Cuatro de las cuales están limitadas a un estrecho borde entorno al río Rímac (Figura 65).

Respecto a las terrazas coluvio-aluviales, se identificaron algunas bastante elevadas respecto a las actuales, que corresponderían a los primeros niveles de depósitos de las quebradas "alimentadoras" al abanico del río Rímac. Esto puede verse en algunos sectores de San Juan de Lurigancho, ATE (Huachipa) y La Molina (quebrada Melgarejo, Foto 23).

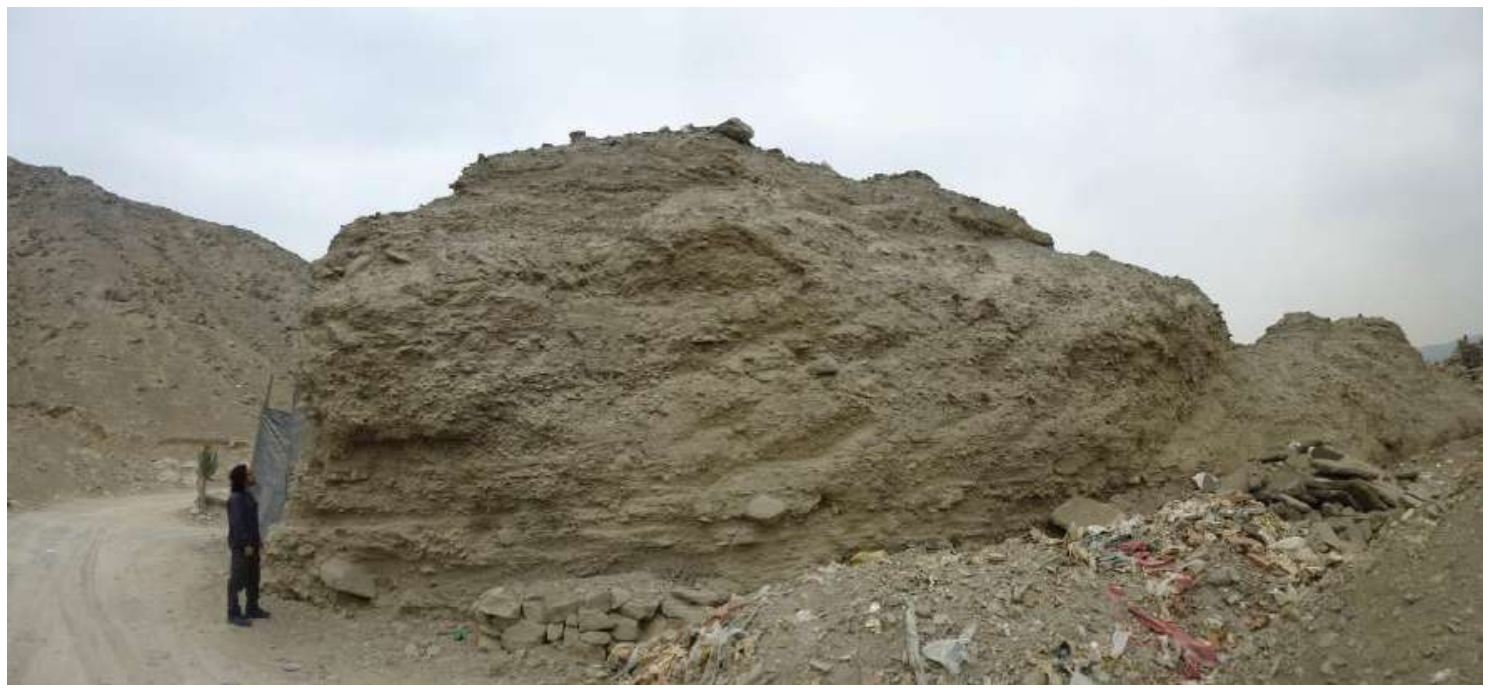

Foto 23. Relicto de terraza aluvial en la quebrada Melgarejo (La Molina-Cieneguilla) 
De otro lado, se identificaron hacia el sur rellenos de glacis y depósitos de arena formando planicies eólicas (hacia San Juan de Miraflores, Villa El Salvador y Chorrillos, figura 65).

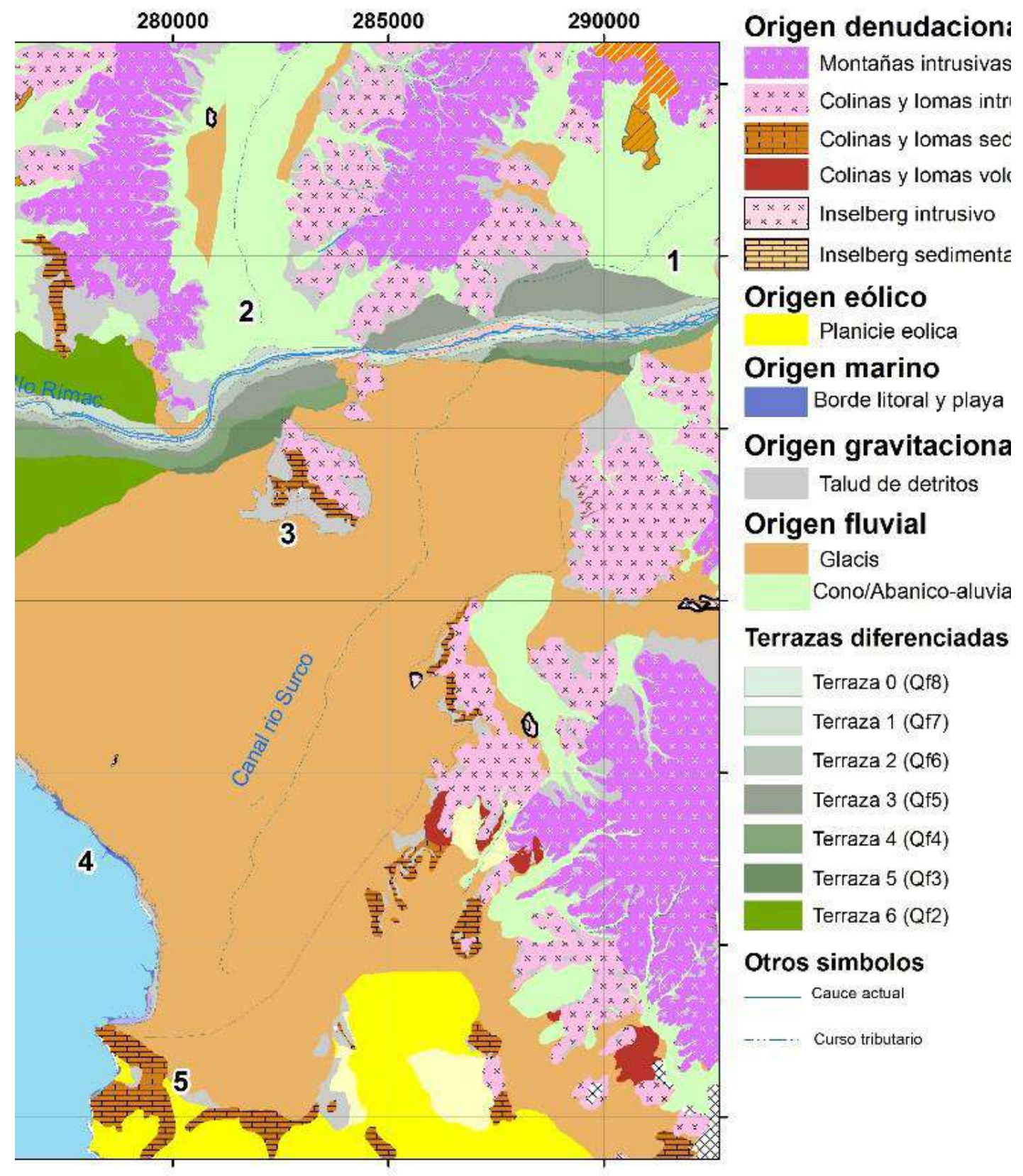

Figura 65. Geoformas identificadas en el área de estudio. 1. Ápice del abanico (Ate), 2. Quebrada Canto Grande, 3. Cerro El Agustino, 4. Circuito de playas de la Costa Verde (Miraflores), 5. Morro Solar. 
Respecto al resultado del análisis estructural (Figura 66), según lo observado existirían al menos dos posibles fallas que habrían controlado el relleno del abanico aluvial hacia el norte y sur del abanico. Estas estructuras habrían determinado el encajamiento del río Rímac, pero después la subsidencia del borde norte fue más importante por lo que el río se desvió hacia allí (figura 67). Es decir se muestra al menos dos controles estructurales, siendo el del norte el que ahora actuaría en mayor medida. En el borde sur también se identificó un alineamiento que podría ser una falla, pues también parece mostrar un corte brusco.

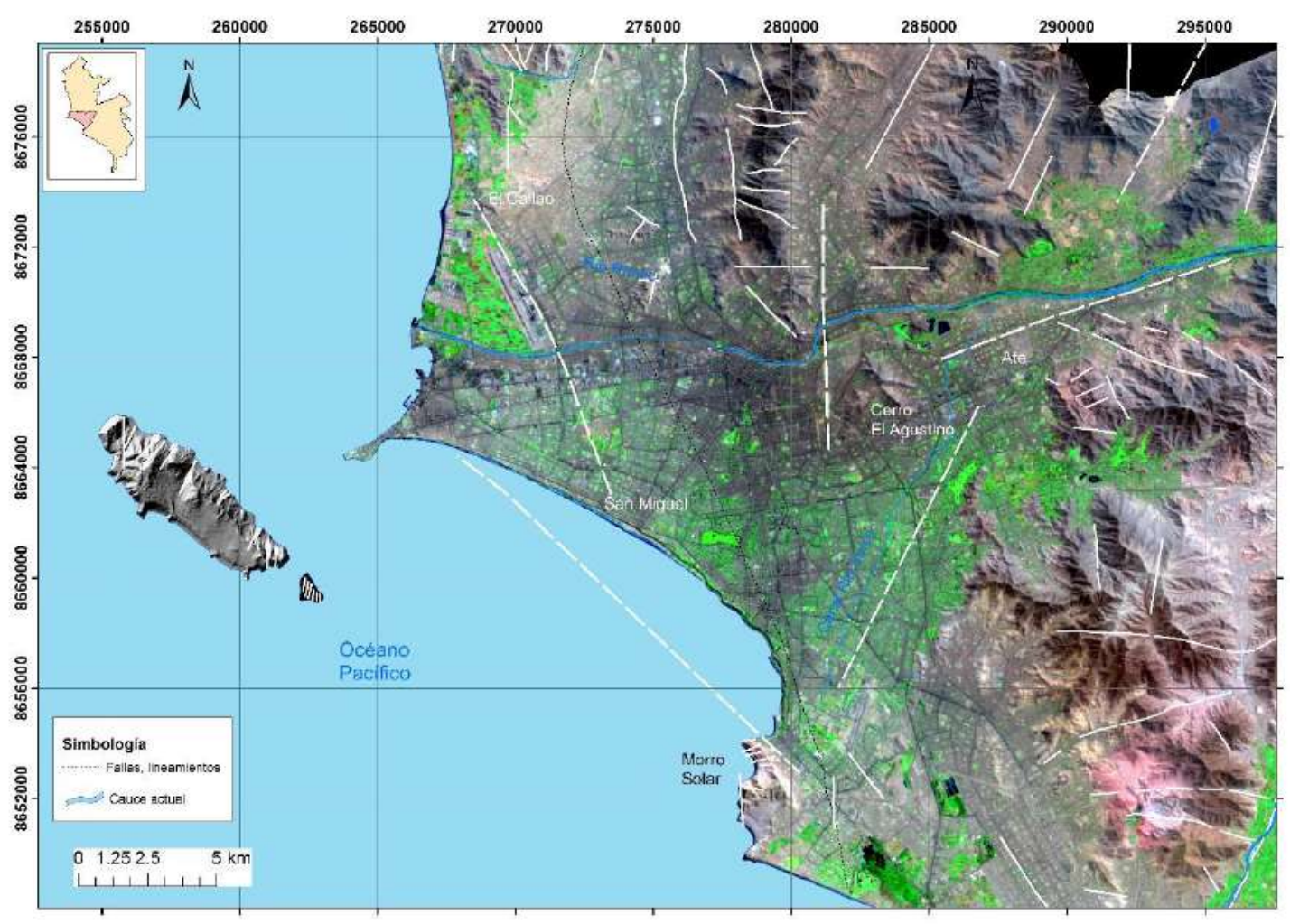

Figura 66. Imagen satelital (2006) donde se han interpretado las estructuras en los alrededores del abanico de Lima. 

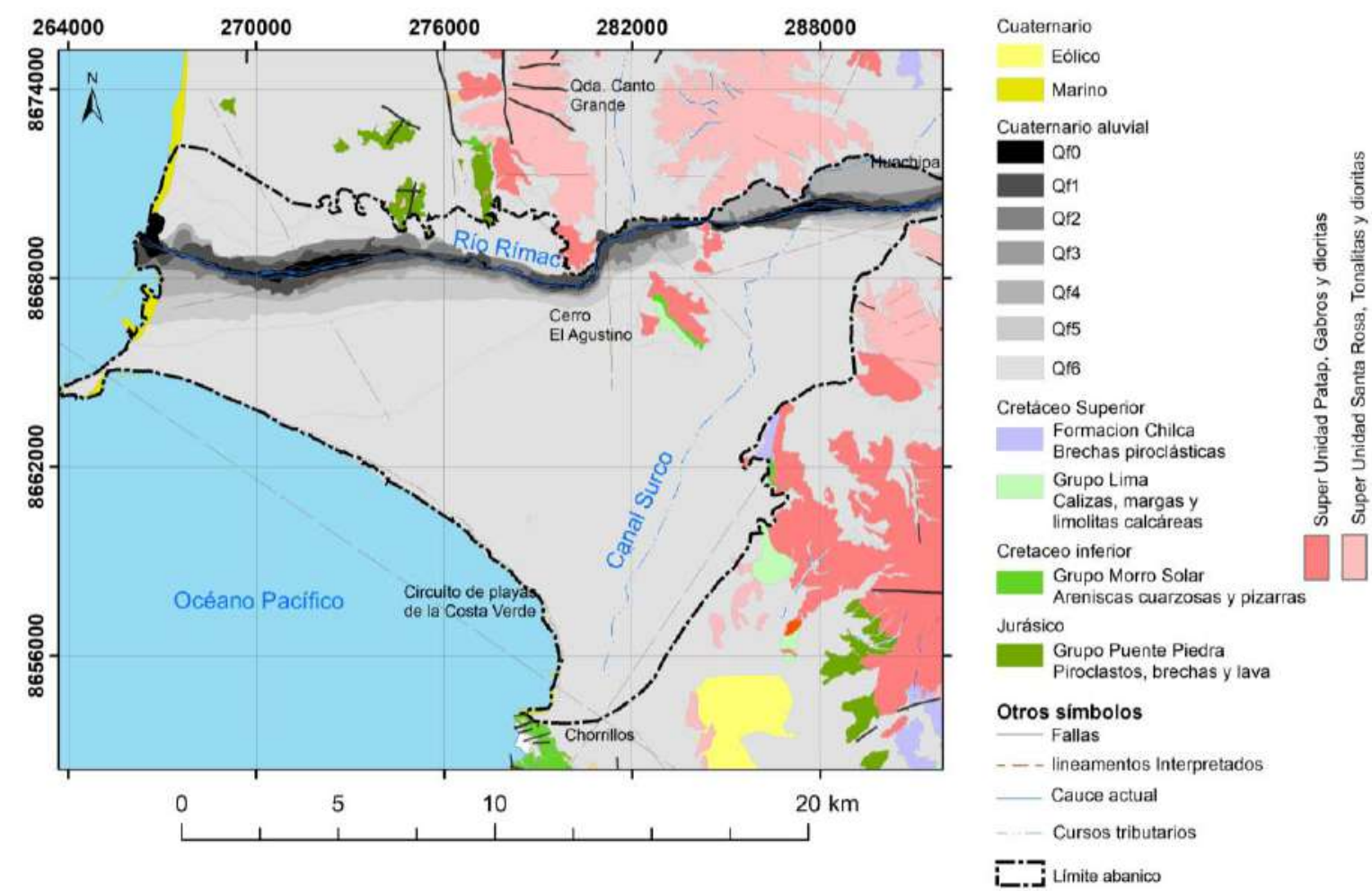

Figura 67. Geología generalizada del Abanico de Lima y alrededores mostrando las estructuras interpretadas.1: Huachipa, 2: San Juan de Lurigancho, 3: Cerro El Agustino, 4: Santa Anita. 5: Circuito de Playas Costa Verde, 6: Morro Solar, 7: San Juan de Miraflores.

\subsection{ANÁLISIS HIDROLÓGICO-HIDRÁULICO}

\subsubsection{Análisis hidrológico}

Los resultados del modelo hidrológico para una simulación de 141 horas con un periodo de retorno de 500 años han proporcionado un hidrograma de salida con un caudal de $583,9 \mathrm{~m} 3 / \mathrm{s}$.

5.3.2 Modelización numérica de flujos híper-concentrados en Flo2D

Como resultado de la simulación en Flo2D, se obtuvieron los siguientes modelos numéricos (Figura 68):

- Mapa de elevación máxima del flujo: muestra las alturas máximas tomadas por el flujo durante la simulación. Se observa que se han alcanzado alturas de hasta 8 m. 
- Mapa de velocidad del flujo: muestra las velocidades y distribuciones del flujo en el río Rímac (zona del abanico).

- Los resultados numéricos de la simulación se resumen en la Tabla 12.

Tabla 12. Resultados de la simulación numérica por flujos de detritos (Q500) en el área del abanico de Lima

\begin{tabular}{|l|l|}
\hline Volumen total del flujo y del depósito & $103,433,028.35 \mathrm{~m}^{3}$ \\
\hline El total de área inundada & $27.656 \mathrm{~km}^{2}$ \\
\hline
\end{tabular}

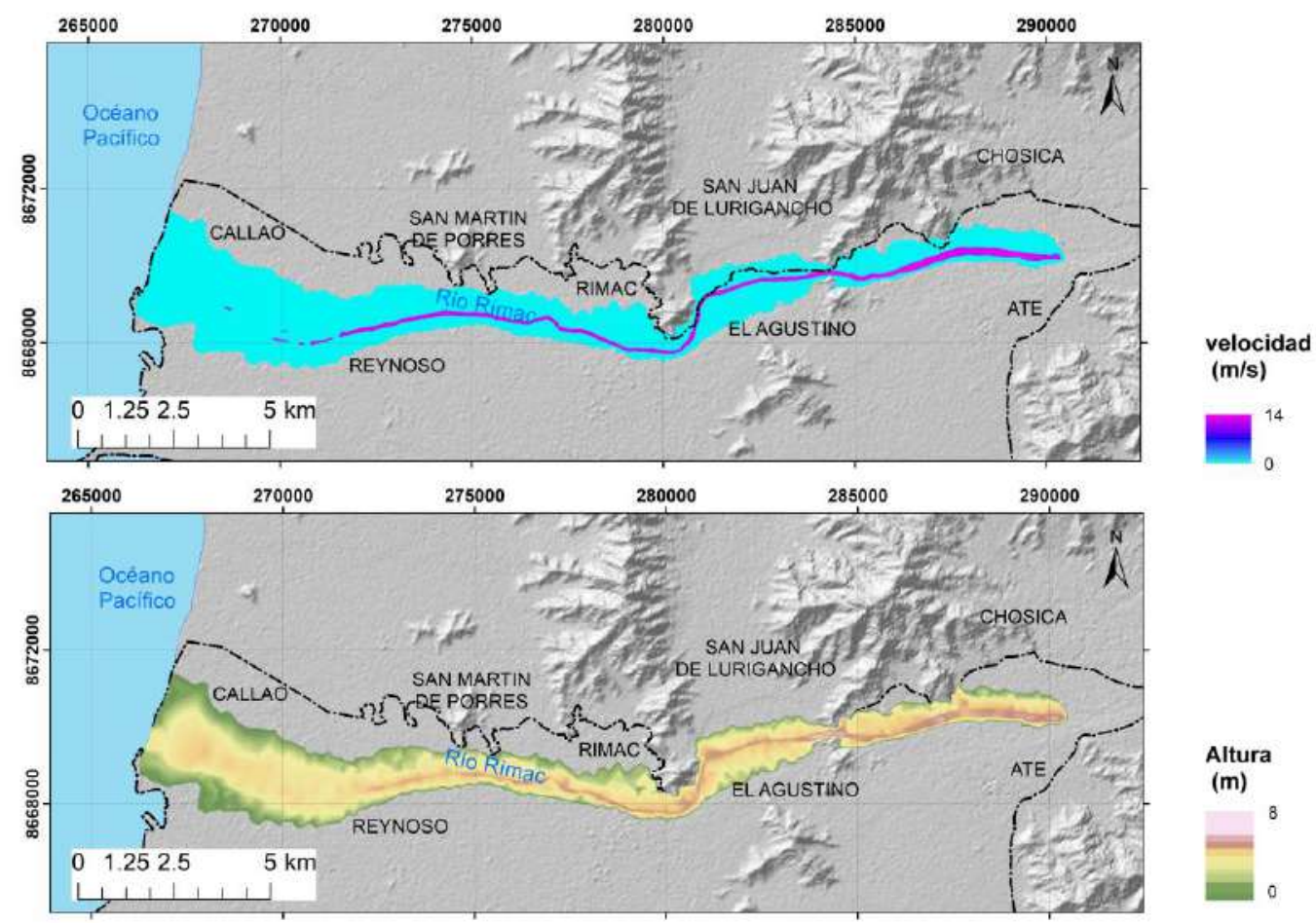

Figura 68. Velicidad y altura de flujo de detrtitos en el río Rímac (apice del abanico hasta desembocadura).

\subsubsection{Peligrosidad flujos híper-concentrados y desbordes}

La peligrosidad se estimó con el módulo Mapper - Hazard Map del FLO2D (Figura 69) que permite calcular la intensidad del evento en función de la altura alcanzada por el material y la velocidad del flujo. Los umbrales entre los niveles de peligrosidad alta (Tabla 13), media y baja, consideran el peligro que una determinada columna de agua puede significar para la infraestructura, las viviendas y la vida de los pobladores (Díez, Laín, \& Llorente, 2008; Rickenmann, 2005). 


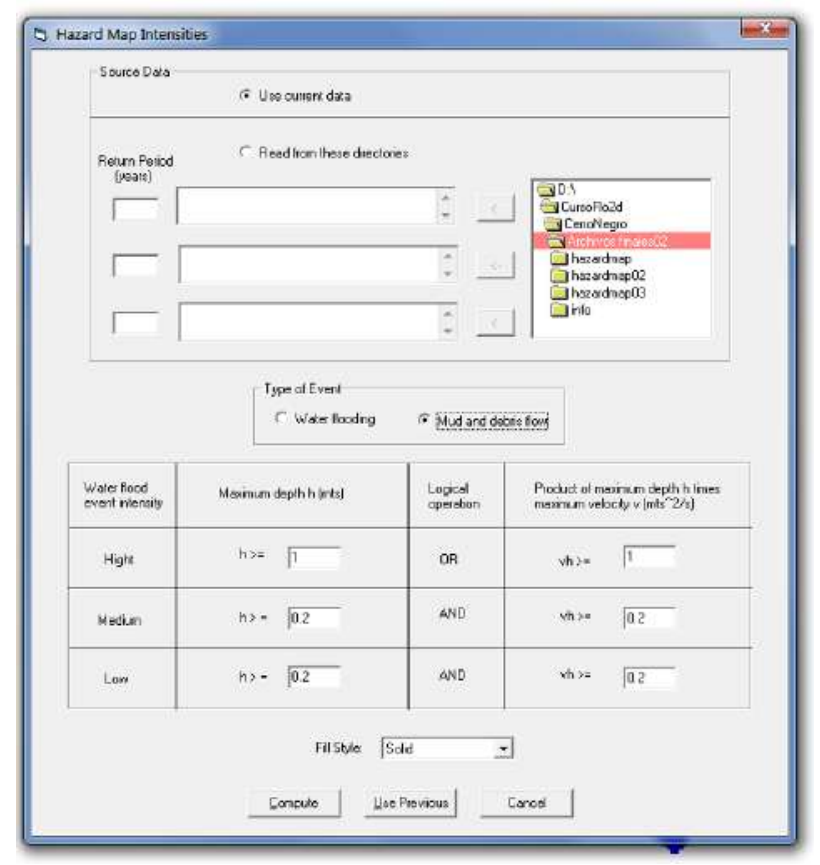

Figura 69. Módulo Hazard Map del FLO2D

Tabla 13. Criterios acerca del nivel de peligrosidad para flujos de detritos $y$ procesos similares (Rickenmann, 2005).

\begin{tabular}{|l|l|}
\hline Nivel de peligrosidad & Criterio \\
\hline Alta & $\mathrm{vxh}>1 \mathrm{~m}^{2} / \mathrm{s}$ \\
\hline Media & $0.2<\mathrm{vxh}<1 \mathrm{~m}^{2} / \mathrm{s}$ \\
\hline Baja & $\mathrm{vxh}<0.2 \mathrm{~m}^{2} / \mathrm{s}$ \\
\hline
\end{tabular}

\subsubsection{Comparación con información histórica y geomorfológica}

La zonificación de la peligrosidad en el área de influencia del río Rímac se comparó con la información histórica y geomorfológica para identificar sectores con probabilidad de sufrir daños por flujos de detritos como el del escenario evaluado (periodo de retorno de 500 años).

De la información histórica (inventario de peligros geológicos del INGEMMET (Villacorta et al., 2015) se tiene datos de flujos de detritos en el área evaluada desde la época Pre-incaica (acápite 3.5). Aparentemente la generación de flujos de detritos, desbordes e inundaciones en este sector estaría relacionada al evento ENSO (acápite 2.6.1.1). 
Comparando los resultados del modelo con el cartografiado geomorfológico y análisis de susceptibilidad por flujos se puede notar que existe una buena correspondencia de lo observado in situ y el modelo generado, sobre todo en las terrazas Q6 y Q5 (Figura 70).

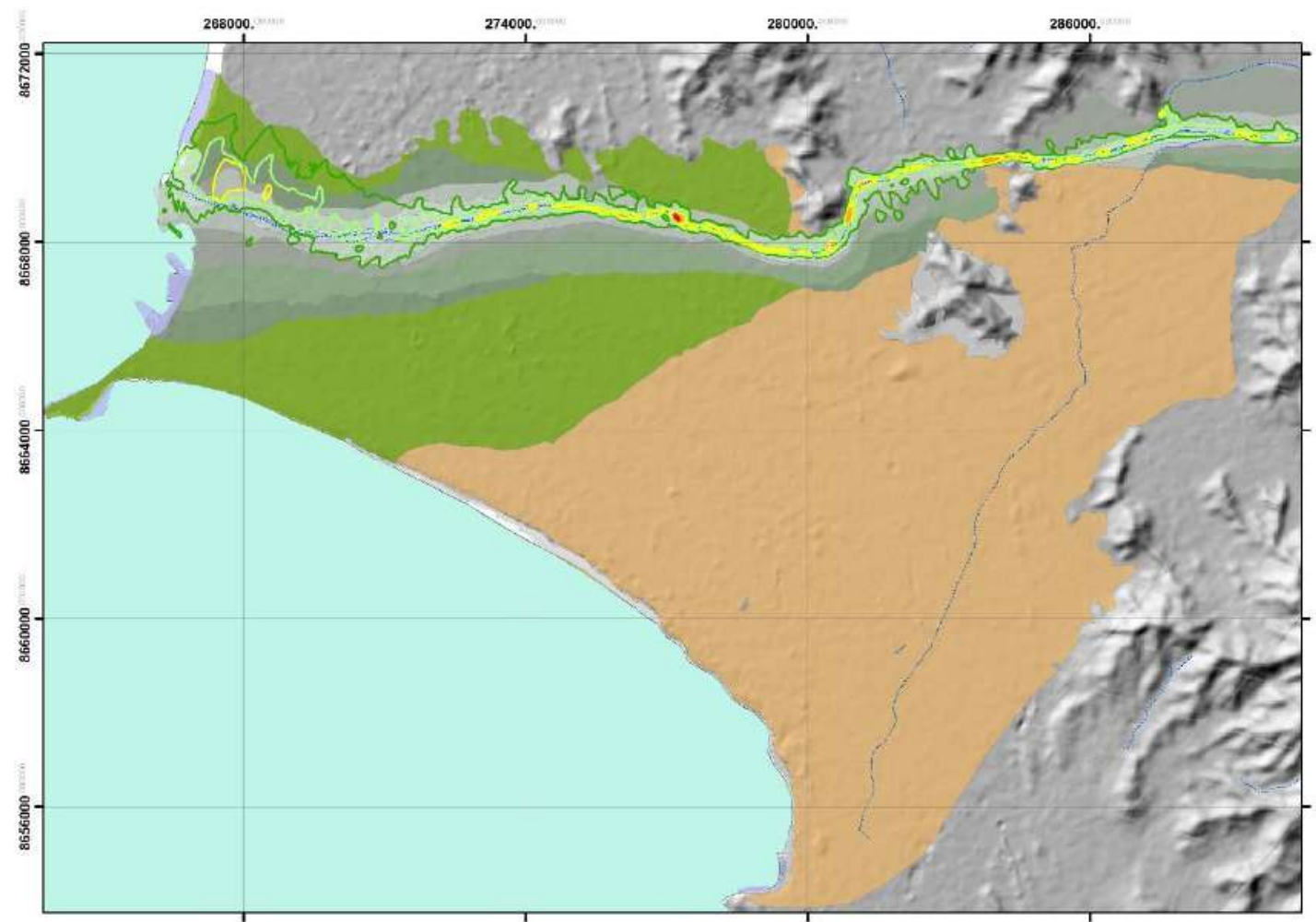

Figura 70. Comparación del cartografiado geomorfológico y el modelo hidraulico desarrollado para un periodo de retorno de 500 años. 


\section{DISCUSIÓN}

En la presente investigación se realizó un análisis de la evolución del abanico de Lima desde su formación a la actualidad. El trabajo ha estado dirigido a explicar su origen, por un lado porque se tiene un relleno de gran espesor en ese sector de la costa peruana y por otro, establecer perspectivas de cómo se comportará a futuro en relación con el tectonismo andino y los cambios climáticos pronosticados a nivel mundial por diversos especialistas (Gosling et al., 2011). A continuación, se resume una interpretación de los resultados obtenidos, comparados y discutidos profundizando en las implicancias que pueden tener y posible aplicación a otros ámbitos del territorio.

En este sentido, las principales discusiones derivadas del presente estudio en relación a su grado de aportación al conocimiento son: propuestas sobre el origen del abanico, sobre el modelo hidrológico-hidráulico y sobre los posibles escenarios de inundaciones en ese sector frente a cambios climáticos.

\subsection{SOBRE EL ORIGEN DEL ABANICO}

La escasez de datos sobre la tectónica reciente ha contribuido a forjar la imagen de que el área de Lima es menos activa en comparación con otras zonas del Perú; sin embargo, ha de considerarse la probabilidad de que la tectónica siga actuando aquí, dado el complejo entorno geológico en el que se encuentra localizada Lima y el Perú. Cobbing (1982) y Aleman et al. (2006) en base a cartografiado estructural regional dedujeron que la zona central, donde se ubica el abanico del rio Rímac, se formó por el hundimiento de bloques fallados, en el marco del tectonismo andino. La observación de alineamientos, cambios de curso del drenaje y diferencia de niveles de los depósitos expuestos en la Costa Verde, observados durante el desarrollo de esta investigación corresponde con dicha teoría y se consideran evidencias de que el abanico está basculando hacia el norte de Lima. Esta propuesta ya había sido mencionada por Le Roux et al. (2000) en alusión a la asimetría observada en el abanico.

Esta teoría también corresponde con las propuestas de Jordan et al. (2001), Hindle et al. (2002), Somoza \& Ghidella, 2005 y Le Roux (2012) acerca de que el levantamiento andino habría influenciado en los patrones de sedimentación de la vertiente pacífica 
de Suramérica. En este caso, se puede deducir que la actividad de la placa obliga a las direcciones de los esfuerzos a girar cambiando hacia la dirección principal de la fuerza; ejerciendo la isla de San Lorenzo un efecto rotacional, con los sedimentos conformantes del abanico.

Los datos registrados en las columnas levantadas han permitido corroborar los múltiples abanicos aluviales superpuestos en el sector y han evidenciado los ciclos de aluvionamiento y encajamiento que sufrió el sector.

Sobre la transgresión marina holocena identificada por Sébrier \& Macharé (1980), en base a sus estudios geomorfológicos en la zona de Asia, Cañete y el río Chillón. Las evidencias observadas en el área de Barranco (Armendáriz) confirman esta hipótesis. Vale mencionar que Le Roux et al. (2000) atribuyen las transgresiones al movimiento y subsidencia de la Placa de Nazca e identifican un gran evento ocurrido en el Pleistoceno (1.7 Ma).

Lo anterior es evidencia de que el abanico se formó en condiciones de tectonismo seguido de una sucesión de eventos de lluvias excepcionales lo cual corresponde con las crisis climáticas señaladas por Dolfus (1964) y Sébrier y Macharé (1980).

La presencia de una importante cantidad de sedimentos depositados evidenciados en una columna de más de $500 \mathrm{~m}$ de espesor (probablemente hace 4ka), permite inferir que debió haber existido en ese sector un paleo-valle subyacente, el cual podría haber sido rellenado aparte del proceso fluvial existente, por el resultado de los deshielos de las etapas interglaciares. La relación entre la superficie de abanico y la zona sumergida a través del ciclo glacial-postglacial, es evidencia de constantes crisis climáticas durante su desarrollo.

De otro lado la desertificación en el Mioceno Superior, desde un clima árido a híperárido induciría un retroceso aluvial resultando en el posterior depósito de gravas de espesores decamétricos evidenciados en los perfiles hacia el norte de la Costa Verde.

Respecto a la edad del abanico, la referencia de Lisson (1907) se basa en el descubrimiento de un molar de Equus curvidens Owen, 1895 de edad pleistocena, descubierto en el techo de una terraza aluvial. Sin embargo, al comprobarse que la ubicación exacta del fósil molar corresponde a la cuenca del río Mantaro (el cual drena 
en dirección contraria al río Rímac), hace difícil que se pueda asociar este dato al abanico de este estudio.

En este estudio las edades de las muestras en el abanico (expuestas en la Costa Verde) oscilan en el rango de $2.2 \mathrm{Ka}$ a $5.8 \mathrm{Ka}$ es decir son edades del Pleistoceno superior-Holoceno. Los datos difieren a las edades obtenidas por Viveen et al. (2016) en la zona sur del abanico ( 0.9 a $0.1 \mathrm{ka}, 3.8$ a $1.2 \mathrm{ka}$ y 3.9 a $0.5 \mathrm{ka}$ ) por los cuales se especulaba que podría configurarse como resultado de la ocupación prehistórica que afectó los patrones de erosión de los cauces hacia el lado sur del abanico (caso desviación del canal Surco, considerado como un paleo-cauce del río Rímac). Los datos hallados en este estudio contestan a las especulaciones de Teves (1975) y Aleman et al. (2006) quienes señalan que por sus características sedimentológicas, era posible que los materiales fuesen más jóvenes al material enterrado.

Sin embargo, si se tiene en cuenta que solo se ha datado los niveles más altos del abanico (los 100 me del acantilado de la Costa Verde) y que los depósitos son más profundos (a $500 \mathrm{~m}$ ), esto permitiría indicar que en su totalidad la edad del abanico es más antigua. Esa teoría podría consolidar lo propuesto por Le Roux et al. (2000) que señala con respecto a cuatro unidades estratigráficas distintas en los conglomerados de la Costa Verde, y en base una hipotética reconstrucción de movimientos verticales del área, que el depósito estaría influenciado por la actividad de la Dorsal de Nazca durante el Mioceno tardío-Plioceno (entre los 10 y 5.3ma), lo cual ha sido interpretado como la causa de la incisión profunda del río Rímac. Además, es necesario tomar en cuenta los datos de Noble et al. (2009) quienes en base a dataciones por radionucleídos Ar-Ar de niveles volcánicos incluidos en depósitos aluviales en Mala, al sur de Lima obtuvieron edades de $8 \mathrm{Ma}$ y $7 \mathrm{Ma}$ (finales del Mioceno) y propusieron que el abanico de Lima podría ser de la misma edad. Pero hacen falta dataciones a mayor profundidad para confirmar esta hipótesis.

\subsection{SOBRE ESCENARIO FUTURO DE SU EVOLUCIÓN}

Las estructuras observadas en el acantilado de la Costa Verde, así como posición de las geoformas identificadas en este trabajo evidencian que durante la formación del abanico se produjeron crisis climáticas y que entre el Pleistoceno y Holoceno han ocurrido levantamientos concomitantes con la tectónica andina, hipótesis que concuerda con lo señalado por Sebrier y Machare (1980) y por Le Roux (2000), en 
relación a los movimientos verticales asociados a la tectónica andina que afectaron a los depósitos aluviales y marinos antiguos.

Es necesario tener en cuenta, en relación a los materiales acarreados por el río Rímac, las eventuales crisis climáticas propuestas por Dollfus (1965); Ortlieb y Machare (1989) que serían las épocas donde habrían circulado (mayores precipitaciones) mayores caudales de agua y de carga sólida por el río Rímac.

Se ha de considerar además que, en las condiciones naturales de formación del abanico, no existían las barreras construidas en la actualidad en el cauce del rio Rímac asociadas a la consolidación de la cuidad. Por ello es difícil que nuevas inundaciones vuelvan a tener las extensiones de los eventos formadores del abanico limeño. Sin embargo, no se puede descartar la continuación de la actuación fluvial en un río joven como el Rímac, considerando los eventos climáticos globales como ENSO que siguen en la actualidad causando daños derivados de la antropización del cauce del río Rímac, sin considerarse los efectos de los procesos naturales formadores del abanico. Recordar además la acción de la Tectónica Andina, con posibles actuaciones a largo plazo debido a la ubicación del territorio peruano en el frente de actividad de las placas de Nazca y Suramericana.

\subsubsection{Modelo hidrológico-hidráulico}

Parte de este estudio se ha dedicado a proponer una metodología basada en el estudio de las paleo-inundaciones, dado que no existe a la actualidad un registro de este tipo en el Perú. Por esta razón, el análisis se ha fundamentado en la interpretación evolutiva del abanico aluvial mediante el uso del análisis paleohidrológico con datos geomorfológicos, como la datación de las terrazas y huellas en el cauce, análisis que ha permitido calibrar los modelos realizados.

En este estudio, suponiendo la condición más crítica se obtuvo un caudal hidrológico de: $583.9 \mathrm{~m}^{3} / \mathrm{s}$ y un caudal hidráulico en el perfil representativo Tokio-Los Laureles de: $18433.659 \mathrm{~m} 3 / \mathrm{s}$.

Resultados de otros estudios (ANA, 2012a; Bernabé, 2010; Apaclla, 2010) indican valores comparables al caudal hidrológico obtenido en este estudio, siendo el caudal máximo histórico según datos de la ANA (1920-2012) de $325 \mathrm{~m}^{3} / \mathrm{s}$. 
Respecto al caudal hidráulico, este se explica considerando que los caudales que dieron origen al abanico de Lima serían diferentes a los actuales. Los datos de caudales analizados corresponden al presente (30-40 años). Sin embargo, datos de menos de 1000 años no recogen la variabilidad climática producida en el Cuaternario. Esta variabilidad esta evidenciada en los datos geomorfológicos recogidos en campo, por ejemplo en los depósitos de flujos y avenidas torrenciales. El gran contraste en los resultados se justifica suponiendo cauces torrenciales con flujos híper-concentrados con abundante carga de material suelto. Durante las crisis climáticas, estos eventos fueron más frecuentes, por lo tanto los períodos de retorno serían distintos. Por todo ello, se considera que los caudales en el pasado debieron ser mayores. 


\section{CONCLUSIONES Y RECOMENDACIONES}

En síntesis, el objetivo principal de la presente investigación ha sido analizar la génesis del abanico del río Rímac y una previsión sobre su futuro comportamiento en relación a los cambios climáticos. En el marco teórico propuesto, la investigación se centró en tres aspectos:

- Aclarar el papel de la tectónica y los cambios climáticos en el pasado en la evolución del abanico del río Rímac.

- Evaluar el comportamiento del río Rímac en la parte urbana de Lima Metropolitana ante fenómenos extremos como las lluvias excepcionales asociadas a El Niño Southern Osciltation (ENSO).

- Ensayar métodos y desarrollar metodologías de modelos numéricos para establecer el peligro asociado a futuros eventos de inundaciones en el valle del río Rímac.

A lo largo del desarrollo de este trabajo se ha intentado cubrir dichos aspectos de los cuales se han obtenido las conclusiones que se presentan a continuación. Adicionalmente se exponen algunas recomendaciones que buscan contribuir a una planificación y ordenamiento territorial más eficaz y con menos índice de riesgo para la capital peruana.

\subsection{CONCLUSIONES}

A modo de resumen, podrían enumerarse una serie de conclusiones sobre los temas abordados en los resultados y su discusión:

\subsubsection{Sobre el origen del abanico}

Los alineamientos, cambios de curso del drenaje, variaciones de espesor en los acantilados de la Costa Verde, la interacción entre el movimiento de las Placas Nazca y Suramericana, así como la posición de la Isla San Lorenzo hacen del Abanico de Lima un basamento fallado y basculado hacia el Norte de la ciudad, debido a los procesos tectónicos de levantamiento neógeno de los Andes centrales. 
La isla de San Lorenzo ejerce un efecto rotacional del paquete de sedimentos de los múltiples abanicos aluviales coalescentes. El basculamiento, que implica cientos de metros de levantamiento de la cordillera, provoca que el río Rímac y el Chillón formen dos sistemas coalescentes de abanicos aluviales, imbricados y erosionados por la acción marina en una costa en emersión que favorece los acantilados.

La sucesión de eventos registrada en el acantilado de la Costa Verde evidencia la naturaleza aluvial de la estructura conformante. Por una parte, las columnas estratigráficas evaluadas, mayormente son grano-decrecientes y están truncadas. Asimismo, la diferencia sedimentológica de norte a sur del abanico señalaría que hacia el sur había canales más jóvenes, donde la incisión fue mucho mayor.

La Geocronología indica que los materiales sedimentarios (los primeros $90 \mathrm{~m}$ ) que conforma el Abanico de Lima son de edad Holocena. Sin embargo, la revisión de las investigaciones previas y la confirmación de que los eventos se han ido superponiendo con el tiempo y han ido rellenando los paleo-cauces y superponiéndose a través del tiempo en diferentes sucesos, indicaría que los $500 \mathrm{~m}$ que se encuentran en el subsuelo son más antiguos. Por ello, la razón de que sean progresivamente mayores y diferentes, por la sedimentación continua producida desde el inicio de la ubicación del abanico en un paleo-valle tectónico.

Las estructuras y depósitos encontrados a la altura de la bajada de Armendáriz (Barranco); las dataciones, el gran espesor y la gran similitud y coherencia interna de las facies de este relleno aluvial señalan que, en la sucesión de procesos que formaron el Abanico de Lima han participado transgresiones marinas comprendidas entre el Pleistoceno y Holoceno.

La desertificación del clima en el Mioceno Superior, desde un clima árido a híper-árido ha inducido a un evento de retroceso aluvial y solapamiento del piedemonte andino, resultando en el posterior depósito de gravas de espesores decamétricos evidenciados en los perfiles levantados hacia el norte de la Costa Verde (por ejemplo en Miraflores y Magdalena). 


\subsubsection{Evolución del Abanico de Lima}

El análisis efectuado permite indicar que la cuenca del río Rímac es inestable desde la cabecera hasta la desembocadura debido a la Tectónica Andina. Esto es común en las cuencas de la Cordillera de los Andes con desembocadura hacia el océano Pacífico donde la influencia de la subducción es importante. Corresponde con un río joven que busca el equilibrio donde los procesos de erosión y fluviales continuaran.

La génesis del abanico del río Rímac es compleja y puede resumirse, de acuerdo con los datos presentados en esta memoria, en nueve etapas de desarrollo y conformación (Figura 71).

\section{1ㄹ Etapa (Qf0: $110 \mathrm{ka} \mathrm{BP)}$}

Durante la primera etapa (figura $71\left[1^{\mathrm{a}}\right]$ ) se produjo la sedimentación de las terrazas Qf0 y Qf1 controlada por la dirección de fallas de rumbo que ponen en contacto rocas sedimentarias de edad cretácica y rocas intrusivas del Eoceno-Mioceno (figura 67). El paleo-río Rímac desembocaba en ese entonces a la altura de Armendariz (BarrancoMiraflores), al SE de su posición actual.

La sedimentación habría ocurrido durante Is regresión marina asociada a la Glaciación Wurm o Wisconsin descrita por Clayton et al. (2006). En Miraflores, Qf0 fue muestreado a una profundidad de $9.6 \mathrm{~m}$ y $11.5 \mathrm{~m}$ (tabla 11) se obtuvo edades de $106,060 \pm 12,090$ ka y $108.960 \pm 7,900$ ka BP (Ml1 y Ml2). Qf0 comprende depósitos fluviales (arena cuarzosa y feldespóatica con limos) del paleo-cauce del río Huatica y es expuesta en la terraza T6 cerca del Museo de la Memoria (distrito de Miraflores).

Hacia el el borde norte del abanico, se tienen los depósitos del río Chillón contemporáneos (Sébrier \& Macharé, 1980). Asimismo, hacia el noreste se tendrían aportes esporádicos de la quebrada Canto Grande y del río Huaycoloro.

\section{$2^{-a}$ y 3를 Etapas (Qf1: 70 -50 ka BP)}

Durante la segunda etapa (figura $71\left[2^{\text {da }}\right]$ ) se produjo la deposición de Qf1, hacia el borde sur y centro del abanico. Los depósitos de Qf1 (muestras USGS-2511 y USGS2512, profundidad de muestreo de 15.6 y $14.6 \mathrm{~m}$ ) pueden observarse a la altura del distrito de Chorrillos. Estos materiales (arena fina, limo y arcilla), son muy diferentes a 
los de Qf0 hallados en Miraflores. El resultado de la datación de USGS-2511 es de $76.070 \pm 5.13 \mathrm{ka}$ BP y el de USGS-2512 es de $66.160 \pm 4.11 \mathrm{ka} \mathrm{BP}$ (tabla 11). No solo son más profundos, sino están aparentemente disturbados por una aparente subsidencia (figura 61).

Durante la 3a etapa, la actividad de una falla NW-SE se reflejó en el cambio de curso en el río Rimac. Como resultado, el cauce del río Rimac migró hacia el norte, aislando

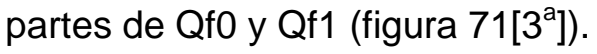

$4^{\text {ta }}, 5^{\text {ta }}$ y $6^{\text {ta }}$ Etapas (Qf2-Qf3: 50 a $20 \mathrm{ka} \mathrm{BP}$ )

En la etapa 4, ocupando el paleo-cauce del río Magdalena, los sedimentos Qf2 (T4) se encontraron en el área central del abanico (muestras MA1 y MA2, profundidad $=8.5 \mathrm{y}$ $8.6 \mathrm{~m}$, edad $=50.7 \pm 0.63$ y $56.6 \pm 0.24 \mathrm{ka} \mathrm{BP}$ ), al norte de Miraflores etapa (figura $\left.71\left[4^{a}\right]\right)$. Se localizan a una posición más alta en la columna, en comparación a las muestras extraídas en Chorrillos y Miraflores, siendo algo más jóvenes que las de Chorrillos. Esto confirma que la actividad fluvial era constante y contemporánea en el centro y al sur del abanico.

Durante este período (Pleistoceno Superior-Holoceno), una probable transgresión marina resultó en el truncamiento de los sedimentos granodecrecientes y agradacionales de la margen derecha de la Etapa 4 (Qf3, terraza fluvial T3). Este fue el comienzo de un período más árido y un glacis erosivo comenzó a formarse hacia las zonas central y sur del abanico de Lima.

Durante la 5aㅡ etapa, el cauce del río Rímac continuó migrando hacia el norte con una dirección general de flujo SW erosionando y retrabajando los sedimentos de sus etapas anteriores dejando paleo-cauces abandonados en el centro de Lima (figura 71 $\left.\left[5^{a}\right]\right)$. La erosión continuó en el área sur del abanico mientras el glacis continuaba formándose.

Durante la etapa 6 (figura $10\left[6^{a}\right]$ ), un posible evento de inundación causó el relleno y abandono de los paleo-cauces ubicados hacia el borde sur del abanico (ríos Surco, Huatica y Magdalena). Por la naturaleza de los depósitos (cantos rodados, gravas y limos de arenas finas y arcilla), que se observan en el perfil levantado en el cruce Tokio-Los Laureles (ATE), diferentes a los observados en los segmentos occidentales del abanico, asi como las orientaciones de clastos marcaron diferentes direcciones de 
paleo-corrientes se puede deducir el contacto entre los depósitos del río Rímac y los del río Huaycoloro (perfil B-B', Figura 54).

$7^{\text {ma }}$ Etapa (Qf4: 20 a 13ka BP)

Durante la $7^{\text {ma }}$ etapa de la evolución del abanico de Lima, Qf4 (T2) se depositó al norte de los depósitos de la $6^{\text {ta }}$ etapa (figura $71\left[7^{a}\right]$ ). En la actualidad, pequeños remanentes de Qf4 pueden ser reconocidos en las áreas adyacentes al río Rímac actual, en el borde norte del abanico. Por ejemplo se observaron cerca del cerro La Milla (distrito de San Matín de Porres, figura 72) y de cerro Partido en la Avenida Ramiro Priale (distrito San Juan de Lurigancho, figura 54). En este último sector, en el área administrada por SEDAPAL Qf4 fue muestreado a una profundidad de $4.5 \mathrm{~m}$ (SE1 Y SE2, tabla 11) y se obtuvieron edades de $13.5 \pm 780$ ka y $20.310 \pm 1,880$ ka BP (Ml1 y $\mathrm{MI}$ ).

En esta etapa, coalescencias de canales habrían ocurrido durante grandes inundaciones, así como el aislamiento del paleo-cauce del río Magdalena, mientras continuaba la incisión del río Rímac en esa posición. Mientras tanto, la erosión y formación del glacis continuaba hacia el sector sur del abanico (figura 71 [7ª).

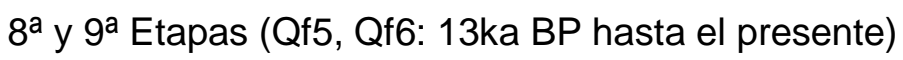

La etapa 8 es la superficie del abanico más joven y corresponde a la deposición activa más reciente Qf6 (T0) con una orientación este-oeste (figura 71 [8ª]). El canal continuo y angosto presenta una superficie diseccionada por el río Rímac. La formación de glacis continuó hacia el sur del abanico (Figura 72, perfil AA'), asi como la acumulación de depósitos eólicos.

La 9aㅡ Etapa corresponde al presente período de urbanización donde el canal actual del río Rimac incide en los sedimentos Qf6, y su flujo está controlado por muros de hormigón que reemplazan las orillas de los ríos activos.

El canal construido ahora conduce los sedimentos desde las partes altas de la cuenca del río Rímac hasta un delta progradante en alta mar con numerosos canales distributarios (figura $71\left[9^{\mathrm{a}}\right]$ ). En la actualidad, los sedimentos del Qf6 se depositan lateralmente por flujos durante grandes inundaciones. 
La urbanización ha restringido el desarrollo del glacis, pero persiste un clima árido. Antes de la urbanización, el piedemonte de Lima se estaba desarrollando a través de la erosión y la aridez al sur del abanico, sin embargo por ajustes isistáticos, su elevación es la más alta (figura 72).

La susceptibilidad a desbordes, aunque ha sido modificada parcialmente por los diques de contención que confinan al río Rímac, no ha desaparecido y la exposición a estos procesos cíclicos continua, principalmente en la terraza Qf5 y Qf6 (sobretodo las viviendas situadas a ambas márgenes del Rímac (distritos de El Rímac, San Martín, ATE y San Juan de Lurigancho).

Los flujos de detritos y lodo del río Huaycoloro y la querbrada de Canto Grande de los años 1987, 1998, 2016 y 2017 demuestran la susceptibilidad de las comunidades modernas a la devastación, por las características de alto riesgo del sector. Estas conclusiones se basan en el registro de los desastres desencadenados en 1998 por los flujos de detritos y de lodo provenientes del río Huaycoloro que provocaron afectación en viviendas y calles del centro de Lima y distritos aledaños (Dávila \& Valenzuela, 1998).

Ha de destacarse que en el 2017 el evento denominado "El Niño costero" (K. Takahashi \& Martínez, 2017) reactivó el flujo del río Huaycoloro y ocasionó la acumulación de sedimentos de uno a dos metros en sus márgenes y en las proximidades del el rio Rímac (a la altura de la estación Cerro Partido de SEDAPAL, en Huachipa, ATE). A causa de este evento, el tránsito de vehículos a lo largo de la avenida Ramiro Prialé, uno de los principales accesos al centro del país, se interrumpió temporalmente. 


\section{Pleistoceno superior}

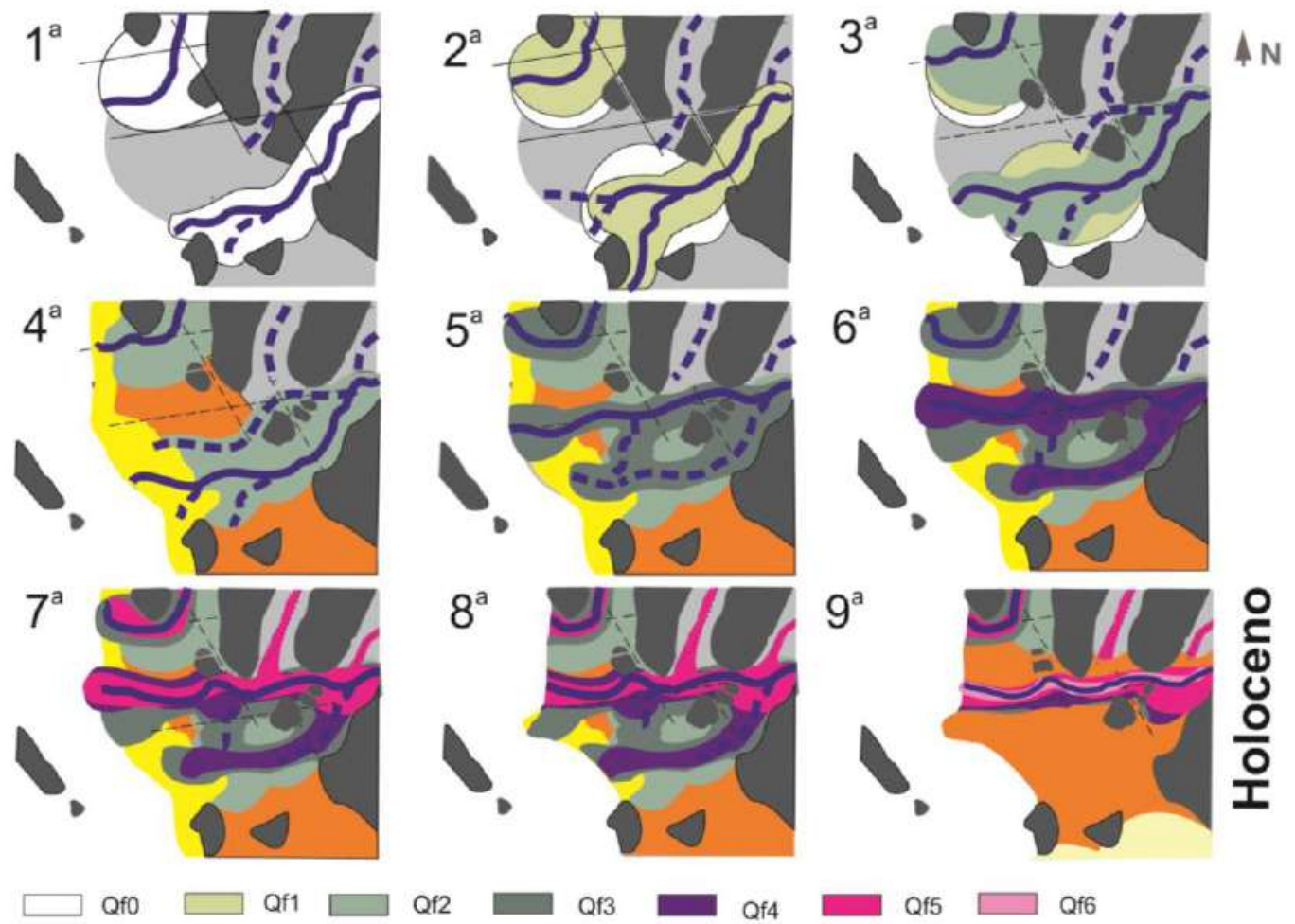

Depósitos eólicos

$\sim$ Cauce actual

Figura 71. Etapas del desarrollo del Abanico aluvial de Lima.

$<10000 \sim 20-10.000 \quad \sim 50-20.000 \quad \sim 110.000 \sim 70-50.000$

Rio Rimac Paleo- Paleo-cauce Paleo-cauce Paleo-cauce

(cauce actual) cauce del truncado del río truncado del truncado del

NW río Rímac Magdalena

río Huatica río Surco

Etapa 7 - Etapas 4,5,6 - Etapa 1 - Qf0

Qf2, Qf3 (T4, T3)

(T6)

A Qf5, Q6 (T1, T0)

Qf4, (T2)

Cerro La Milla

(Distrito de San $300 \mathrm{~m}$ Martin)
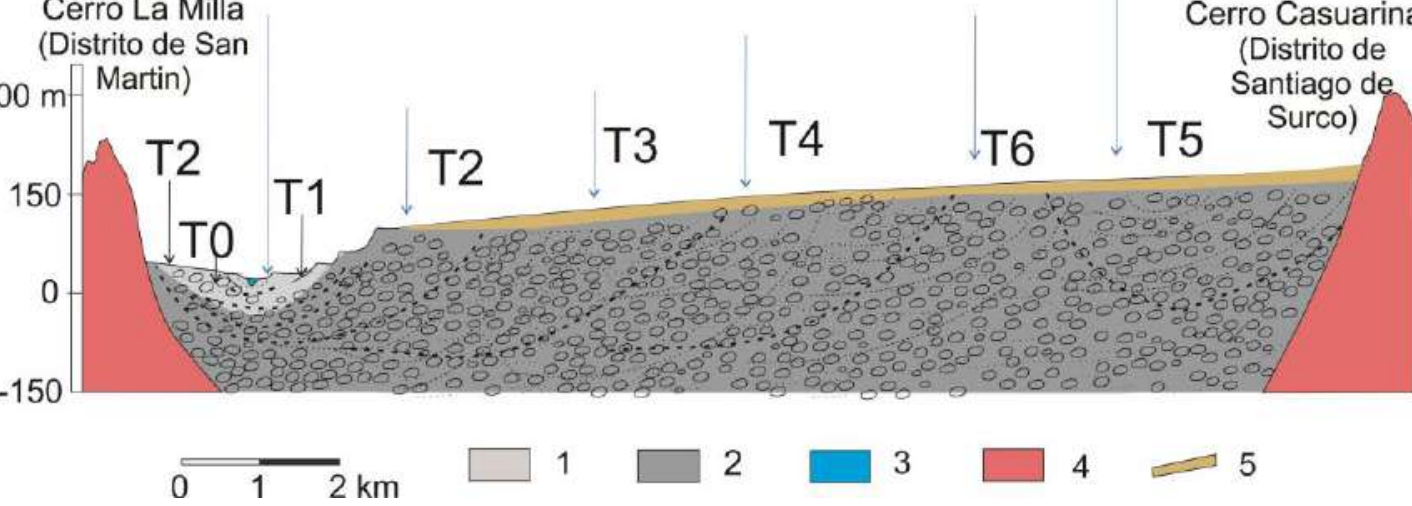

\section{3}

rio Surco
Etapas 2,3 -

SE

Qf1(T5) $\mathbf{A}^{\prime}$

Cerro Casuarinas

(Distrito de

antiago de

Figura 72. Sección transversal esquemática entre los cerros La Milla (San Martin) y Casuarinas (Santiago de Surco) de que muestra las etapas de sedimentación en el abanico de Lima. T0 a T6: terrazas fluvioaluviales. 1. Materiales del Holoceno, 2. Materiales del Pleistoceno, 3. Canal actual, 4. Substrato intrusivo. 5. Glacis. 


\subsubsection{Sobre escenario futuro de su evolución}

En relación a la ocurrencia de flujos e inundaciones en el área de Lima Metropolitana, estas se producen por un lado debido a la actividad fluvial y la precipitación, que funciona como detonante de los eventos. Estos ocurren mayormente en las áreas de confluencia entre las micro-cuencas de las quebradas que rodean Lima Metropolitana como: Huaycoloro, Canto Grande y Pedregal y el río Rímac, donde se concentra parte de la población metropolitana de Lima.

Al haberse restringido parte del cauce natural del río Rímac (acápite 4.2.1), a largo plazo se producirían problemas de erosión aguas más abajo del ápice del abanico, por el aumento de la velocidad del material acarreado en el sector no encauzado (problemas de erosión y socavamiento como los ocurridos en marzo del 2017 en el Malecón Checa en el distrito limeño de San Juan de Lurigancho).

Las características del área del abanico del rio Rímac permiten indicar que es susceptible a proceso de desborde asociados a lluvias excepcionales (como las producidas durante el evento ENSO u otros). La relación entre la ocurrencia de procesos de avenidas y lluvias fuertes ha quedado evidenciada en los daños generados por los flujos en Chosica de los años 1987, 1998, 2012, 2015 y 2017. Estos eventos movilizaron grandes volúmenes de material en cortos recorridos y con lluvias por demás escasas (considerando otras zonas del territorio peruano donde esa cantidad de lluvia pasaría desapercibida). El área fuente de estos procesos tiene pendientes elevadas, lo cual justifica la inestabilidad de los materiales susceptibles a remoción en el Batolito de la Costa, tanto por escorrentía como por el discurrir de agua en los cauces de flujos esporádicos cuando se presentan lluvias excepcionales como las producidas en el verano de 2017.

Todo ello indica que el riesgo de futuros, e inminentes sucesos de inundación en esta área es potencialmente muy alto para la capital peruana. Las consecuencias futuras de eventos de esta naturaleza pueden ser desastrosas debido al creciente desarrollo poblacional de Lima, considerada una mega ciudad capital. De hecho, la modelización de un evento considerando la máxima avenida, corroborada con los depósitos aluviales encontrados en campo señala una probable afectación de los distritos de Ate (Huachipa), Lurigancho (Chosica) y San Juan de Lurigancho (desembocadura de la quebrada Canto Grande), especialmente de las viviendas ubicadas en las 
proximidades del cauce que serían alcanzadas por la mezcla de lodos, piedras y agua (a una altura de $7 \mathrm{~m}$ ).

Vale mencionar que en el diseño de algunas estructuras viales existentes en el área metropolitana del río Rímac, no se habría considerado las geoformas fluviales preexistentes en su valle de inundación. Lo cual ha llevado a construir estructuras que encajan al río en un cauce estrecho considerando solo el caudal histórico del Rímac y no el geológico. El ancho actual de la canalización es casi la tercera parte del evidenciado en los estudios geomorfológicos, y podría resultar insuficiente para proteger a las vías construidas en ambas márgenes del río Rímac de las inundaciones, de cara a futuros eventos de cambios climáticos. En consecuencia, existe la posibilidad de eventos futuros de flujos e inundaciones con consecuencias potencialmente catastróficas para los sectores adyacentes al río Rímac debido a los efectos de cambios climáticos en el sector (Gosling et al., 2011) que provocarían un pico de descarga en las inundaciones fluviales. 


\subsection{RECOMENDACIONES}

Por lo señalado, es necesario tener en cuenta, para el diseño de futuras estructuras en el cauce del río Rímac, los volúmenes de material que pueden originar eventos de gran dimensión de flujos, avenidas e inundaciones asociados a cambios climáticos.

Se requiere medidas que puedan reducir el peligro y la vulnerabilidad de la población de Lima Metropolitana ante la ocurrencia de flujos y desbordes, procesos naturales propios de la evolución de un abanico aluvial en el área estudiada. Por esto se debe fomentar un uso de suelo compatible con la dinámica natural del abanico de Lima. Asimismo es recomendable aplicar técnicas internacionales comprobadas que busquen acondicionar los espacios adecuadamente, enfocándose en la seguridad de la población asentada en zonas de riesgo (por ejemplo la tecnología japonesa o la suiza).

Por otro lado, siendo un buen conocimiento del registro climático fundamental para entender la frecuencia y magnitud de los procesos descritos, es necesario caracterizar climática-hidrológicamente cada región del Perú, para así poder establecer relaciones directas entre la ocurrencia de eventos geohidrológicos y las precipitaciones (umbrales de detonación de eventos). En este sentido, es recomendable continuar en la investigación de la aplicación de técnicas paleo-hidrológicas dendro-geomorfológicas, entre otras, que han demostrado ser eficaces en la reconstrucción de eventos pasados. El empleo de estas técnicas aportaría información para completar el registro climático ante la falta de datos.

Asimismo es necesario realizar correlaciones de los máximos climáticos con proxies internacionales para abordar así todos los eventos registrados en las lluvias excepcionales corresponden a ENSO.

Asimismo, se considera que las variables regionales (estructuras tectónicas, etc.) del abanico y deben ser analizadas con mayor profundidad en relación a la investigación de su actividad actual y con el aporte de más dataciones por OSL u otros métodos. Asimismo, es conveniente aplicar la nueva tecnología para desarrollar nuevos estudios geofísicos y analizar información de pozos para el aprovechamiento hídrico en el área del abanico a fin de refinar los resultados de esta tesis doctoral. 


\subsubsection{Propuestas enfocadas a la prevención de desastres}

Si se quiere reducir la probabilidad de desborde del rio Rímac es importante limitar el aporte a su cauce, lo cual implica una reducción del material que ingrese al mismo. Por ellos es importante establecer propuestas a nivel de cuenca. En tal sentido, a fin de actuar sobre las quebradas que aportan al río Rímac, se presenta el siguiente proyecto piloto, el cual busca minimizar los aportes hacia el rio Rímac, en base a la modelización de flujos de detritos en la quebrada Rayos de Sol (Chosica) se ha diseñado un plan preliminar para el control de dichos procesos. El planteamiento propuesto (Figura 74) propone la implementación de un plan maestro SABO para probar la eficacia en el Perú de una gestión integral de desastres en una de las microcuencas más afectadas por flujos de detritos, que luego pueda replicarse a otros sitios con características similares.

SABO en japonés significa "control de la erosión" y con ese nombre se conoce a la tecnología que fue introducida en el Japón en 1860 por especialistas holandeses y posteriormente se perfeccionó en dicho país con apoyo de expertos suizos y alemanes. Actualmente el término SABO en Japón incluye todos los trabajos de prevención y mitigación de movimientos en masa, considerando la influencia futura de las medidas de control adoptadas con énfasis en su calidad y diseño (Ikeya, 1976; Osanai, Mizuno, \& Mizuyama, 2010).

\subsubsection{Plan maestro SABO}

Contempla todas las fases de un estudio de mitigación de riesgos geológicos, desde la investigación de los peligros geológicos, su comportamiento, la modelización de escenarios hasta la planificación de la construcción de las estructuras de mitigación (Foto 24). 


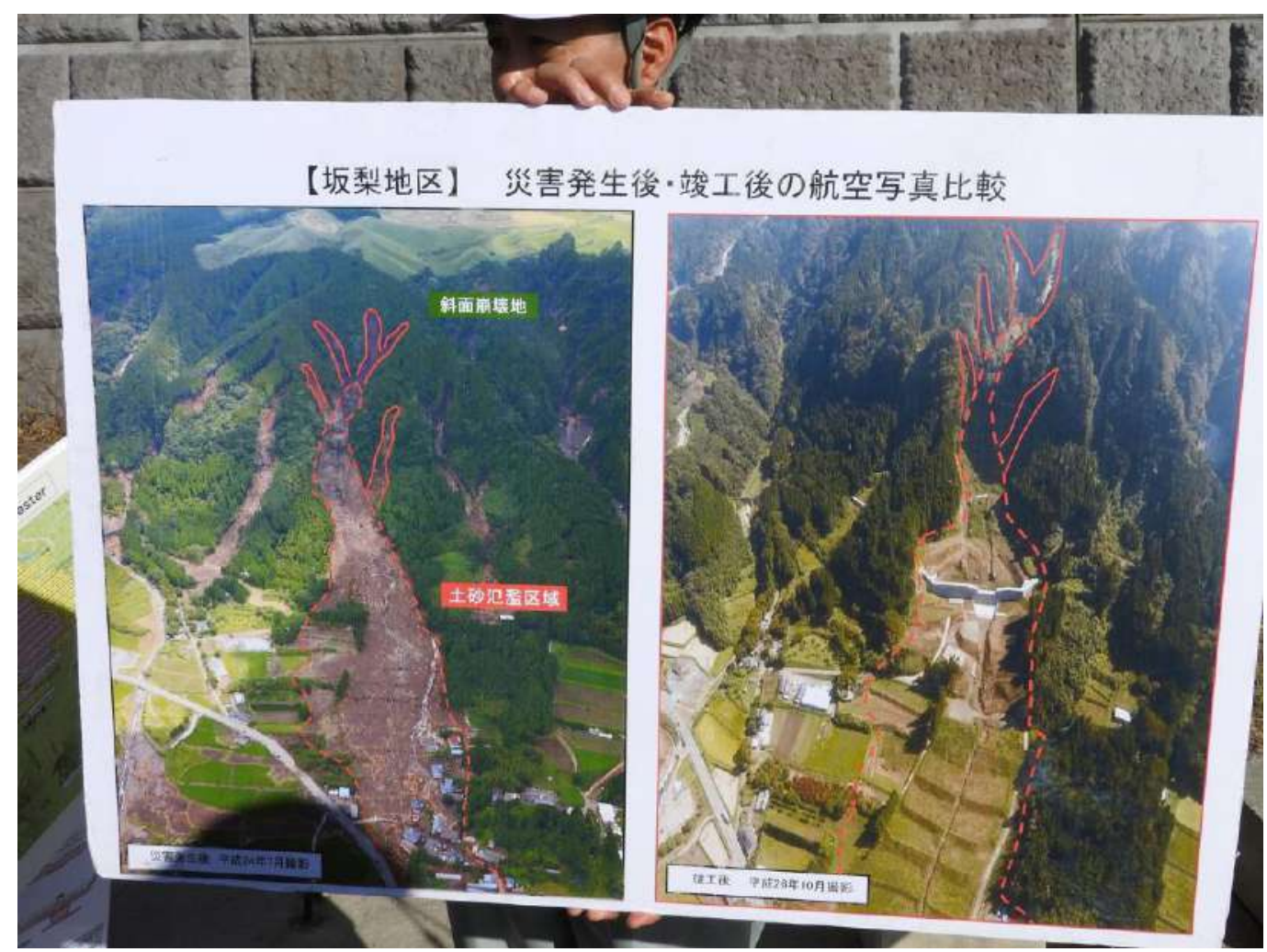

Foto 24. Esquema del Plan Maestro SABO en Minami-Aso Village (Kumamoto). Fotos: S. Villacorta (2015).

En la fase de planificación de las estructuras, de acuerdo a la geodinámica del sitio y el proceso evaluado se elige uno u otro tipo de estructura de control.

Así por ejemplo en el caso de los flujos de detritos se eligen represas que almacenen una cantidad esperada de sedimentos y que a su vez disminuyan la energía cinética (capacidad destructora y erosiva) de los mismos.

\subsubsection{Las presas SABO}

Son estructuras que permiten estabilizar los márgenes de cauces de quebradas de fuerte pendiente en las cuencas altas y medias, deteniendo los grandes bloques movilizados por flujos de detritos y eventos similares (Foto 25). El principal beneficio de una presa SABO radica en su funcionamiento ya que permite atrapar los sedimentos que bajan por el cauce activo y, una vez colmatada esta, se produce un cambio en la pendiente del cauce que se traduce en la disminución de la fuerza de futuros eventos. Por consiguiente, disminuye la velocidad de transporte de materiales, lo que incide en una menor erosión que protege frente a nuevos eventos (Mizuyama \& Mizuno, 1997). 
Están construidas principalmente de "suelo-cemento" (cemento ciclópeo con material del sitio) y tienen los siguientes componentes: cuerpo de la presa, muros laterales (aguas abajo), piso de fondo, contra-presa y agujeros disipadores de energía (Figura 73). El cuerpo principal permite el almacenamiento de sedimentos, lo que poco a poco va disminuyendo la pendiente del río. Los muros unen la presa con la contra-presa. El piso de fondo protege a la presa contra la caída del agua e impacto de los sedimentos. La contra-presa disminuye la energía del agua y permite la formación de un colchón amortiguador hidráulico. Las perforaciones en el cuerpo principal alivian la presión hidráulica que tiende a socavar la contra-presa.

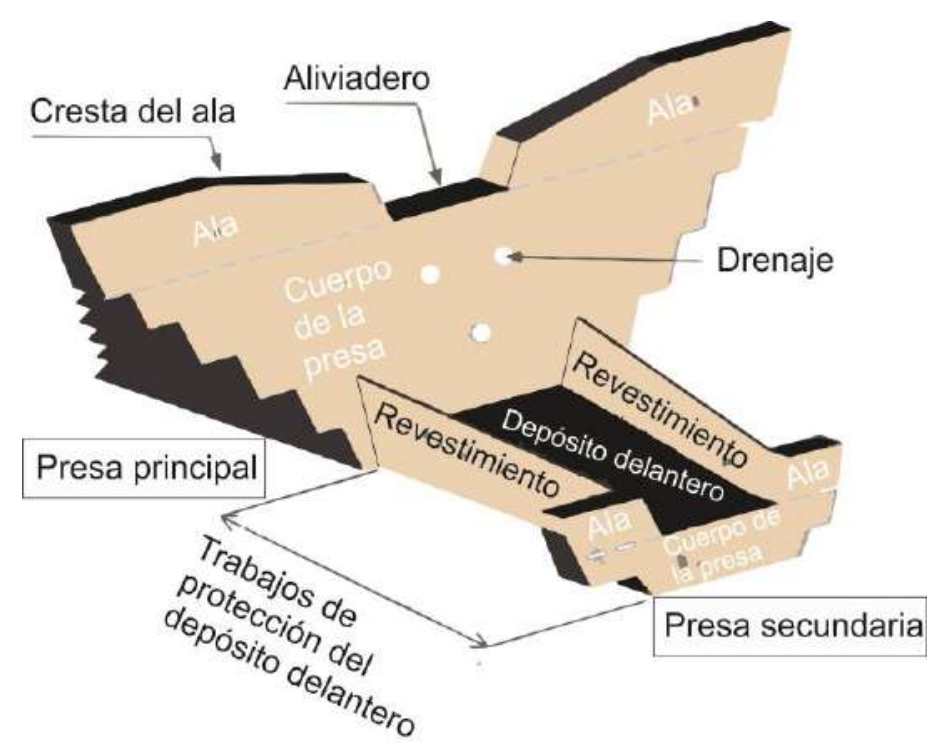

Figura 73. Partes de una represa SABO tipo. Traducido de: Ikeda (2015)

El diseño de estas presas, considerando la colmatación de sedimentos, es tal que no necesita un proceso de limpieza constante. La aplicación de modelos numéricos permite la selección del modelo de presa, así como planificar el proceso de supervisión (Mizuyama \& Mizuno, 1997). 


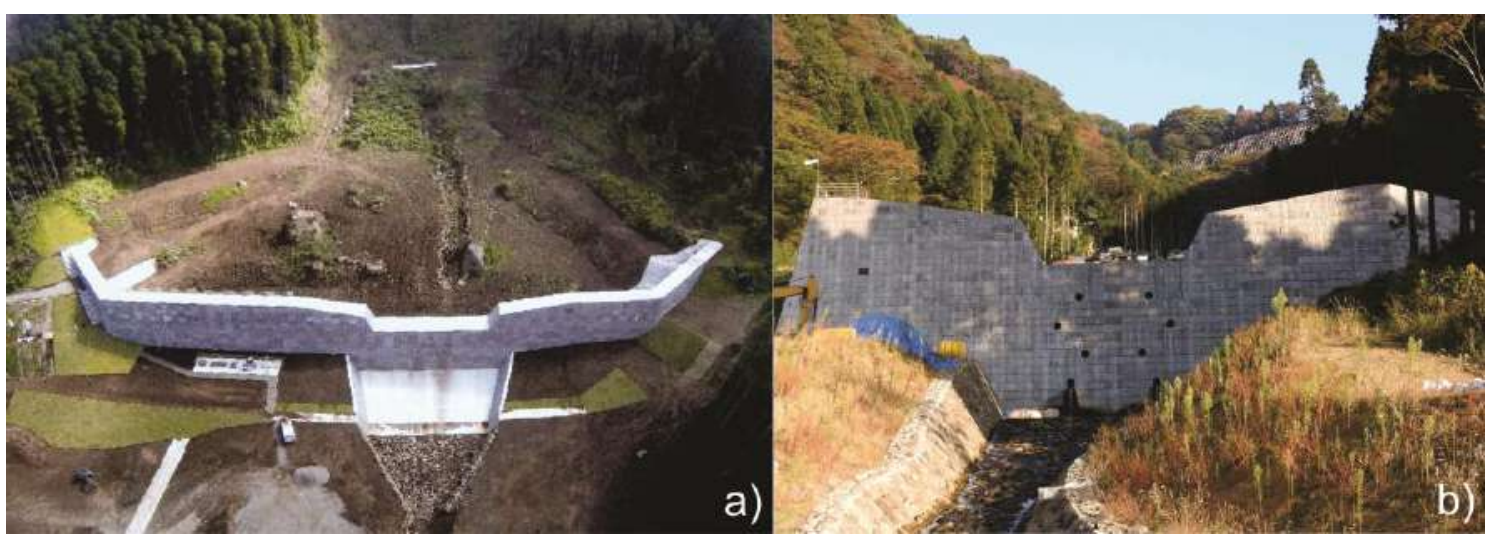

Foto 25. Represa SABO para el control de flujos de detritos en Minami-Aso Village (Kumamoto), a) vista de planta, b) vista frontal. Foto: S. Villacorta (2015).

\section{Presupuesto}

Para tener una idea del costo de la instalación de una presa tipo SABO en Perú, se puede estimar, a partir de las inversiones realizadas para represas con volúmenes de almacenamiento de $2.095 \mathrm{~m}^{3}$ instaladas en el Parque Nacional de El Ávila (Caracas, Venezuela), después del desastre de Vargas de 1999 (García-Martínez \& López, 2005); que el costo en el 2004 giraba en torno a los 610,000,000 de Bolívares (Agencia de Cooperación Internacional de Japón, 2004) equivalente a 57,300,000 euros. Incluyendo las actuaciones indirectas (trabajos de excavación, remoción de material, etc.).

\subsubsection{Propuesta en la quebrada Rayos de Sol (Chosica)}

Las represas proyectadas deben ser complementadas con diques disipadores, canales de drenaje. Asimismo, se contempla la canalización del cauce hasta su desembocadura y la ubicación de áreas para el depósito final de los detritos (Sand pocket). Estas obras complementarias significan una vida más larga para las presas SABO lo que permitiría proteger con efectividad a la población ubicada aguas abajo. Para la parte alta, que tiene mayor pendiente, se propone una presa SABO abierta (Foto 26) que permite la retención de los bloques más grandes y disminuye la velocidad de los detritos de menor tamaño, los cuales serían almacenados en represas SABO cerradas, ubicadas aguas abajo.

El plan maestro SABO incluye además de las medidas estructurales, las no estructurales, tales como un sistema de alerta y evacuación basado en los modelos generados y en el monitoreo en tiempo real de la actividad de los flujos de detritos. 
Ello implica la instalación de cámaras de vigilancia y sensores de las precipitaciones ocurridas en la parte alta y baja de la cuenca.

El proyecto debe incluir además un estudio socio-económico para la propuesta de reordenamiento urbano: las casas construidas deben ubicarse lejos de la canalización y del área de amortiguamiento.

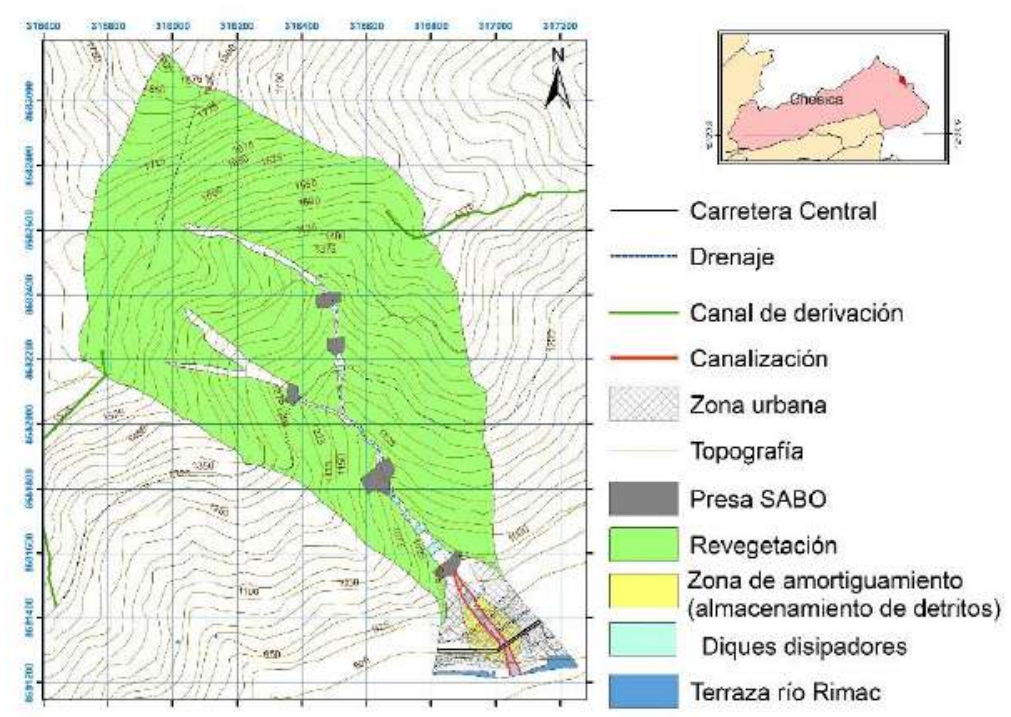

Figura 74. Propuesta de Plan maestro SABO en la cuenca de la quebrada Rayos de Sol

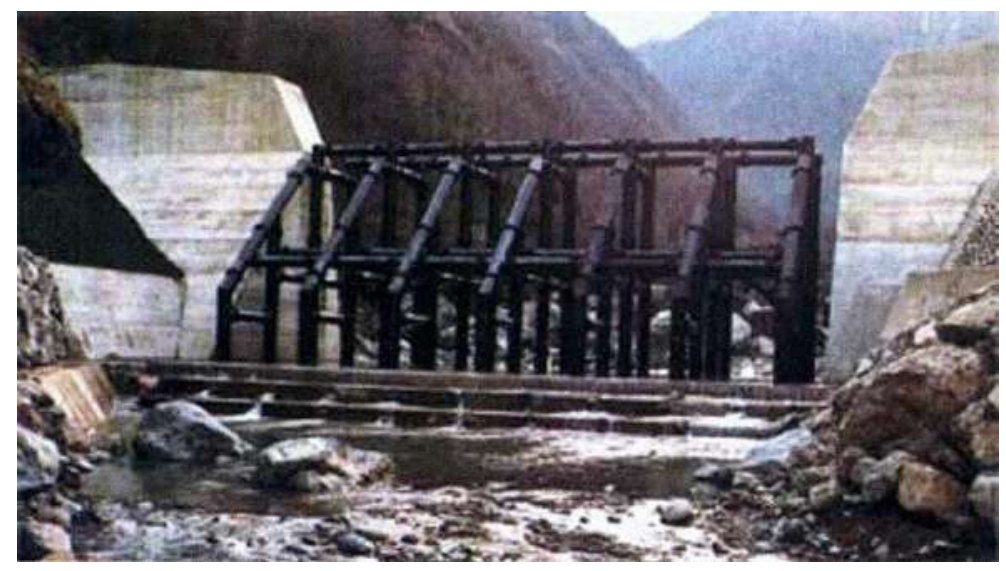

Foto 26. Presa SABO tipo abierta. Tomado de: Ikeda (2015)

Finalmente, se debe incluir como parte del plan, un programa de concientización de las autoridades locales y la comunidad, con simulacros de flujos periódicamente. 
En resumen, el Plan Maestro SABO para el caso de la quebraba Rayos de Sol contempla el desarrollo de los siguientes estudios específicos:

- Caracterización de las precipitaciones (escenarios para diferentes periodos de retorno).

- Análisis de datos históricos de eventos de flujos relacionados con las precipitaciones (para hallar el umbral de lluvias que detona los flujos).

- Simulación de flujos de detritos (incluyendo la caracterización de los depósitos, etc.).

- Evidencia de daños de sucesos pasados (casas destruidas, inundaciones, etc.).

- Estudios de costo-beneficio para definir el número y ubicación de las presas

- Estudios sociales para reubicar las casas lejos del área de influencia de los flujos de detritos.

Es necesario mencionar que para concretar la propuesta se requiere una simulación numérica de flujos de detritos para diferentes periodos de retorno. En el caso de Japón, cuando se diseña represas SABO para el control de flujos se toma como referencia un periodo de retorno de 100 años (Ikeda, 2015). La modelización debe incluir la ubicación probable de las represas SABO para evaluar su funcionamiento (Takahama, Fujita, Kondo, \& Hachiya, 2002; Egashira \& Itoh, 2004; Nakatani et al., 2007) 


\section{REFERENCIAS}

Abad, C. (2009). Huaycos en 1987 en el distrito de Lurigancho-Chosica (lima-Perú). Bulletin De L'Institut Français D'Études Andines, (38 (3)), 475-486.

Abalos, B. (1987). Controles, facies y relación con el tectonismo de los abanicos aluviales. Estudio Tecto-estratigráfíco de los materiales aluviales oligocenos de los Montes De Vitoria Occidentales. Estadios Del Instituto Alavés De La Naturaleza, 2 , 91-137.

Abbott, M. B., Bathurst, J. C., Cunge, J. A., O'Connell, P. E., \& Rasmussen, J. (1986). An introduction to the European hydrological System-Systeme hydrologique European, "SHE", 1: History and philosophy of a physically-based, distributed modelling system. Journal of Hydrology, 87(1), 45-59.

Aceituno, P. (1998). Climate elements of the South American Altiplano. Rev. GeofísicaIPGH, 44, 37-55.

Agencia de Cooperación Internacional de Japón. (2004). Informe de Soporte S15. Instalación de equipos hidro-meteorológicos. Informe técnico inédito. Venezuela: JICA.

Aitken, M. (1985). Thermoluminescence dating: Past progress and future trends. Nuclear Tracks and Radiation Measurements (1982), 10(1-2), 3-6.

Akan, A. O. (1993). Urban stormwater hydrology: A guide to engineering calculations CRC Press.

Al-Farraj, A. (1996). Late Pleistocene Geomorphology in Wadi Al-Bih Northern UAE and Oman: With Special Emphasis on Wadi Terraces and Alluvial Fans. Tesis Doctoral, University of Liverpool.

Aleman, A., Benavides, V., \& León, W. (2006). Estratigrafía, Sedimentología y evolución tectónica del área de Lima. Guía de campo №11. Sociedad Geológica del Perú, Lima. 
Alfaro, E., Cid, L., \& Enfield, D. (1998). Relaciones entre el inicio y el término de la estación lluviosa en Centroamérica y los océanos Pacífico y Atlántico tropical. Investigaciones Marinas, 26, 59-69.

Allen, P. A. (1981). Sediments and processes on a small stream-flow dominated, Devonian alluvial fan, Shetland Islands. Sedimentary Geology, 29(1), 31-66.

ANA. (2012a). Resumen ejecutivo: Delimitación y codificación de unidades hidrográficas del Perú. Informe técnico inédito. Autoridad Nacional del Agua, Lima.

ANA. (2012b). Tratamiento del cauce del río Rímac y principales quebradas tributarias para mitigar efectos de eventos hidrológicos extremos. Informe técnico inédito. Dirección de Estudios de Proyectos Hidráulicos Multisectoriales). Lima: Autoridad Nacional del Agua.

Andres, N., Vegas, F., Lavado, W., \& Zappa, M. (2014). Water resources and climate change impact modelling on a daily time scale in the Peruvian Andes. Hydrological Sciences Journal, 59(11), 2043-2059.

Andreu, J. (1983). Modelos agregados y distribuidos. Modelos unicelulares. Modelos Glover-Jenkins. Utilización Conjunta de Aguas Superficiales y Subterráneas. En: Curso sobre "Utilización conjunta de aguas superficiales y subterráneas". Universidad Politécnica de Valencia. Castellón de la Plana (Valencia, España).

Anstey, R. (1966). A comparison of alluvial fans in West Pakistan and the United States. Pakistan Geographical Review, 21, 14-20.

Apaclla, R. (2010). Estudio de máximas avenidas en las cuencas de la zona centro de la vertiente del Pacífico. Informe técnico inédito. Dirección de Conservación y Planeamiento de Recursos Hídricos. Lima: Autoridad Nacional del Agua-ANA.

Aparicio, F. (1997). Fundamentos de hidrología de superficie. Balderas, México: Limusa.

Arce, J. (1984). Estructura geo-eléctrica del subsuelo Rímac-chillón. En: Lima: Sociedad geológica del Perú. Volumen Jubilar LX Aniversario, Homenaje Al Dr. Georg Petersen G., (1) 
Arzani, N. (2005). The fluvial mega-fan of Abarkoh basin (central Iran): An example of flash-flood sedimentation in arid lands. Geological Society, London, Special Publications, 251(1), 41-59.

Association Louis Berger International -Tropical. Research - ECSA Ingenieros. (1998). Plan de Manejo y Estudios de Factibilidad del programa Ambiental de la Cuenca del Río Rímac. Informe técnico inédito. INADE.

Avendaño, C., Cobo, R., Gómez, J. L., \& Sanz, E. (1995). Procedimiento para evaluar la degradación específica (erosión) de cuencas de embalses a partir de los sedimentos acumulados en los mismos. Aplicación al estudio de embalses españoles. Ingeniería Civil, 99, 51-58.

Ayala-Carcedo, F., \& Olcinas, J. (Eds.). (2002). Riesgos naturales. Barcelona: Ariel.

Bagnold, R. A. (1954). (1954). Experiments on a gravity-free dispersion of large solid spheres in a newtonian fluid under shear. Proceeding Paper, Royal Society of London A: Mathematical, Physical and Engineering Sciences, 225(1160) 49-63.

Baker, V. R. (1977). Stream-channel response to floods, with examples from central Texas. Geological Society of America Bulletin, 88(8), 1057-1071.

Bateman, A., Medina, V., Hürlimann, M., \& Velasco, D. (2007). Modelo bidimensional para simulación de flujos detríticos: FLATModel. Aplicación a una cuenca del pirineo catalán. Ing. Hidrául Méx, 22(4), 5-20.

Bateman, A., Medina, V., \& Velasco, D. (2010). (2010). Soil infiltration effect in flat areas floods simulation. Proceeding Paper, XVIII International Conference on Water Resources, CIMNE, Barcelona, Spain.

Beaty, C. B. (1963). Origin of alluvial fans, white mountains, California and Nevada. Annals of the Association of American Geographers, 53(4), 516-535.

Beaty, C. B. (1970). Age and estimated rate of accumulation of an alluvial fan, white mountains, California, USA. American Journal of Science, 268(1), 50-77. 
Beaumont, P. (1972). Alluvial fans along the foothills of the Elburz mountains, Iran. Palaeogeography, Paleoclimatology, Palaeoecology, 12(4), 251-273.

Bell, V. A., \& Moore, R. J. (1998). A grid-based distributed flood forecasting model for use with weather radar data: Part 2. case studies. Hydrology and Earth System Sciences Discussions, 2(2/3), 283-298.

Benavides-Caceres, V. (1999). Orogenic evolution of the Peruvian Andes: The Andean cycle. Geology and Ore Deposits of the Central Andes. Special Publication, (7), 61-107.

Benito, G., Rico, M., Díez-Herrero, A., Sánchez, Y., Sopeña, A., \& Thorndycraft, V. R. (2004). (2004). Hidrología de paleo crecidas y seguridad de presas. Resumen extendido. En: Los Riesgos Naturales y Antrópicos en Geomorfología. Actas de la VIII Reunión Nacional De Geomorfología, Toledo, 89-98.

Benito, G., Gutie, M., \& Sancho, C. (1992). Erosion rates in badland areas of the central Ebro basin (NE-Spain). Catena, 19(3-4), 269-286.

Benson, M. A., \& Dalrymple, T. (1967). General Field and Office Procedures for Indirect Discharge Measurements: U.S. Geological Survey Techniques of WaterResources Investigations, book 3, chap. Al, 30 p., Disponible en: http://pubs.er.usgs.gov/publication/twri03A1.

Bernabé, M. (2010). Estudio Hidrológico y Ubicación de la Red de Estaciones Hidrométricas en la Cuenca del Río Rímac. Informe técnico inédito. Autoridad Nacional del Agua, Dirección de Conservación y Planeamiento de Recursos Hídricos. Lima.

Beven, K. J. (1991). Spatially distributed modelling: Conceptual approach to runoff prediction. Recent advances in the modelling of hydrologic systems. pp. 373-387. Springer.

Beven, K. J., \& Kirkby, M. J. (1979). A physically based, variable contributing area model of basin hydrology/un modèle à base physique de zone d'appel variable de l'hydrologie du bassin versant. Hydrological Sciences Journal, 24(1), 43-69. 
Bingham, E. C. (1922). Fluidity and plasticity. New York: McGraw-Hill Book Company, Incorporated.

Bingham, E. C., \& Green, H. (1919). (1919). Paint, a plastic material and not a viscous liquid; the measurement of its mobility and yield value. Proceeding Paper, Am. Soc. Test. Mater, 19, 640-664.

Bjerknes, J. (1966). Survey of El Niño 1957-58 in its relation to tropical pacific meteorology. Inter-American Tropical Tuna Commission Bulletin, 12(2), 1-62.

Bladé, E., Sánchez-Juny, M., Sánchez, H. P., Niñerola, D., \& Gómez, M. (2009). Modelación numérica en ríos en régimen permanente y variable. Una visión a partir del modelo HEC-RAS. Universitat Politecnica de Catalunya. Iniciativa Digital Politécnica.

Blair, T. C., \& McPherson, J. G. (1994). Alluvial fans and their natural distinction from rivers based on morphology, hydraulic processes, sedimentary processes, and facies assemblages. Journal of Sedimentary Research, 64(3)

Blair, T. C., \& McPherson, J. G. (1998). Recent debris-flow processes and resultant form and facies of the dolomite alluvial fan, Owens valley, California. Journal of Sedimentary Research, 68(5)

Blissenbach, E. (1954). Geology of alluvial fans in semiarid regions. Geological Society of America Bulletin, 65(2), 175-190.

Blum, M. D., \& Törnqvist, T. E. (2000). Fluvial responses to climate and sea-level change: A review and look forward. Sedimentology, 47(s1), 2-48.

Bobee, B., \& Robitaille, R. (1977). The use of the Pearson type 3 and log Pearson type 3 distributions revisited. Water Resources Research, 13(2), 427-443.

Bodoque, J. M. (2007). Ensayos metodológicos para la cuantificación de procesos geomorfológicos activos asociados a la hidrología de superficie en las Sierras de Guadarrama y Gredos. Tesis Doctoral. Universidad Complutense de Madrid. Facultad de Ciencias Geológicas. 
Bonacci, O. (1984). Rainfall as the basis for urban Runoff-Experience and practice in Yugoslavia. Water Science and Technology, 16(8-9), 101-108.

Boothroyd, J. C., \& Ashley, G. M. (1975). Processes, bar morphology, and sedimentary structures on braided outwash fans, north-eastern gulf of Alaska. In: AV Jopling and BC. McDonald (eds). Glaciofluvial and Glaciolacustrine sedimentation. Soc. Econ. Paleont. Mineral. Spec. Pub., 23, pp. 193-222.

Boothroyd, J. C., \& Nummedal, D. (1978). Proglacial braided outwash: A model for humid alluvial-fan deposits. In: Fluvial Sedimentology, Miall, AD. (Ed) Canadian Society of Petroleum Geologists, Memoir 5; 641-668.

Bøtter-Jensen, L. (2000). Development of optically stimulated luminescence techniques using natural minerals and ceramics, and their application to retrospective dosimetry. Copenhagen: Risø National Laboratory (Risø-R-1211). 186 pgs.

Bovis, M., \& Dagg, B. (1992). Debris flow triggering by impulsive loading: Mechanical modelling and case studies. Canadian Geotechnical Journal, 29(3), 345-352.

Box, G., \& Jenkins, G. M. (Eds.). (1976). Time series analysis: forecasting and control (2dth ed.). San Francisco, California: Holden Day, Inc.575 p.

Bradley, A. A. (1998). Regional frequency analysis methods for evaluating changes in hydrologic extremes. Water Resources Research, 34(4), 741-750.

Bradley, A., \& Zhao, H. (1997). Climatic variations in extreme precipitation in the Midwest. Journal of Hydrologic Engineering. University of lowa. 20 pp.

Bras, R. L. (1990). Hydrology: An introduction to hydrologic science. Addison-Wesley Publishing Company. Series in civil engineering. Reading, MA, p 643.

Brázdil, R., Kundzewicz, Z. W., \& Benito, G. (2006). Historical hydrology for studying flood risk in Europe. Hydrological Sciences Journal, 51(5), 739-764. 
Brazier, V., Whittington, G., \& Ballantyne, C. K. (1988). Holocene debris cone evolution in glen active, western Grampian highlands, Scotland. Earth Surface Processes and Landforms, 13(6), 525-531.

Bryan, K. (1922). Erosion and sedimentation in the Papago country', United States geol. Survey Bulletin, 730

Boughton, W. C. (1989). A review of the USDA SCS Curve Number method. Soil Research, 27(3), 511-523.

Bull, W. B. (1962). Relations of alluvial fan size and slope to drainage basin size and lithology in western Fresno County, California. US Geological Survey Professional Paper, Washington: U.S. Geological Survey. 450, 51-53.

Bull, W. B. (1964a). Geomorphology of segmented alluvial fans in western Fresno county, California. US Geological Survey Professional Paper, 352E, Washington: U.S. Geological Survey.

Bull, W. B. (1964b). History and causes of channel trenching in western Fresno county, California. American Journal of Science, 262(2), 249-258.

Bull, W. B. (1968). Alluvial fans. Journal of Geological Education, 16 (3), 101-106.

Bull, W. B. (1977). The alluvial fan environment. Progress in Physical Geography, 1(2), 222-270.

Campetella, C., \& Possia, N. (2007). Upper-level cut-off lows in southern South America. Meteorology and Atmospheric Physics, 96(1-2), 181-191.

Cannon, S., Gartner, J., Parrett, C., \& Parise, M. (2003). Wildfire-related debris-flow generation through episodic progressive sediment-bulking processes, western USA. Debris Flow Hazards Mitigation: Mechanics, Prediction, and Assessment. Millpress, Rotterdam, the Netherlands, 71-82.

Capel, J. (1999a). El fenómeno ENSO (El Niño-Oscilación del Sur) en 1997-1998: Alteraciones climáticas inducidas en el mundo. Nimbus: Revista de Climatología, Meteorología y Paisaje, (3), 37-62. 
Capel, J. (1999b). Lima, un clima de desierto litoral. Anales de Geografía de la Universidad Complutense, 19, 25-45, Madrid.

Carryer, S. (1966). A note on the formation of alluvial fans. New Zealand Journal of Geology and Geophysics, 9(1-2), 91-94.

Casas, A. (1995). Geomorphological and sedimentary features along an active rightlateral reverse fault. Zeitschrift Fur Geomorphologie, 39(3), 363-380.

Castelltort, F., \& Marzo, M. (1986). Un modelo deposicional de abanicos aluviales arenosos originados por corrientes efímeras: El Muschelkalk medio de los catalanides. XI Congr. Español de Sedimentología. Resúmenes y Comunicaciones, 47

Castillo Navarro, L. F. (2006). Aplicación de un modelo numérico de flujos de escombros y lodos en una quebrada en el Perú. Facultad de Ingeniería Civil, Universidad Nacional de Ingeniería. Perú). Tesis de pregrado, 240 pags.

Cazenave, G. (2006). Modelación numérica del escurrimiento superficial de la cuenca del arroyo del Azul: Aplicación de modelos agregados y distribuidos. Tesis de Maestría. Facultas de Ciencias Éxactas, Ingeniería y Agrimensura. Universidad Nacional de Rosario, Santa Fe, Argentina.

Chang-Xing, J. (1992). A deterministic gamma-type geomorphologic instantaneous unit hydrograph based on path types. Water Resources Research, 28(2), 479-486.

Chauchat, C. (1987). Niveau Marin, écologie et climat sur la côte nord du Pérou à la transition Pléistocène-Holocène. Bulletin De L'IFEA, Lima, XVI, (1-2), 21-27.

Chow, V. (Ed.). (1964). Handbook of applied hydrology. New York: McGraw-Hill Book Co.

Chow, V., Maidment, D., \& Mays, L. (Eds.). (1994). Hidrología aplicada. Santafé de Bogotá, Colombia: Ed. McGraw-Hill Interamericana S.A. 
Church, M., \& Ryder, J. M. (1972). Paraglacial sedimentation: A consideration of fluvial processes conditioned by glaciation. Geological Society of America Bulletin, 83(10), 3059-3072.

Clapperton, C. (1993). Quaternary geology and geomorphology of South America Elsevier Amsterdam etc.

Clarke, K. C. (1997). Getting started with geographic information systems Prentice Hall Upper Saddle River, NJ.

Clayton, L., Attig, J. W., Mickelson, D. M., Johnson, M. D., \& Syverson, K. M. (2006). Glaciation of Wisconsin. Wisconsin Geological and Natural History Survey. Report. Madison Wisconsin. 4 pags.

Cobbing, E. (1973). Geología de los cuadrángulos de Barranca, Ámbar, Oyón, Huacho, Huaral y Canta. Boletín del Instituto Geológico Minero y Metalúrgico del Perú, A (26). Lima

Cobbing, E. (1982). The segmented coastal batholith of Peru; its relationship to volcanocity and metallogenesis. Earth-Science Reviews, 18, 241-251.

Coe, J. A., Kinner, D. A., \& Godt, J. W. (2008). Initiation conditions for debris flows generated by runoff at chalk cliffs, central Colorado. Geomorphology, 96(3), 270297.

Colombo, F. (1979). Introducción a l'estudi sedimentològic dels cons de dejecció (alluvial fans) i dels sediments associats. Institució Catalana d' Historia Natural. Barcelona. $163 \mathrm{pp}$

Colombo, F. (2010). Abanicos aluviales: procesos de transporte y acumulación de materiales detríticos. In A. Arche (Ed.). Sedimentología. Del proceso físico a la cuenca sedimentaria (pp. 85-130). Madrid: Consejo Superior de Investigaciones Científicas, 85-130.

Costa, J. E. (1984). Physical geomorphology of debris flows. Developments and applications of Geomorphology. Springer, 268-317. 
Coussot, P., Leonov, A. I., \& Piau, J. M. (1993). Rheology of concentrated dispersed systems in a low molecular weight matrix. Journal of Non-Newtonian Fluid Mechanics, 46(2), 179-217.

Coussot, P., \& Meunier, M. (1996). Recognition, classification and mechanical description of debris flows. Earth-Science Reviews, 40(3), 209-227.

Coussot, P., \& Piau, J. M. (1994). On the behavior of fine mud suspensions. Rheologica Acta, 33(3), 175-184.

Craig, A. K. (1985). Cis-Andean environmental transects: Late quaternary ecology of northern and southern Peru. Andean Ecology and Civilization: An Interdisciplinary Perspective on Andean Ecological Complementarity, University of Tokyo Press, Tokyo, 23-44.

Craig, A. K., \& Shimada, I. (1986). El Niño flood deposits at Batan Grande, northern Peru. Geoarchaeology, 1(1), 29-38.

Cronin, S. J., Neall, V., Lecointre, J., \& Palmer, A. (1997). Changes in Whangaehu river lahar characteristics during the 1995 eruption sequence, Ruapehu volcano, New Zealand. Journal of Volcanology and Geothermal Research, 76(1), 47-61.

Crosta, G., Chen, H., \& Lee, C.F. (2004). Replay of the 1987 Val Pola landslide, Italian Alps. Geomorphology, 60(1), 127-146.

Crowell, J. C. (1974). Sedimentation along the San Andreas Fault, California Modern and Ancient Geosynclinal. Soc. Econ. Paleont. Mineral, (19), 292-303.

Cudennec, C., Fouad, Y., Sumarjo, I., \& Duchesne, J. (2004). A geomorphological explanation of the unit hydrograph concept. Hydrological Processes, 18(4), 603621.

Cudworth, A. G. (1989). Flood hydrology manual. Denver: US Dept. of the Interior, Bureau of Reclamation. Technical Publication. (1st ed.). Denver, CO, 243 p.

Cunge, J. A. (1969). On the subject of a flood propagation computation method (Musklngum method). Journal of Hydraulic Research, 7(2), 205-230. 
Dalmayrac, B., Laubacher, G., \& Marocco, R. (1988). Caracteres generales de la evolución geológica de los Andes Peruanos. Boletín del Instituto Geológico Minero y Metalúrgico del Perú, D (12). Lima

Darcy, H. P. G. (1856). Les Fontaines publiques de la ville de Dijon. Exposition et application des principes à suivre et des formules à employer dans les questions de distribution d'eau, etc. V. Dalamont (ed). Paris, 647 pags.

Davis, W. M. (1905). The geographical cycle in an arid climate. The Journal of Geology, 13(5), 381-407.

Dee, D. P., Uppala, S. M., Simmons, A. J., Berrisford, P., Poli, P., Kobayashi, S., Andrae, U. Balmaseda, M. A., Balsamo, G., Bauer, P., Bechtold, P., Beljaars, A. C. M., Van de Berg, L., Bidlot, J., Bormann, N., Delsol, C., Dragani, R., Fuentes, M., Geer, A. J., Haimberger, L., Healy, S. B., Hersbach, H., Hólm, E. V., Isaksen, L., Kållberg, P., Köhler, M., Matricardi, M., McNally, A. P., Monge-Sanz, B. M., Morcrette, J.-J., Park , B.-K., Peubey, C., de Rosnay, P., Tavolato, C., Thépaut, J.-N., Vitart , F. (2011). The ERA-Interim reanalysis: Configuration and performance of the data assimilation system. Quarterly Journal of the Royal Meteorological Society, 137(656), 553-597.

Del Ángel, M., \& Dominguez, R. (2013). Ecuaciones universales ajustadas para el cálculo de lluvias máximas de corta duración. GEOS, 33(2)

Del Río, J. A., \& Lopez de Haro, M. (1990). On the Criteria for Deriving Approximations of Different Orders in Extended Irreversible Thermodynamics. Journal of NonEquilibrium Thermodynamics, 15(1), pp. 59-72. Retrieved 22 Aug. 2018, from doi:10.1515/jnet.1990.15.1.59

Denny, C. S. (1967). Fans and pediments. American Journal of Science, 265(2), 81105.

Denny, C. S. (1965). Alluvial fans in the Death Valley region, California and Nevada (No. 466). US Government Printing Office. 
DeVries, T. J. (1987). A review of geological evidence for ancient El Niño activity in Peru. Journal of Geophysical Research: Oceans, 92(C13), 14471-14479.

DeVries, T. J., Ortlieb, L., Diaz, A., Wells, L., \& Hillarie-Marcel, C. I. (1997). Determining the early history of El Niño. Science, 276(5314), 965-967.

Di Crescenzo, G., \& Santo, A. (2005). Debris slides-rapid earth flows in the carbonate massifs of the Campania region (southern Italy): Morphological and morphometric data for evaluating triggering susceptibility. Geomorphology, 66(1), 255-276.

Dietrich, W. E., \& Dunne, T. (1993). The channel head. In: Beven, K. J., \& Kirkby, M. J eds. (1993). Channel Network Hydrology. Wiley, Chichester.175-219

Díez-Herrero, A. (2004). Geomorfología e hidrología fluvial del río Alberche: Modelos y SIG para la gestión de riberas. Tesis Doctoral. Universidad Complutense de Madrid.

Díez, A., Laín, L., \& Llorente, M. (2008). Mapas de peligrosidad por avenidas e inundaciones: guía metodológica para su elaboración IGME. № 1, IGME.

Dollfus, O. (1964). Préhistoire et changements climatiques post-würmiens au Pérou. Bulletin De L'Association Française Pour L'Étude Du Quaternaire, 1(1), 6-12.

Dollfus, O. (1966). Les Andes centrales du Pérou et leurs piémonts (entre Lima et le Péréné): etude géomorphologique. Revue de Géographie Alpine, 54(4), 683-684.

Dollfus, O., \& Lavallee, D. (1973). Ecología y ocupación del espacio en los Andes tropicales durante los últimos veinte milenios. Bull-Inst. Fr. Et. And, 2(3), 75-92.

Dracup, J., \& Kahya, E. (1994). The relationships between U.S. streamflow and La Niña events. Water Resources Research, 30(7), 2133-2141.

Dresch, J. (1961). Observations sur le désert cotier du Pérou. Annales de Géographie, 70(378), 179-184.

Drew, F. (1873). Alluvial and lacustrine deposits and glacial records of the upper-indus basin. Quarterly Journal of the Geological Society, 29(1-2), 441-471. 
Dunai, T. J., López, G. A. G., \& Juez-Larré, J. (2005). Oligocene-Miocene age of aridity in the Atacama desert revealed by exposure dating of erosion-sensitive landforms. Geology, 33(4), 321-324.

Ebel, A., Hass, H., Jakobs, H.J., Laube, M., Memmesheimer, M., Oberreuter, A., Geiss, H., Kuo, Y. (1991). Simulation of ozone intrusion caused by a tropopause fold and cut-off low. Atmospheric Environment. Part A. General Topics, 25(10), 2131-2144.

Eckis, R. (1928). Alluvial fans of the Cucamonga district, southern California. The Journal of Geology, 224-247.

Egashira, S., \& Itoh, T. (2004). Numerical simulation of debris flow. Journal of Japan Society of Computational Fluid Dynamics, 12(2), 33-43.

Enfield, D. (1989). El Niño, past and present. Reviews of Geophysics, 27(1), 159-187. doi:10.1029/RG027i001p00159

Engel, Z., Skrzypek, G., Chuman, T., Šefrna, L., \& Mihaljevič, M. (2014). Climate in the western cordillera of the central Andes over the last 4300 years. Quaternary Science Reviews, 99, 60-77.

Engelund, F., \& Zhaohui, W. (1984). Instability of hyper-concentrated flow. Journal of Hydraulic Engineering, 110(3), 219-233.

Ericksen, G. E., Plafker, G., \& Concha, J. (1970). Preliminary report on the geologic events associated with the May 31, 1970, Peru earthquake. 36 pags. Geological Survey Circular 639. Washington: US Geological Survey.

Evans, S. G., Bishop, N. F., Smoll, L., Murillo, P., Delaney, K. B., \& Oliver-Smith, A. (2009). A re-examination of the mechanism and human impact of catastrophic mass flows originating on nevado Huascaran, cordillera Blanca, Peru in 1962 and 1970. Engineering Geology, 108(1), 96-118.

Fernández, M., Vela, A., \& Castaño, S. (1997). La utilización de modelos en hidrología. Ensayos: Revista de la Facultad de Educación de Albacete, (12), 305-318. 
Ferrer, M. (1993). Recomendaciones para el Cálculo Hidrometeorológico de Avenidas. Madrid: Centro de Estudios Hidrográficos (CEDEX, MOPTMA) Ministerio de Fomento.

Ferrer, M., Rodríguez, J., \& Estrela, T. (1995). Generación automática del Número de Curva con sistemas de información geográfica. Ingeniería Del Agua, 2(4)

Fisher, W. L., \& Brown, L. F. (1984). Clastic Depositional Systems: A Genetic Approach to Facies Analysis: Annotated Outline and Bibliography. Bureau of Economic Geology, University of Texas at Austin. 230 pags.

Flanagan, D. C., \& Nearing, M. A. (1995). USDA-Water Erosion Prediction Project: Hillslope profile and watershed model documentation (Vol. 10). NSERL report.

Fontaine, T. A., \& Potter, K. W. (1989). Estimating probabilities of extreme rainfalls. Journal of Hydraulic Engineering, 115(11), 1562-1575.

Fortin, M., \& Fortin, A. (1989). A new approach for the FEM simulation of viscoelastic flows. Journal of Non-Newtonian Fluid Mechanics, 32(3), 295-310.

Freeze, R. A., \& Harlan, R. L. (1969). Blueprint for a physically-based, digitallysimulated hydrologic response model. Journal of Hydrology, 9(3), 237-258.

Froehlich, D. C. (1995). Intermediate-duration-rainfall intensity equations. Journal of Hydraulic Engineering, 121(10), 751-756.

Fro stick, L. E., \& Reid, I. (1989). Climatic versus tectonic controls of fan sequences: Lessons from the dead sea, Israel. Journal of the Geological Society, 146(3), 527538.

Fuller, W. E. (1914). Flood flows. Transactions of the American Society of Civil Engineers, 77(1), 564-617.

Gábris, G., \& Nagy, B. (2005). Climate and tectonically controlled river style changes on the Sajó-hernád alluvial fan (Hungary). Geological Society, London, Special Publications, 251(1), 61-67. 
Gamión, F., \& Jhon, F. (2014). Modelo de flujo de escombros y lodo aplicando FLO2D, caso sub cuenca del río Shullcas. Tesis de pregrado. Universidad Nacional del Centro del Perú.

García-Martínez, R., \& López, J. L. (2005). Debris flows of December 1999 in Venezuela. Debris-flow hazards and related phenomena. pp. 519-538. Springer.

García-Tortosa, F., Alfaro, P., De Galdeano, C., \& Galindo-Zaldívar, J. (2011). Glacis geometry as a geomorphic marker of recent tectonics: The Guadix-Baza basin (south Spain). Geomorphology, 125(4), 517-529.

García-Tortosa, F., Alfaro, P., Galindo-Zaldívar, J., Gibert, L., López-Garrido, A., De Galdeano, C., \& Ureña, M. (2008). Geomorphologic evidence of the active Baza fault (Betic cordillera, south Spain). Geomorphology, 97(3), 374-391.

García, R., \& Conesa, C. (2011). Estimación de caudales de avenida y delimitación de áreas inundables mediante métodos hidro-meteorológicos e hidráulicos y técnicas SIG, estudio aplicado al litoral sur de la región de Murcia. Papeles de Geografía, (53-54), 107-123.

Garen, D. C., \& Moore, D. S. (2005). Curve Number Hydrology in Water Quality Modelling: Uses, Abuses, and Future Directions 1, JAWRA Journal of the American Water Resources Association, 41(2), 377-388.

Gaspari, F., \& Senisterra, G. (2006). Zonificación del número de la curva (CN) en la cuenca del arroyo Pillahuincó grande. Proceeding Paper, Coronel Pringles. Tercer Congreso De La Ciencia Cartográfica, 26. Buenos Aires, 26 - 29 de junio de 2006. 10 pags.

Gaume, E., Bain, V., Bernardara, P., Newinger, O., Barbuc, M., Bateman, A., Blaškovičová, L., Blöschl, G., Borga, M., Dumitrescu, A., Daliakopoulos, I., García, J., Irimescu, A., Kohnova, S., Koutroulis, A., Marchi, L., Matreata, S., Medina, V., Preciso, E., Sempere-Torres, D., Stancalie, G., Szolgay, J., Tsanis, I., Velasco, D., Viglione, A. (2009). A compilation of data on European flash floods. Journal of Hydrology, 367(1), 70-78. 
Gaume, E., Livet, M., Desbordes, M., \& Villeneuve, J. (2004). Hydrological analysis of the river Aude, France, flash flood on 12 and 13 November 1999. Journal of Hydrology, 286(1), 135-154.

Gile, L. H., \& Hawley, J. W. (1966). Periodic sedimentation and soil formation on an Alluvial-Fan Piedmont in Southern New Mexico. Soil Science Society of America Journal, 30(2), 261-268.

Giles, B., Moroco, R., \& Jacay, J. (2002). Depósitos de ríos trenzados conglomerádicos del abanico aluvial del río Rímac. . Resumen extendido. IX Congreso Peruano De Geología. Lima.

Gimeno, L., Trigo, R., Ribera, P., \& García, J. (2007). Editorial: Special issue on cut-off low systems (COL). Meteorology and Atmospheric Physics, 96(1), 1-2.

Glantz, M. (1997). A Systems approach to ENSO: Atmospheric, oceanic, societal, environmental, and policy perspectives. Informe técnico inédito. Program Summer Colloquium on ENSO. 20 July-1 August 1997, Boulder, CO: National Center for Atmospheric Research, Colorado. 191 pp

Glaser, R. (2001). Klimageschichte Mitteleuropas: 1000 Jahre Wetter, Klima, Katastrophen. Primus Verlag, Darmstadt. un vol. in- $4^{\circ}, \mathrm{VIII}-227 \mathrm{p}$

Godunov, S. K. (1959). A difference method for numerical calculation of discontinuous solutions of the equations of hydrodynamics. Matematicheskii Sbornik, 89(3), 271306.

Gohain, K. (1990). Morphology of the Kosi megafan. In: Alluvial Fans - A Field Approach, Rachocki, A. H. and Church, M. (eds.). Wiley, Chichester, 151-178.

Gómez, A. (1996). Abanicos aluviales: Aportación teórica a sus aspectos más significativos. Cuatern. Geomorfol. 10(3-4), 77-124.

Gomez, B. I., Carter, L., Trustrum, N. A., Palmer, A. S., \& Roberts, A. P. (2004). El Niño-Southern Oscillation signal associated with middle Holocene climate change in intercorrelated terrestrial and marine sediment cores, north island, New Zealand. Geology, 32(8), 653-656. 
González Díaz, E. F., \& Di Tommaso, I. (2011). Evolución geomorfológica y cronología relativa de los niveles aterrazados del área adyacente a la desembocadura del río Chubut al atlántico (provincia del Chubut). Revista de la Asociación Geológica Argentina, 68(4), 507-525.

Gosling, S. N., Dunn, R., Carrol, F., Christidis, N., Fullwood, J., Gusmao, D., Golding, N., Good, L., Hall, T., Kendon, L., Kennedy, J., Lewis, K., McCarthy, R., McSweeney, C., Morice, C., Parker, D., Perry, M., Stott, P., Willett, K., Allen, M., Arnell, N., Bernie, D., Betts, R., Bowerman, N., Brak, B., Caesar, J., Challinor, A., Dankers, R., Hewer, F., Huntingford, C., Jenkins, A., Klingaman, N., Lewis, K., Lloyd-Hughes, B., Lowe, J., Miller, J., Nicholls, R., Noguer, M., Otto, F., Van der Linden, P., Warren. R. (2011). Climate: Observations, projections and impacts. Climate: Perú. Observations, Projections and Impacts. University of Nottingham. Disponible en: http://eprints.nottingham.ac.uk/2040/18/Peru.pdf, 124 p.

Graf, W. H., \& Altinakar, M. S. (1998). Fluvial hydraulics: Flow and transport processes in channels of simple geometry (No. $551.483 \mathrm{G7}$ ). Wiley, London.

Green, W. H., \& Ampt, G. A. (1911). Studies on soil phyics. The Journal of Agricultural Science, 4(01), 1-24.

Grierson, I., \& Oades, J. (1977). A rainfall simulator for field studies of run-off and soil erosion. Journal of Agricultural Engineering Research, 22(1), 37-44.

Grimm, A., Vera, C., \& Mechoso, R. (2005). The American monsoon systems: An introduction. (WMO/TD 1266-TMRP No. 70). Ginebra: World Meteorological Organization.

Grogler, N., Houtermans, F., \& Stauffer, H. (1960). Ueber die datierung Von Keramik und ziegel durch thermolumineszenz. Helvetica Physica Acta, 33, 595-596.

Gupta, V. K., Waymire, E., \& Wang, C. T. (1980). A representation of an instantaneous unit hydrograph from geomorphology. Water Resources Research, 16(5), 855-862.

Gustavson, T. C. (1974). Sedimentation on gravel outwash fans, Malaspina glacier foreland, Alaska. Journal of Sedimentary Research, 44(2), 374-389. 
Hack, J. T. (1965). Geomorphology of the Shenandoah Valley, Virginia and West Virginia, and Origin of the Residual Ore Deposits. 84 pags. US Government Printing Office.

Haddad, B. (2007). Modelización numérica mediante elementos finitos y SPH de los geomateriales fluidificados: aplicación a los deslizamientos rápidos de ladera. Tesis Doctoral. Universidad Complutense de Madrid.

Hampel, A. (2002). The migration history of the Nazca ridge along the Peruvian active margin: A re-evaluation. Earth and Planetary Science Letters, 203(2), 665-679.

Harris, S. A., \& Gustafson, C. A. (1993). Debris flow characteristics in an area of continuous permafrost, St. Elias range, Yukon territory. Zeitschrift Fur Geomorphologie, 37, 41-41.

Harvey, A. M. (1989). The occurrence and role of arid-region alluvial fans. Arid Region Geomorphology, 136-158. Thomas D.S.G. (Ed.), Halsted Press, New York, 136158.

Harvey, A. M. (1990). Factors influencing quaternary alluvial fan development in southeast Spain. En: Alluvial Fans: A Field Approach. Wiley, Chichester, 247-269.

Harvey, A. M. (1997). The role of alluvial fans in arid zone fluvial systems. Arid Zone Geomorphology: Processes, Form and Change in Drylands, 231-259.

Harvey, A. M. (2002). The relationships between alluvial fans and fan channels within Mediterranean mountain fluvial systems. En: Bull, LJ and Kiekby, MJ (eds.), Dryland Rivers: Hydrology and Geomorphology of Semiarid Channels, Wiley, Chichster, 205-226.

Harvey, A. M., Mather, A. E., \& Stokes, M. (2005). Alluvial fans: Geomorphology, sedimentology, dynamics-introduction. A review of alluvial-fan research. Geological Society, London, Special Publications, 251(1), 1-7.

Harvey, A. M., \& Wells, S. G. (1994). Late Pleistocene and Holocene changes in hillslope sediment supply to alluvial fan systems: Zzyzx, Wiley, London. 
Harvey, A. M., \& Wells, S. G. (2003). Late quaternary alluvial fan development, relations to climatic change, Soda Mountains, Mojave Desert, California. En: Environmental Change in the Mojave Desert. Geological Society of America, 368, 207-230.

Hastenrath, S. (1990). Diagnostics and prediction of anomalous river discharge in northem South America. Journal of Climate, 3, 1080; 1080-1096; 1096.

Haug, E. W., Kraal, E. R., Sewall, J. O., Van Dijk, M., \& Diaz, C., G. (2010). Climatic and geomorphic interactions on alluvial fans in the Atacama desert, Chile. Geomorphology, 121(3), 184-196.

Hernández, A. (1999). Un estudio estadístico sobre depresiones aisladas en niveles altos (DANAS) en el sudoeste de Europa basado en mapas isentrópicos de vorticidad potencial. Resumen extendido.IV Simposio Nacional De Predicción, Instituto Nacional De Meteorología, Serie Monogr, 351.

Heward, A. P. (1978). Alluvial fan and lacustrine sediments from the Stephanian A and B (la Magdalena, Cinera-Matallana and Sabero) coalfields, northern Spain. Sedimentology, 25(4), 451-488.

Hindle, D., Kley, J., Klosko, E., Stein, S., Dixon, T., \& Norabuena, E. (2002). Consistency of geologic and geodetic displacements during Andean orogenesis. Geophysical Research Letters, 29(8), 29-1-29-4.

Hocquenghem, A. M., \& Ortlieb, L. (1992). Eventos el niño y lluvias anormales en la costa del Perú: Siglos XVI-XIX. Bull.Inst.Fr.Études Andines, 21(1), 197-278.

Hooke, R. L. B. (1968). Steady-state relationships on arid-region alluvial fans in closed basins. American Journal of Science, 266(8), 609-629.

Hooke, R. L. B., \& Rohrer, W. L. (1977). Relative erodibility of source-area rock types, as determined from second-order variations in alluvial fan size. Soc.Am, 88, 11771182. 
Horton, B. K., \& DeCelles, P. G. (2001). Modern and ancient fluvial megafans in the foreland basin system of the central Andes, southern Bolivia: Implications for drainage network evolution in fold-thrust belts. Basin Research, 13(1), 43-63.

Horton, R. E. (1933). The role of infiltration in the hydrologic cycle. EOS, Transactions American Geophysical Union, 14(1), 446-460.

Horton, R. E. (1941). An approach toward a physical interpretation of infiltrationcapacity. Soil Science Society of America Journal, 5(C), 399-417.

Huang, C., Gascuel-Odoux, C., \& Cros-Cayot, S. (2002). Hillslope topographic and hydrologic effects on overland flow and erosion. Catena, 46(2), 177-188.

Huertas, L. (2009). Injurias del Tiempo. Desastres naturales en la Historia del Perú. Lima: Universidad Ricardo Palma. Editorial Universitaria.

Huggel, C., Zgraggen-Oswald, S., Haeberli, W., Kääb, A., Polkvoj, A., Galushkin, I., \& Evans, S. (2005). The 2002 rock/ice avalanche at Kolka/Karmadon, Russian Caucasus: Assessment of extraordinary avalanche formation and mobility, and application of Quick Bird satellite imagery. Natural Hazards and Earth System Science, 5(2), 173-187.

Hungr, O. (1995). A model for the runout analysis of rapid flow slides, debris flows, and avalanches. Canadian Geotechnical Journal, 32(4), 610-623.

Hungr, O., Morgan, G. C., \& Kellerhals, R. (1984). Quantitative analysis of debris torrent hazards for design of remedial measures. Canadian Geotechnical Journal, 21(4), 663-677.

Huntley, D. J., Godfrey-Smith, D. I., \& Thewalt, M. L. (1985). Optical dating of sediments. Nature, 313(5998), 105.

Hürlimann, M., Rickenmann, D., Medina, V., \& Bateman, A. (2008). Evaluation of approaches to calculate debris-flow parameters for hazard assessment. Engineering Geology, 102(3), 152-163. 
Hutchinson, J. N. (1986). A sliding-consolidation model for flow slides. Canadian Geotechnical Journal, 23(2), 115-126.

Hütt, G., Jaek, I., \& Tchonka, J. (1988). Optical dating: K-feldspars optical response stimulation spectra. Quaternary Science Reviews, 7(3), 381-385.

Ikeda, A. (2015). Design of SABO Dam. PowerPoint presentation of international course: "Disaster Management for Landslide and Sediment-Related Disasters (triggered by heavy rainfall, earthquake and volcanic activity). Unpublished manuscript. Tokyo: Sabo and Landslide Technical Center. Japan International Cooperation Agency - JICA.

Ikeya, H. (Ed.). (1976). Introduction to Sabo works. The Japan SABO Association. Tokio, Japón, 168 pgs.

INGEMMET. (1997). Álbum de Mapas de Zonificación de Riesgos Fisiográficos y Climatológicos del Perú. Boletín del Instituto Geológico Minero y Metalúrgico del Perú, C (17). Lima

Instituto Metropolitano de Planificación (Ed.). (2008). Atlas Ambiental de Lima Metropolitana. Lima: IMP, Municipalidad de Lima Metropolitana. 155.p

Instituto Nacional de Estadística e Informática (Ed.). (2014). Una Mirada a Lima Metropolitana. Informe técnico inédito. Lima: INEI. Disponible en: https://www.inei.gob.pe/media/MenuRecursivo/publicaciones_digitales/Est/Lib1168 /libro.pdf.

Iverson, R. M. (1997). The physics of debris flows. Reviews of Geophysics, 35(3), 245296. doi:10.1029/97RG00426

Iverson, R. M., \& Denlinger, R. (2001). Flow of variably fluidized granular masses across three-dimensional terrain: 1. coulomb mixture theory. Journal of Geophysical Research: Solid Earth, 106(B1), 537-552. doi:10.1029/2000JB900329

Iverson, R. M., Reid, M. E., \& LaHusen, R. G. (1997). Debris-flow mobilization from landslides 1. Annual Review of Earth and Planetary Sciences, 25(1), 85-138. 
Jacay, J. (2013). Evidencias de paleosismicidad en la región de Lima (costa del Perú central). Revista del Instituto de Investigación de la Facultad de Ingeniería Geológica, Minera, Metalúrgica y Geográfica, 16(32).

Jacay, J., Castillo, J., \& Ingaruca, Y. (2000). Evidencias de Tectónica Transpresiva en Terrenos del Berriasiano-Valanginiano (Segmento Comas-Zapallal). Resumen extendido. X Congreso Peruano De Geología, Lima.

James, W. P., Winsor, P. W., \& Williams, J. R. (1987). Synthetic unit hydrograph. Journal of Water Resources Planning and Management, 113(1), 70-81.

Jansson, P., Jacobson, D., \& Le Hooke, R. B. (1993). Fan and playa areas in southern California and adjacent parts of Nevada. Earth Surface Processes and Landforms, 18(2), 109-119.

Jarrett, R. D. (1987). Errors in slope-area computations of peak discharges in mountain streams. Journal of Hydrology, 96(1), 53-67.

Johnson, A. M., \& Rodine, J. R. (1984). Debris flow. En: Brunsden, D. and Prior, D. B. Eds), Slope Instability, 257-361.

Johnson, D. W. (1932). Rock fans of arid regions. American Journal of Science, (137), 389-416.

Jordan, T. E., Burns, W. M., Veiga, R., Pángaro, F., Copeland, P., Kelley, S., \& Mpodozis, C. (2001). Extension and basin formation in the southern Andes caused by increased convergence rate: A mid-Cenozoic trigger for the Andes. Tectonics, 20(3), 308-324. DOI:10.1029/1999TC001181

Julien, P. Y., \& Lan, Y. (1991). Rheology of hyper-concentrations. Journal of Hydraulic Engineering, 117(3), 346-353.

Kaliser, B. N., \& Fleming, R. W. (1986). (1986). The 1983 landslide dam at Thistle, Utah. In: Landslide Dams: Processes, Risk, and Mitigation, Proceeding Paper, American Society of Civil Engineers, 59-83. 
Kanner, L. C., Burns, S. J., Cheng, H., Edwards, R. L., \& Vuille, M. (2013). Highresolution variability of the South American summer monsoon over the last seven millennia: Insights from a speleothem record from the Central Peruvian Andes. Quaternary Science Reviews, 75, 1-10.

Keefer, D. K., De France, S. D., Moseley, M. E., Richardson, J. B.,3rd, Satterlee, D. R., \& Day-Lewis, A. (1998). Early maritime economy and El Niño events at Quebrada Tacahuay, Peru. Science, New York, 281(5384), 1833-1835.

Kesel, R. H., \& Lowe, D. R. (1987). Geomorphology and sedimentology of the Toro Amarillo alluvial fan in a humid tropical environment, Costa Rica. Geografiska Annaler.Series A.Physical Geography, 85-99.

Kesel, R. (1985). Alluvial fan systems in a wet tropical environment, Costa Rica. National Geographic Research, 1(4), 450-469.

Kesel, R., \& Spicer, B. (1985). Geomorphologic relationships and ages of soils on alluvial fans in the Rio General valley, Costa Rica. Catena, 12(1), 149-166.

Kite, G. W. (1988). Frequency and risk analyses in Hydrology. No. 224, p. 257. Littleton, Colorado: Water resources publications.

Klemeû́, V. (1988). The improbable probabilities of extreme floods and droughts. En: Starosolszky, O., Melde, O.M (eds). Hydrology of Disasters: Proceeding Paper, World Meteorological Organization Technical Conference, Geneva. Noviembre 1988. James and James, London, 43-51.

Kochel, R. C. (1990). Humid fans of the Appalachian Mountains. Alluvial Fans: A Field Approach. Wiley, New York, 109-129.

Kostaschuk, R., MacDonald, G., \& Putnam, P. (1986). Depositional process and alluvial fan-drainage basin morphometric relationships near Banff, Alberta, Canada. Earth Surface Processes and Landforms, 11(5), 471-484.

Kottegoda, N., Natale, L., \& Raiteri, E. (2000). Statistical modelling of daily streamflows using rainfall input and curve number technique. Journal of Hydrology, 234(3), 170-186. 
Koutsoyiannis, D. (2004). On the appropriateness of the Gumbel distribution for modelling extreme rainfall. En: Hydrological Risk: recent advances in peak river flow modelling, prediction and real-time forecasting. Assessment of the impacts of land-use and climate changes, Brath, A., Montanari, A. and Toth,E (eds). Bologna, 303-319, doi:10.13140/RG.2.1.3811.6080, Editoriale Bios, Castrolibero, Italy.

Kowalski, J., \& McElwaine, J. (2013). Shallow two-component gravity-driven flows with vertical variation. Journal of Fluid Mechanics, 714, 434-462.

Kozanis, S., Christoforides, A., \& Efstratiadis, A. (2010). Scientific documentation of Hydrognomon software (version 4). development of database and software application in a web platform for the "National database and meteorological information". ITIA Research Team, National Technical University of Athens Disponible en: Http:// Www. Itia. Ntua. Gr/ Getfile, 928(1)

Kukal, Z. (1971). Geology of recent sediments. Academia Publishing House of Czechoslovak Academy of Sciences, Academic Press Inc. Prague. 490 pp., 142.

Kundzewicz, Z. W., \& Strupczewski, W. G. (1982). Approximate translation in the Muskingum model. Hydrological Sciences Journal, 27(1), 19-27.

Lacho, E., \& Rodríguez, J. C. (2016). Modelamiento de flujos de detritos en la quebrada San Antonio de Pedregal (Chosica) usando FIO2D. Resumen extendido. XXVII Congreso Latinoamericano De Hidráulica, Lima, Perú.

Lang, A. (2013). Luminescence dating of alluvial fans and cones. En: SchneuwlyBollschweiler, M., Stoffel, M., \& Rudolf-Miklau, F. (eds.). Dating torrential processes on fans and cones: methods and their application for hazard and risk assessment(Vol. 47). pp. 283-295. Springer, Dordrecht.

Langford, A., Masters, C., Proffitt, M., Hsie, E., \& Tuck, A. (1996). Ozone measurements in a tropopause fold associated with a cut-off low system. Geophysical Research Letters, 23(18), 2501-2504.

Lavigne, F., \& Suwa, H. (2004). Contrasts between debris flows, hyperconcentrated flows and stream flows at a channel of Mount Semeru, East Java, Indonesia. Geomorphology, 61(1), 41-58. 
Lawson, A. C. (1913) The petrographic designation of alluvial-fan formations. University of California. Department of Geology. Bulletin, v. 7, p. 325-334.

Le Roux, J. P. (2012). A review of tertiary climate changes in southern south America and the Antarctic peninsula. part 1: Oceanic conditions. Sedimentary Geology, 247, 1-20.

Le Roux, J. P., Tavares Correa, C., \& Alayza, F. (2000). Sedimentology of the RimacChillon alluvial fan at Lima, Peru, as related to Plio-Pleistocene sea-level changes, glacial cycles and tectonics. Journal of South American Earth Sciences, 13(6), 499-R10. doi:http://dx.doi.org/10.1016/S0895-9811(00)00044-4

Lecarpentier, C., \& Motti, R. (1968). Note sur les Accumulations quaternaires des Vallées du Chillon, Lurin et de Chilca (Désert Côtier Péruvien). Revue De Géomorphologie Dynamique, 18(2), 73-82.

Lecce, S. A. (1990). The alluvial fan problem. En: Rachoki, AH. And Church, M. (eds). Alluvial Fans: A Field Approach. Wiley, Chichester, 3-24.

Lecce, S. A. (1991). Influence of lithologic erodibility on alluvial fan area, western white mountains, California and Nevada. Earth Surface Processes and Landforms, 16(1), 11-18.

Leier, A. L., DeCelles, P. G., \& Pelletier, J. D. (2005). Mountains, monsoons, and megafans. Geology, 33(4), 289-292.

Leonard, J. B. (2000). City profile: Lima. Cities, 17(6), 433-445. doi:http://dx.doi.org/10.1016/S0264-2751(00)00047-0

Li, Y., Poesen, J., Yang, J. C., Fu, B., \& Zhang, J. H. (2003). Evaluating gully erosion using $137 \mathrm{Cs}$ and $210 \mathrm{~Pb} / 137 \mathrm{Cs}$ ratio in a reservoir catchment. Soil and Tillage Research, 69(1), 107-115.

Lillo Carpio, M. (1999). Consideraciones sobre los endorreismos de la costa norte de Perú en su relación con eventos de El Niño. Papeles de Geografía, (30), 87-102. 
Linsley, R. K., Kohler, M. A., \& Paulhus, J. L. H. (1975). Hydrology for engineers. McGraw-Hill, 482 pags.

Lisson, C. (1907). Contribución a la Geología de Lima y sus alrededores. Lima: Imprenta Gil, 124 pags.

Liu, K., Reese, C. A., \& Thompson, L. G. (2007). A potential pollen proxy for ENSO derived from the Sajama ice core. Geophysical Research Letters, 34(9)

Llanos, H., Díaz, C., Garfias, J., Antigüedad, I., \& Llamas, J. (2004). Contribución al estudio de las precipitaciones máximas en la provincia de Álava (País Vasco): Análisis de diferentes funciones de distribución. Ingeniería Civil, 98, 120-128.

Llorente, M. (2014). Evaluación cuantitativa de pérdidas por peligros geológicos. Caso del archipiélago de Canarias: Inundaciones, sismicidad y vulcanismo. Tesis Doctoral. E.T.S.I. de Minas y Energía (UPM).

Lockyer, N., \& Lockyer, W. J. S. (1902). On the similarity of the short-period pressure variation over large areas. Proceeding Paper, Royal Society of London, 71(467476), 134-135.

Longwell, C. R. (1930). Faulted fans west of the sheep range, southern Nevada. American Journal of Science, (115), 1-13.

Luna, B., Remaître, A., Van Asch, T., Malet, J., \& Van Westen, C. (2012). Analysis of debris flow behavior with a one dimensional run-out model incorporating entrainment. Engineering Geology, 128, 63-75.

Lustig, L. K. (1965). Clastic Sedimentation in Deep Springs Valley, California. Vol. 352. US Government Printing Office. 70 págs.

Macharé, J., Benavente, C., \& Audin, L. (2009). Síntesis descriptiva del mapa neotectónico del Perú. Boletín del Instituto Geológico Minero y Metalúrgico del Perú, C (40). Lima

Macharé, J., \& Ortlieb, L. (1992). Plio-quaternary vertical motions and the subduction of the Nazca ridge, central coast of Peru. Tectonophysics, 205(1-3), 97-108. 
Macharé, J., \& Ortlieb, L. (1993). Registros del fenómeno El Niño en el Perú. Bulletin De l'Institut Française d'Études Andines, 22(1), 35-52.

Magilligan, F., Goldstein, P. S., Fisher, G., Bostick, B., \& Manners, R. (2008). Late quaternary hydroclimatology of a hyper-arid Andean watershed: Climate change, floods, and hydrologic responses to the El Niño-Southern oscillation in the Atacama desert. Geomorphology, 101(1), 14-32.

Mahan, S. A., Noe, D. C., \& McCalpin, J. P. (2009). Use of OSL dating to establish the stratigraphic framework of quaternary Aeolian sediments, Anton scarp upper trench, northeastern Colorado high plains, USA. Quaternary International, 199(1), 92-103.

Manning, J. C. (1997). Applied principles of Hydrology. 113 Sylvan Ave. Englewood Cliffs NJ 07632 USA: Prentice-Hall, Inc.

Manning, R., Griffith, J. P., Pigot, T., \& Vernon-Harcourt, L. F. (1890). (1890). On the flow of water in open channels and pipes. Paper presented at Proceeding Paper, Institution of Civil Engineers of Ireland, 20, 161-207.

Manual de carreteras: Hidrología, hidráulica y drenaje. Resolución directoral № 202011-MTC/14, (2014). Lima, Perú, 221 pags.

Marchi, L., Pasuto, A., \& Tecca, P. R. (1993). Flow processes on alluvial fans in the eastern Italian alps. Zeitschrift Fur Geomorphologie, 37(4), 447-458.

Marco, J. (1993). Hidrología estocástica y planeamiento hidráulico. Conceptos y métodos para la planificación hidrológica. Barcelona: CIMNE, 97-105.

Martín León, F. (2003). Las gotas Frías/DANAS: Ideas y conceptos básicos. Nota técnica S.T.A.P. 38. Instituto Nacional de Meteorología. 24 págs. ISBN: 84-8320247-6

Martín-Serrano, Á. (2004). Mapa geomorfológico de España a escala 1: 50.000: guía para su elaboración. IGME. 128 págs. 
Martín Vide, J. P. (2007). Ingeniería de ríos. Servicio de Publicaciones de la Universitat Politécnica de Catalunya, (2dth ed.). Barcelona, ISBN: 84-8301-900-0. 331 pp.

Martin, L., Absy, M. L., Fournier, M., Mouguiart, P., Sifeddine, A., \& Volkmer-Ribeiro, C. (1992). Some climatic alterations recorded in South America during the last 7000 years may be expounded by long-term El Niño like conditions. Paleo-ENSO Records, Lima: OSRTOM-CONCYTEC, 187-192.

Masiokas, M. H., Rivera, A., Espizua, L. E., Villalba, R., Delgado, S., \& Aravena, J. C. (2009). Glacier fluctuations in extratropical South America during the past 1000years. Palaeogeography, Palaeoclimatology, Palaeoecology, 281(3), 242268.

Mathys, N., Klotz, S., Esteves, M., Descroix, L., \& Lapetite, J. M. (2005). Runoff and erosion in the black marls of the French Alps: Observations and measurements at the plot scale. Catena, 63(2), 261-281.

Matthes, F. E. (1939). Report of committee on glaciers, April 1939. EOS, Transactions American Geophysical Union, 20(4), 518-523.

McEwen, M. B., \& Pratt, M. I. (1957). The gelation of montmorillonite. Part 1. The formation of a structural framework in sols of Wyoming Bentonite. Transactions of the Faraday Society, 53, 535-547.

McGee, W. J. (1896). Sheetflood erosion. Geological Society of America Bulletin, 8(1), 87-112.

McGowen, J. (1971). Gum hollow fan delta, Nueces bay, Texas. Bureau of Economic Geology, University of Texas, Austin.

Mechoso, C., \& Perez, G. (1992). Streamflow in southeastern South America and the Southem Oscillation. Journal of Climate, 5, 1535-1539.

Meckel, L. (1975). Holocene sand bodies in the Colorado delta area, northern Gulf of California. En: Broussard MC. (ed). Deltas, model for exploration. Houston Geol Soc., Houston, 239-265. 
Medina, L., Villacorta, S., Zavala, B., Vílchez, M., Núñez, S., Luque, G., \& Calderón, E. (2014). Caracterización geomorfológica del norte peruano. Resumen extendido. XVII Congreso Peruano de Geología. Lima. Sociedad Geológica del Perú, 12-15.

Mégard, F. (1979). Estudio geológico de los Andes del Perú central. Boletín del Instituto Geológico Minero y Metalúrgico del Perú, D (8). Lima.

Mélice, J. L., \& Reason, C. J. C. (2007). Return period of extreme rainfall at George, South Africa. South African Journal of Science, 103(11-12), 499-501.

Melton, M. A. (1965). The geomorphic and paleoclimatic significance of alluvial deposits in southern Arizona. The Journal of Geology, 1-38.

Miall, A. D. (1978). Tectonic setting and syndepositional deformation of molasse and other nonmarine-paralic sedimentary basins. Canadian Journal of Earth Sciences, 15(10), 1613-1632.

Miller, H. (1883). River-terracing: Its methods and their results. Proc. Roy. Phys. Soc. Edimburg. VII 263-305

Ministerio del Ambiente. (2015). Mapa nacional de cobertura vegetal: Memoria descriptiva. Lima: Dirección General de Evaluación, Valoración y Financiamiento del Patrimonio Natural.

Mishra, S., Takara, K., \& Tachikawa, Y. (2008). NRCS Curve Number based hydrologic regionalization of Nepalese river basins for flood frequency analysis. Annals of Disaster Prevention Research Institute, Kyoto University, Japan, 51, 93-102.

Benavides V., Montoya M., Quevedo C. and Cardozo M. (eds.) (2008). Rutas Geológicas y Circuito histórico (1a ed.). Lima: Mixmade S.A.C.

Mizuyama, T., \& Mizuno, H. (1997). Prediction of debris flow hydrographs passing through grid type control structures. Proceeding Paper, First conference on DebrisFlow Hazards Mitigation: Mechanics, Prediction, and Assessment, California, USA, pp 74-82. 
Mockus V. (1972). Chapter 21. Design hydrographs En: McKeever, v. Owen, w., Rallison, r. (eds.). National Engineering Handbook, section 4, Hydrology. USDASCS Report, 127 pags

Mogrovejo, J., \& Makowsky, K. (1999, Cajamarquilla y los mega-Niños en el pasado prehistórico. Iconos, Revista Peruana de Conservación Arte y Arqueología., 1, 4657.

Molodkov, A. (2007). IR-OSL dating of uranium-rich deposits from the new Late Pleistocene section at the Voka site, north-eastern Estonia. Quaternary Geochronology, 2(1), 208-215.

Montero, J. (2007). Flujos de detritos (lahares) catastróficos del volcán nevado del Ruiz, Colombia, 11 de noviembre de 1985. En: Proyecto multinacional andino: Geociencias para las comunidades andinas. Movimientos en masa en la región andina: Una guía para la evaluación de amenazas. Servicio nacional de geología y minería. Publicación Geológica Multinacional, 4, 369-385.

Montgomery, D. R., \& Buffington, J. M. (1998). Channel processes, classification, and response. River Ecology and Management: Lessons from the Pacific Coastal Ecoregion, RJ Naiman and RE Bilby (eds.). Springer-Verlag, New York, 13-42.

Morelli, S., Salvatici, T., Nolesini, T., Di Traglia, F., Del Ventisette, C., Casagli, N., Bertagnini, A. (2016). Analogue and numerical modelling of the Stromboli hot avalanches. Proceeding Paper, 12th International Symposium on Landslides, Napoli, Italy, 3 1493-1500.

Morgan, P. C. (1997). Erosión y conservación del suelo. Mundi-prensa, Madrid. 343 p.

Mörner, N. A. (1984a). Climatic changes on a yearly to millennial basis. Concluding remarks. En: Mörner, N.A., Karlén, W. (eds.). Climatic changes on a yearly to millennial basis. Springer, Dordrecht, 637-651.

Mörner, N. A. (1984b). Planetary, solar, atmospheric, hydrospheric and endogene processes as origin of climatic changes on the Earth. En: Mörner, N.A., Karlén, W. (eds.). Climatic changes on a yearly to millennial basis. Springer, Dordrecht, 483507. 
Mörner, N. A. (1985). Possible super-ENSO in the past. Proceeding Paper, IAMAP/IAPSO Joint Assembly, p. 31, Honolulu, Hawaii, August 5-16. 128 pags.

Mörner, N. A. (1988). Terrestrial variations within given energy, mass and momentum budgets; paleoclimate, sea level, paleomagnetism, differential rotation and geodynamics. En: Stephenson, F.R., Wolfendale, A.W. (eds.). Secular solar and geomagnetic variations in the last 10,000 years (pp. 455-478) Springer, Dordrecht.

Mörner, N. A. (1993a). Global change: The high-amplitude changes 13-10 ka ago. Novel aspects. Global and Planetary Change, 7(1-3), 243-250.

Mörner, N. A. (1993b). Present El Niño-ENSO events and past super-ENSO events. Bulletin De Institut Francais D'Etudes Andines, 22(1), 3-12.

Moseley, M. E., Feldman, R., Moseley, M., \& Feldman, R. (1981). Living with crises: Human perception of process and time. En: Nitecki, M. (eds). Biotic Crises in Ecological and Evolutionary Time. 314 pags. Academic Press (pp. 231-267).

Mukerji, A. (1976a). Rural settlements of the Chandigarh Siwalik Hills (India): A morphogenetic analysis. Geografiska Annaler.Series B.Human Geography, 95115.

Mukerji, A. (1976b). Terminal fans of inland streams in Sutlej-Yamuna plain, India. Zietschrift Fur Geomorphologie, 190, 190-204.

Mulvaney, T. (1851). On the use of self-registering rain and flood gauges in making observations of the relations of rainfall and flood discharges in a given catchment. Proceeding Paper, Institution of Civil Engineers of Ireland, 4(2), 18-33.

Murcia, H. F., \& Macías, J. L. (2009). Registro geológico de inundaciones recurrentes e inundación del 4 de octubre de 2005 en la ciudad de Tapachula, Chiapas, México. Revista Mexicana de Ciencias Geológicas, 26.

Naef, D., Rickenmann, D., Rutschmann, P., \& McArdell, B. (2006). Comparison of flow resistance relations for debris flows using a one-dimensional finite element simulation model. Natural Hazards and Earth System Science, 6(1), 155-165. 
Nakatani, K., Satofuka, Y., \& Mizuyama, T. (2007). Development of 'KANAKO', a wide use debris flow simulator equipped with GUI. Proceeding Paper, 32nd Congress of IAHR International Association for Hydraulic Research, Venice, Italy. 32(1) 430439.

Nash, J. E. (1957). The form of the instantaneous unit hydrograph. International Association of Scientific Hydrology, Publ, 3, 114-121.

Navas, A., Alberto, F., Machín, J., \& Galán, A. (1990). Design and operation of a rainfall simulator for field studies of runoff and soil erosion. Soil Technology, 3(4), 385-397.

Newell, R. E., \& Hsiung, J. (1984). Sea surface temperature, atmospheric CO2 and the global energy budget: Some comparisons between the past and present. En: Mörner, N.A., Karlén, W. (eds.). Climatic changes on a yearly to millennial basis. Springer, Dordrecht, 533-561.

Nials, F., Deeds, E., \& Moseley, M. E. (1978). El Niño: The catastrophic flooding of coastal Peru. Field Museum of Natural History.7-8.

Nichols, G. (1987). Syntectonic alluvial fan sedimentation, southern Pyrenees. Geological Magazine, 124(02), 121-133.

Nilsen, T. H., \& Moore, T. E. (1984). Bibliography of alluvial-fan deposits. Geo Books. Norwich, England, 96 pags.

Noble, D., Wise, J., Zanetti, K., Vidal, C., \& McKee, E. (2009). Edad miocena tardía para los conglomerados y gravas del "Cuaternario" en las planicies costaneras del Perú central y otras evidencias concernientes a la evolución Neógena en la vertiente occidental de los andes peruanos. Boletín de la Sociedad Geológica del Perú. Volumen Especial, (7). Lima, Perú

Nossin, J. J. (1971). Outline of the geomorphology of the Doon valley, Northern UP, India. Zietschrift Fur Geomorphologie, 12, 18-50. 
O'Brien, J. S., \& Julien, P. Y. (1988). Laboratory analysis of mudflow properties. Journal of Hydraulic Engineering, 114(8), 877-887.

O'brien, J. S., Julien, P. Y., \& Fullerton, W. T. (1993). Two-dimensional water flood and mudflow simulation. Journal of Hydraulic Engineering, 119(2), 244-261.

O'Connor, H. (1988). Investigación del Huayco de Chosica 1987, sus efectos y medidas de mitigación. Tesis de pregrado. Lima: Universidad Nacional de Ingeniería. 99 pags.

O'Connor, J. E., Webb, R. H., \& Baker, V. R. (1986). Paleohydrology of pool-and-riffle pattern development: Boulder Creek, Utah. GSA Bulletin, 97(4), 410-420.

Olave, P. E. (2015). Generación de montos diarios de precipitación a partir de series observadas rellenadas con datos de re-análisis. Tesis de pregrado. Santiago (Chile): Universidad de Chile, facultad de Ciencias Fisicas y Matematicas. Departamento de ingeniería civil. 178 pags.

Olivares, G., Gómez, M., Candela, L., \& Tamoh, K. (2009). Adaptaciones en el uso del agua a los cambios climáticos en el mediterráneo: Desarrollo de un primer modelo simple de escorrentía (caja negra) para el cálculo de la escorrentía superficial en una subcuenca del fluvià. Resumen extendido. Jornadas De Ingeniería del Agua 2009: Agua y Energía, 1-11.

Ore, J. (2016). Application of flexible ring net barriers technology for debris-flow control in san martin torrent, Ayacucho-Perú. Proceeding Paper, 36th IAHR World Congress, The Hague, The Netherlands. Disponible en: https://www.iahr.org/site/cms/contentDocumentView.asp?chapter=42\&category=3 71

Ortlieb, L., \& Macharé, J. (1989). Evolución climática al final del Cuaternario en las regiones costeras del norte peruano: Breve reseña. Bull.Inst.Fr.Et.Andines, 18(2), 143-160.

Ortlieb, L., Macharé, J., Fournier, M., \& Woodman, R. (1989). La secuencia de cordones litorales de Colán (Piura): Un registro del fenómeno "El Niño" en el Holoceno superior. Boletín de la Sociedad Geológica del Perú, 80, 107-121. 
Osanai, N., Mizuno, H., \& Mizuyama, T. (2010). Design standard of control structures against debris flow in Japan. Journal of Disaster Research, 5(3), 307-314.

Owen, R. (1845). Descriptive and illustrated catalogue of the fossil organic remains of mammalia and aves contained in the museum of the royal college of surgeons of England. London: R \& J.E. Taylor.

Pack, F. (1923). Transportative potential of desert waters: Pan. Am. Geologist, 40, 349-356.

Palacios, O., Caldas, J., \& Vela, C. (1992). Geología de los Cuadrángulos de Lima, Lurín, Chancay y Chosica. Boletín del Instituto Geológico Minero y Metalúrgico del Perú, A (43). Lima

Parsons, M. H. (1970). Preceramic subsistence on the Peruvian coast. American Antiquity, 35(3) 292-304.

Pastor, M., Quecedo, M., Fernández, J. A., Herrores, M. I., Gonzalez, E., \& Mira, P. (2002). Modelling tailings dams and mine waste dumps failures. Geotechnique, 52(8), 579-591.

Payrastre, O., Gaume, E., \& Andrieu, H. (2005). Use of historical data to assess the occurrence of floods in small watersheds in the French Mediterranean area. Advances in Geosciences, 2, 320.

Pérez-Latorre, F. J., De Castro, L., \& Delgado, A. (2010). A comparison of two variable intensity rainfall simulators for runoff studies. Soil and Tillage Research, 107(1), 11-16.

Pernas, J. (2002). El hidrograma unitario geomorfológico y su aplicación en tres cuencas catalanas. Tesis Doctoral. Universitat de Barcelona. Departament de Geografia Física i Anàlisi Geogràfica Regional. 233 pag.

Perry, L. B., Seimon, A., \& Kelly, G. M. (2014). Precipitation delivery in the tropical high Andes of southern Peru: New findings and paleoclimatic implications. International Journal of Climatology, 34(1), 197-215. 
Petersen, G. (1954). Informe preliminar sobre la Geología de la faja costanera del departamento de Ica. Informe técnico inédito, 1. Lima: Empresa Petrolera Fiscal.

Pezet, F. (1896). La contra-corriente 'El Niño', en la costa norte del Perú. En: Boletín de la Sociedad Geográfica de Lima, 5, 457-461.

Pierson, T. C. (2005). Hyperconcentrated flow-transitional process between water flow and debris flow. En: Jakob, M., Hungr, O., \& Jakob, D. M.. (eds). Debris-flow hazards and related phenomena Berlin: Springer, pp. 159-202.

Pitcher, W. (1978). The anatomy of a batholith. President's anniversary addresses 1977. Journal of the Geological Society, 135.2(2), 157-182.

Ponce, V. (1989). Engineering hydrology: Principles and practices. Vol. 640. Englewood Cliffs, NJ: Prentice Hall.

Pope, R. J., \& Wilkinson, K. N. (2005). Reconciling the roles of climate and tectonics in late quaternary fan development on the Spartan piedmont, Greece. Geological Society, London, Special Publications, 251(1), 133-152.

Pozorski, S., \& Pozorski, T. (2003). La arquitectura residencial y subsistencia de los habitantes del sitio de moche: Evidencia recuperada por el proyecto ChanchánValle de Moche. En: Uceda, S., \& Mujica, E. (eds). Moche: hacia el final del milenio: actas del segundo Coloquio sobre la Cultura Moche: Trujillo, 1 a 7 de agosto de 1999 (Vol. 1). Pontificia Universidad Católica del Perú, Fondo Editorial. 119-150.

Prescott, J. R., \& Hutton, J. T. (1994). Cosmic ray contributions to dose rates for Luminescence and ESR dating: Large depths and long-term time variations. Radiation Measurements, 23(2), 497-500.

Proyecto Multinacional Andino (Ed.). (2007). Movimientos en masa en la región andina: una guía para la evolución de amenazas. Canadá: Proyecto Multinacional Andino: Geociencias para las Comunidades Andinas. 
Rabatel, A., Francou, B., Jomelli, V., Naveau, P., \& Grancher, D. (2008). A chronology of the little ice age in the tropical andes of Bolivia (16 S) and its implications for climate reconstruction. Quaternary Research, 70(2), 198-212.

Rachocki, A. (1981). Alluvial fans: An attempt at an empirical approach. Wiley, Chichester. 161 pags.

Ramos, V., \& Aleman, A. (2000). (2000). Tectonic evolution of the Andes. Poceedings Paper, Tectonic Evolution of South America: 31 International Geological Congress, Rio de Janeiro, 635-685.

Rasmusson, E. M., \& Carpenter, T. H. (1982). Variations in tropical sea surface temperature and surface wind fields associated with the Southern Oscillation/EI Niño. Monthly Weather Review, 110(5), 354-384.

Rech, J. A., Currie, B. S., Michalski, G., \& Cowan, A. M. (2006). Neogene climate change and uplift in the Atacama desert, Chile. Geology, 34(9), 761-764.

Reineck, H. E., \& Singh, I. B. (1980). Tidal flats. Depositional sedimentary environments (pp. 430-456) Springer.

Richardson, J. B. (1978). Early man on the Peruvian north coast, early maritime exploitation and the Pleistocene and Holocene environment. Early Man in America, 274-289.

Rickenmann, D. (2005). Debris flows and risk assessment. Birmensdorf, Zürich. Swiss Federal Institute for Forest, Snow and Landscape Research report.

Rickenmann, D. (1991). Hyperconcentrated flow and sediment transport at steep slopes. Journal of Hydraulic Engineering, 117(11), 1419-1439.

Rico, M., Benito, G., \& Barnolas, A. (2001). Combined palaeoflood and rainfall-runoff assessment of mountain floods (Spanish Pyrenees). Journal of Hydrology, 245(1), 59-72.

Rockwell, T., Keller, E., \& Johnson, D. (1985). Tectonic geomorphology of alluvial fans and mountain fronts near Ventura, California. Proceeding Paper, Tectonic 
Geomorphology: The 15th Annual Geomorphology Symposium. Allen and Unwin Publishers, Boston, MA, 183-207.

Rodríguez-Iturbe, I., \& Valdes, J. B. (1979). The geomorphologic structure of hydrologic response. Water Resources Research, 15(6), 1409-1420.

Ross, C. (1921). The calculation of flood discharges by the use of a time contour plan. Poceedings Paper, Institution of Engineers, Australia, 2, 85.

Ruiz-Villanueva, V. (2013). Nuevas Metodologías para el análisis de la peligrosidad y riesgo por inundación en zonas de montaña. Tesis Doctoral. Universidad Complutense de Madrid.

Rutllant, J. (1985). Natural desertification mechanisms along the arid west coast of South America. Poceedings Paper, International Workshop on Sand Transportation and Desertification in Arid Lands, Khartoum, Sudan. 235-252.

Ryder, J. (1971). The stratigraphy and morphology of para-glacial alluvial fans in southcentral British Columbia. Canadian Journal of Earth Sciences, 8(2), 279-298.

Sáez, A. (1985). Upper Eocene-lower Oligocene terminal fan deposits. easthern part of the Ebro basin (Suria-Cardona, Spain). Poceedings Paper, 6th European Regional Meeting, International Association of Sedimentologists. Lérida, Abril 1985, pp. 854867.

Saint-Venant, A. J. (1871). Theorie du mouvement non-permanent des Eaux, avec application aux Crues des rivieres et a l'introduction de marees dans leurs lits. Comptes Rendus Des Seances De l'Academie Des Sciences, 36, 174-154.

Saito, K., 1988. Alluvial fans in Japan. Kokon-Shoin, Tokyo. 280 pags.

Saito, K., \& Oguchi, T. (2005). Slope of alluvial fans in humid regions of Japan, Taiwan and the Philippines. Geomorphology, 70(1), 147-162.

Sancho, C., Benito, G., \& Gutiérrez, M. (1991). Agujas de Erosión y Perfiladores Microtopográficos. Cuadernos Técnicos de la Sociedad Española de Geomorfología, 2, 3-28. 
Sara, L. M., Jameson, S., Pfeffer, K., \& Baud, I. (2016). Risk perception: The social construction of spatial knowledge around climate change-related scenarios in Lima. Habitat International, 54, 136-149.

Sarango, D., Gástelo, J., Velásquez, T., Alata, C., \& Montalvo, C. (2014). Simulación del sistema hidráulico e hidrológico de la cuenca del río Rímac-Santa Eulalia. Revista de Investigación de Física, 17(2)

Saurral, R. I., Barros, V. R., \& Lettenmaier, D. P. (2008). Land use impact on the Uruguay river discharge. Geophysical Research Letters, 35(12)

Scherrenberg, A., Holcombe, R., \& Rosenbaum, G. (2014). The persistence and role of basin structures on the $3 \mathrm{D}$ architecture of the Marañon fold-thrust belt, Peru. Journal of South American Earth Sciences, (51)

Schick, A., \& Lekach, J. (1987). A high magnitude flood in the Sinai desert. Catastrophic Flooding, 18, 381-410.

Schumm, S. A. (1981). Evolution and response of the fluvial system, sedimentological implications. En: Ethridge, F. G., \& Flores, R. M. (Eds.). Recent and Ancient Nonmarine Depositional Environments: Models for Exploration. Society of Economic Paleontologists and Mineralogists. Rocky Mountain Section Special Publication, 31, pp. 19-30.

Schuster, R. L., \& Wieczorek, G. F. (2002). Landslide triggers and types. Proceeding Paper, First European Conference on Landslides, Taylor \& Francis, Prague, 59-78.

Scott, K. M. (1971). Origin and sedimentology of 1969 debris flows near Glendora, California. US Geological Survey Professional Paper, 750, 242-247.

Sébrier, M., \& Macharé, J. (1980). Observaciones acerca del cuaternario de la costa del Perú central. Bulletin De L'Institut Français D'Études Andines, 9, 25-32.

Seluchi, M. E., Garreaud, R. D., Norte, F. A., \& Saulo, A. C. (2006). Influence of the subtropical Andes on baroclinic disturbances: A cold front case study. Monthly Weather Review, 134(11), 3317-3335. 
Shaw, E. M., Beven, K. J., Chappell, N. A., \& Lamb, R. (2010). Hydrology in practice $4^{\text {th }}$ edition. London: Spon Press (Taylor and Francis). 546 pags.

Sherman, L. K. (1932). Streamflow from rainfall by the unit-graph method. Engineering News-Record, 108, 501; 501-505; 505.

Shields, A. (1936). Application of similarity principles ai1d turbulence research to bedload movement. Report. No. 167. Pasadena, California: Lab. of Hydraulics and Water Resources-California Institute of Technology.

Simpson, B. B. (1975). Glacial climates in the eastern tropical south pacific. Nature, 253(5486), 34-36.

Simpson, B. B., \& Haffer, J. (1978). Speciation patterns in the Amazonian forest biota. Annual Review of Ecology and Systematics, 9(1), 497-518.

Sirvent, J., Desir, G., Gutierrez, M., Sancho, C., \& Benito, G. (1997). Erosion rates in badland areas recorded by collectors, erosion pins and profilometer techniques (Ebro basin, NE-Spain). Geomorphology, 18(2), 61-75.

Snyder, F. F. (1938). Synthetic unit-graphs. EOS, Transactions of American Geophysical Union, 19(1), 447-454.

Somoza, R., \& Ghidella, M. (2005). Convergencia en el margen occidental de América del Sur durante el Cenozoico: subducción de las placas de Nazca, Farallón y Aluk. . Revista de la Asociación Geológica Argentina, 60(4), 797-809.

Soulas, J. (1978). Tectonique quaternaire: La cóte Pacifique et la chaine Andine du Pérou Central. Rev. Géog.Phys. Géol.Dyn. 20(5), 399-414.

Spearing, D. (1974). Alluvial fan deposits. Geological Society of America Summary Sheets of Sedimentary Deposits, Sheet, 1

Stedinger, J. R. (1993). Frequency analysis of extreme events. Handbook of Hydrology, 18 
Steel, R. J. (1974). New red sandstone floodplain and piedmont sedimentation in the Hebridean province, Scotland. Journal of Sedimentary Research, 44(2)

Steel, R. J., Næhle, S., Nilsen, H., Roe, S. L., \& Spinnangr, A. (1977). Coarseningupward cycles in the alluvium of Horne Len basin (Devonian) Norway: Sedimentary response to tectonic events. Geological Society of America Bulletin, 88(8), 1124-1134.

Steel, R. J., \& Wilson, A. C. (1975). Sedimentation and tectonism (Permo-Triassic) on the margin of the North Minch basin, Lewis. Journal of the Geological Society, 131(2), 183-200.

Steffen, D., Preusser, F., \& Schlunegger, F. (2009). OSL quartz age underestimation due to unstable signal components. Quaternary Geochronology, 4(5), 353-362.

Steffen, D., Schlunegger, F., \& Preusser, F. (2010). Late Pleistocene fans and terraces in the Majes valley, southern Peru, and their relation to climatic variations. International Journal of Earth Sciences, 99(8), 1975-1989.

Steinmann, G. (1904). Observaciones Geológicas efectuadas desde Lima hasta Chanchamayo. No. 12. Lima: Cuerpo de Ingenieros de Minas del Perú. Disponible en: https://books.google.com.pe/books?id=1 nimMwAACAAJ

Stokes, S. (1999). Luminescence dating applications in geomorphological research. Geomorphology, 29(1-2), 153-171.

Surrel, A. (1841). Etude sur Les torrents des Hautes-Alpes (2e ed.). Paris, Dunod: Carilian-Gœury et Dalmont V. (eds.), 283 pags

Suvires, G. M. (2013). Geomorfología tectónica y evolución del relieve en un sector del piedemonte occidental de la sierra chica de zonda, pre-cordillera oriental, argentina. Revista Mexicana De Ciencias Geológicas, 30(2), 324-335.

Takahama, J., Fujita, Y., Kondo, Y., \& Hachiya, K. (2002). Two layer model for analysis of deposition and erosion processes of debris flows. Proceeding Paper, Hydraulic Engineering, 46, 677-682. 
Takahashi, K., \& Martínez, A. G. (2017). The very strong coastal El Niño in 1925 in the far-eastern pacific. Climate Dynamics, 1-27.

Takahashi, T. (1983). Debris flow and debris flow deposition. Advances in the Mechanics and Flow of Granular Materials, 2, 57-77.

Takahashi, T. (1978). Mechanical characteristics of debris flow. Journal of the Hydraulics Division, 104(8), 1153-1169.

Takahashi, T. (1981). Debris flow. Annual Review of Fluid Mechanics, 13, 57-77. doi:\{10.1146/annurev.fl.13.010181.000421

Tayfur, G., Kavvas, M. L., Govindaraju, R. S., \& Storm, D. E. (1993). Applicability of St. Venant equations for two-dimensional overland flows over rough infiltrating surfaces. Journal of Hydraulic Engineering, 119(1), 51-63.

Témez, J. R. (1978). Cálculo Hidro-meteorológico de Caudales de Avenida en Pequeñas Cuencas Naturales. Madrid: MOPU. Dirección General de Carreteras.

Témez, J. R. (1991). Generalización y mejora del método racional, versión de la dirección general de carreteras de España. Ingeniería Civil, CEDEX-MOPT, 82, 51-56.

Teves, N. (1975). Aspectos sedimentarios y estructurales del sector costanero frente a la dorsal de nazca. Boletín de la Sociedad Geológica del Perú, 50, 87-98.

Tieje, A. (1923). The red beds of the front range in Colorado: A study in sedimentation. The Journal of Geology, 31(3), 192-207.

Triviño, A., \& Ortiz, S. (2004). Metodología para la modelación distribuida de la escorrentía superficial y la delimitación de zonas inundables en ramblas y ríosrambla mediterráneos. Investigaciones Geográficas, 35, pp.67-83,

Trowbridge, A. C. (1911). The terrestrial deposits of Owens Valley, California. The Journal of Geology, 19(8), 706-747. 
Turnbull, B., Bowman, E., \& McElwaine, J. (2015). Debris flows: Experiments and modelling. Comptes Rendus Physique, 16(1), 86-96.

Uceda, S. (1986). Le Paijanien De La Région De Casma (Pérou): Industrie Litigue Et Relations Avec Les Autres Industries Précéramiques, Tesis Doctoral, I'Universite de Bordeaux (France).

Uceda, S., \& Canziani, J. (1993). Evidencias de grandes precipitaciones en diversas etapas constructivas de la huaca de La Luna, costa norte del Perú. Bull. Inst. fr. études andínes, 22(1), 313-343.

Varas, E., \& Farías de Reyes, M. (2000). (2000). Estudio comparativo de relaciones intensidad-duración-frecuencia. Resumen extendido. XIX Congreso Latinoamericano De Hidráulica, Córdoba, Argentina, 2 359-366.

Vargas, G., Ortlieb, L., \& Rutllant, J. (2000). Aluviones históricos en Antofagasta y su relación con eventos El Niño/Oscilación del Sur. Revista Geológica De Chile, 27(2), 157-176.

Vélez, J. I., Poveda, G., Mesa, O., Hoyos, C. D., Mejía, J. F., Quevedo, D. I., Vieira, S. C. (2002). Aplicación de diferentes metodologías para estimación de curvas Intensidad-Frecuencia-Duración en Colombia. Meteorología Colombiana, (6), 91100.

Verstappen, H., Zuidam, R. v., Meijerink, A., \& Nossin, J. (1991). The ITC system of geomorphologic survey: A basis for the evaluation of natural resources and hazards 89 pags. Enschede: ITC.

Verstraeten, G., \& Poesen, J. (2002). Using sediment deposits in small ponds to quantify sediment yield from small catchments: Possibilities and limitations. Earth Surface Processes and Landforms, 27(13), 1425-1439.

Vílchez, M., \& Pari, W. (2012). Geodinámica de los flujos de detrito y lodo que afectaron el sitio histórico cultural de Chan Chan. Resúmenes Extendidos. XV Congreso Peruano De Geología. Lima. (XV Congreso Peruano de Geología). 
Vilímek, V., Zvelebil, J., Klimeš, J., Patzelt, Z., Astete, F., Kachlík, V., \& Hartvich, F. (2007). Geomorphological research of large-scale slope instability at Machu Picchu, Peru. Geomorphology, 89(3), 241-257.

Villacorta, S., De Torres, T., Pérez-Puig, C., Llorente, M., \& Ayala, L. (2015). Estudio preliminar de la evolución geomorfológica del abanico aluvial de Lima (Perú) e implicancias en el análisis de amenazas asociadas al cambio climático. Serie Correlación Geológica, 31(2), 173-182.

Villacorta, S., Fidel, L., \& Zavala, B. (2012). Mapa de susceptibilidad por movimientos en masa del Perú. Revista De La Asociación Geológica Argentina, 69(3), 393-399.

Villacorta, S., Núñez, S., \& Huarez, C. (2015). Evaluación geodinámica de los flujos de detritos del 23-03-15 en el distrito de Lurigancho - Chosica. Resumen extendido. Foro internacional sobre la gestión del riesgo geológico, Arequipa, Perú, 1. 156160.

Villacorta, S., Núñez, S., Tatard, L., Pari, W., \& Fidel, L. (2015). Peligros Geológicos en el área de Lima Metropolitana y la región Callao (Lima-Perú). Boletín del Instituto Geológico Minero y Metalúrgico del Perú, C (59). Lima

Von Haast, J. (1879). Geology of the provinces of Canterbury and Westland, New Zealand: A report comprising the results of official explorations. Christchurch: Times Office. $486 \mathrm{p}$

Wainwright, J., Parsons, A. J., \& Abrahams, A. D. (2000). Plot-scale studies of vegetation, overland flow and erosion interactions: Case studies from Arizona and New Mexico. Hydrological Processes, 14(16-17), 2921-2943.

Walker, G. (1928). World weather. Quarterly Journal of the Royal Meteorological Society, 54(226), 79-87.

Wallinga, J. (2002). On the detection of OSL age overestimation using single-aliquot techniques. Geochronometria, 21(1), 17-26.

Wang, Z., Larsen, P., \& Xiang, W. (1994). Rheological properties of sediment suspensions and their implications. Journal of Hydraulic Research, 32(4), 495-516. 
Wasklewicz, T., Mihir, M., \& Whitworth, J. (2008). Surface variability of alluvial fans generated by disparate processes, eastern death valley, CA. The Professional Geographer, 60(2), 207-223.

Wasklewicz, T., \& Scheinert, C. (2016). Development and maintenance of a telescoping debris flow fan in response to human-induced fan surface channelization, chalk creek valley natural debris flow laboratory, Colorado, USA. Geomorphology, 252, 51-65.

Wasson, R. J. (1975). Evolution of Alluvial Fans in Two Areas of South-Eastern Australia. Tesis Doctoral, Macquarie University, School of Earth Sciences, New South Wales.

Wasson, R. J. (1977). Catchment processes and the evolution of alluvial fans in the lower Derwent valley, Tasmania. Zeitschrift Fur Geomorphologie, 21(2), 147-168.

Webb, R. H., \& Jarrett, R. D. (2002). One-Dimensional estimation techniques for discharges of paleo floods and historical floods. Ancient Floods, Modern Hazards, 111-125.

Webb, S. D. (1978). A history of savanna vertebrates in the new world. Part II: South America and the great interchange. Annual Review of Ecology and Systematics, 9(1), 393-426.

Wells, S. G., \& Harvey, A. M. (1987). Sedimentologic and geomorphic variations in storm-generated alluvial fans, Howgill Fells, northwest England. Geological Society of America Bulletin, 98(2), 182-198.

Wescott, W. A., \& Ethridge, F. G. (1980). Fan-delta sedimentology and tectonic setting-yallahs fan delta, southeast Jamaica. AAPG Bulletin, 64(3), 374-399.

Whipple, K. X., \& Dunne, T. (1992). The influence of debris-flow rheology on fan morphology, Owens valley, California. Geological Society of America Bulletin, 104(7), 887-900.

Wiesner, C. (1970). Hydrometeorology. London: Chapman and Hall. 
Wilches-Chaux, G. (2005). 10. el terremoto, la avalancha y los deslizamientos de la cuenca del río Páez, 1994. En: Hermelin M. (eds.). Desastres De Origen Natural en Colombia, 1979-2004, Medellín: Fondo editorial Universidad EAFIT. Pp. 121.

Williams, G. E. (1969). Characteristics and origin of a Precambrian pediment. The Journal of Geology, 183-207.

Williams, G. P., \& Costa, J. E. (1988). Geomorphic measurements after a flood. Flood Geomorphology. Wiley, New York.1988. P 65-77.3 Fig, 1 Tab, 54 Ref.

Winkle, A., \& Huntley, D. (1982). Thermoluminescence dating of sediments. Quaternary Science Reviews, 1(1), 31-53.

Wohl, E. E. (1995). Estimating flood magnitude in ungauged mountain channels, Nepal. Mountain Research and Development, 69-76.

Wood, E. F., Sivapalan, M., Beven, K. J., \& Band, L. (1988). Effects of spatial variability and scale with implications to hydrologic modelling. Journal of Hydrology, 102(1-4), $29-47$.

Wu, I. P. (1963). Design hydrographs for small watersheds in Indiana. Journal of the Hydraulics Division, 89(6), 35-66.

Zalina, M. D., Desa, M. N. M., Nguyen, V. T. A., \& Kassim, A. H. M. (2002). Selecting a probability distribution for extreme rainfall series in Malaysia. Water Science and Technology, 45(2), 63-68.

Zanon, F., Borga, M., Zoccatelli, D., Marchi, L., Gaume, E., Bonnifait, L., \& Delrieu, G. (2010). Hydrological analysis of a flash flood across a climatic and geologic gradient: The September 18, 2007 event in western Slovenia. Journal of Hydrology, 394(1), 182-197.

Zavala, B., Vílchez, M., \& Núñez, S. (2012). Flujos de detritos del 05-04-12 entre las quebradas La Ronda y Los Cóndores, margen izquierda del río Rímac. Informe técnico inédito No. A6608. Lima: Instituto Geológico Minero y Metalúrgico del Perú. 


\section{ANEXOS}

8.1 Datos de precipitación máxima diaria anual empleados

8.2 Funciones de probabilidad de ajuste

8.3 Mapa Geomorfologico

8.4 Mapa Geológico

8.5 Velocidad y Altura de depósito asociado al mapa de peligrosidad

8.6 Mapa de Peligrosidad por flujo de detritos y desbordes para un periodo de retorno de 500 años en el río Rímac

8.7 Guía para la extracción de datos climático del modelo internacional ERAINTERIM Reanalysis

8.8 Guía para el uso del modelo MAGRITH para la afinación de cauces 
8.1 Datos de precipitación máxima diaria anual empleados 
ANEXO 1

\begin{tabular}{|c|c|c|c|c|c|c|c|c|c|c|c|c|c|c|c|c|c|c|c|c|}
\hline Año & 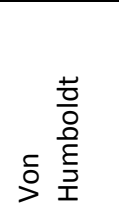 & 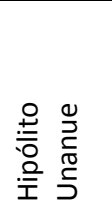 & 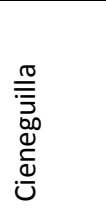 & 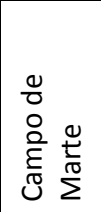 & $\begin{array}{l}\frac{\widetilde{N}}{\tilde{N}} \\
\stackrel{0}{U}\end{array}$ & 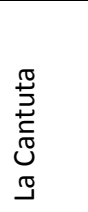 & $\begin{array}{l}\frac{\pi}{2} \\
\frac{1}{0} \\
\frac{0}{2} \\
\sum_{0}^{\pi} \\
\sum\end{array}$ & $\frac{\frac{\pi}{2}}{\frac{2}{\frac{\pi}{0}}}$ & 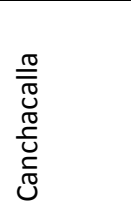 & 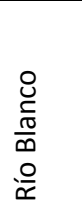 & $\begin{array}{l}\frac{\pi}{2} \\
\frac{0}{U} \\
\frac{0}{0} \\
\frac{\pi}{2} \\
\frac{\pi}{\pi} \\
0\end{array}$ & $\begin{array}{l}\frac{\pi}{5} \\
\frac{5}{5} \\
\frac{3}{4}\end{array}$ & 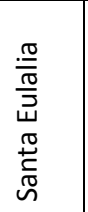 & $\begin{array}{l}\bar{J} \\
\overline{0} \\
\frac{\pi}{0} \\
\mathbb{J} \\
\end{array}$ & 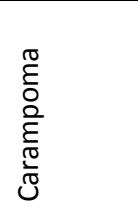 & 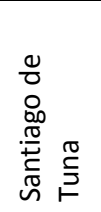 & 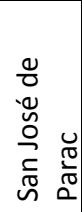 & $\frac{\text { o }}{\stackrel{\overline{\underline{z}}}{\bar{z}}}$ & & 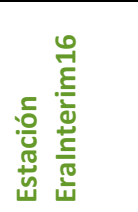 \\
\hline 1979 & 1.7 & 2.9 & 0.3 & 0.8 & 7.5 & 30.4 & 12.3 & 9.8 & 16.2 & 15.4 & 20.4 & 10.3 & 10 & 29.6 & 20.3 & 31.1 & 17.7 & 21.1 & 2.671 & 28.991 \\
\hline 1980 & 0 & 1 & 0.7 & 4 & 8.7 & 1.2 & 8.8 & 46.5 & 15.3 & 19 & 32.5 & 16.5 & 10 & 27.1 & 20.6 & 20.6 & 22.9 & 24.8 & 0.772 & 32.692 \\
\hline 1981 & 3.5 & 5.8 & 2.2 & 3 & 5.7 & 5.4 & 12.5 & 15.9 & 65.2 & 25.7 & 46.2 & 13.7 & 10 & 55.9 & 30.3 & 46.5 & 42 & 37.9 & 5.574 & 45.793 \\
\hline 1982 & 1 & 0.7 & 0.5 & 1.8 & 14 & 8.3 & 9.5 & 11.2 & 31.4 & 32.7 & 27.2 & 11.2 & 6.3 & 31.7 & 15.5 & 35.8 & 28.5 & 26.2 & 0.473 & 34.088 \\
\hline 1983 & 2.5 & 5.8 & 1.5 & 7 & 7.2 & 15.4 & 25 & 30 & 13.1 & 22.8 & 27.2 & 20.5 & 10.2 & 25.9 & 31.2 & 46.3 & 27.7 & 38.3 & 5.571 & 46.187 \\
\hline 1984 & 2.2 & 2 & 0.7 & 1.4 & 5.4 & 6.6 & 21.5 & 32.5 & 51.4 & 21.8 & 19.2 & 14 & 10.5 & 36.9 & 20.8 & 38.6 & 29.1 & 59.8 & 1.772 & 67.694 \\
\hline 1985 & 1.5 & 0.4 & 1.3 & 0.9 & 10.5 & 1.5 & 19.8 & 14 & 65.2 & 23.9 & 29 & 6.4 & 0.4 & 40.9 & 21.4 & 18.6 & 24.3 & 37 & 0.174 & 44.883 \\
\hline 1986 & 1 & 3.3 & 2 & 0.5 & 7.3 & 0.9 & 27.2 & 14.9 & 32 & 18.9 & 39.5 & 12.8 & 2 & 29.9 & 33.3 & 30.7 & 25 & 34.6 & 3.068 & 42.493 \\
\hline 1987 & 0.9 & 1.3 & 0.8 & 1.4 & 16.1 & 8.4 & 20.9 & 13 & 27.2 & 14.9 & 22.7 & 11.6 & 36 & 24 & 22.7 & 22 & 21.2 & 20 & 1.071 & 27.886 \\
\hline 1988 & 0.8 & 1.3 & 1 & 0.3 & 2.9 & 4.6 & 12.3 & 20 & 11.9 & 21.3 & 28.5 & 9.8 & 9.7 & 29.9 & 31.5 & 28.2 & 22.9 & 32.4 & 1.069 & 40.294 \\
\hline 1989 & 1.4 & 2 & 1.7 & 0.5 & 5.2 & 2.6 & 10.7 & 17.7 & 16.7 & 17.6 & 21 & 20.3 & 27.6 & 22.7 & 19.6 & 33.5 & 15.8 & 33.1 & 1.767 & 40.991 \\
\hline 1990 & 1.5 & 1.6 & 0.6 & 1 & 3.2 & 4.1 & 10.6 & 22 & 6.5 & 20.1 & 20.9 & 14.7 & 6.5 & 19.2 & 25.6 & 36.8 & 14.6 & 46.2 & 1.373 & 54.094 \\
\hline 1991 & 0.7 & 2.5 & 0.9 & 3.2 & 3.7 & 1.9 & 17.6 & 21.4 & 13.4 & 18.7 & 19.5 & 29.7 & 3 & 26.6 & 23.3 & 33.2 & 18.4 & 44.4 & 2.267 & 52.288 \\
\hline 1992 & 1 & 2.9 & 0.2 & 0.6 & 2.3 & 14.3 & 30.5 & 12 & 8.4 & 10.9 & 26.8 & 6.3 & 0.5 & 20 & 19.2 & 5.8 & 12.4 & 30.8 & 2.674 & 38.694 \\
\hline 1993 & 0.9 & 2.4 & 2.3 & 3.2 & 2.4 & 1.6 & 30.3 & 27 & 17.4 & 21.3 & 24.8 & 23.3 & 2 & 20.3 & 22.4 & 38.7 & 19.7 & 37.6 & 2.172 & 45.494 \\
\hline 1994 & 2.1 & 1.5 & 2.1 & 0.6 & 16 & 1.5 & 15.5 & 16.5 & 16.4 & 27 & 27.7 & 11.2 & 13.5 & 30.9 & 17.9 & 14.9 & 25.4 & 49.2 & 1.269 & 57.091 \\
\hline 1995 & 0.7 & 1.8 & 2 & 2.9 & 3 & 3 & 22.3 & 11.4 & 11.5 & 22.3 & 29.2 & 9.3 & 3.8 & 17.1 & 15.1 & 12.2 & 28.8 & 54.4 & 1.573 & 62.289 \\
\hline 1996 & 2 & 1.2 & 0.6 & 0.9 & 5.8 & 1.5 & 13.6 & 18.5 & 18 & 18.5 & 17.7 & 18.4 & 4.5 & 17.7 & 17.2 & 15.7 & 17.8 & 23.8 & 0.966 & 31.688 \\
\hline 1997 & 4.6 & 5.1 & 1 & 1.2 & 2.8 & 2.8 & 9.5 & 25.4 & 12.1 & 18.9 & 24.2 & 10.2 & 4.9 & 24.8 & 15.7 & 15.1 & 18.1 & 18.3 & 4.868 & 26.194 \\
\hline 1998 & 3.4 & 1.4 & 0.2 & 0.6 & 13.2 & 0.1 & 21.9 & 30.2 & 46.7 & 18.5 & 38 & 22.2 & 6 & 26.8 & 24.1 & 30.2 & 18.8 & 27.5 & 1.173 & 35.392 \\
\hline 1999 & 2.3 & 0.4 & 3.8 & 0.8 & 6.5 & 6.1 & 19.8 & 23.8 & 39.5 & 26.5 & 20.9 & 22.1 & 14.7 & 22.6 & 15.5 & 19.6 & 28.4 & 28.3 & 0.173 & 36.188 \\
\hline 2000 & 0.9 & 1.7 & 0.6 & 0.8 & 6 & 4.4 & 14.3 & 31.7 & 24.3 & 24.1 & 25 & 9.5 & 6.4 & 19.5 & 15.2 & 17.9 & 28.9 & 31.3 & 1.474 & 39.194 \\
\hline 2001 & 2.7 & 0.3 & 0.4 & 1.7 & 5.2 & 5.4 & 16.2 & 21.5 & 18.9 & 18.6 & 22.6 & 14.1 & 8 & 26.2 & 17.4 & 13.5 & 23.5 & 45.6 & 0.065 & 53.493 \\
\hline 2002 & 2.2 & 1.9 & 1.4 & 1.7 & 30.7 & 37.2 & 15.7 & 27.2 & 18.1 & 20 & 18.4 & 16.4 & 25.9 & 23.3 & 21.2 & 15.4 & 19.9 & 24.7 & 1.667 & 32.587 \\
\hline 2003 & 2.1 & 1.2 & 2.2 & 0.7 & 2.8 & 5.2 & 19.5 & 22.9 & 24.4 & 23.2 & 23.3 & 25.5 & 16.8 & 21.5 & 18.3 & 14 & 26.6 & 17.6 & 0.974 & 25.491 \\
\hline
\end{tabular}




\begin{tabular}{|c|c|c|c|c|c|c|c|c|c|c|c|c|c|c|c|c|c|c|c|c|}
\hline 2004 & 2.3 & 1.4 & 1 & 0.4 & 1.6 & 2.8 & 18 & 25.5 & 32.7 & 17.5 & 16 & 14.4 & 2.5 & 21.2 & 14.8 & 11.7 & 18.1 & 21.1 & 1.171 & 28.993 \\
\hline 2005 & 2.7 & 1.5 & 1 & 0.8 & 1.2 & 36.6 & 21.5 & 12.1 & 15.8 & 13.7 & 18.1 & 11.7 & 1.5 & 16.5 & 16.3 & 18 & 23.4 & 19.3 & 1.273 & 27.194 \\
\hline 2006 & 0.3 & 6.5 & 0.3 & 0.8 & 5.6 & 5.6 & 14.3 & 19.8 & 31.4 & 21.2 & 20.6 & 30.8 & 7.8 & 19.4 & 24.1 & 15.1 & 23.6 & 23.2 & 6.268 & 31.085 \\
\hline 2007 & 0.9 & 1 & 0.7 & 1.1 & 7.7 & 9.1 & 16.6 & 15.7 & 21.7 & 53 & 21.2 & 27.8 & 4.1 & 23.6 & 18.6 & 10.5 & 24.4 & 27.5 & 0.767 & 35.387 \\
\hline 2008 & 5.4 & 3 & 0.1 & 2.3 & 4 & 29.6 & 16.5 & 20.6 & 44.5 & 24 & 18.9 & 16.9 & 5.3 & 25.7 & 17.5 & 30.8 & 23.5 & 19.3 & 2.774 & 27.194 \\
\hline 2009 & 1.1 & 1 & 2 & 2.5 & 8 & 1.1 & 23.1 & 40.5 & 15 & 19.2 & 20.8 & 19.30 & 11.2 & 27.9 & 18.7 & 38 & 22.7 & 26.2 & 0.772 & 34.094 \\
\hline 2010 & 4.9 & 1.73 & 6.901 & 3.658 & 0.8 & 2.185 & 20.6 & 10 & 17.90 & 12.5 & 26.2 & 19.60 & 4.5 & 21.9 & 17.3 & 11.1 & 25.2 & 8 & 1.541 & 15.892 \\
\hline 2011 & 5.4 & 1.72 & 7.666 & 3.734 & 5.7 & 6.092 & 14.4 & 13.9 & 11.80 & 18.8 & 21 & 17.60 & 5.5 & 21.2 & 18.7 & 13.8 & 27.1 & 24.7 & 1.492 & 32.593 \\
\hline 2012 & 11.2 & 3.78 & 18.512 & 8.26 & 37 & $\begin{array}{r}31.77 \\
9 \\
\end{array}$ & 19.8 & 18.8 & 23.3 & 24 & 28.8 & 21.30 & 12.5 & 21.1 & 22.6 & 31 & 21.5 & 22.6 & 3.551 & 30.494 \\
\hline 2013 & 7 & 2.725 & 10.765 & 5.742 & 2.3 & 3.691 & 21.3 & 13.3 & 24.60 & 24.7 & 17.7 & 18.00 & 4.2 & 28.6 & 26 & 35.6 & 22.1 & 117.7 & 2.495 & 125.593 \\
\hline 2014 & 5.4 & 3.143 & 8.949 & 6.157 & 6.2 & 6.211 & 9.9 & 7.8 & 23.40 & 18.2 & 18.5 & 10.00 & 3.5 & 14.8 & 17.1 & 23.7 & 20.5 & 42.2 & 2.913 & 50.086 \\
\hline 2015 & 9.4 & 3.048 & 15.127 & 6.672 & 18.3 & $\begin{array}{r}18.26 \\
2 \\
\end{array}$ & 21.3 & 15.6 & 23.40 & 17.6 & 19 & 7.20 & 17.2 & 19.6 & 23.4 & 37 & 19.5 & 23.4 & 2.818 & 31.287 \\
\hline $\begin{array}{l}\text { № } \\
\text { datos }\end{array}$ & 37.00 & 37.00 & 37.00 & 37.00 & 37.00 & 37.00 & 37.00 & 37.00 & 37.00 & $\begin{array}{r}37.0 \\
0 \\
\end{array}$ & 37.00 & 37.00 & $\begin{array}{r}37.0 \\
0 \\
\end{array}$ & 37.00 & 37.00 & 37.00 & $\begin{array}{r}37.0 \\
0 \\
\end{array}$ & 37.00 & 37.00 & 37.00 \\
\hline $\begin{array}{l}\text { Promedi } \\
\text { o }\end{array}$ & 2.69 & 2.24 & 2.81 & 2.26 & 7.91 & 8.85 & 17.71 & 20.29 & 24.51 & $\begin{array}{r}21.2 \\
7 \\
\end{array}$ & 24.30 & 16.07 & 8.89 & 25.20 & 20.82 & 24.63 & $\begin{array}{r}22.9 \\
7 \\
\end{array}$ & 32.98 & 2.01 & 40.87 \\
\hline Desv.Est & 2.49 & 1.53 & 4.23 & 2.11 & 7.66 & 10.58 & 5.65 & 8.67 & 14.46 & 6.86 & 6.58 & 6.39 & 7.75 & 7.60 & 4.89 & 11.12 & 5.32 & 18.20 & 1.53 & 18.20 \\
\hline Máxima & 11.2 & 6.5 & 18.512 & 8.26 & 37 & 37.2 & 30.5 & 46.5 & 65.2 & 53 & 46.2 & 30.8 & 36 & 55.9 & 33.3 & 46.5 & 42 & 117.7 & 6.268 & 125.593 \\
\hline Mínima & 0 & 0.3 & 0.1 & 0.3 & 0.8 & 0.1 & 8.8 & 7.8 & 6.5 & 10.9 & 16 & 6.3 & 0.4 & 14.8 & 14.8 & 5.8 & 12.4 & 8 & 0.065 & 15.892 \\
\hline Sesgo & 1.84 & 1.33 & 2.49 & 1.42 & 2.40 & 1.75 & 0.38 & 1.08 & 1.48 & 2.82 & 1.54 & 0.56 & 1.84 & 2.08 & 1.03 & 0.27 & 1.01 & 2.97 & 1.33 & 2.97 \\
\hline $\begin{array}{l}\text { Varianz } \\
\text { a }\end{array}$ & 6.21 & 2.33 & 17.91 & 4.45 & 58.72 & $\begin{array}{r}111.9 \\
5 \\
\end{array}$ & 31.89 & 75.22 & 209.05 & $\begin{array}{r}47.0 \\
1 \\
\end{array}$ & 43.33 & 40.89 & $\begin{array}{r}60.0 \\
9 \\
\end{array}$ & 57.70 & 23.89 & $\begin{array}{r}123.5 \\
7\end{array}$ & $\begin{array}{r}28.3 \\
1 \\
\end{array}$ & $\begin{array}{r}331.3 \\
1 \\
\end{array}$ & 2.33 & 331.32 \\
\hline
\end{tabular}

Datos de precipitación máxima diaria anual entre los años 1979 y 2009 en las estaciones de Lima. Tomado de: ANA 2010. Estudio de los recurso hidricos del rio Rímac

Datos de precipitación máxima diaria anual entre los años 2010 y 2016 del SENAMHI

Datos del modelo Era-Interim (Dee et al., 2011) 
8.2 Funciones de probabilidad de ajuste 


\section{ARAHUAY}

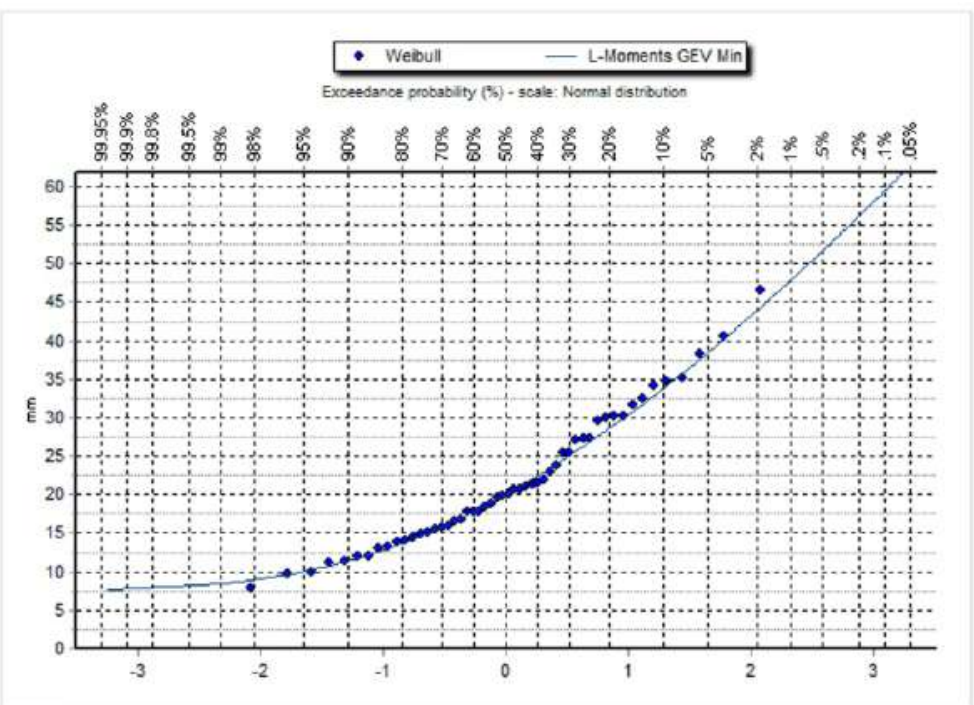

\section{AUTISHA}

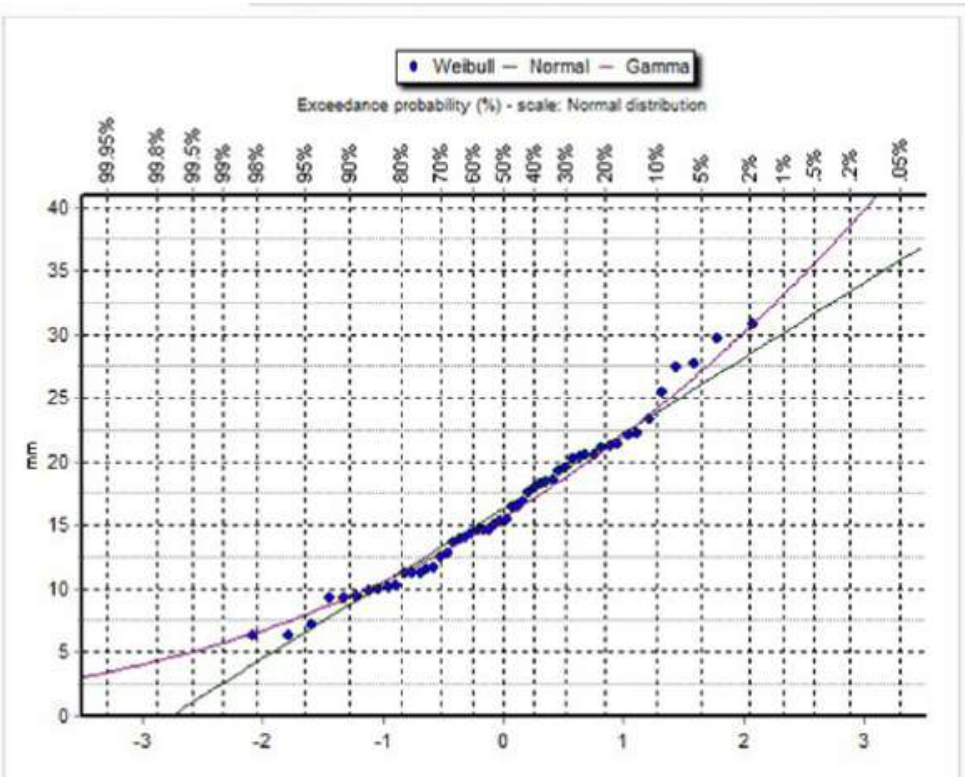

CAMPO DE MARTE

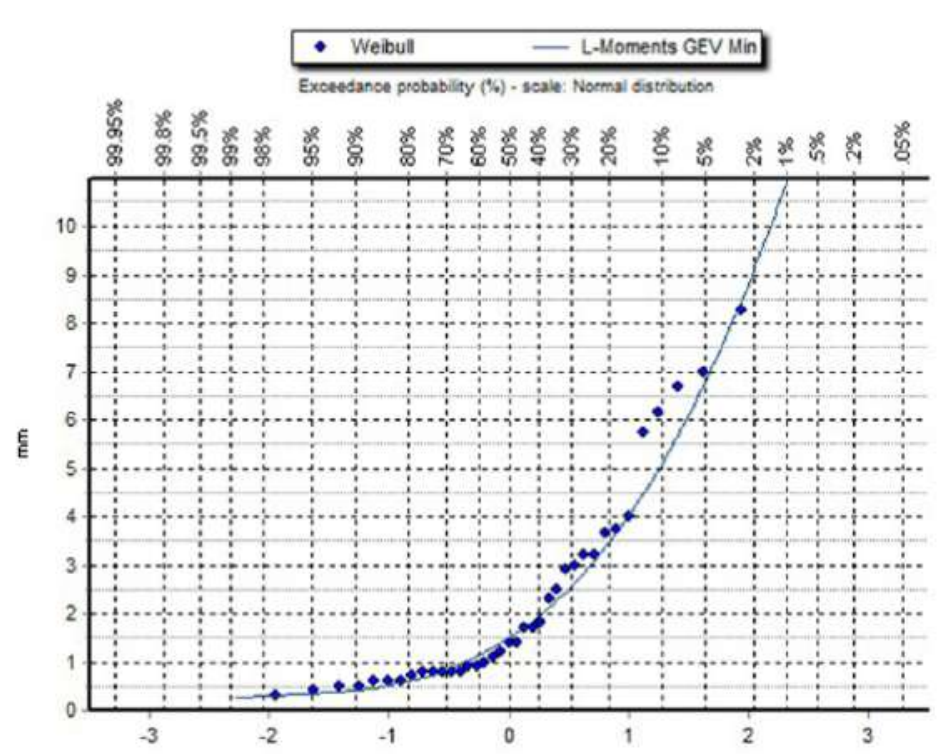




\section{CANCHACALLA}

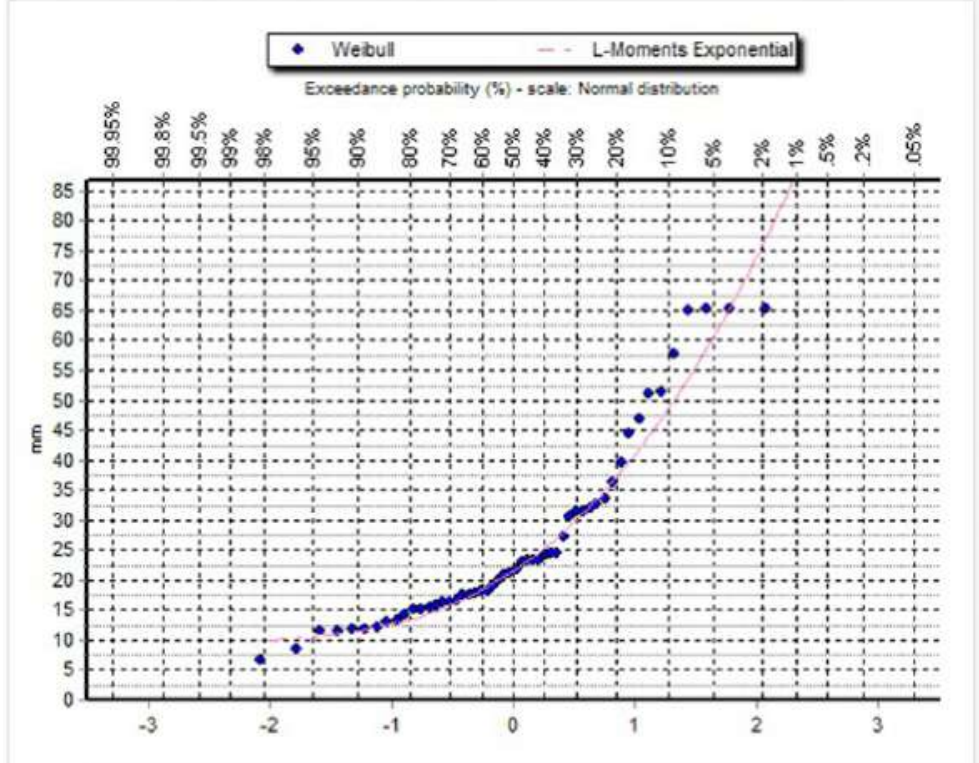

\section{CARAMPOMA}

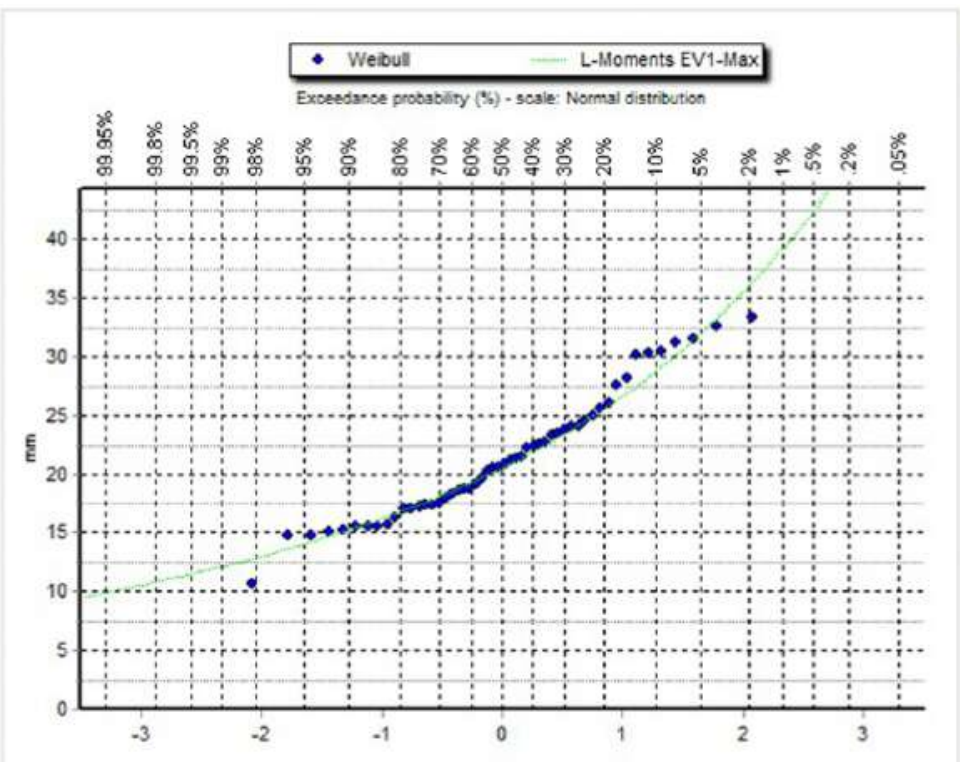

CHOSICA

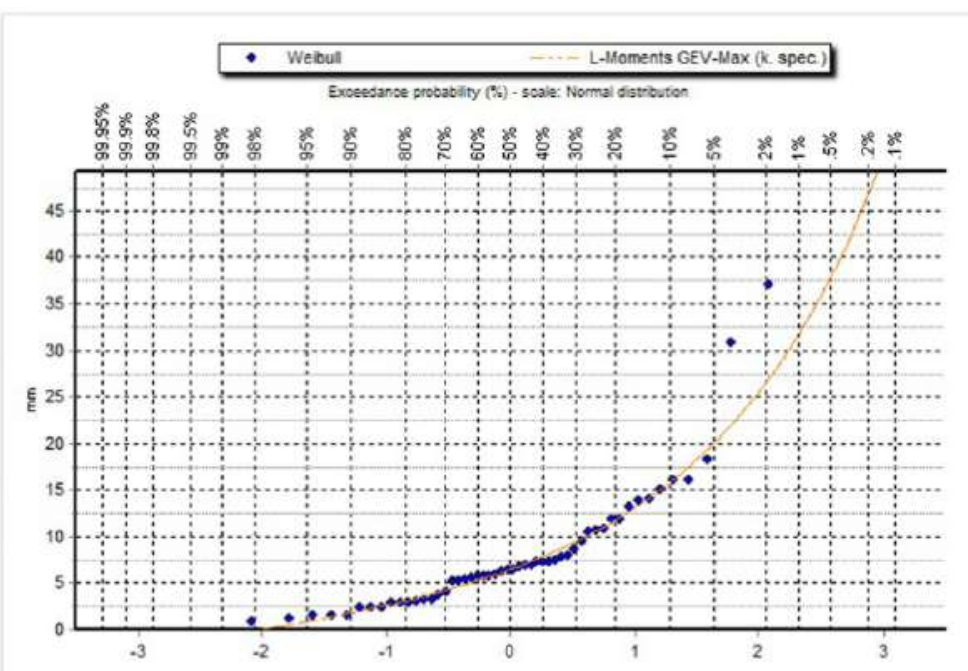




\section{CIENEGUILLA}
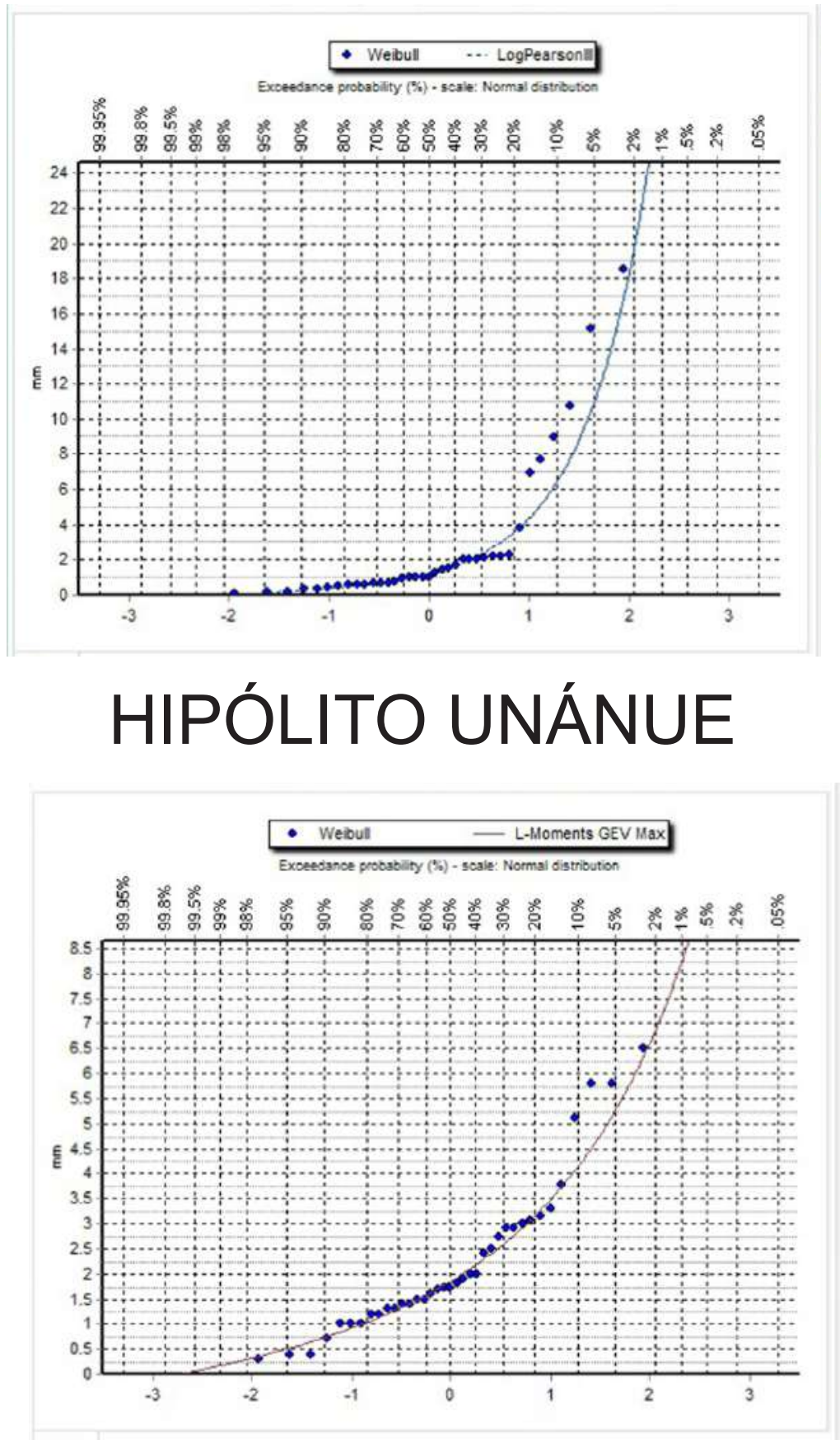

\section{LA CANTUTA}

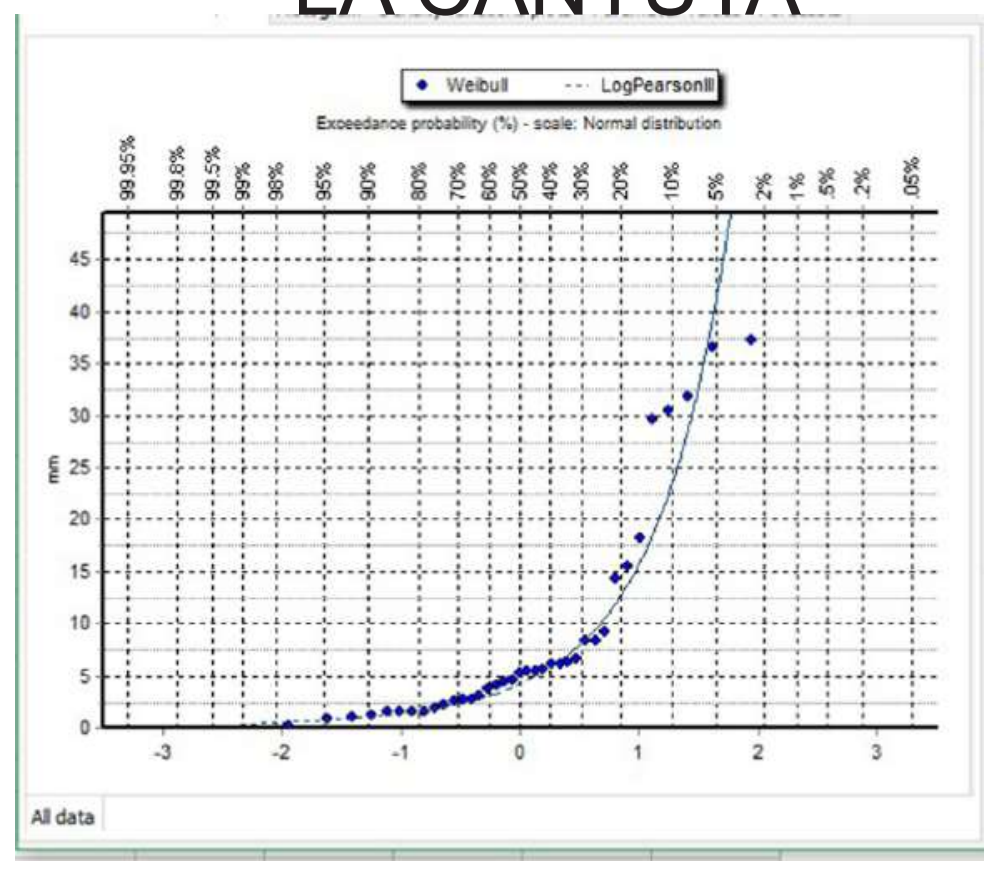




\section{LACHAQUI}

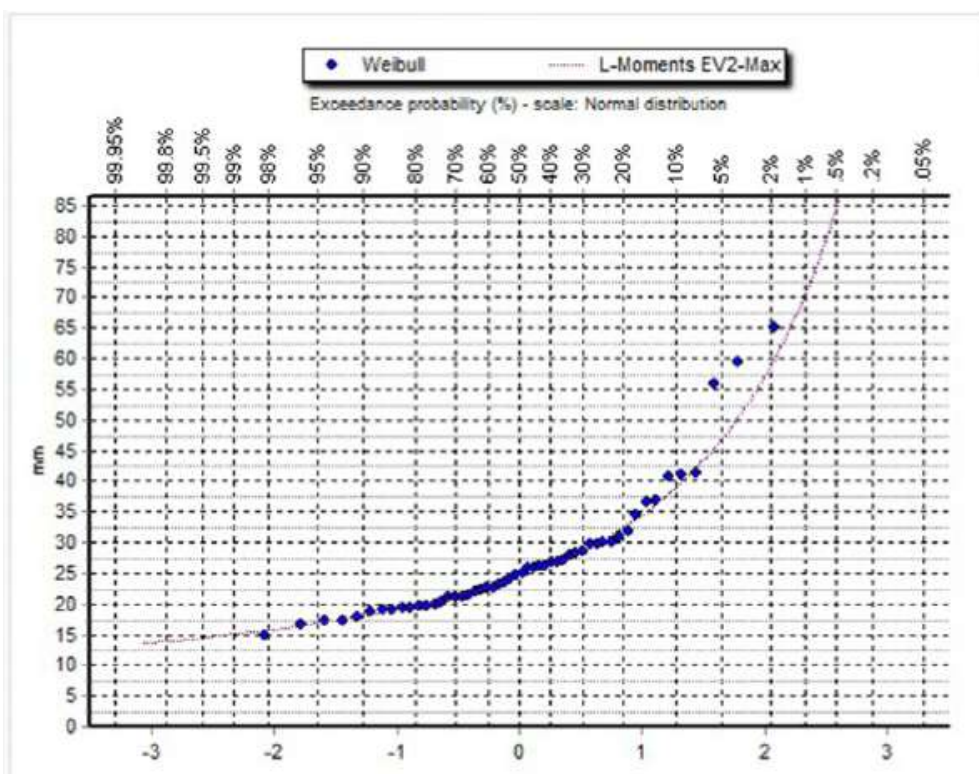

MATUCANA
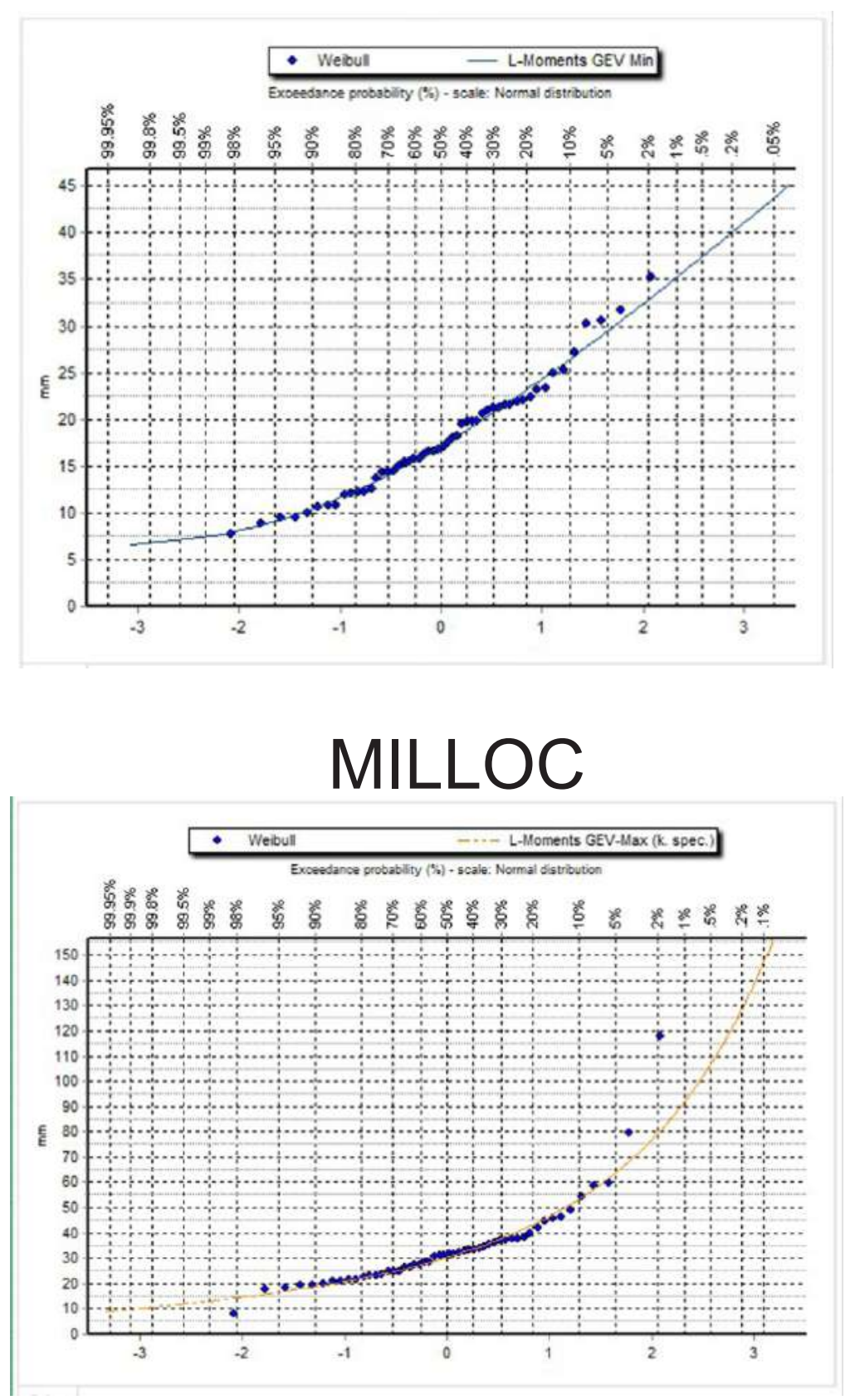


\section{PARIACANCHA}
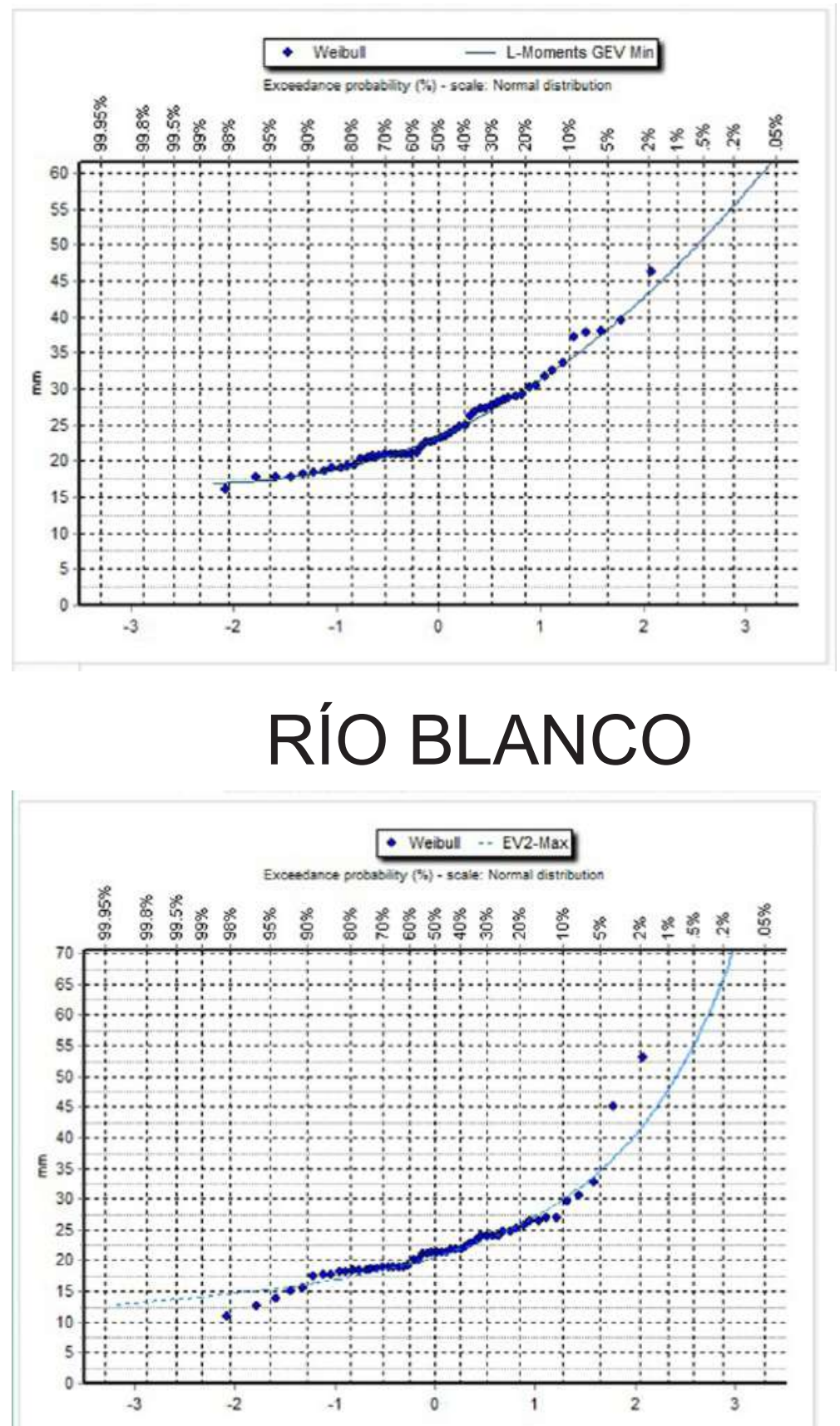

\section{SAN JOSÉ DE PARAC}

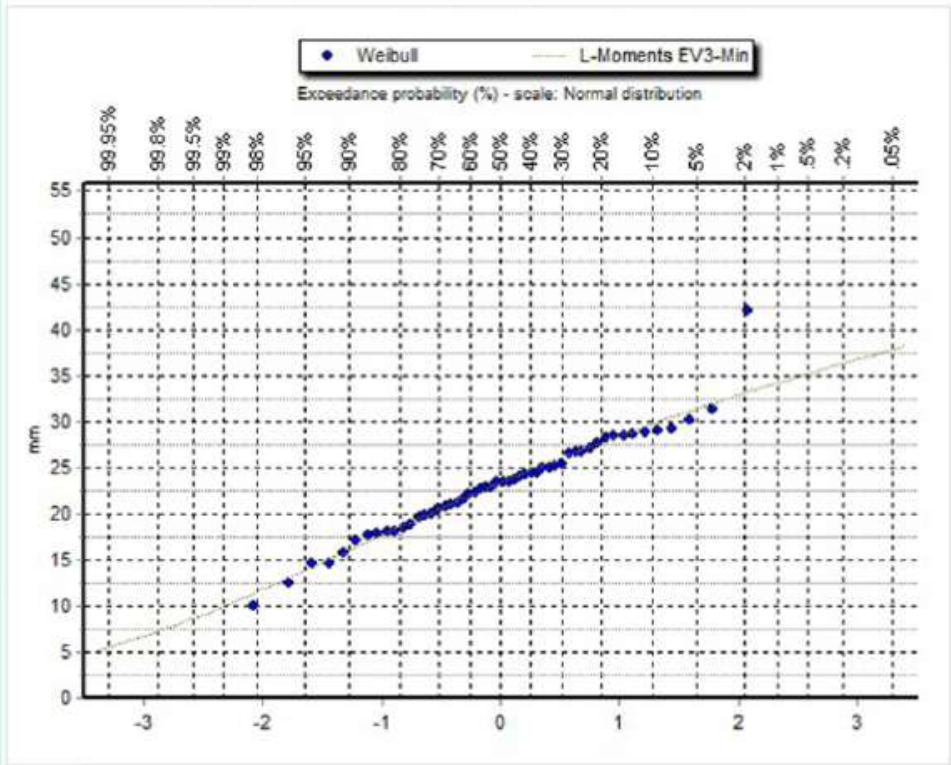




\section{SANTA EULALIA}

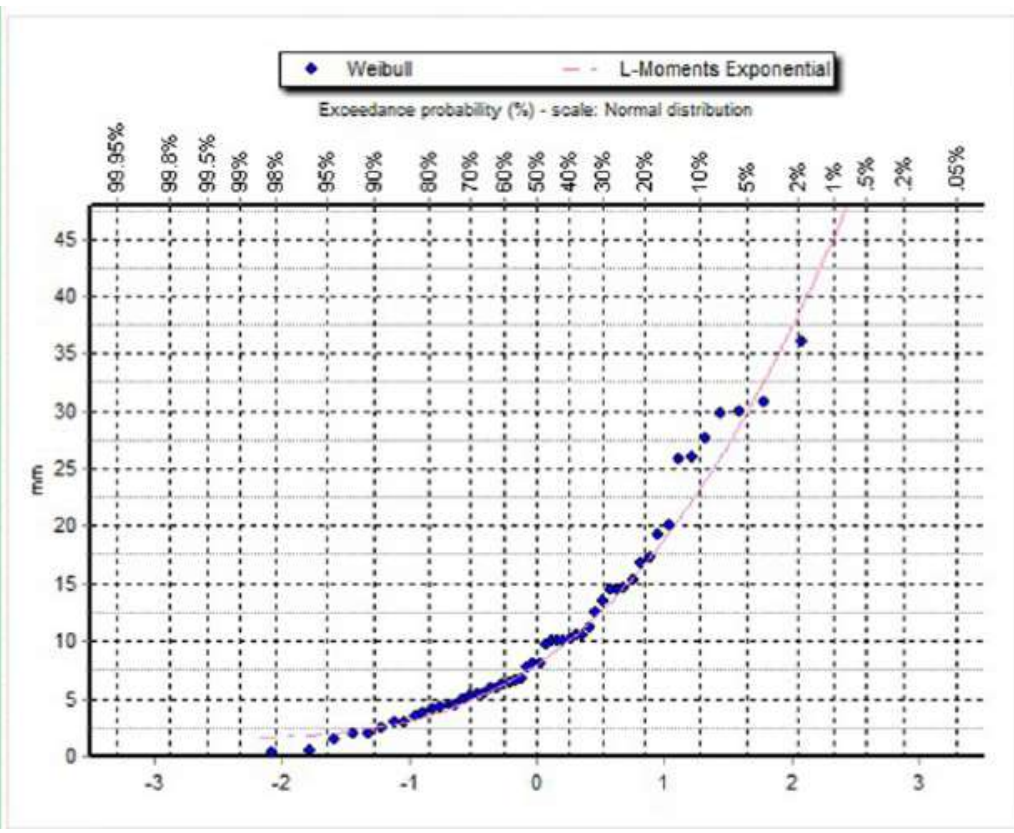

\section{SANTIAGO DE TUNA}

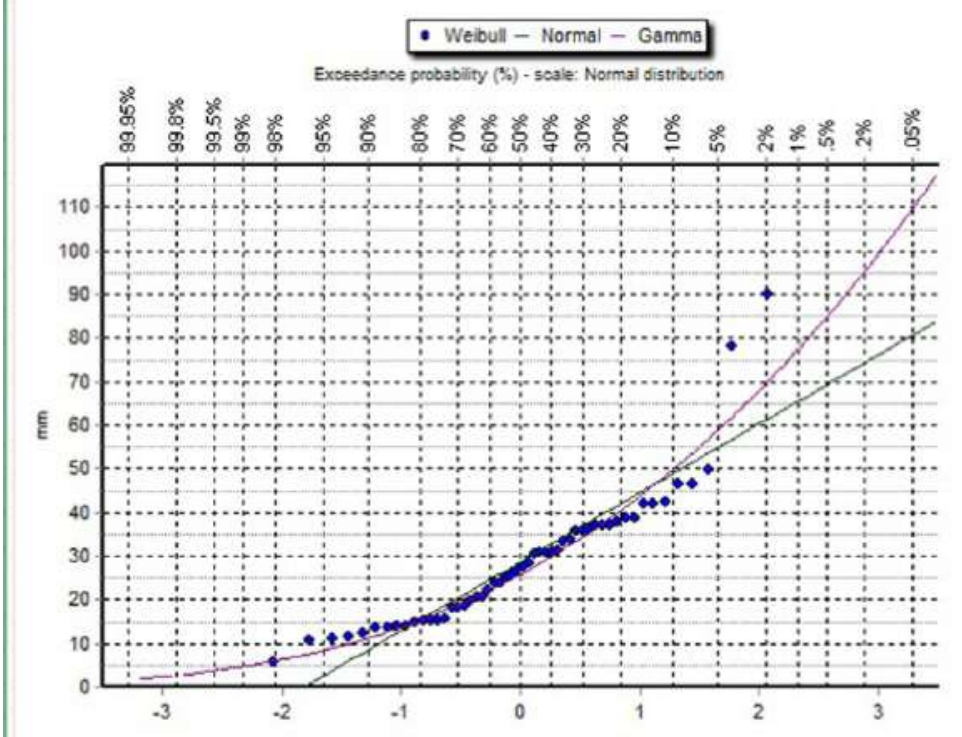

\section{VON HUMBOLDT}

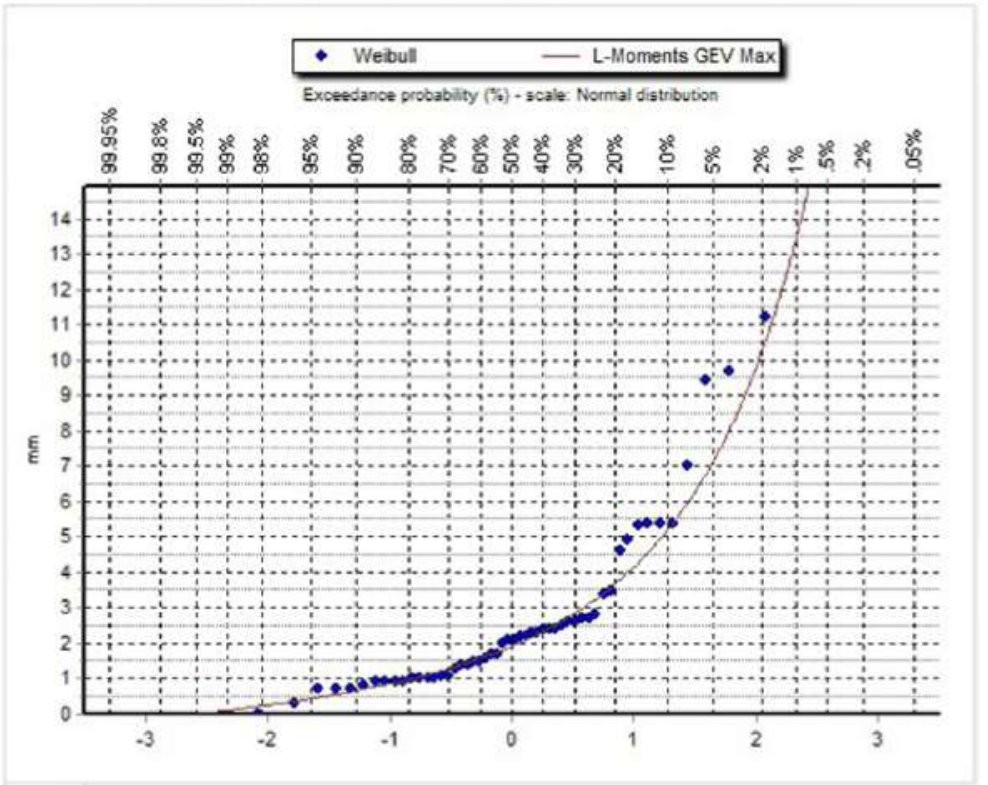


8.3 Mapa Geomorfológico 


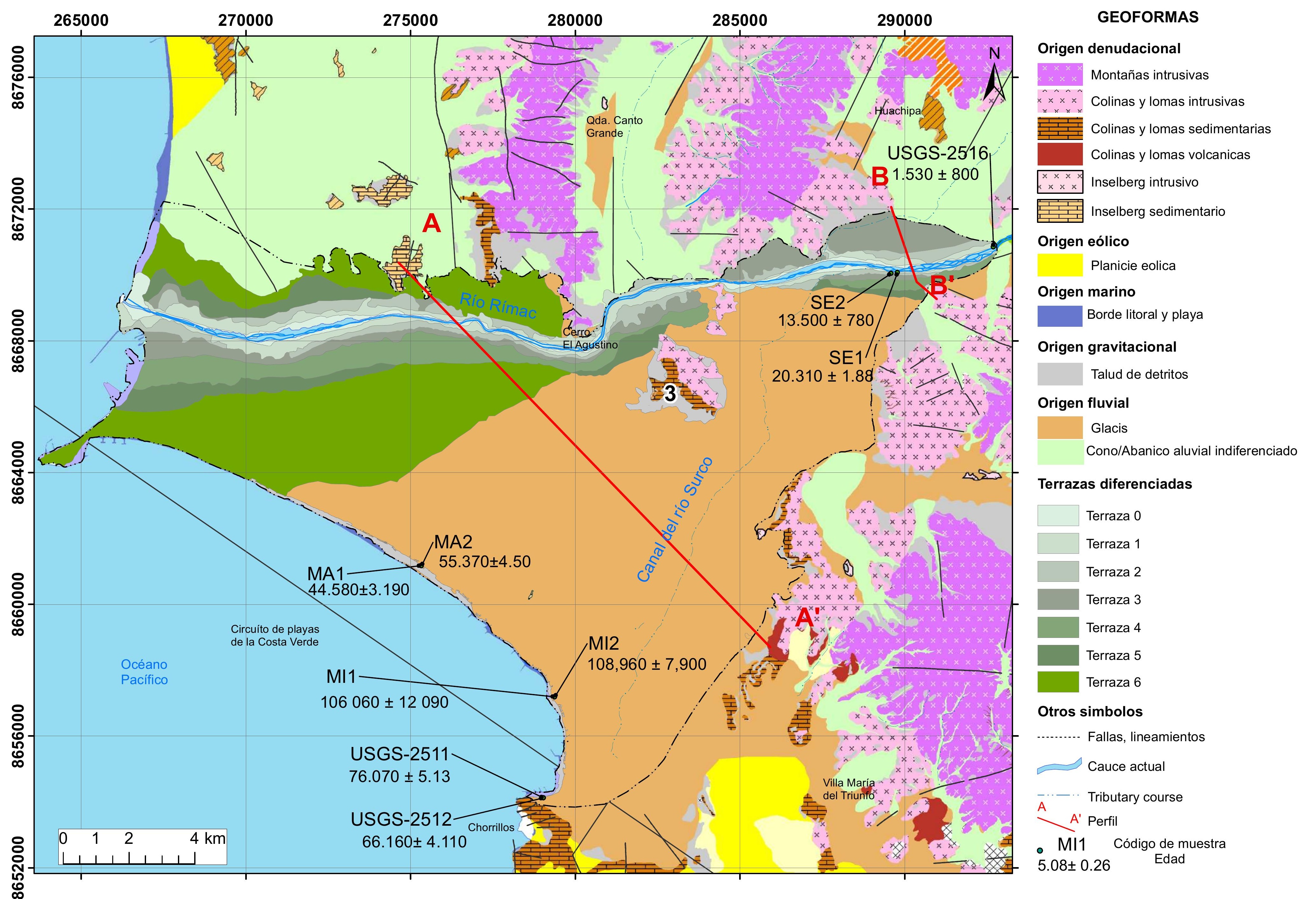


8.4 Mapa Geológico 


\subsection{Modelo de Velocidad x Altura}




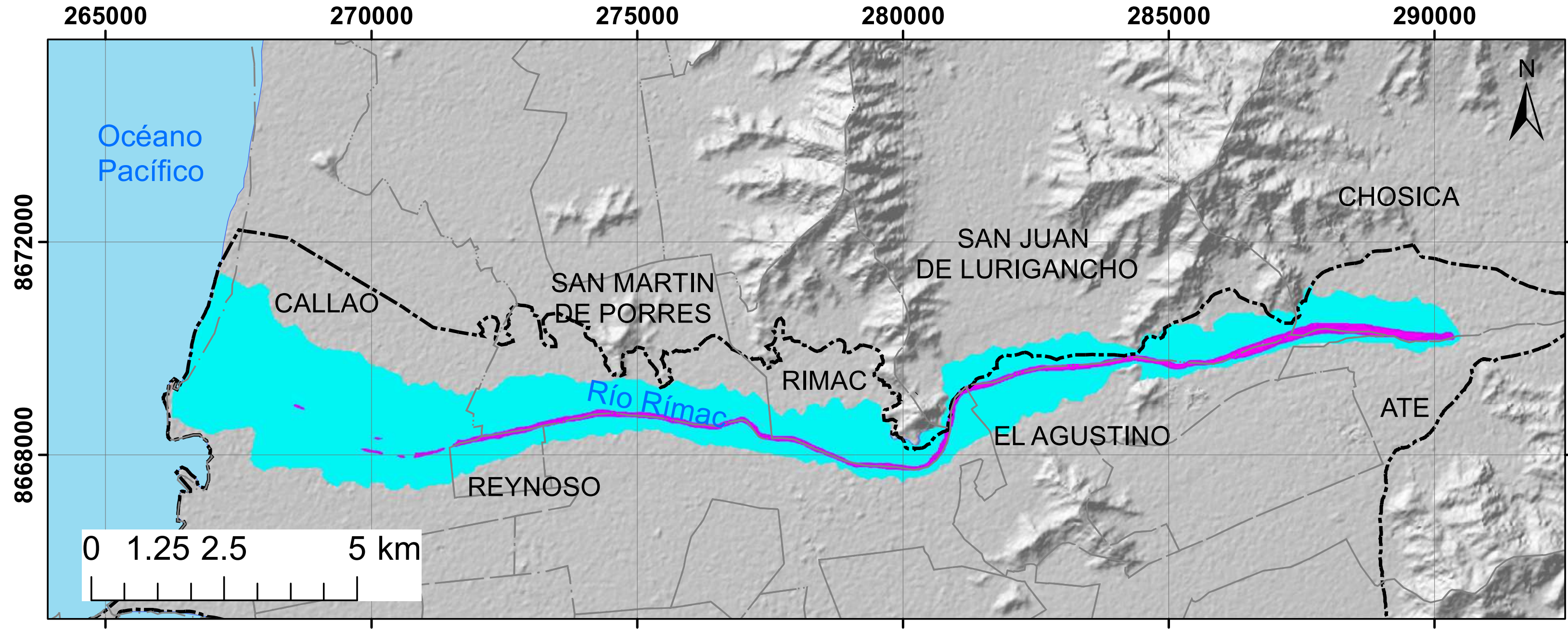

\section{velocidad}

(m/s)
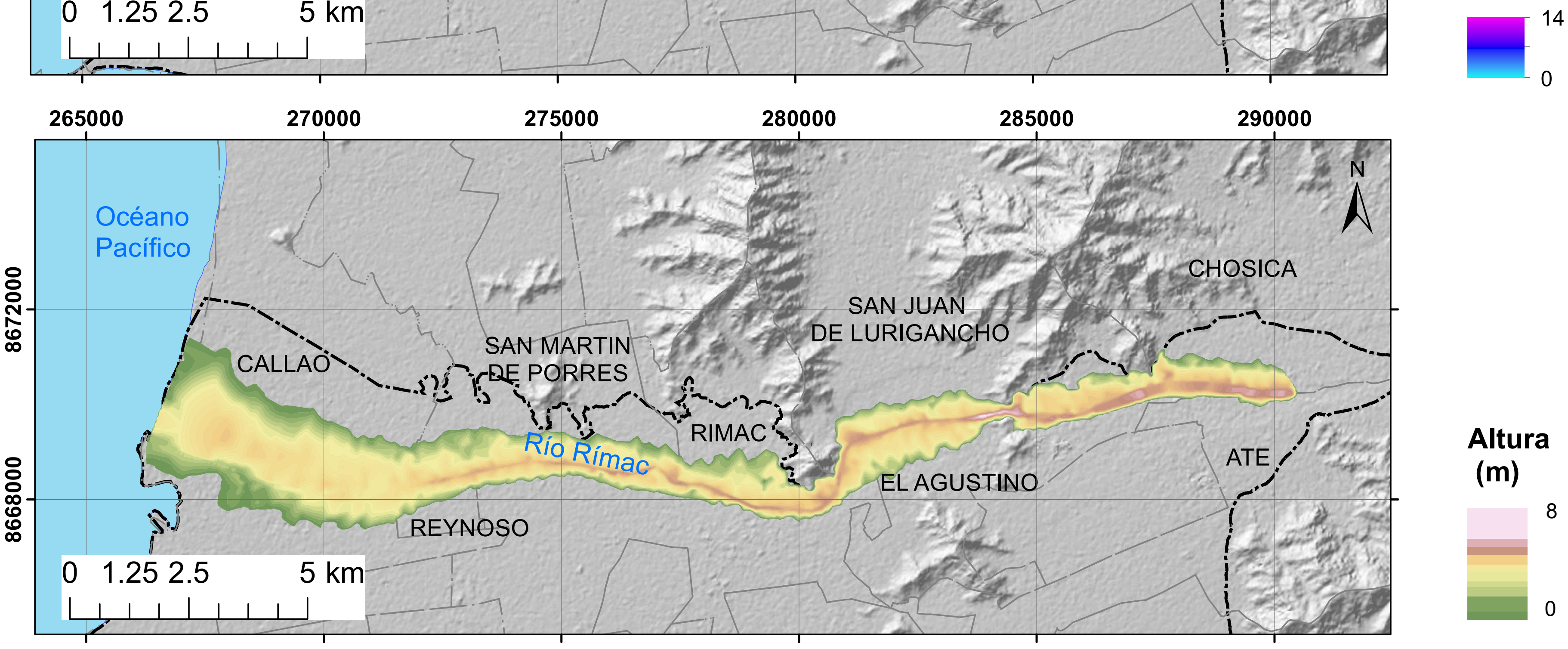

Altura

(m) 
8.6 Mapa de Peligrosidad por flujo de detritos y

desbordes para un periodo de retorno de 500 años en el río Rímac 


\section{GUÍA EXTRACCIÓN DE DATOS DEL MODELO INTERNACIONAL ERA-INTERIM REANALYSIS \\ Por: SANDRA VILLACORTA \\ NOVIEMBRE - 2018}

\section{INTRODUCCIÓN}

Los datos de re-análisis han demostrado ser útiles para completar información climática basada en el modelamiento y diagnóstico, así como estudios sinópticos (Andres, Vegas, Lavado, \& Zappa, 2014; Olave, 2015). Ante la falta de información meteorológica fiable es necesario apelar a este tipo de modelos para completar los datos faltantes o contrastar la información con la que se cuenta (Villacorta, Rodríguez, Peña, Jaimes, \& Luza, 2016).

EI ECMWF (https://www.ecmwf.int/), con sede en Reino Unido, es a la vez un instituto de investigación y un servicio operativo 24 horas al día, 7 días a la semana, produciendo y difundiendo predicciones numéricas del tiempo a sus Estados miembros. Estos datos están totalmente a disposición de los servicios meteorológicos nacionales de los Estados miembros. El Centro también ofrece un catálogo de datos de pronóstico que pueden ser adquiridos por empresas de todo el mundo y otros clientes comerciales. La instalación de supercomputación (y los archivos de datos asociados) en el ECMWF es una de las más grandes de su tipo en Europa y los Estados miembros pueden utilizar el $25 \%$ de su capacidad para sus propios fines.

Todos los parámetros de pronóstico, tanto de superficie como de estratosfera, están basados en HRES y ENS de 00 y 12 UTC, están disponibles en intervalos de 3 horas hasta +144 horas y en intervalos de 6 horas de +150 a +240 horas. Los parámetros están disponibles cada hora hasta +90 horas. Las estimaciones de precipitación se proporcionan como valores acumulados desde el inicio de la integración prevista (Persson, 2001).

\section{OBJETIVO}

EL presente manual tiene como objetivo presentar los pasos a seguir para extraer información del Modelo internacional ERA-Interim Reanalysis generado por el Centro Europeo de Pronósticos de Parámetros Climáticos (ECMWF por sus siglas en inglés, (Dee et al., 2011). 


\section{DESCRIPCIÓN DE LA SISTEMÁTICA}

1. Para poder acceder a los datos colgados por el ECMWF, en primer lugar es necesario darse de alta en su página web: https://apps.ecmwf.int/auth/login/ y crearse un usuario.

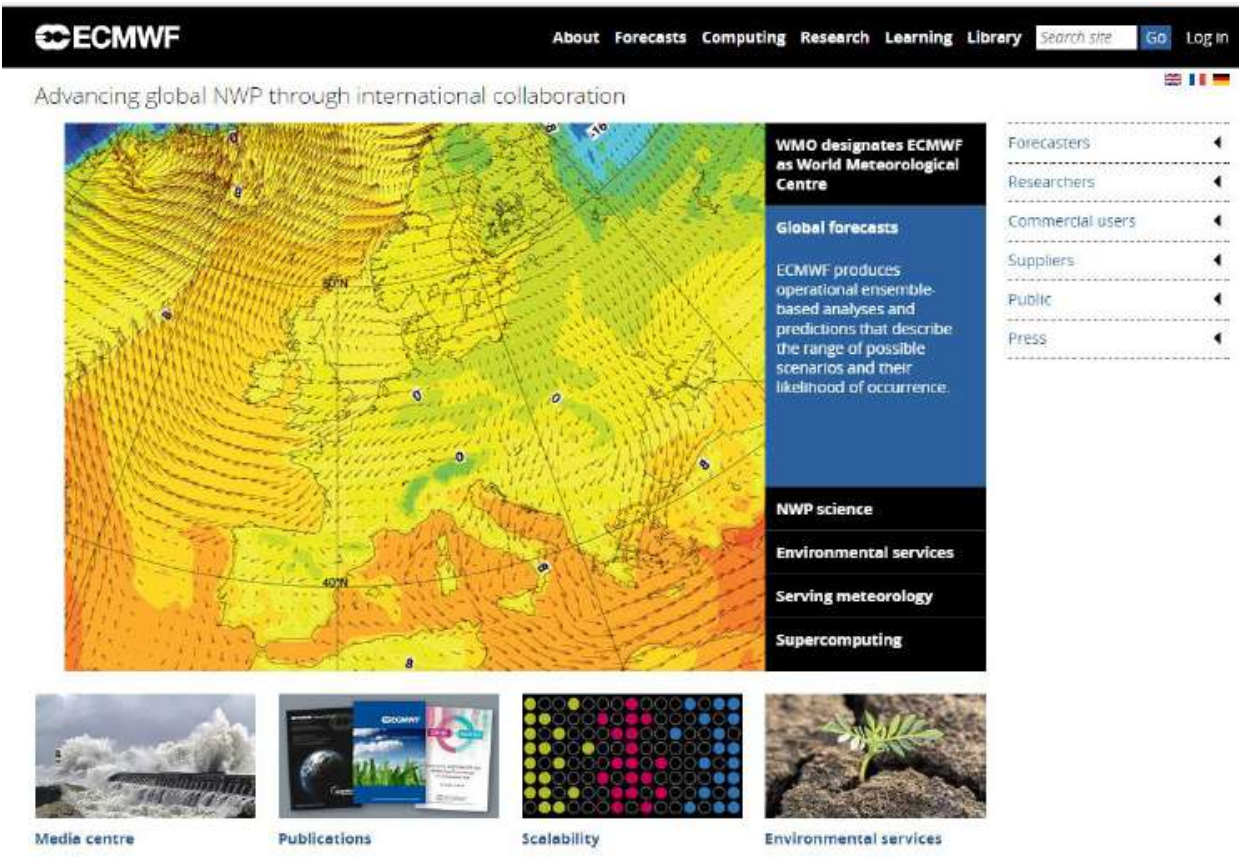

2. Seleccionar Forecast - Datasets y escoger en Climate reanalysis "Browse reanalysis datasets".

\section{Datasets}

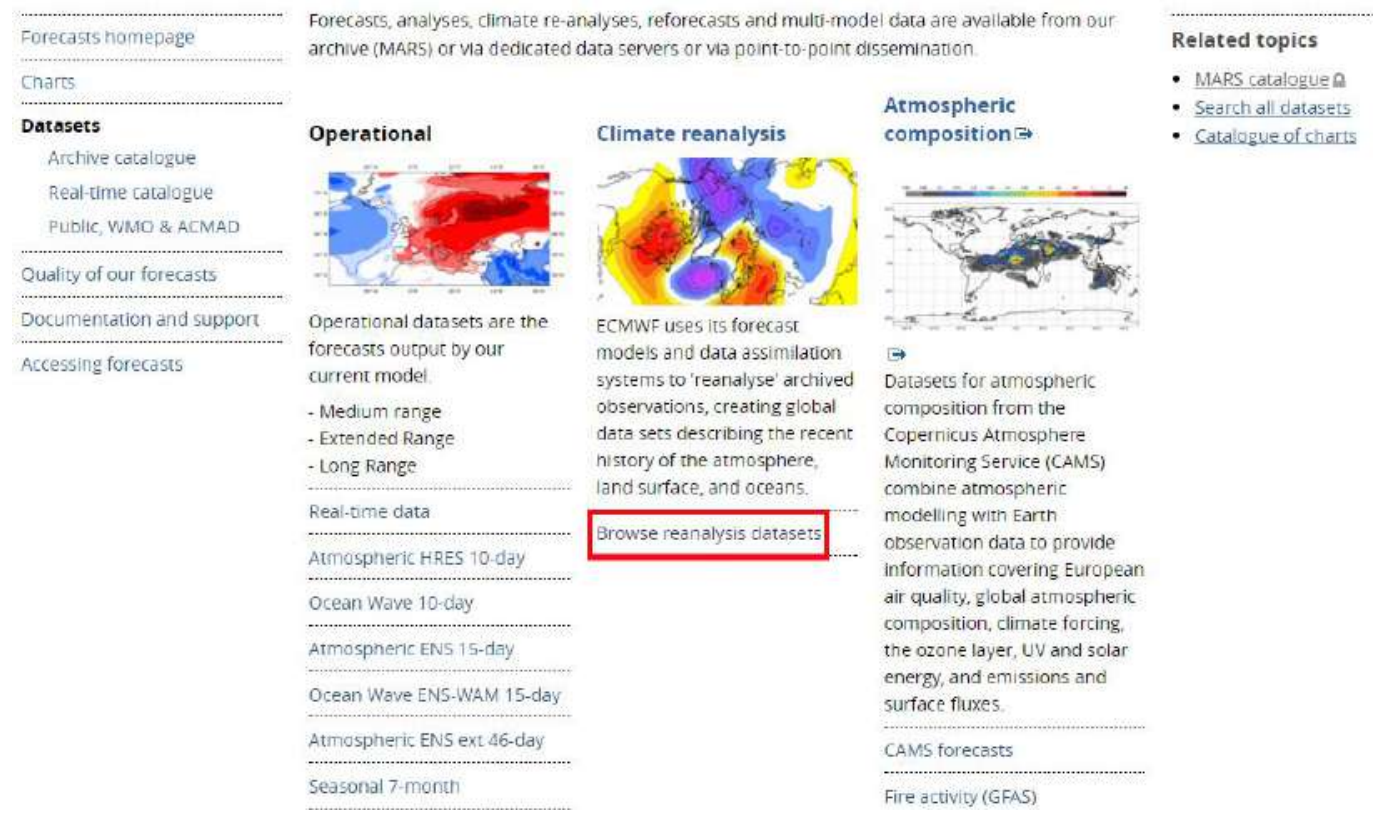


3. Se abrirá otra ventana de dialogo donde se debe seleccionar "Era Interim, (Time period: 1979-present" el más recomendado por los especialistas del ECMWF para Suramérica. Hacer clic en "Download".

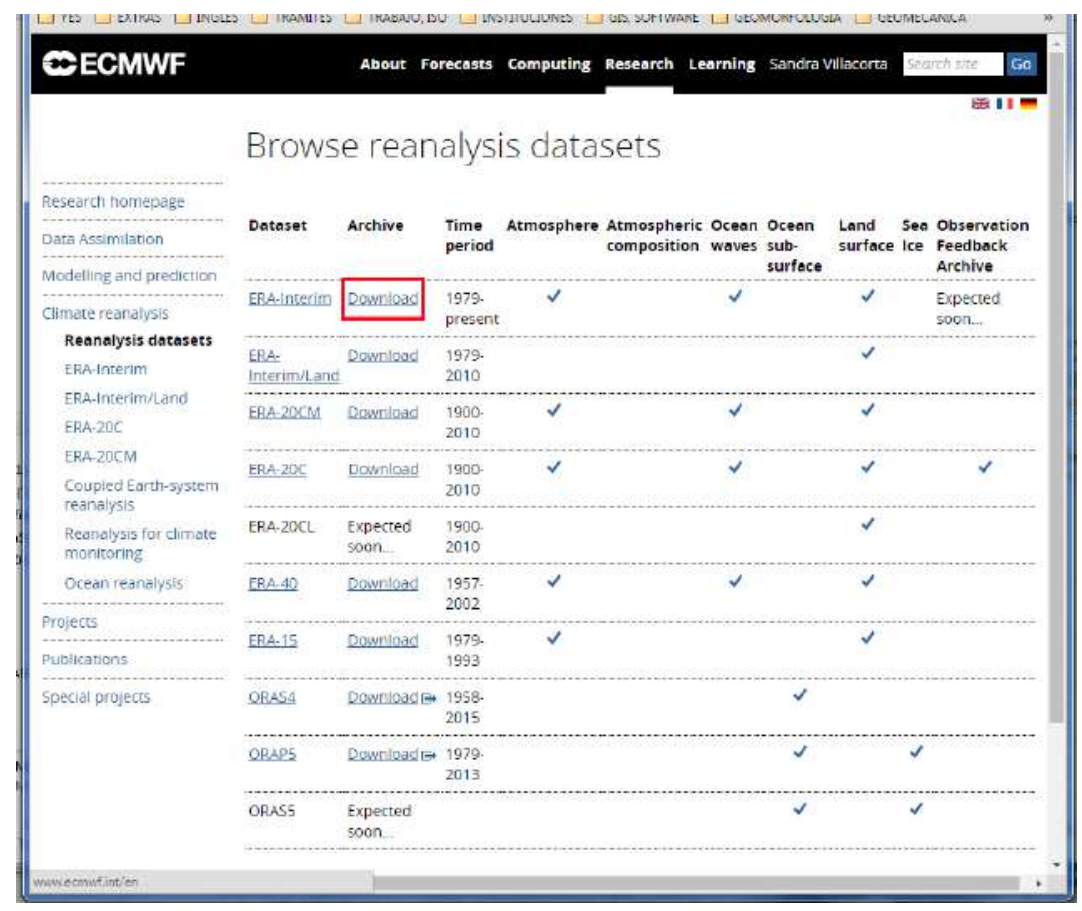

4. Se abrirá otra ventana de dialogo donde se puede seleccionar las fechas (meses y años). Por ejemplo si deseo los datos entre los años 2010 y 2015, se procede a activar las casillas de todos los meses de cada año. 


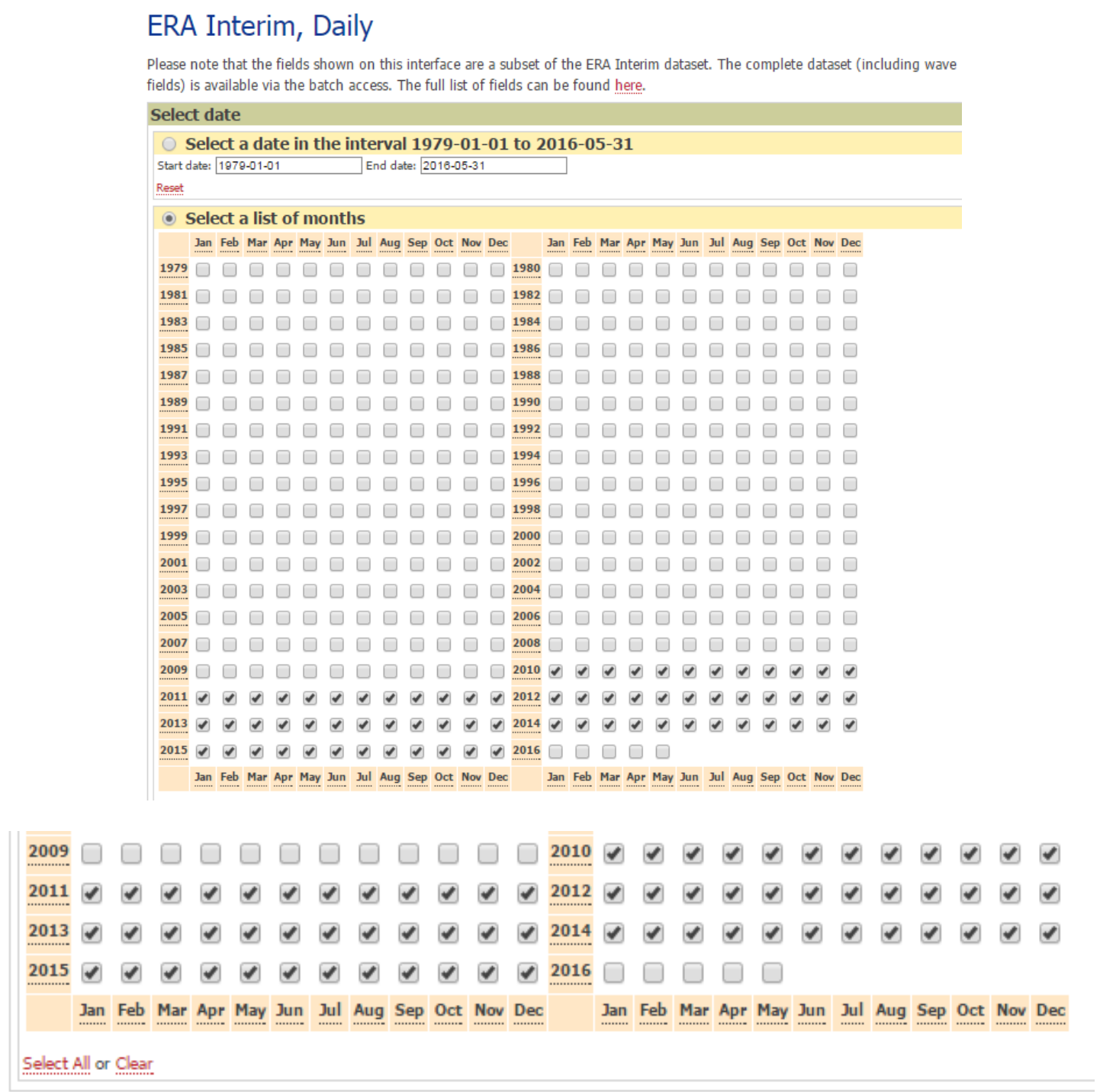

5. Seleccionar el tiempo, que se refiere a cuántas horas desde el tiempo de inicio hasta el momento en el que se quiere el pronóstico. También se debe indicar los pasos de tiempo $(3,6,9$ o 12).

- Ejemplo para parámetros instantáneos: vamos a decir que se quiere extraer Temperatura a las 3 pm (15:00). Primero se selecciona como tiempo de inicio: 12:00 (mediodía), con paso 3 (+3 horas). Eso daría el dato a las 15:00 horas.

- Ejemplo para parámetros acumulados: vamos a decir que se quiere la precipitación total diaria. Se debe seleccionar como tiempo de inicio las 00:00 (medianoche) y 12:00 (mediodía), ambos con paso 12. Esto generará dos registros, cuya suma permitirá obtener los valores para obtener la precipitación diaria total:

$>$ Precipitación acumulada desde las 00:00 a las 12:00 (medianoche +12 horas) 
Precipitación acumulada desde las 12:00 a las 24:00 (mediodía +12 horas)

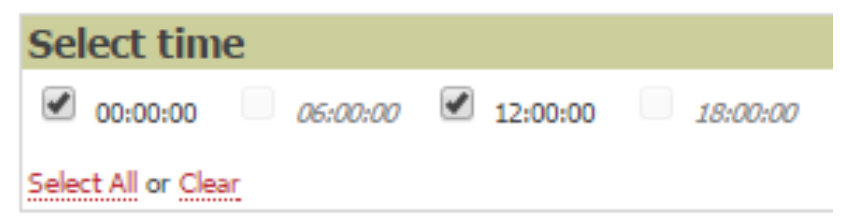

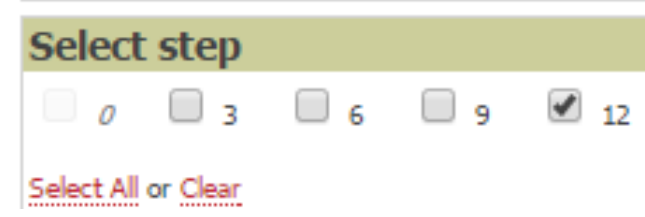

6. Elegir la variable que se necesita (en este caso precipitación total) y dar clic en "Retrieve NetCDF".
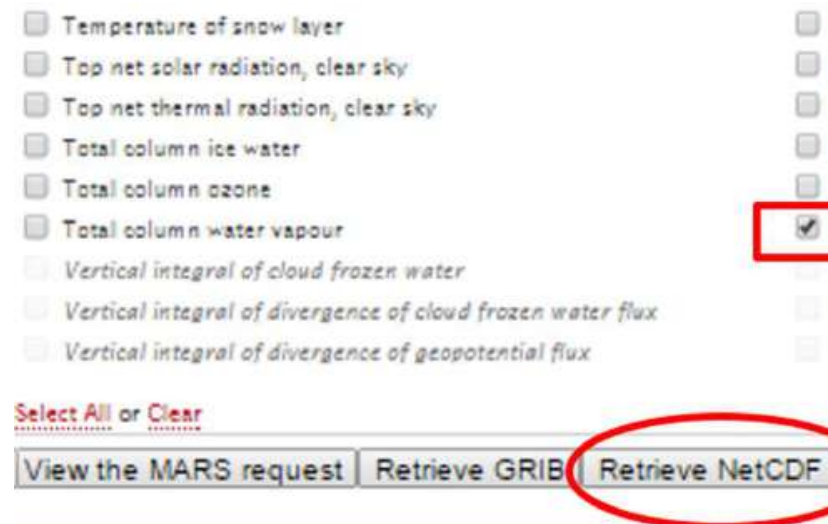

7. Se abrirá la ventana de diálogo "Additional filtering" donde se ubicará el área de interés. Por defecto salen diferentes áreas pero en "Custom" se puede personalizar las coordenadas geográficas. Por ejemplo en para la zona central de Perú se puede colocar: N-11.55, W-78, S-13.67, E-76.55. Luego hacer clic en "Retrieve now" 


\begin{tabular}{|l|}
\hline Navigation \\
\hline Home \\
Public Datasets \\
Job list \\
\hline See also... \\
\hline Access Public Datasets \\
General FAQ \\
WebAPI FAQ \\
Accessing forecasts \\
GRIB decoder \\
\hline
\end{tabular}

$<$ Return to selection

\section{Additional filtering}

Current request

\begin{tabular}{ll}
\hline Stream: & Atmospheric model \\
\hline Parameter: & Total precipitation \\
\hline Dataset: & interim_daily \\
\hline Step: & 12 \\
\hline Version: $\quad 1$ \\
\hline Type of level: Surface \\
See full request
\end{tabular}

The request will be done using the following attributes:

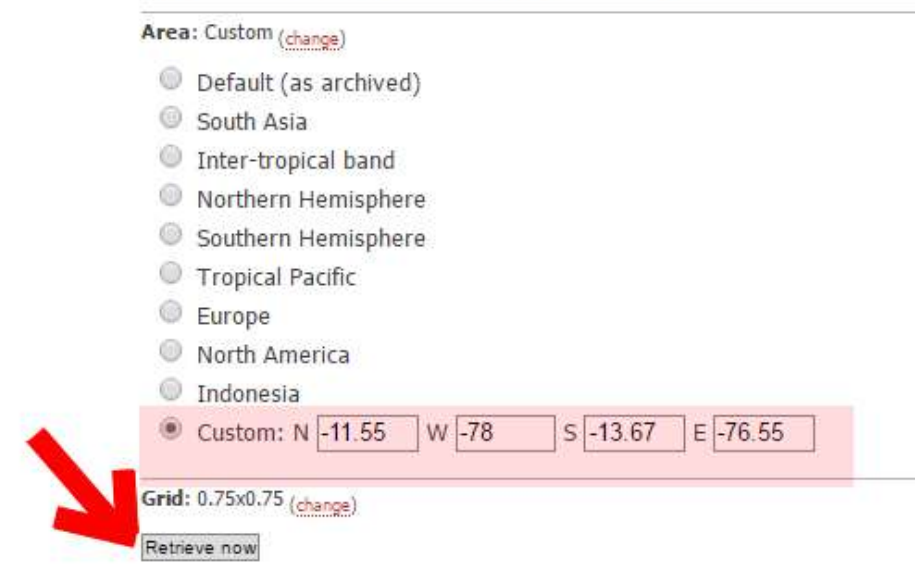

8. Se abrirá la ventana "netcdf" donde se observa, al final de la descripción de la consulta, que el estado de la misma es "active". Esto cambiará a "complete" cuando el archivo esté listo para descargarse (puede tardar si son áreas muy grandes). 
$<$ Return to selection

\section{netcdf}

Final request

\begin{tabular}{ll}
\hline Stream: & Atmospheric model \\
\hline Area: $\quad 11.55^{\circ} \mathrm{S} 78.0^{\circ} \mathrm{W} 13.67^{\circ} \mathrm{S} 76.55^{\circ} \mathrm{W}$ \\
\hline Parameter: & Total precipitation \\
\hline Dataset: $\quad$ interim_daily \\
\hline Step: $\quad 12$ \\
\hline Version: $\quad 1$ \\
See full request
\end{tabular}

The status of the request is: active

Request output:

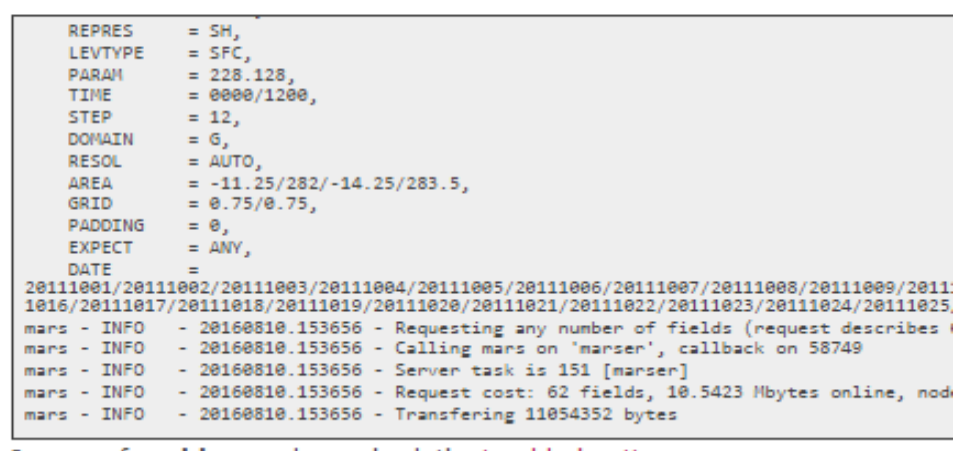

In case of problems, please check the troubleshooting page.

9. Cuando el estado de la consulta está completo se puede descargar dando click en "Download".

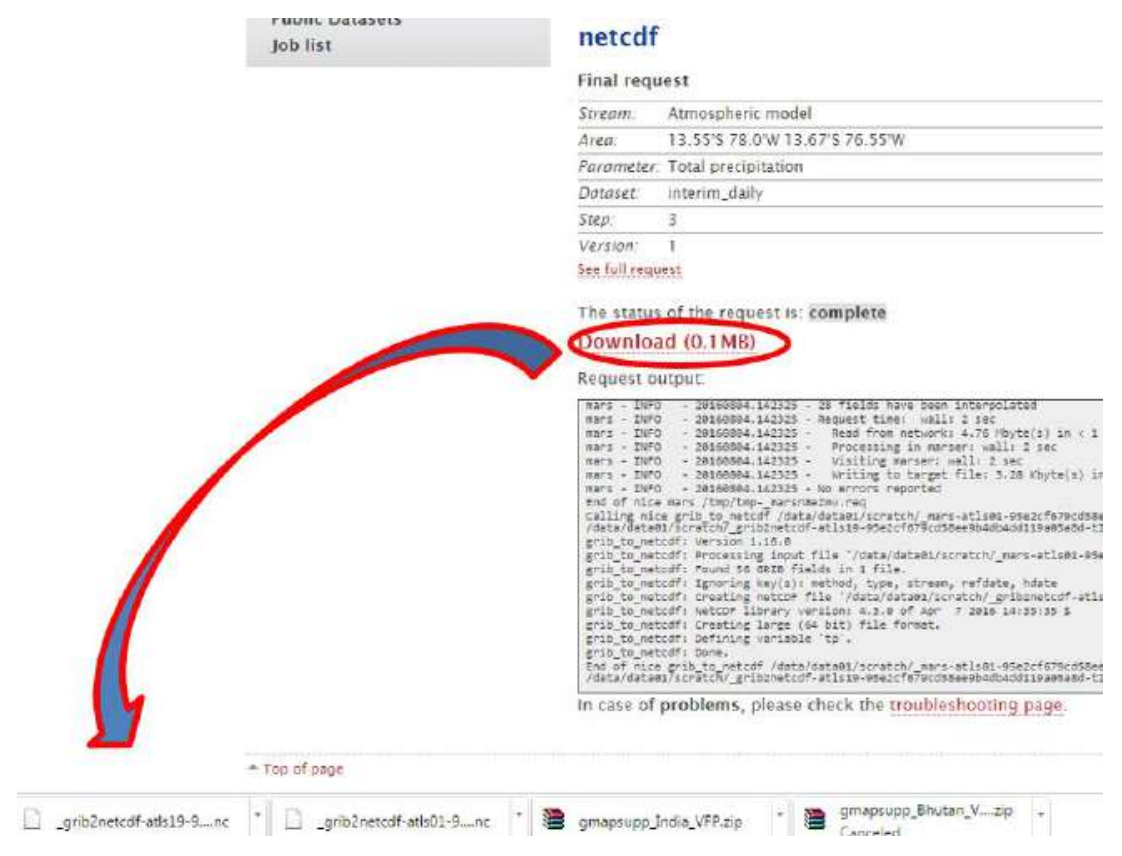

10. Descargar el software Panoply de: https://www.giss.nasa.gov/tools/panoply/ para la visualización de los datos y su exportación. 
11. Abrir en la carpeta "Descargas" de la pc y arrastrar directamente el archivo (nc es la extensión de los archivos netCDF) a la pantalla principal de Panoply*.

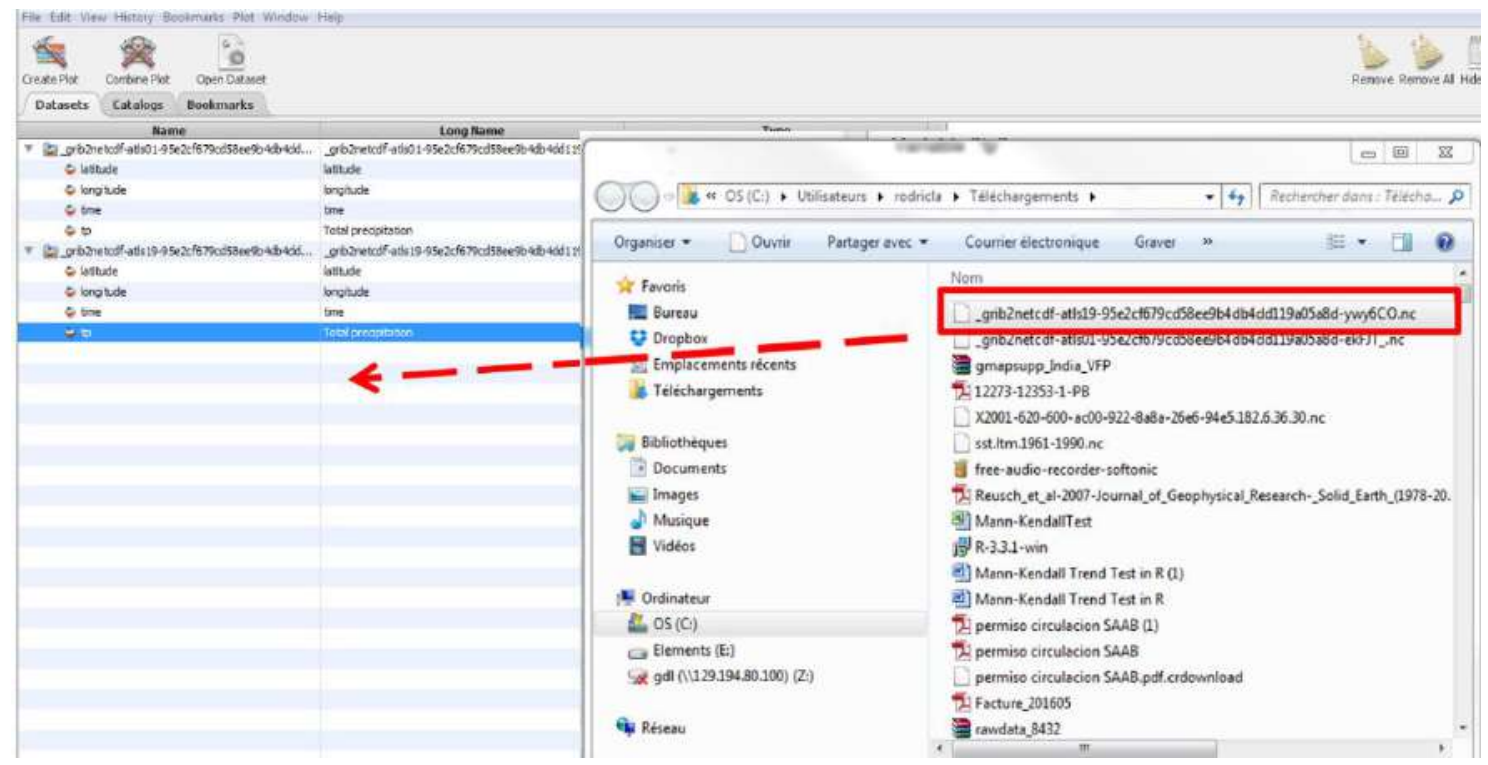

12. Una vez en Panoply, para visualizar los datos extraídos, hacer clic sobre la línea que pone "tp" (total precipitation) y ubicar arriba a donde se señala "Create plot".

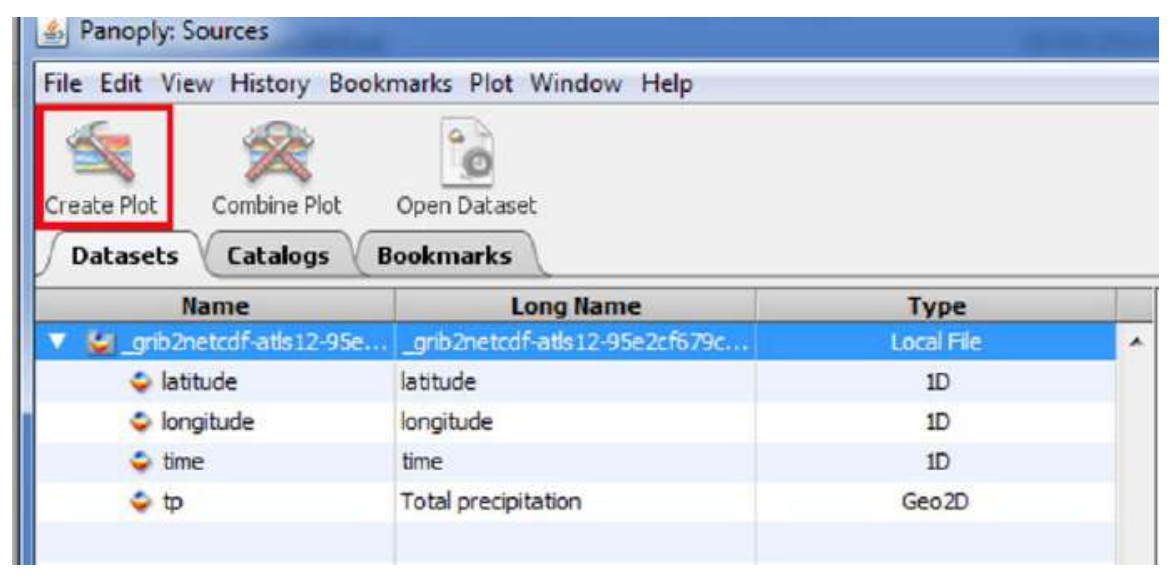

*Nota: no bajar los datos en formato "grib" porque Panoply solo lee los datos tipo "NetCDF".

13. Se visualizará un mapa cómo el que sigue (abajo). Nota: aunque parezca que no se ve nada en realidad sí está ahí la información, lo que pasa es que el área del ejemplo es muy pequeña y no se ve por la escala (círculo rojo). 


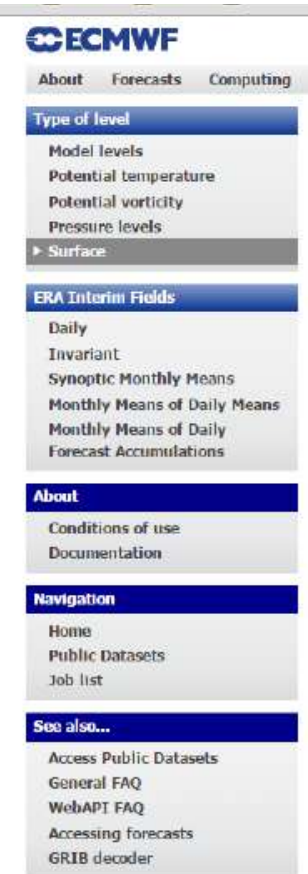

Research Learning

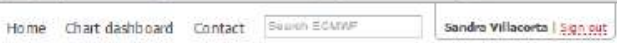

\section{ERA Interim, Daily}

Please note that the fiedds shown on this inteface are a subset of the ERA Interin dataset. The complete datase: (including wave eldss) is available via the batch access. The full list of fields can be found here

Select date

Select a date in the interval 1979-01-01 to 2016-05-31

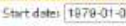

est

- Select a list of monthis

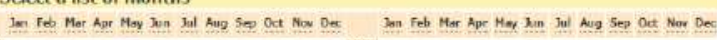

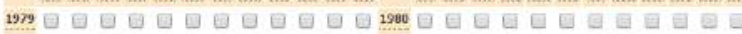

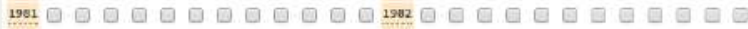
1983

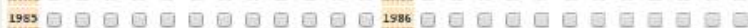

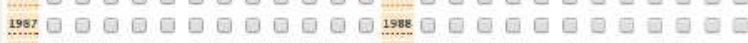

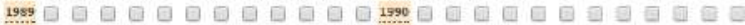
$19910^{\circ}$

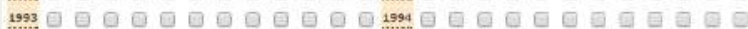

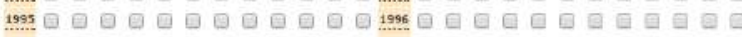

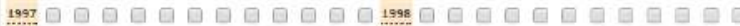

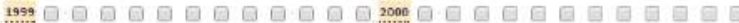

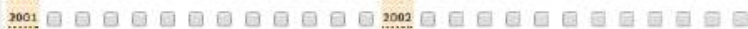

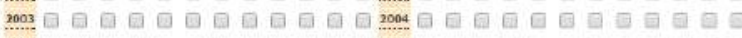

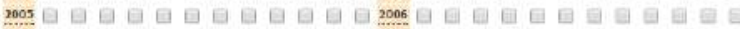

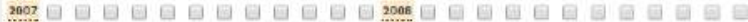

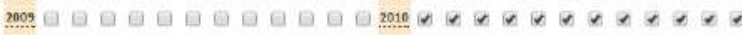

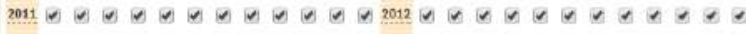
2013 由 2015

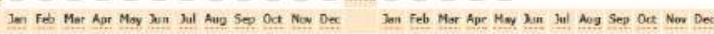
Stettal o the

$2001 \square \square \square \square \square \square \square \square \square \square \square \square 2002 \square \square \square \square \square \square \square \square \square \square \square \square$

Access Public Datasets

General FAQ

WebAPI FAQ

Accessing forecasts

GRIB decoder

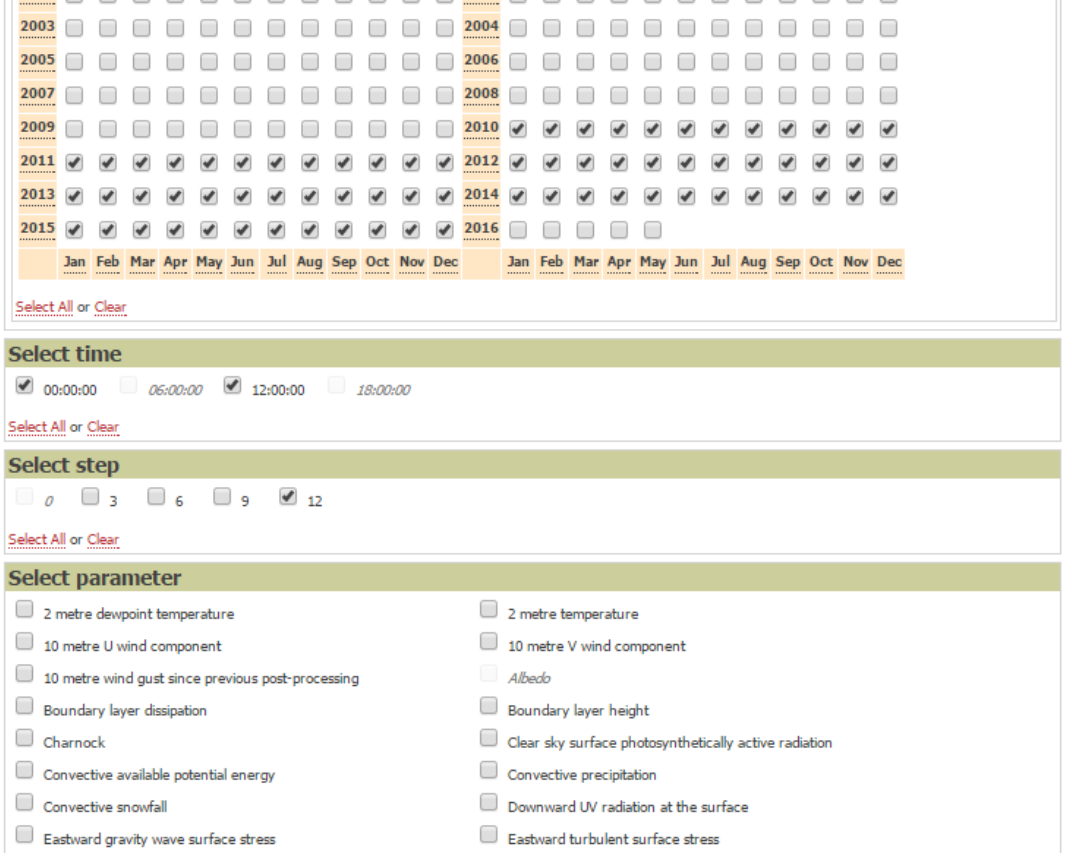

N-11.55, W-78, S-13.67, E-76.55 


\begin{tabular}{l}
\hline Navigation \\
\hline Home \\
Public Datasets \\
Job list \\
\hline See also... \\
\hline
\end{tabular}

Access Public Datasets

General FAQ

WebAPI FAQ

Accessing forecasts

GRIB decoder

\section{$<$ Return to selection}

\section{netcdf}

Final request

Stream: Atmospheric model

Area: $\quad 11.55^{\circ} 578.0^{\circ} \mathrm{W} 13.67^{\circ} \mathrm{S} 76.55^{\circ} \mathrm{W}$

Parameter: Total precipitation

Dataset: interim_daily

Step: 12

Version: 1

See full request

The status of the request is: active

Request output:

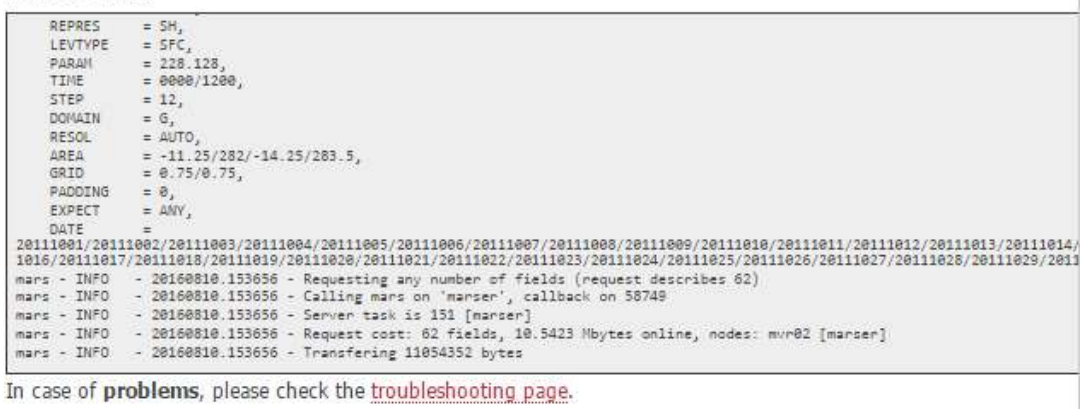

\section{EN PANOPLY:}

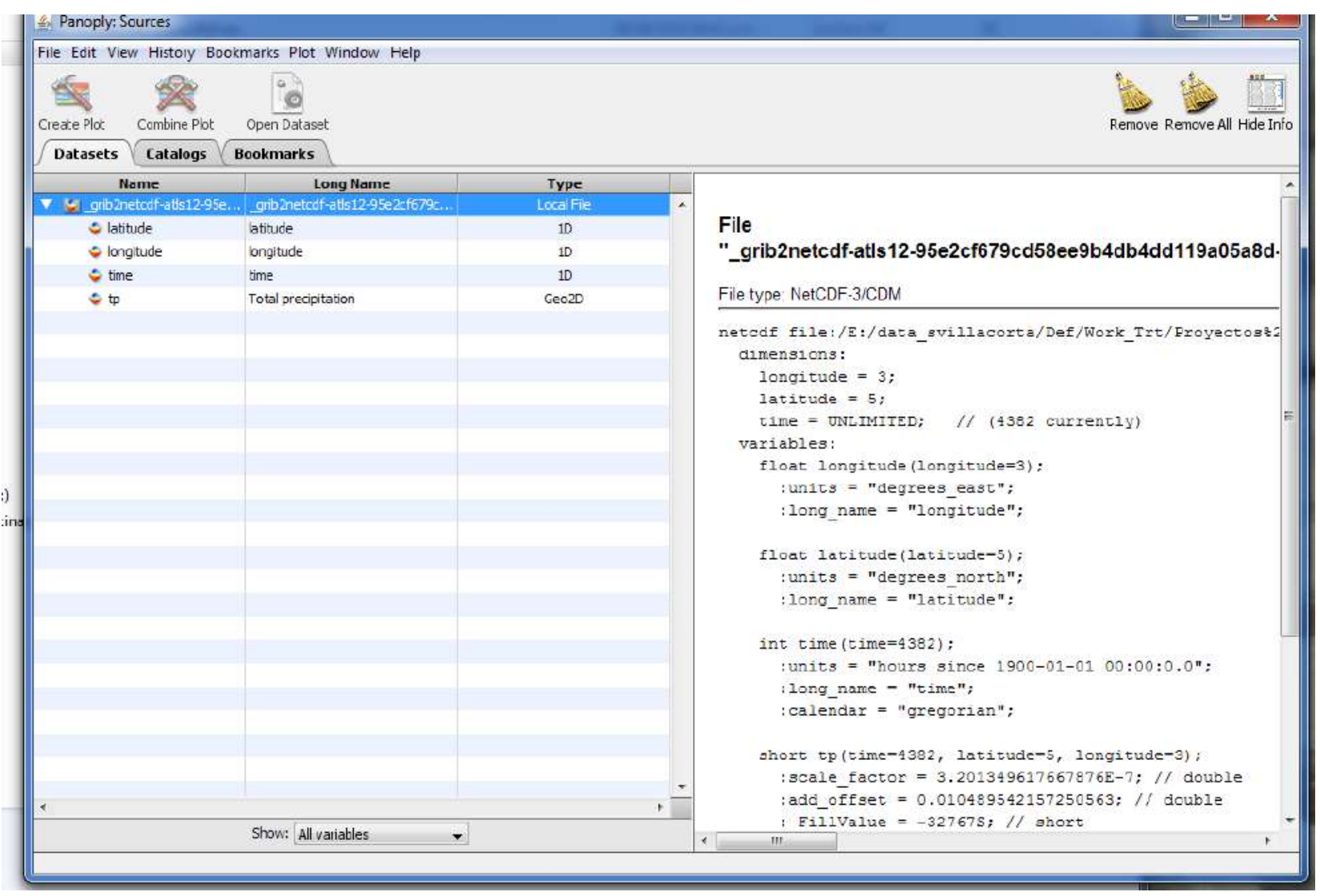


Evolución geomorfológica del abanico aluvial de Lima y su relación con el análisis de Peligrosidad por Inundaciones - Anexo 8.7

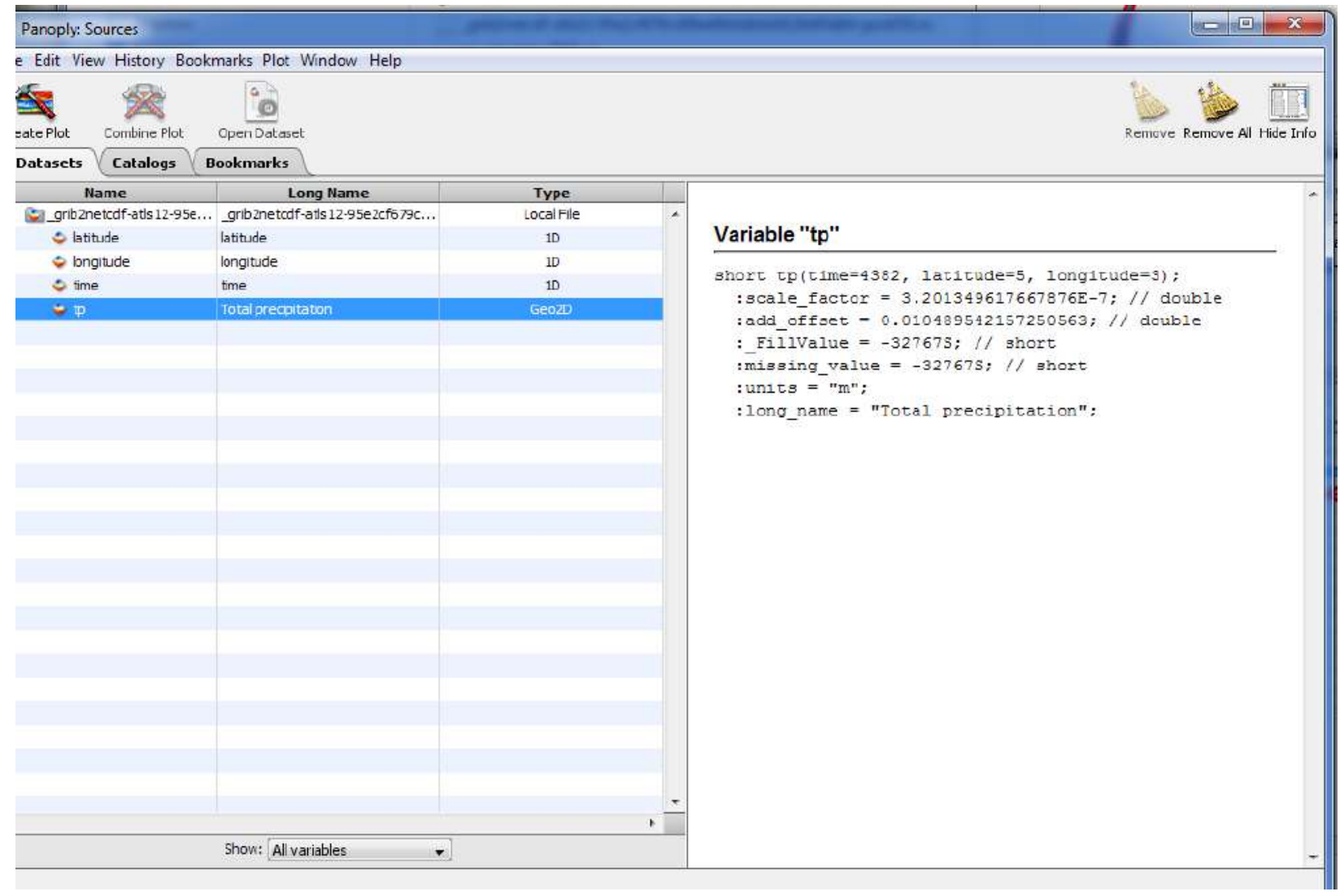

\section{Resultado:}

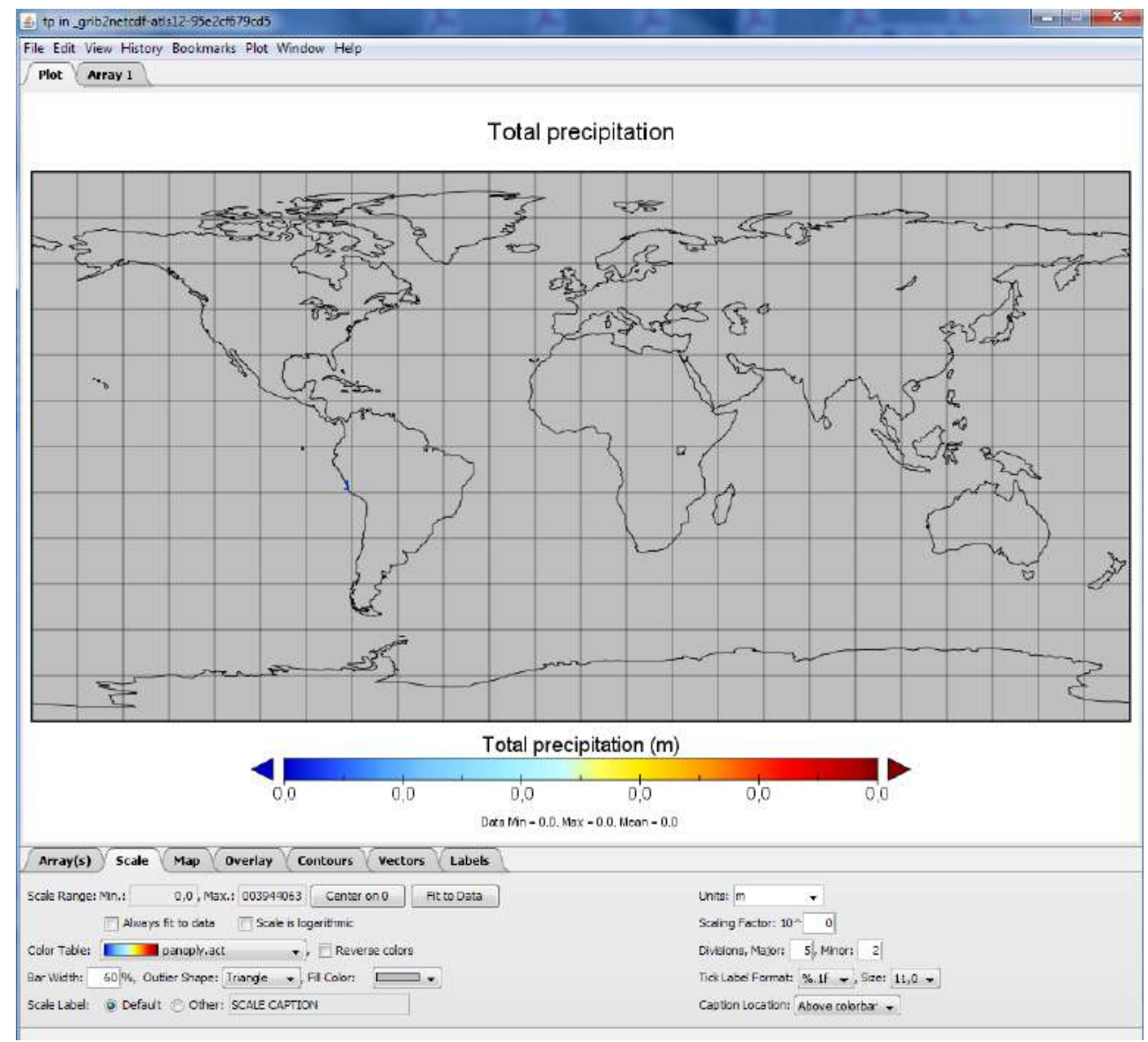




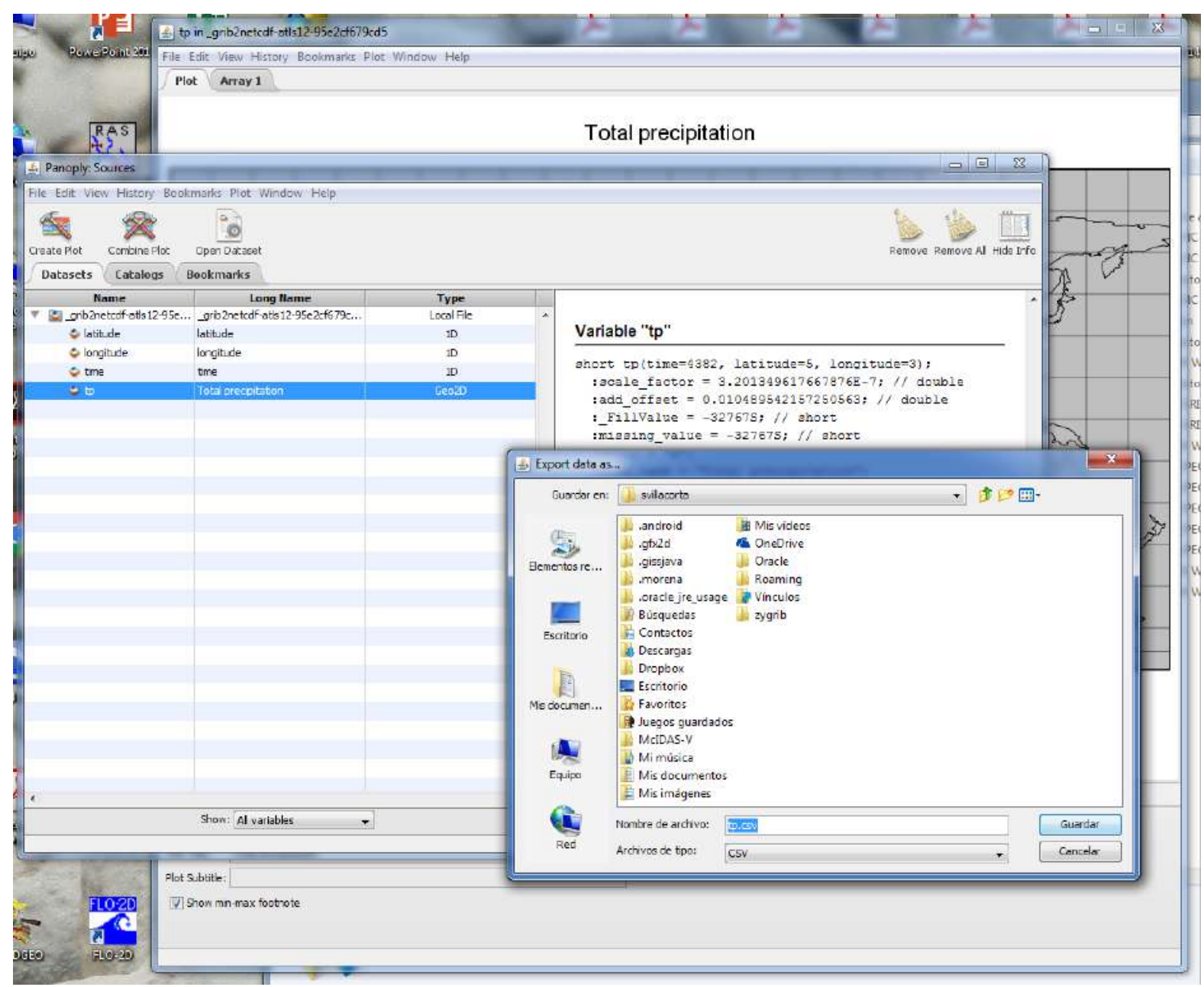

14. IMPORTANTE: Después de descargar la data (tp) exportar como "labeled text" (txt) para poder convertir en Excel (datos separados por tabulaciones) y emplear las coordenadas geográficas (convertir con ArcGis). 
Evolución geomorfológica del abanico aluvial de Lima y su relación con el análisis de Peligrosidad por Inundaciones - Anexo 8.7

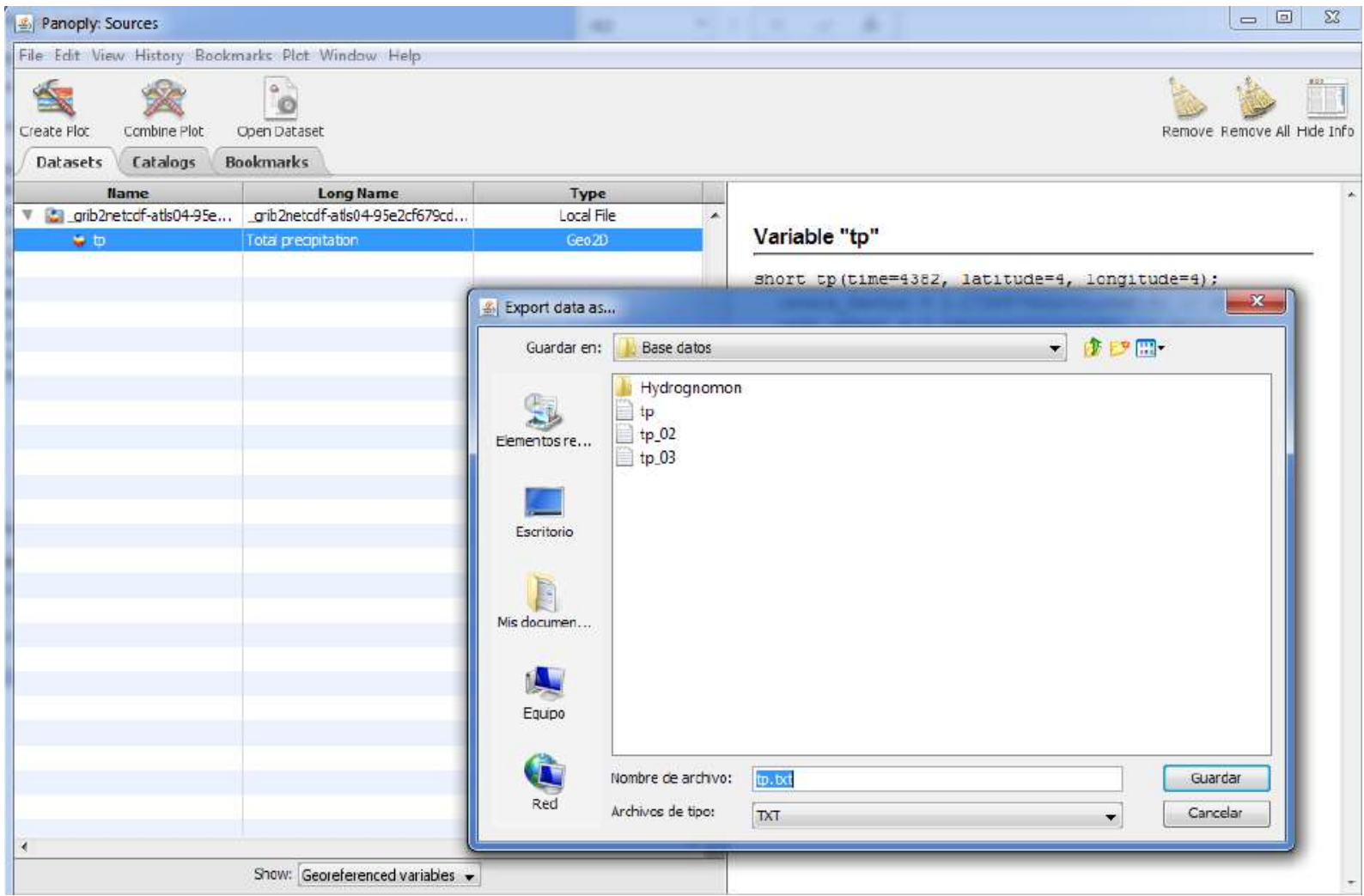

15. Finalmente así se verá al exportar la data y abrirla en una hoja de Excel:

\begin{tabular}{|c|c|c|c|c|c|}
\hline A & A & B & C & D & E \\
\hline 1 & time & latitude & longitude & $t p$ & \\
\hline 2 & 692508 & -11.1999998 & 282.799988 & 0 & \\
\hline 3 & 692508 & -11.1999998 & 283.200012 & $2.25 E-04$ & \\
\hline 4 & 692508 & -11.1999998 & 283.600006 & $6.15 E-04$ & \\
\hline 5 & 692508 & -11.1999998 & 284 & 0.00120456 & \\
\hline 6 & 692508 & -11.1999998 & 284.399994 & 0.0071957 & \\
\hline 7 & 692508 & -11.1999998 & 284.799988 & 0.01383759 & \\
\hline 8 & 692508 & -11.6000004 & 282.799988 & 0 & \\
\hline 9 & 692508 & -11.6000004 & 283.200012 & 0 & \\
\hline 10 & 692508 & -11.6000004 & 283.600006 & 0 & \\
\hline 11 & 692508 & -11.6000004 & 284 & 0.00176827 & \\
\hline 12 & 692508 & -11.6000004 & 284.399994 & 0.00779502 & \\
\hline 13 & 692508 & -11.6000004 & 284.799988 & 0.01496303 & \\
\hline 14 & 692508 & -12 & 282.799988 & 0 & \\
\hline 15 & 692508 & -12 & 283.200012 & 0 & \\
\hline 16 & 692508 & -12 & 283.600006 & 0 & \\
\hline 17 & 692508 & -12 & 284 & 0.00141817 & \\
\hline 18 & 692508 & -12 & 284.399994 & 0.00593379 & \\
\hline 19 & 692508 & -12 & 284.799988 & 0.01128804 & \\
\hline 20 & 692508 & -12.3999996 & 282.799988 & 0 & \\
\hline 21 & 692508 & -12.3999996 & 283.200012 & 0 & \\
\hline 22 & 692508 & -12.3999996 & 283.600006 & 0 & \\
\hline 23 & 692508 & -12.3999996 & 284 & 0.00100083 & \\
\hline 24 & 692508 & -12.3999996 & 284.399994 & 0.00389652 & \\
\hline
\end{tabular}




\section{DOCUMENTACIÓN A CONSULTAR}

Andres, N., Vegas, F., Lavado, W., \& Zappa, M. (2014). Water resources and climate change impact modelling on a daily time scale in the peruvian andes. Hydrological Sciences Journal, 59(11), 2043-2059.

Dee, D. P., Uppala, S. M., Simmons, A. J., Berrisford, P., Poli, P., Kobayashi, S. Bauer, P. (2011). The ERA-Interim reanalysis: Configuration and performance of the data assimilation system. Quarterly Journal of the Royal Meteorological Society, 137(656), 553-597.

Olave, P. E. (2015). Generación de montos diarios de precipitación a partir de series observadas rellenadas con datos de reanálisis.

Persson, A. (2001). User Guide to ECMWF Forecast Products,

Villacorta, S., Rodríguez, C., Peña, F., Jaimes, F., \& Luza, C. (2016). Caracterización geodinámica y dendrocronología como base para la evaluación de procesos geohidrológicos en la cuenca del río mariño, abancay (perú). Serie Correlación Geológica, (32), 25-42. 


\title{
GUÍA PARA EL USO DEL MODELO MAGRITH PARA LA AFINACIÓN DE CAUCES
}

\author{
Por: SANDRA VILLACORTA \\ NOVIEMBRE - 2018
}

\section{INTRODUCCIÓN}

El modelo MAGRITH (Método avanzado para la generación de un modelo digital de elevaciones según una red irregular de triángulos para cálculo hidráulico) busca obtener el máximo rendimiento de los datos de elevación del terreno.

Se puede aplicar ante la falta de datos fiables de elevación del terreno, cuando se requiere efectuar una modelización hidráulica. También es aplicable a otras circunstancias que requieran obtener el máximo rendimiento de modelos de elevación del terreno. Esta técnica es de utilidad cuando no se obtiene datos de elevación de forma distribuida como los del LIDAR (Llorente, 2007).

La presente guía contiene acápites que explican cómo aplicar el geo-procesamiento MAGRITH con el uso el software ArcGIS para preparar información que se emplee en el cálculo de caudales de avenidas y/o inundaciones.

\section{OBJETIVO}

El presente manual tiene como objetivo presentar los pasos a seguir para emplear el Modelo MAGRITH en la obtención de un modelo digital de elevación (MDE) óptimo a ser empleado en una modelización hidráulica. 


\section{DESCRIPCIÓN DE LA SISTEMÁTICA}

1. Para poder desarrollar el Geoprocesamiento MAGRITH, en primer lugar es necesario contar con el software ArcGIS, de preferencia la versión 10 o superior.

2. Una vez obtenido el modelo digital del terreno a trabajar, se procederá a visualizar y analizar dicha información mediante la aplicación ArcMap del ArcGIS.

3. ArcMap representa la información geográfica como una colección de capas y otros elementos en un mapa. En ArcMap se puede asignar símbolos, editar y diseñar mapas para imprimir o publicar (ESRI, 2016).

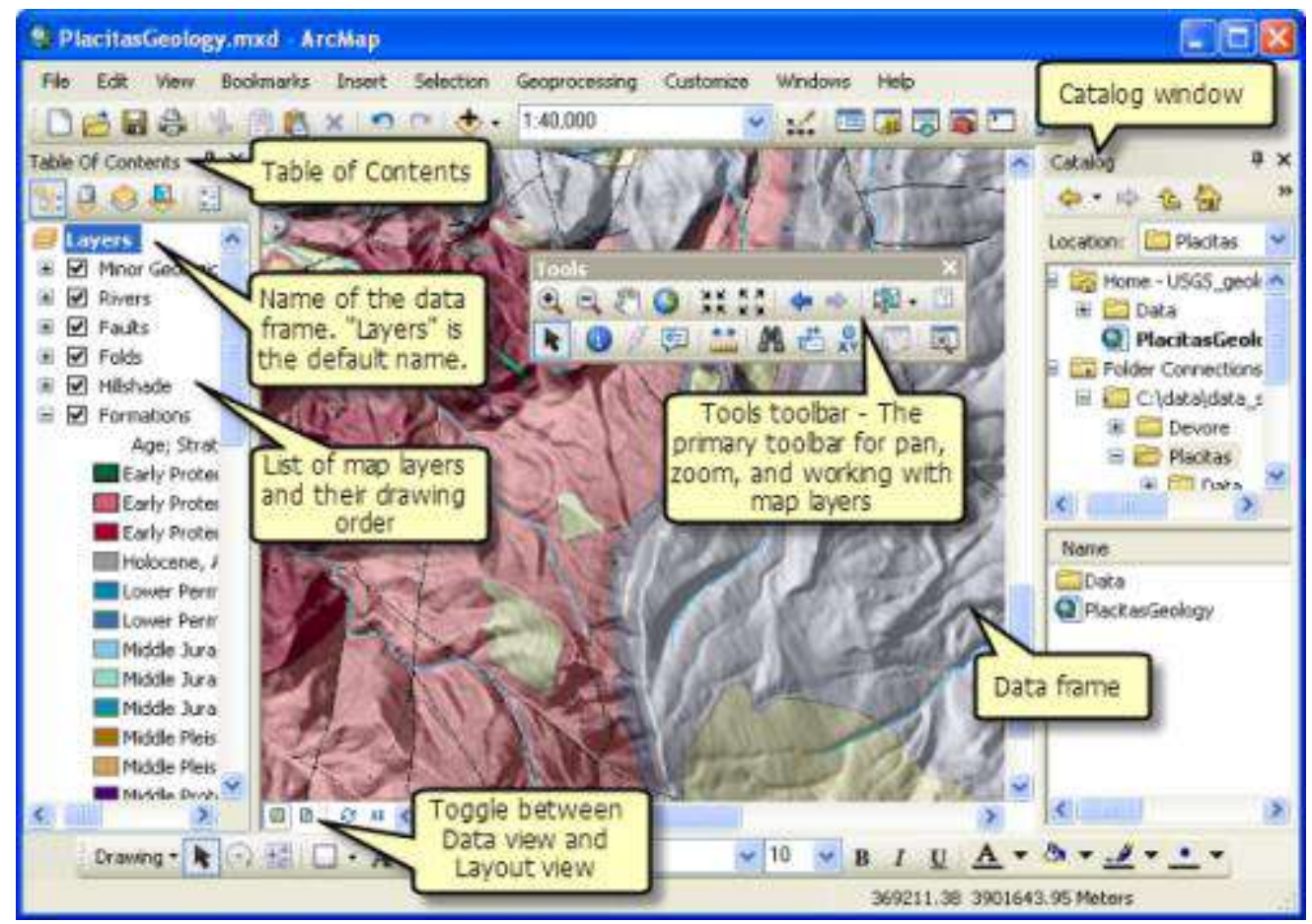

Tomado de: http://desktop.arcgis.com/es/arcmap/10.3/main/map/a-quick-tour-of-arcmap.htm

1. A fin de mostrar la utilidad del modelo MAGRITH y para una mejor comprensión de esta guía se mostrará como ejemplo de aplicación la definición del cauce del río Rímac, en su área Metropolitana (datos correspondientes al presente estudio).

2. Tomando el modelo digital del valle del Rímac, se verificó que la definición del cauce no tenía la calidad adecuada para efectuar un modelamiento hidráulico. Entonces se recurrió a la cartografía geomorfológica. Se delimitó el cauce actual (fondo de valle) en detalle y las terrazas adyacentes. 
3. De acuerdo al método MAGRITH se deben generar interpolaciones sucesivas para parcelas aisladas del territorio (Parcelas de Aislamiento, PAs). La definición de estas PAs se apoya en que los vectores del gradiente de elevaciones no tiendan a formar fuertes ángulos y en que se discriminen zonas con desigual densidad de información (Llorente, 2007).

4. Para nuestro caso, las PASs corresponden a los polígonos de las zonas de influencia: fondo de valle, margen derecha y margen izquierda.

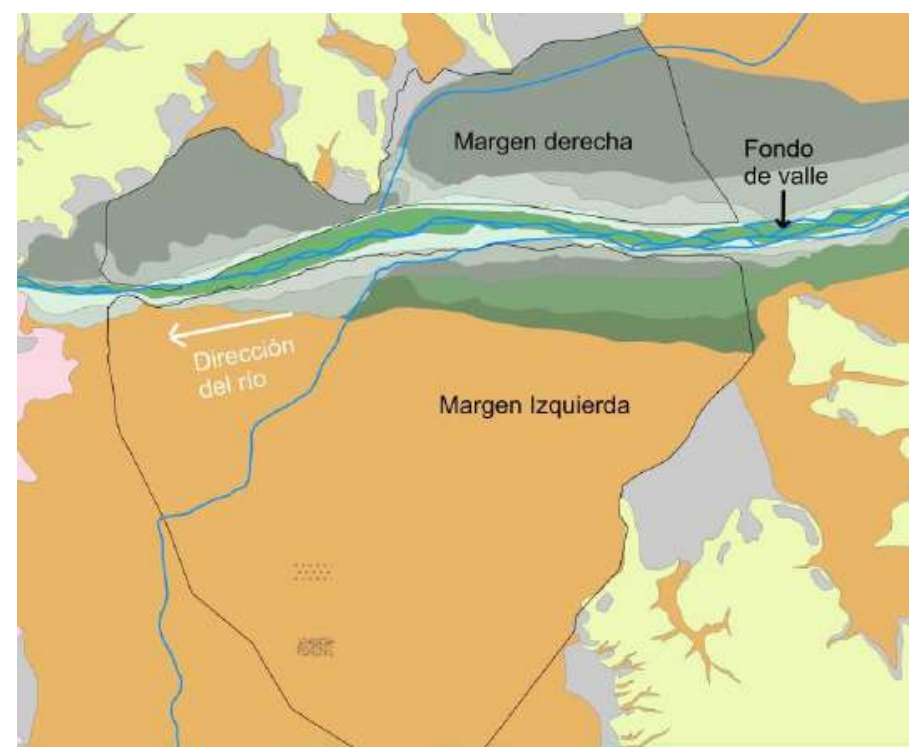

5. Se digitalizan tres polígonos: fondo de valle y las llanuras de inundación (derecha e izquierda).

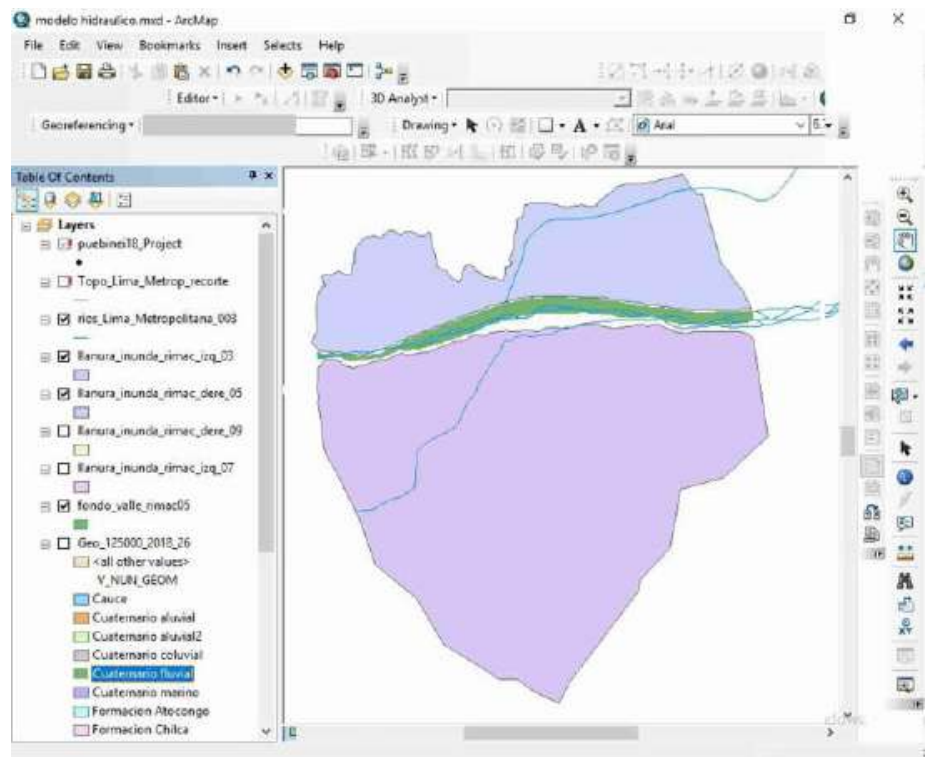

6. Se procede a elaborar los TIN de las llanuras de inundación y del fondo de valle. Para ello, las herramientas a emplear del ArcGIS son: 
Evolución geomorfológica del abanico aluvial de Lima y su relación con el análisis de Peligrosidad por Inundaciones - Anexo 8.8

\section{D Analyst Tools > Data Management $>$ TIN >Create TIN}

of Create TIN

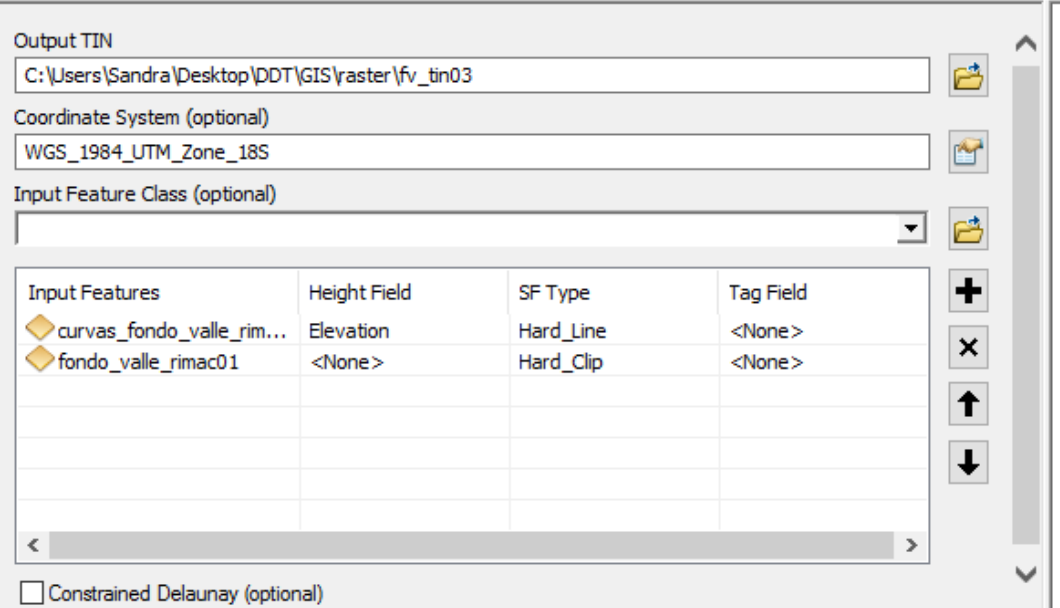

Input Feature Class (optional)

Add references to one or more feature classes that will be included in the TIN For each feature class you'll need to set properties that indicate how it's used to define the surface.

in feature class: The feature class whose features will be imported into the TIN.

height_field: The field that specifies the source of

elevation values for the

Tool Help

7. Así quedan los TIN de las tres partes:

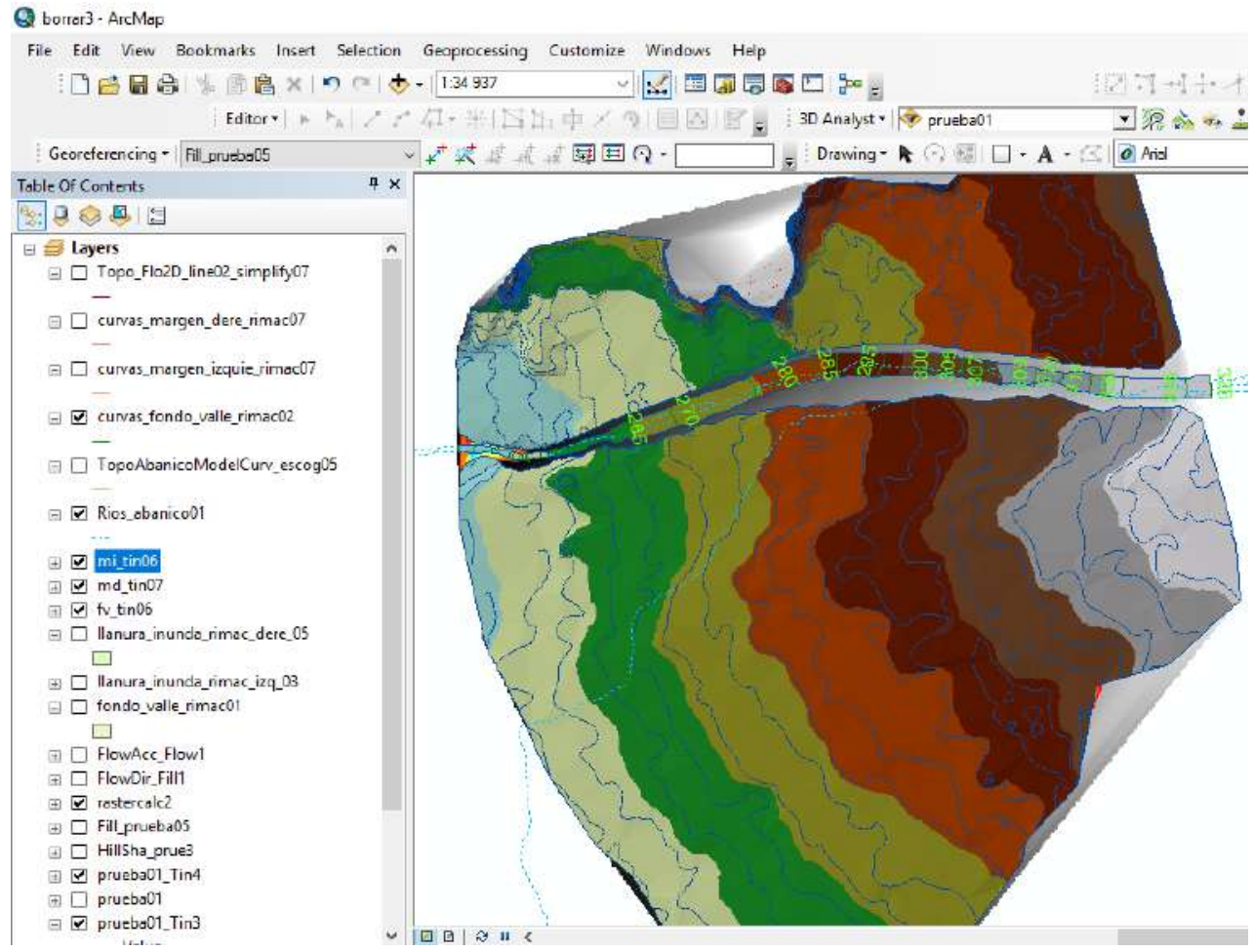

8. Los TIN creados se convierten al formato ráster: 

Inundaciones - Anexo 8.8

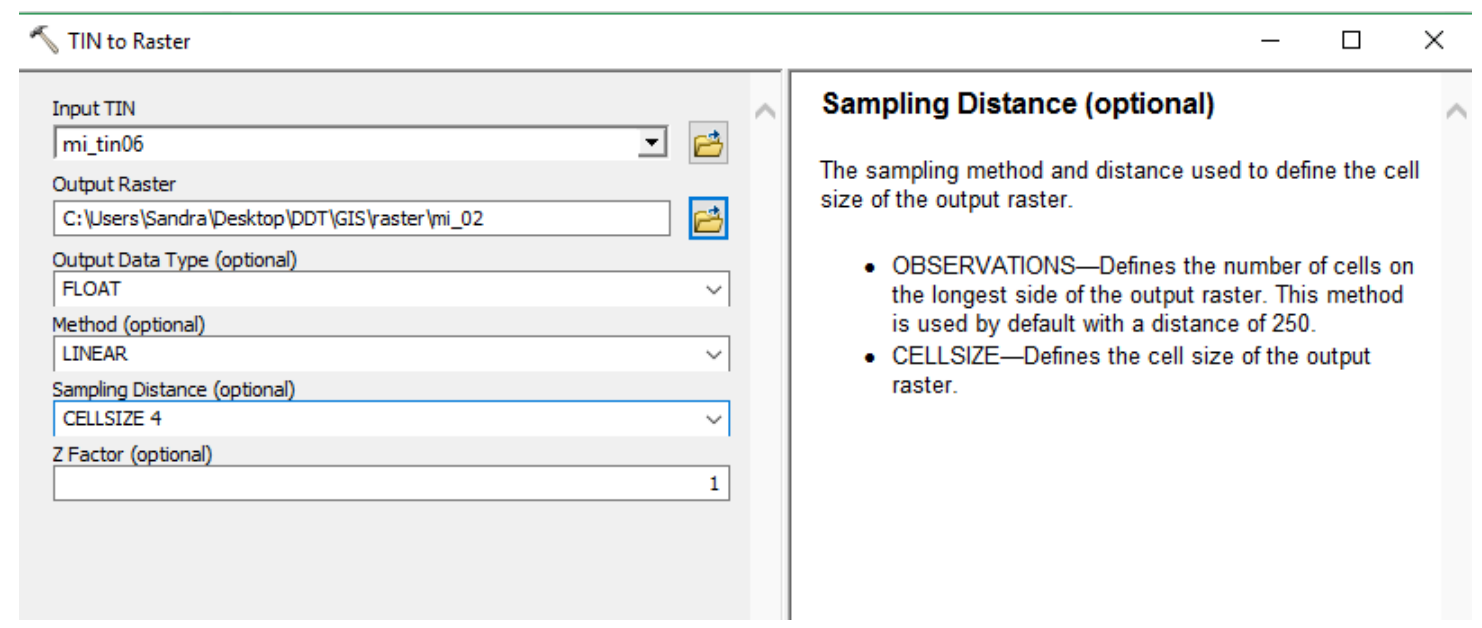

9. Resultado de los tres raster:

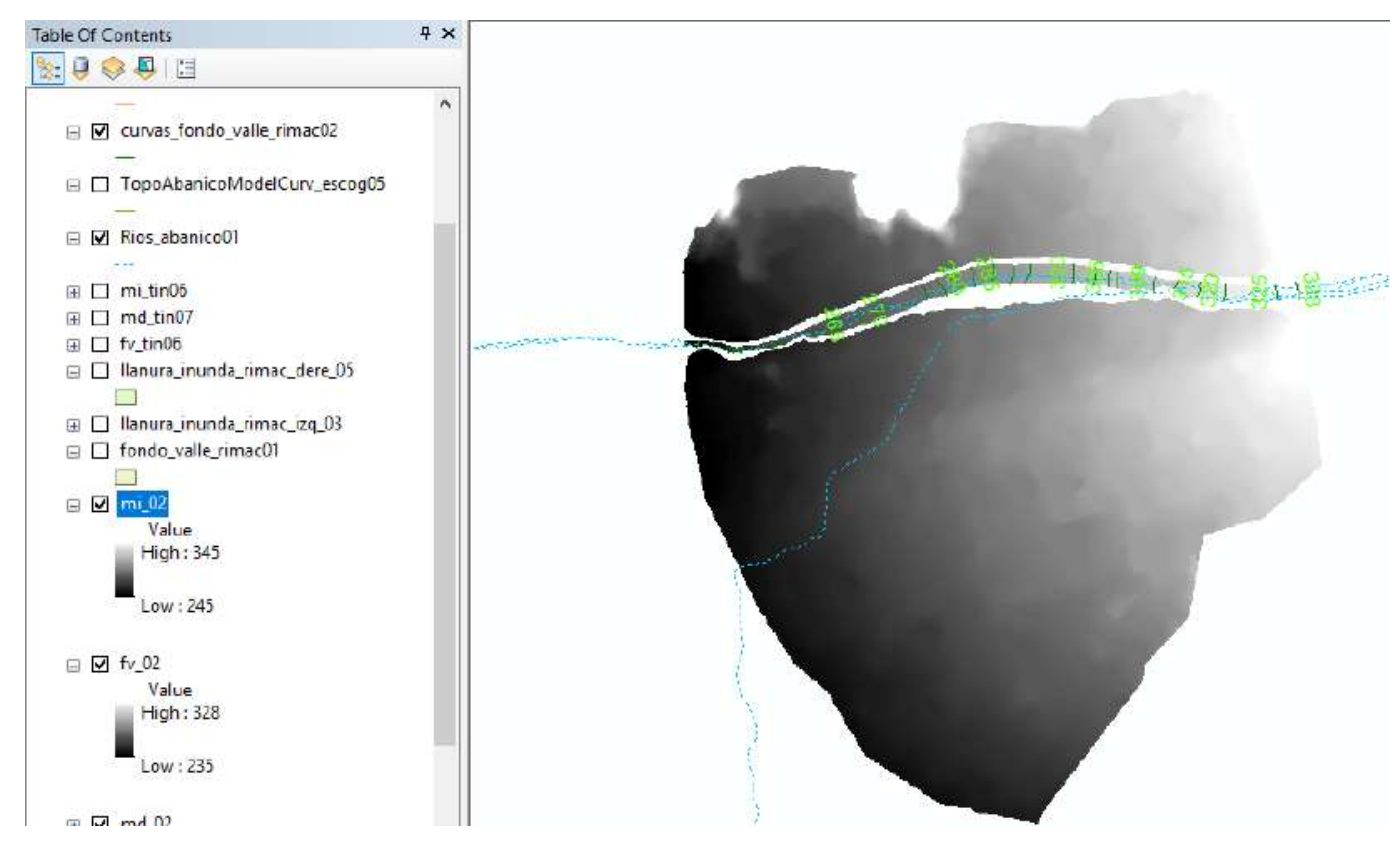

10. Una vez interpoladas las elevaciones en las parcelas de manera aislada se genera el curvado para cada PA con la finalidad de igualar la densidad de información en parcelas contiguas. Para ello, se procede a crear isolíneas de cada ráster empleando la herramienta Contour del ArcGIS:

\section{ArcToolbox>SpatialAnalyst Tools>Surface>Contour}

11. Generar las curvas de nivel a $x$ metros ( $x$ debe ser $\ll<$ al espaciado actual) de un modelo digital del terreno (ráster). En el caso de estudio por ejemplo, las curvas están cada $5 \mathrm{~m}$ y las nuevas curvas de nivel a una distancia $0.4 \mathrm{~m}$. 


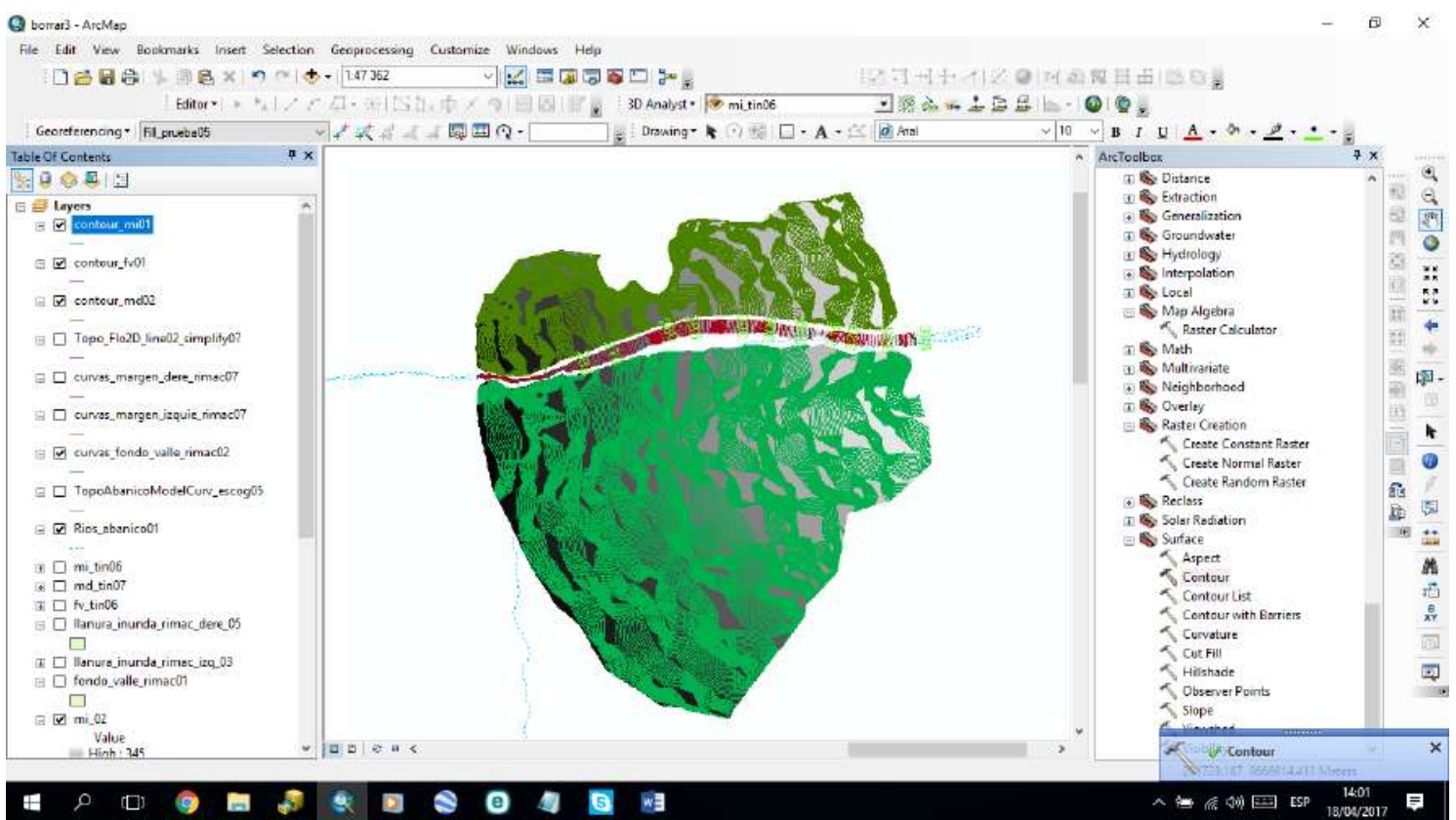

12. Unir los shapes ( Data Management Tools>General >Merge) y volver a hacer otro TIN que se pasará a raster.

13. Para comprobar la eficiencia del método se procede a hacer dos o tres secciones representativas del MDE final (transversales y longitudinales). En el MDE se necesitan dos cosas:

$>$ Un cauce con datos homogéneos o suavizados que expresen teóricamente el terreno.

$>$ Que la extensión de la información siempre supere la extensión previsible que ocuparía el flujo.

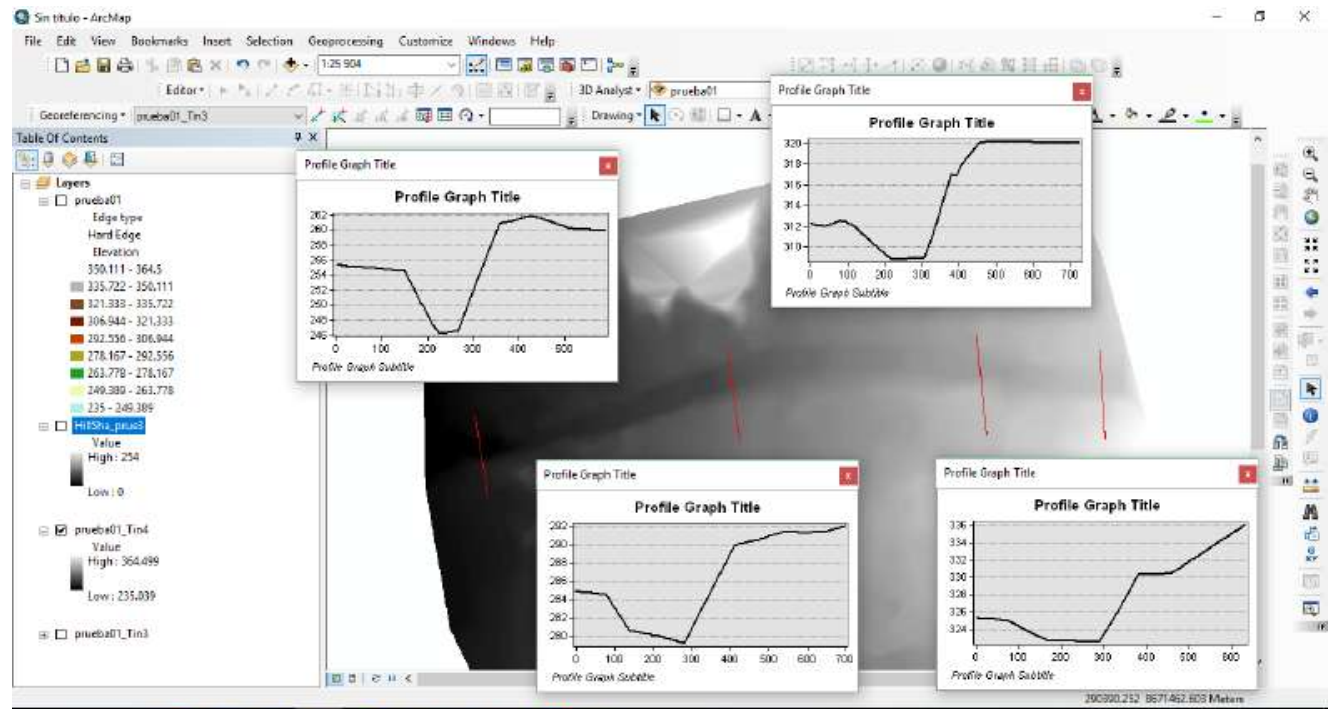


Evolución geomorfológica del abanico aluvial de Lima y su relación con el análisis de Peligrosidad por Inundaciones - Anexo 8.8

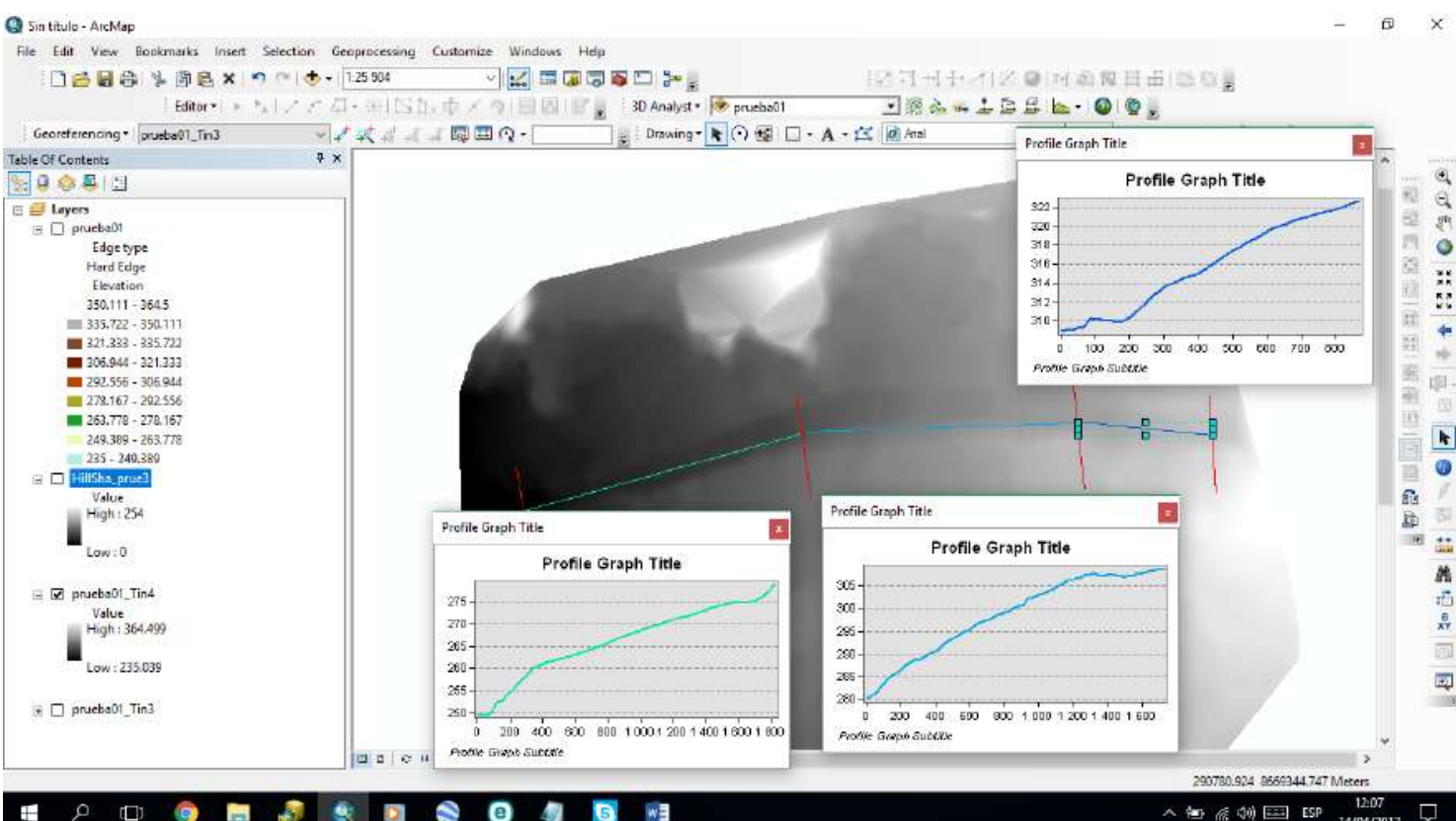

Nota opcional: Recortar con un polígono el área de influencia definida en las imágenes. Para ello se puede emplear:

Spatial Analyst Tools >Extraction>Extract by Mask

\begin{tabular}{|c|c|}
\hline ArcToolbox & $\square \times$ \\
\hline 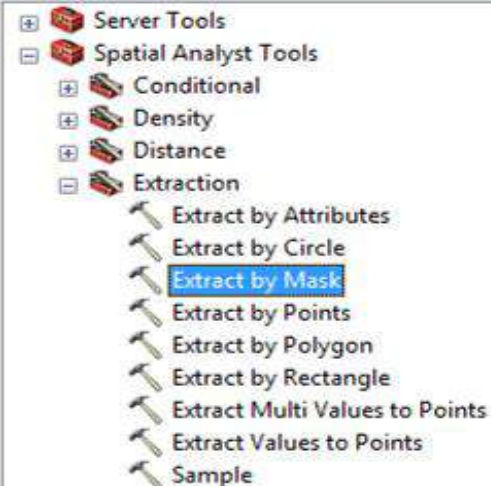 & $\wedge$ \\
\hline
\end{tabular}




\section{COMPARACIÓN DE RESULTADOS}
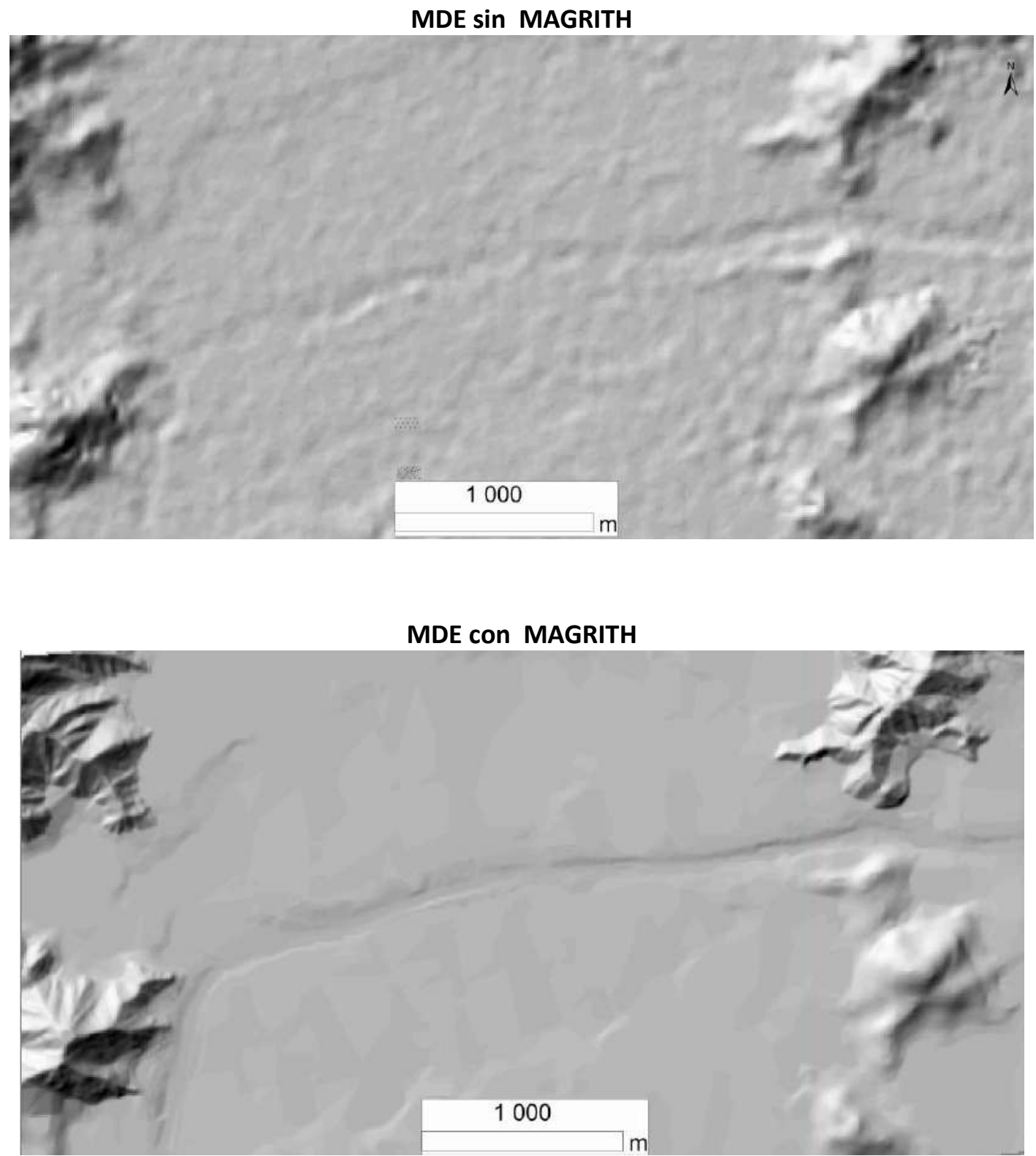

\section{DOCUMENTACIÓN A CONSULTAR}

Llorente, M. 2007. MAGRITH. Método avanzado para la generación de un modelo digital de elevaciones según una red irregular de triángulos para cálculo hidráulico. Triangulación por pasos. Informe técnico IGME, 11 págs. Inédito.

ESRI, 2016. ArcGIS Desktop. Manual del uso del ArcGIS. ESRI. Redlands, CA: Environmental Systems Research Institute. On line. Disponible en: http://desktop.arcgis.com/es/ 